ERDA-76-43

VOL. 1 of 5

\title{
Alternatives For Managing Wastes From Reactors And Post-Fission Operations In The LWR Fuel Cycle
}

Volume 1:

Summary

Alternatives For The Back End Of The LWR Fuel Cycle Types And Properties Of LWR Fuel Cycle Wastes Projections Of Waste Quantities Selected Glossary 


\title{
NOTICE
}

This report was prepared as an account of work sponsored by the United States Government Neither the United States nor the United States Energy Research and Development Administration, nor any of their employees, nor any of their contractors, subcontractors, or their empioyees, makes any warranty, express or implied, or assumes any legal ilability or responsibility for the accuracy, completeness or usefulness of any information, apparatus, product or process disclosed, or represents that its use would not infringe privately owned rights

PACIFIC NORTHWEST LABORATORY

operated by

BATTELLE

for the

U.S. ENERGY RESEARCH AND DEVELOPMENT ADMINISTRATION

Under Contract E(45-1)-1830

\author{
Printed in the Linted States of America \\ Alaslable trom \\ National Techucal Information service \\ US Department of Commerce \\ 5285 Port Roval Ruad \\ Sprungfield Lirginta 22151 \\ Price Pruted Copy $\$ 750$, Mucrofiche $\$ 22.5$
}




\section{DISCLAIMER}

This report was prepared as an account of work sponsored by an agency of the United States Government. Neither the United States Government nor any agency Thereof, nor any of their employees, makes any warranty, express or implied, or assumes any legal liability or responsibility for the accuracy, completeness, or usefulness of any information, apparatus, product, or process disclosed, or represents that its use would not infringe privately owned rights. Reference herein to any specific commercial product, process, or service by trade name, trademark, manufacturer, or otherwise does not necessarily constitute or imply its endorsement, recommendation, or favoring by the United States Government or any agency thereof. The views and opinions of authors expressed herein do not necessarily state or reflect those of the United States Government or any agency thereof. 


\section{DISCLAIMER}

Portions of this document may be illegible in electronic image products. Images are produced from the best available original document. 


\section{Alternatives For Managing Wastes From Reactors And Post-Fission Operations In The LWR Fuel Cycle}

MAY 1976

Volume 1

(1 of 5 Volumes)
Thes report was prepartice

sponsored by the prepared as an account of work United States Government Nether Research and Development the United States Energy subcontractoyees not any of theis cor any of warranty express or their employees makes any

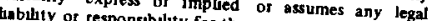
or usefulness of any inform acoracy completeness process disclosed of represents apparatus product or unfinge privately owned rughts that its use would not

NOTICE

PORTIONS OF THIS REPORT ARE ILIEGIPLE. It has been reproduced from the best available oopy to permit the broadest possible availab121ty. .
Report Coordinated By Battelle, Pacific Northwest Laboratories At The Request Of The Division Of Nuclear Fuel Cycle And Production 
-

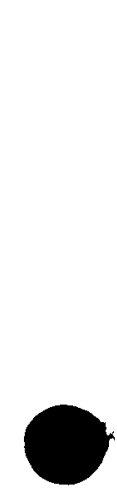




\section{FOREWORD}

This report describes technical alternatives for managing wastes from the back end of the commercial LWR fuel cycle. It describes waste types, the alternative technologies that can be used to manage the wastes, and the state of availability of those technologies.

The report does not select preferred waste management technologies or make comparative assessments. Its purpose is to provide a comprehensive digest of technical information expected to serve as a basis for future decisions, assessments, and environmental impact statements. The technology is still evolving, and this report will be subjected to public review and comment. Its contents therefore serve as a baseline subject to future supplementation and updating.

There are four major waste management functions: treatment, interim storage, transportation, and final storage or disposal. This report is structured in five volumes that reflect these functions. Volume 1 summarizes the report, describes alternatives for the back end of the LWR cycle, and provides background information on waste types and quantities. Volume 2 describes alternatives for waste treatment. Volume 3 discusses interim storage and transportation. Alternatives for final storage and disposal are described in Volume 4. The Appendices, Volume 5, provide supplementary information, with emphasis on characteristics of geologic formations that might be used for final storage or disposal.

Preparation of this report was started in August of 1975, in response to a directive from ERDA's Nuclear Fuel Cycle and Production Division. The report was authored by personnel of ERDA's contractors, of industry, and of universities; coordination was provided by Battelle's Pacific Northwest Laboratories. The report was completed in March of 1976. The cutoff date for characterizing the status of the technologies was September $1,1975$. 
-

- 
Battelle Memorial Institute

Pacific Northwest Laboratories

Report Coordinators

John W. Bartlett

John R. Carrel1

Max R. Kreiter

Allison M. Platt

Judith A. Powell

(Editorial and Production) 
0 
Following is a listing of the primary study contributors, with their affiliations, to this volume.

\section{INTRODUCTION \& TECHNICAL}

SUMMARY

J. W. Bartlett, Battelle, Pacific Northwest Laboratories (PNL)

J. E. Mende 1, PNL

1.0 ALTERNATIVES FOR THE BACK END OF THE LWR FUEL CYCLE

Task Leader

J. W. Bartlett, PNL

Contributors

G. R. Bray, Science Applications, Inc.

R. M. Fle ischman, PNL

J. E. Mende l, PNL

E. T. Merrill, PNL

W. A. Muckerheide, PNL

\subsection{LWR FUEL CYCLE WASTES}

$\frac{\text { Task Leader }}{M . j .}$

M. J. Steindler, Argonne

National Laboratory (ANL)

\section{Contributors}

J. 0. Blomeke, Oak Ridge

National Laboratory (ORNL)

C. W. Kee, ORNL

B. J. Kullen, ANL

G. L. Richardson, Hanford

Engineering Development

Laboratory (HEDL)

L. E. Trevorrow, ANL

\subsection{PROJECTIONS OF LWR FUEL CYCLE QUANTITIES}

Task Leader

M. J. Steindler, ANL

Contributors

J. O. Blomeke, ORNL

C. W. Kee, ORNL

B. J. Kullen, ANL

L. E. Trevorrow, ANL

\subsection{SELECTED GLOSSARY}

J. W. Bartiett, PNL

M. R. Kreiter, PNL

J. A. Powe II, PNL 
•

○ 


\section{CONTENTS - TOTAL REPORT}

Abbreviated contents of the total 5-volume report are listed here. Detailed contents for this specific volume are listed following this overview table of contents.

\section{VOLUME 1}

1.0 ALternatives fOR THE BACK END OF THE LWR FUEL CYCLE . . . 1.1 1.1 FUEL CYCLE OPTIONS • . . . . . . . . . . . . . . 1.1

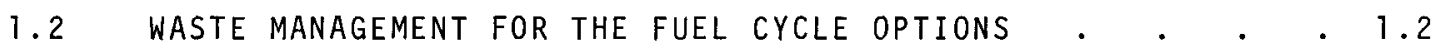
2.0 LWR FUEL CYCLE WASTES . . . . . . . . . . . . . . . . 2.1 2.1 DESCRIPTION OF THE LIGHT WATER REACTOR (LWR) FUEL CYCLE . 2.1 2.2 WASTE FROM REACTORS . . . . . . . . . . . . 2.15

2.3 WASTES FROM SPENT FUEL STORAgE FACILITIES • • • • . $\quad 2.28$

2.4 WASTES FROM FUEL REPROCESSING PLANTS . . . . . . . . 2.43

2.5 WASTES FROM MIXED OXIDE FUEL FABRICATION PLANTS . . . 2.84

2.6 WASTES FROM DECOMMISSIONING OF FUEL CYCLE FACILITIES • $\quad 2.95$

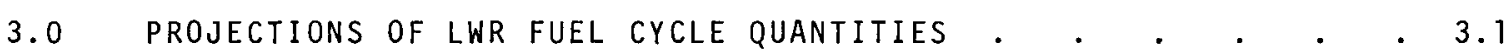

3.1 BASIC ASSUMPTIONS . . . . . . . . . . . . . . . . 3.1

3.2 PROJECTIONS • • • • • • • • • • • • • . 3.6

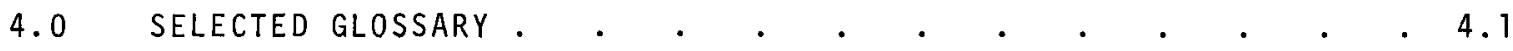

\section{VOLUME 2}

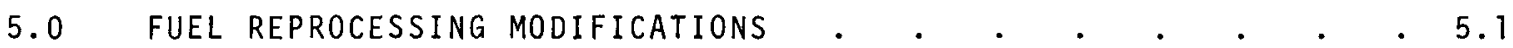

5.1 INSOLUBLE RESIDUES GENERATED IN FUEL REPROCESSING . . . 5.3

5.2 SOLVENT TREATMENT FOR RECYCLE, AND WASTE SOLVENT DISPOSAL • 5.4

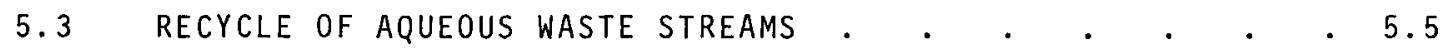

5.4 OFF-GAS TREATMENT WASTES . . . . . . . . . . . . . 5.6

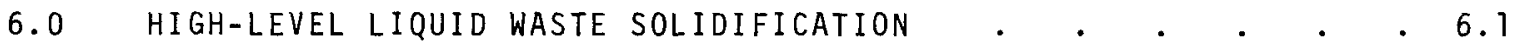

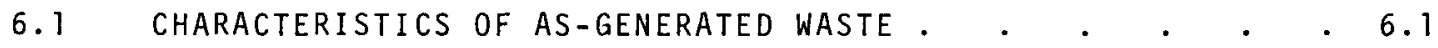

6.2 FEATURES COMMON TO SOLIDIFICATION PROCESSES . . . . $\quad$. 6.4

6.3 ALTERNATIVE SOLIDification PROCESSES . . . . . . . . 6.13

6.4 EXISTING COMMERCIAL HIGH-LEVEL WASTE $. \quad . \quad . \quad . \quad . \quad 6.89$ 
7.0 TREATMENT AND IMMOBILIZATION OF CHOP-LEACH FUEL BUNDLE

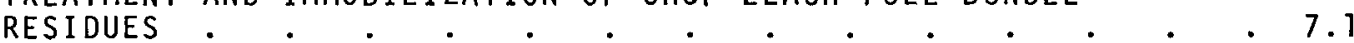

7.1 CHARACTERISTICS OF CHOP-LEACH FUEL BUNDLE RESIDUES $\quad . \quad 7.1$

7.2 ALTERNATIVE TREATMENTS AND IMMOBILIZATION TECHNOLOGIES $\quad .7 .8$

8.0 TREATMENT OF NONCOMBUSTIBLE SOLID WASTES $\quad . \quad . \quad . \quad . \quad . \quad . \quad . \quad 8.1$

8. 1 CHARACTERISTICS OF AS-GENERATED WASTES $\quad . \quad$. $\quad . \quad . \quad . \quad 8.1$

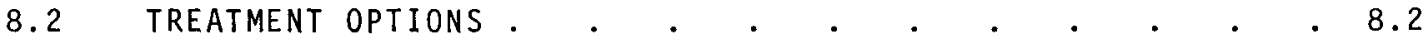

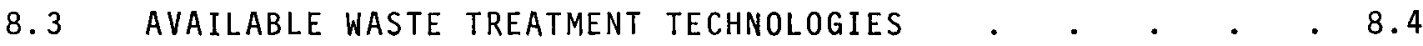

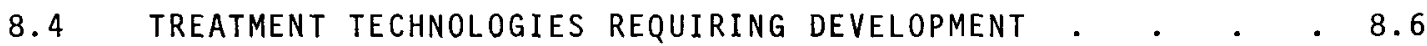

8.5 SECONDARY WASTE TREATMENT . 5 . $5 . \quad . \quad . \quad . \quad . \quad . \quad . \quad . \quad . \quad 8.15$

9.0 TREATMENT OF COMBUSTIBLE WASTES $. \quad . \quad . \quad . \quad . \quad . \quad . \quad . \quad . \quad .9 .1$

9.1 CHARACTERISTICS OF AS-GENERATED WASTES $\quad . \quad$. $\quad . \quad$. $\quad .9 .1$

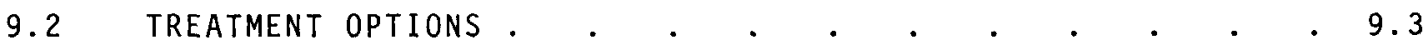

9.3 MECHANICAL SORTING AND VOLUME REDUCTION TECHNIQUES $\quad . \quad . \quad 9.12$

9.4 FEATURES COMMON TO COMBUSTION PROCESSES $\quad . \quad$. . . . $\quad . \quad 9.20$

9.5 COMBUSTION TECHNOLOGIES $5 . \quad . \quad . \quad . \quad . \quad . \quad . \quad . \quad . \quad . \quad .9 .28$

10.0 TREATMENT OF NON-HIGH-LEVEL LIQUID WASTES • • • • • • • • 10.1

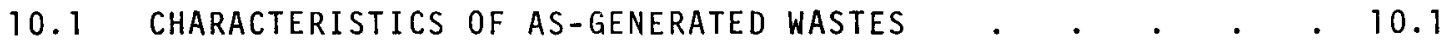

10.2 TREATMENT ALTERNATIVES FOR PRIMARY WASTES . . . . . . 10.2

10.3 TREATMENT REQUIREMENTS FOR SECONDARY WASTES $\quad$ • . $\quad . \quad 10.7$

10.4 ALTERNATIVE TREATMENT TECHNOLOGY DESCRIPTIONS • . $\quad . \quad . \quad 10.7$

11.0 RECOVERY OF TRANSURANICS FROM NON-HIGH-LEVEL WASTES . . . 11.1

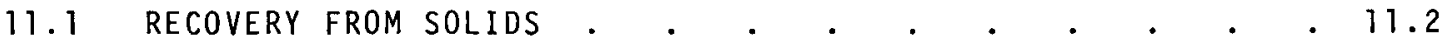

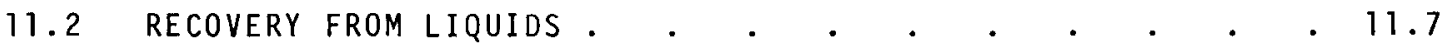

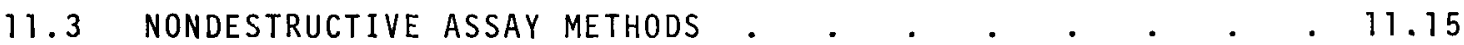

12.0 IMMOBILIZATION OF MISCELLANEOUS NON-HIGH-LEVEL WASTES ..$\quad 12.1$

12.1 IMMOBILIZATION TREATMENT ALTERNATIVES $. \quad . \quad . \quad . \quad . \quad 12.1$

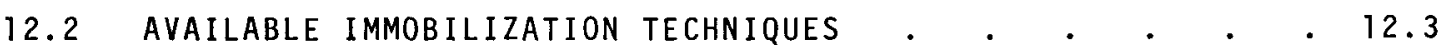

12.3 IMMOBILIZATION TECHNOLOGIES REQUIRING DEVELOPMENT • • • 12.28

13.0 VOLATILE RADIOISOTOPE RECOVERY AND OFF-GAS TREATMENT . . . 13.1

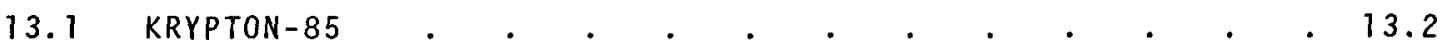

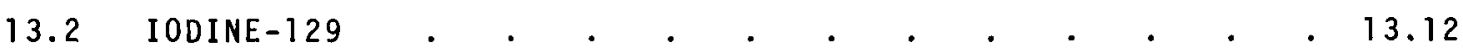




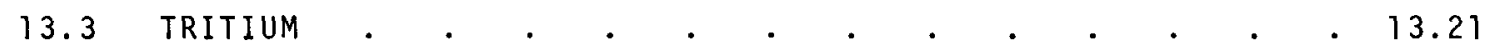

13.4 OXIDES OF NITROGEN $\quad . \quad . \quad . \quad . \quad . \quad . \quad . \quad . \quad . \quad . \quad . \quad 13.44$

13.5 HYDROGEN CHLORIDE . . . . . . . . . . . . . . . 13.49

13.6 CARBON-14. . . . . . . . . . . . . . . 13.52

13.7 RUTHENIUM-106

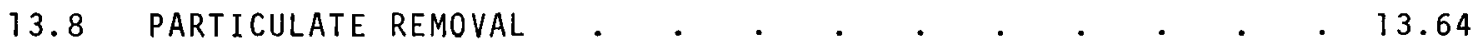

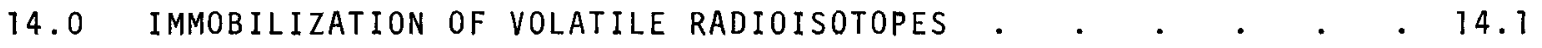

14.1 KRYPTON-85 $. \quad . \quad . \quad . \quad . \quad . \quad . \quad . \quad . \quad . \quad . \quad . \quad .14 .1$

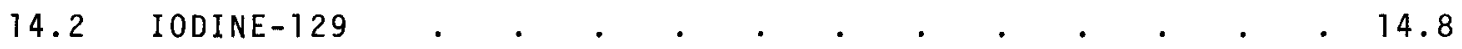

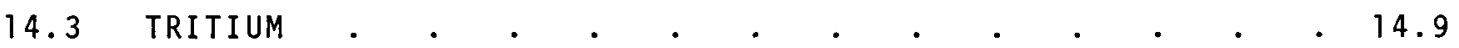

15.0 RETIRED FACILITIES (DECONTAMINATION AND DECOMMISSIONING) • • 15.1

\begin{tabular}{l}
15.1 ALTERNATIVE DECONTAMINATION AND DECOMMISSIONING (D\&D) \\
MODES. \\
\hline
\end{tabular}

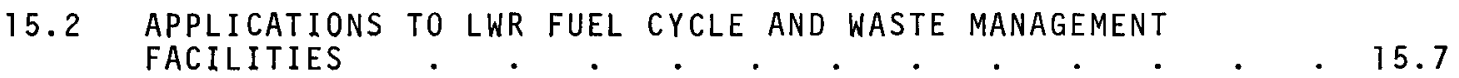

15.3 D\&D TECHNOLOGY

15.4 REGULATIONS AND CRITERIA

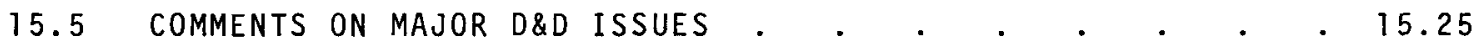

16.0 MODIFICATION AND USE OF SELECTED FUEL REPROCESSING WASTES . $\quad 16.1$

16.1 POTENTIAL BENEFICIAL APPLICATIONS OF HIGH-LEVEL WASTE . . 16.1

16.2 TECHNICAL CONSIDERATIONS IN WASTE FRACTIONATION $\quad \cdot \quad \cdot \quad \cdot 16.5$

16.3 ENERGY RECOVERY FROM BULK SOLIDIFIED WASTE (BSW) . . . 16.6

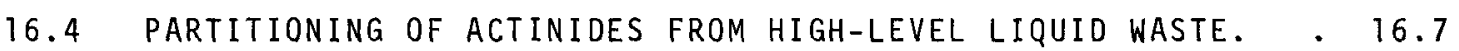

VOLUME 3

17.0 INTERIM STORAGE OF SPENT FUEL ELEMENTS $\quad \cdot \quad \cdot \quad \cdot \quad \cdot \quad \cdot \quad \cdot \quad 17.1$

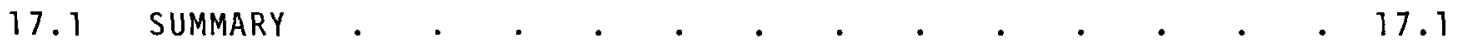

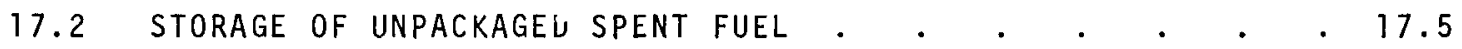

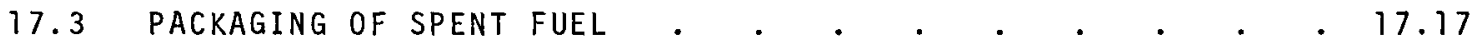

17.4 STORAGE OF PACKAgED SPENT FUEL.$\quad$. . . . . . . . 17.27

18.0 INTERIM STORAGE OF CHOP-LEACH FUEL BUNDLE RESIDUES . • . 18.1

18.1 CHARACTERISTICS OF PRIMARY WASTE CONTAINMENT AND

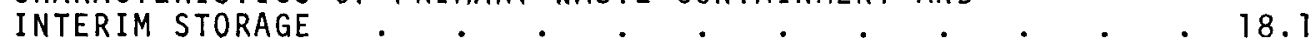


18.2 CHARACTERISTICS OF TREATED WASTE CONTAINMENT AND INTERIM STORAGE

19.0 TANK STORAGE OF HIGH-LEVEL LIQUID WASTE

18.6

\subsection{TANK STORAGE OF HIGH-LEVEL LIQUID WASTE}

19.1

19.1 HISTORICAL REVIEW. • • • • • • • • • • • • 19.1

19.2 CURRENT TECHNOLOGY . . . . . . . . . . . . . . . . 19.10

20.0 INTERIM STORAGE OF SOLID NON-HIGH-LEVEL WASTES $\quad . \quad$. $\quad . \quad$. $\quad 20.1$

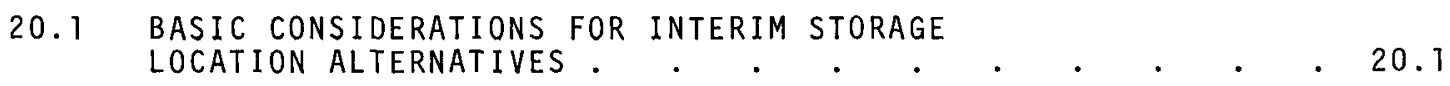

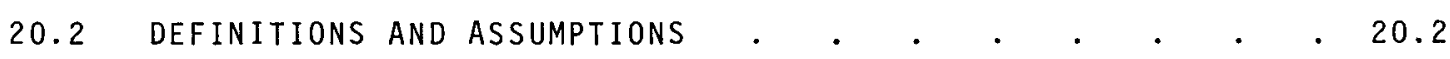

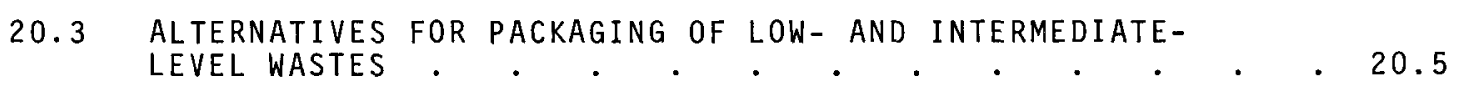

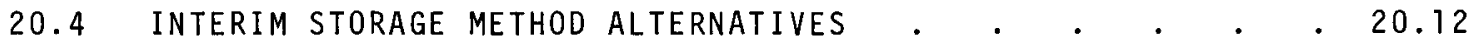

20.5 REPORTING AND RECORDS REQUIREMENTS . • • • • • . . 20.30

20.6 RETRIEVAL OF PACKAGED WASTE AFTER INTERIM STORAGE . . . 20.32

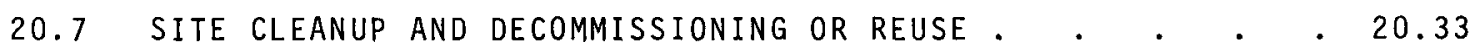

21.0 INTERIM STORAGE OF SOLIDIFIED HIGH-LEVEL WASTE $\quad$ • $\quad$ • $\quad$ • 21.1

21.1 BASIC CRITERIA FOR INTERIM STORAGE FACILITIES • • • • 21.3

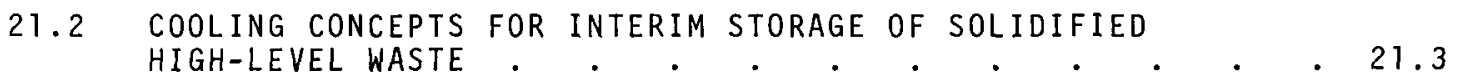

21.3 UNDERGROUND FACILITY (NEAR SURFACE) FOR INTERIM
STORAGE OF SOLIDIFIED HIGH-LEVEL WASTE ALTERNATIVE . . $\quad 21.34$

21.4 ALTERNATIVE LOCATIONS FOR INTERIM STORAGE OF
SOLIDIFIED HIGH-LEVEL WASTE $. \quad . \quad \cdot \quad \cdot \quad \cdot \quad \cdot \quad . \quad 21.36$

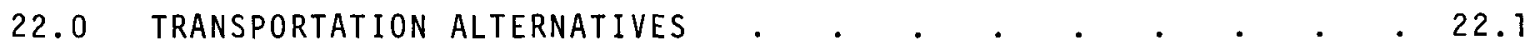

22.1 INTRODUCTION

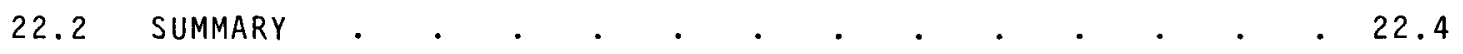

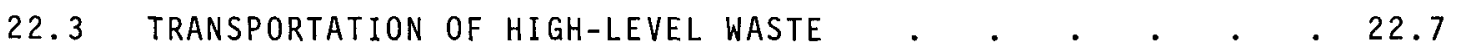

22.4 TRANSPORTATION OF SPENT FUEL . . . . . . . . . . . 22.13

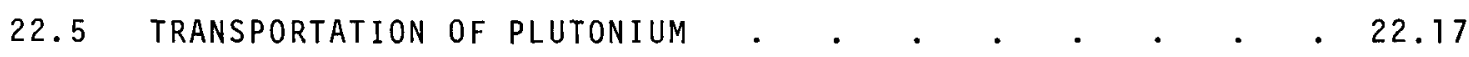

22.6 TRANSPORTATION OF CLADDING HULLS . . . . . . . . . . . 22.31

22.7 TRANSPORTATION OF NON-HIGH-LEVEL WASTE $\quad . \quad . \quad . \quad . \quad 22.39$

\section{VOLUME 4}

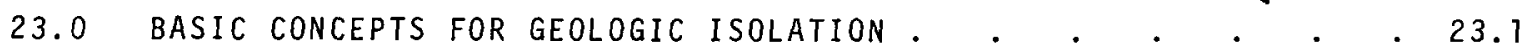
23.1 SYSTEM CONCEPTS . . . . . . . . . . . . . 23.1 
23.2 SITE SELECTION

23.3 QUALIFICATION OF SYSTEMS . . . . . . . . . . . . . 23.15

23.4 DECOMMISSIONING AND CONVERSION OF GEOLOGIC
STORAGE REPOSITORIES . $. . \quad . \quad . \quad . \quad . \quad . \quad . \quad . \quad 23.25$

24.0 GEOLOGIC STORAGE ALTERNATIVES . . . . . . . . . . . . . . 24.1

24.1 BURIAL GROUNDS . . . . . . . . . . . . . . . . . 24.1

24.2 STORAGE IN DEEP CONTINENTAL GEOLOGIC FORMATIONS • • $\quad 24.49$

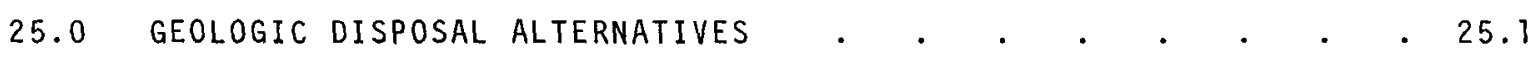

25.1 DEEP CONTINENTAL GEOLOGIC FORMATIONS • • • • • • • 25.1

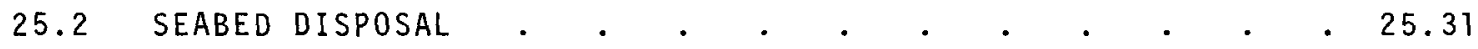

25.3 ICE SHEET DISPOSAL $. \quad . \quad . \quad . \quad . \quad . \quad . \quad . \quad . \quad . \quad 25.52$

26.0 EXTRATERRESTRIAL DISPOSAL • . . . . . . . . . . . . . . 26.1

26.1 CONCEPT DESCRIPTION

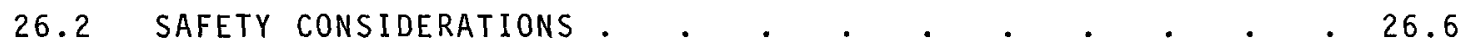

26.3 STATUS OF TECHNOLOGY . . . . . . . . . . . . . . 26.7

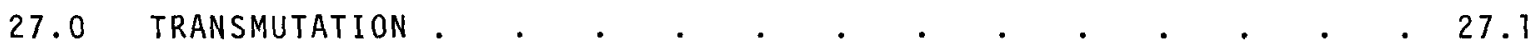

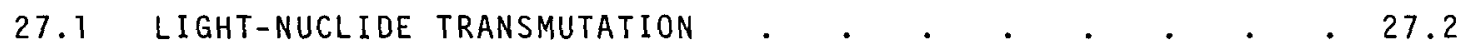

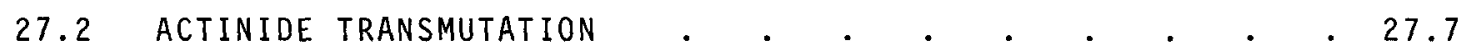

VOLUME 5

APPENDIX A. SELECTED GLOSSARY •

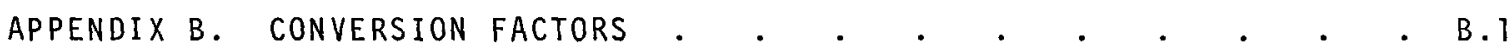

APPENDIX C. GEOLOGIC ISOLATION . . . . . . . . . . . . . . . c.1

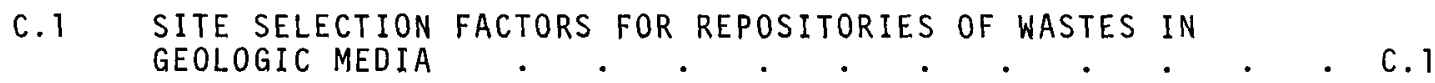

C.2 ROCK TYPES - GEOLOGIC OCCURRENCE . • . . . . . . . c. c. c.

GLOSSARY OF GEOHYDROLOGIC TERMS . . . . . . . . . . . . C.225

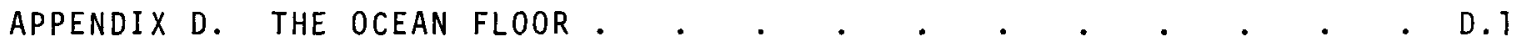

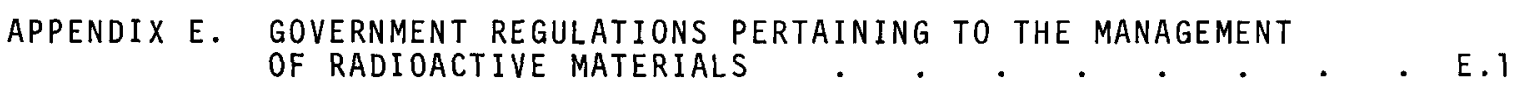


•

• 


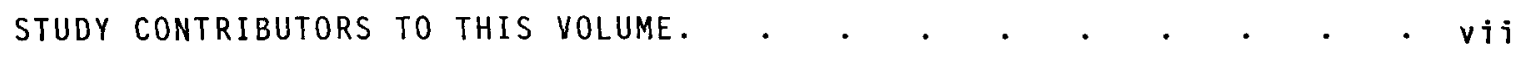

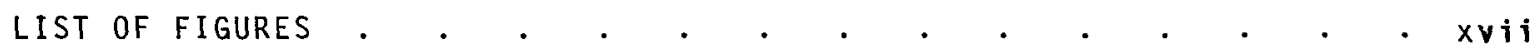

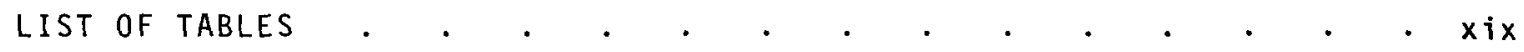

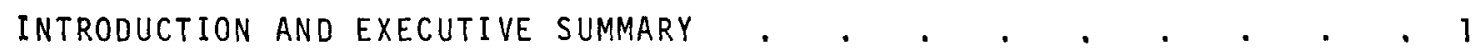

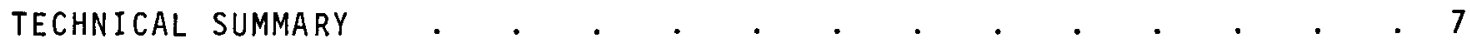

1.0 ALTERNATIVES FOR THE BACK END OF THE LWR FUEL CYCLE . . . 1.1

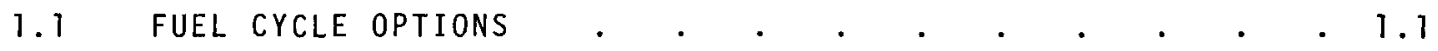

1.2 WASTE MANAGEMENT FOR THE FUEL CYCLE OPTIONS $\quad$ • $\quad$ • $\quad . \quad 1.2$

1.2.1 Waste Management Systems for the Fuel Cycle Options . 1.2

1.2.2 Impact of Fuel Cycle Options on Waste Generation . . 1.7

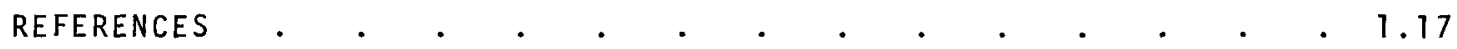

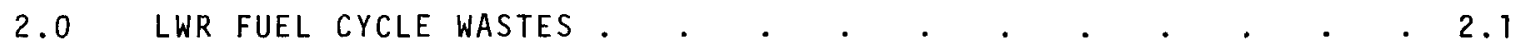

2.1 DESCRIPTION OF THE LIGHT WATER REACTOR (LWR) FUEL CYCLE • 2.1

2.7 .1 Mining . . . . . . . . . . . . . . . 2.1

2.1 .2 Miling . . . . . . . . . . . . . . . . . . 2.3

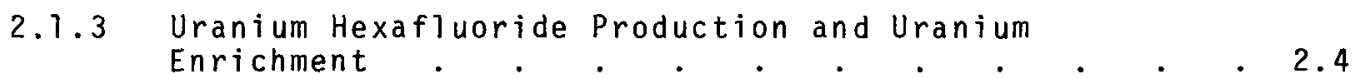

2.1 .4 Fuel Fabrication . . . . . . . . . . . . . 2.7

2.1 .5 Irradiation in Reactor . . . . . . . . . . . . 2.9

2.1.6 Reprocessing of Irradiated Fuel . . . . . . . 2.9

2.1 .7 Transportation . . . . . . . . . . . . . . 2.10

2.1.8 Alternative Fuel Cycles . . . . . . . . . . . . 2.10

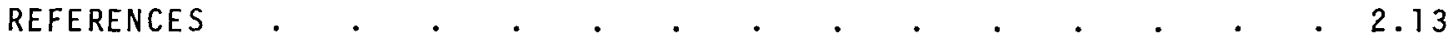

2.2 WASTE FROM REACTORS $. \quad . \quad . \quad . \quad . \quad . \quad . \quad . \quad . \quad . \quad . \quad 2.15$

2.2.1 Management and Cleanup Operations on Internal LWR

Liquid Streams . . . . . . . . . 2.18

2.2.2 Management of Primary Coolant $. \quad . \quad . \quad . \quad . \quad .2 .18$

2.2.3 Typical Waste Management Schemes and Solid Waste . . 2.27

2.2.4 Summary of Reactor Waste Volumes . . . . . . . . . 2.21

2.2.5 Reactor Component Wastes . . . . . . . . . . . . 2.21

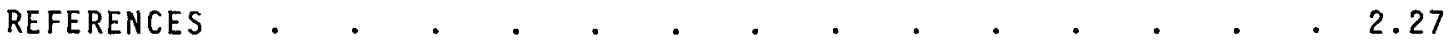


$x v i$

2.3 WASTES FROM SPENT FUEL STORAgE FACILITIES . . . . . 2.28

2.3.1 Description of Spent Fuel. . . . . . . . 2.28

2.3.2 Properties of Spent Fuel. . . . . . . . 2.29

2.3.3 Quantities of Spent Fuel . . . . . . . . 2.34

2.3.4 Characteristics and Operations of Reactor Pools . . 2.34

2.3.5 Characteristics and Operations of Pools at Fuel
Reprocessing Plants and Independent Locations

2.3.6 Waste-Generating Operations and Magnitude of Waste
Streams.. .5 .39

REFERENCES . . . . . . . . . . . . . . . . 2.42

2.4 WASTES FROM FUEL REPROCESSING PLANTS . . . . . . . . 2.43

2.4.1 Process Outline and Sources of Waste . . . . 2.43

2.4.2 Organization and Descriptions of Waste Streams . . 2.55

2.4.3 Alternative Fuel Cycles . . . . . . . . 2.67

2.4 .4 Summary $. \quad . \quad . \quad . \quad . \quad . \quad . \quad . \quad .79$

REFERENCES . . . . . . . . . . . . . . . . . . 2.82

2.5 WASTES FROM MIXED OXIDE FUEL FABRICATION PLANTS . $\quad . \quad 2.84$

2.5.1 Process Description . . . . . . . . . 2.84

2.5.2 Transuranic-Contaminated Combustible Solid Waste. . 2.84

2.5.3 Transuranic Noncombustible Solid Waste . . . . 2.88

2.5.4 Transuranic Liquid Waste . . . . . . . . 2.90

2.5 .5 HEPA Filter Waste . . . . . . . . . 2.92

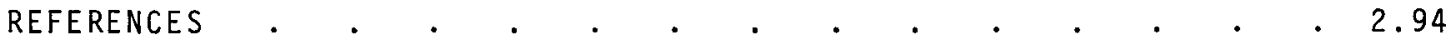

2.6 WASTES FROM DECOMMISSIONING OF FUEL CYCLE FACILITIES $\quad . \quad 2.95$

REFERENCES . . . . . . . . . . . . . . 2.98

3.0 PROJECTIONS OF LWR FUEL CYCLE QUANTITIES . . . . . . . . 3.1

3.1 BASIC ASSUMPTIONS . $. \quad . \quad . \quad . \quad . \quad . \quad . \quad . \quad . \quad . \quad 3.1$

3.1.1 Total Electric and Nuclear Capacities . . . . 3.1

3.1.2 Bases for Projections of Electric Operating Capacity, Materials Flows, and Waste Generation Involving LWRs. 3.1

3.2 PROJECTIONS

REFERENCES . . . . . . . . . . . . . . . 3.23

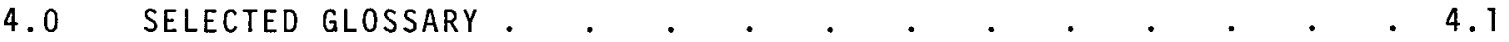




\section{LIST OF FIGURES}

$1 \quad$ Process operations and Wastes in the LWR Fuel Cycle

1.1 Origin, Treatment and Disposition of Radioactive Wastes from a Power Reactor (Mode I)

1.3

1.2 Origin, Treatment and Disposition of Radioactive Wastes from a Power Reactor (Modes II and III)

1.3 Origin, Treatment and Disposition of Radioactive Wastes from a Reprocessing Plant (Mode II)

1.4 Origin, Treatment and Disposition of Radioactive Wastes from a Reprocessing Plant (Mode III)

1.5 Origin, Treatment and Disposition of Radioactive Wastes from a MOX Fuel Fabrication Plant (Mode III)

1.6 Mode I - 10 Year Spent Fuel Cooling, Then Engineered Storage

1.7 Mode II - 5 Year Spent Fuel Cooling, 1 Year HLLW Cooling U Recycle Only

1.8 Mode III - 5 Year Spent Fuel Cooling, I Year HLLW Cooling

1.9 Modes Compared in Terms of Materials Processed in the Year 2000

2.1 The LWR Fuel Cycle

2.2

2.2 Alternative Fuel Cycles

2.3 Waste Sources from Alternative Fuel Cycles

2.4 Typical Flow Pattern of Radioactive Wastes in the BWR system

\subsection{6}

2.5 Typical Flow Pattern of Radioactive Wastes in the PWR System

2.6 General Scheme for Management of Liquid Wastes at Reactors

2.7 Sources and Characteristics of Non-Gaseous Wastes from l-GWe BWR with Deep-Bed Condensate Cleanup

2.8 Sources and Characteristics of Non-Gaseous Wastes from 1-GWe BWR with Powdered Resin Condensate Cleanup

2.9 Sources and Characteristics of Non-Gaseous Wastes from 1-GWe PWR with Powdered Resin Condensate Cleanup

2.10 Sources and Characteristics of Non-Gaseous Wastes from 1-GWe PWR with Deep-Bed Condensate Cleanup 
2.13 PWR Fue1 Assemb1y

2.14 Fuet Storage Canister

2.15 Operations and Waste Generation Involving Reactor Fue Storage Pools

2.16 Operations and Waste Generation Involving Fuel Storage Pools at Reprocessing Plants and Independent Locations

2.17 Reprocessing of LWR Fuel

2.18 Waste Generation Flow Sheet for Fuel Reprocessing I. Head-End

2.19 Waste Generation Flow Sheet for Fuel Reprocessing II. Solvent Extraction

2.20 Waste Generation Flow Sheet for Fuel Reprocessing III. Uranium Purification and Product Formation

2.21 Waste Generation Flow Sheet for Fuel Reprocessing IV. Plutonium Purification and Product Formation

2.22 Waste Generation Flow Sheet for Fuel Reprocessing V. Process Support

2.23 Waste Generated in Fuel Reprocessing Operations I. High Level, Intermediate Leve1, and Low Level Liquid Waste

2.24 Waste Generated in Fuel Reprocessing Operations I . Gaseous and Solid Waste

2.25 Distribution of Tritium in Fuel Reprocessing Wastes

2.26 Plutonium Combustible Solid Waste from the Mixed-0xide Fuel Fabrication Plant

2.27 Plutonium Noncombustible Solid Waste from the Mixedoxide Fuel Fabrication Plant

2.28 Plutonium Liquid Waste from the Mixed-0xide Fuel Fabrication Plant

2.29 Plutonium Ventilation-Filter Waste from the Mixed-0xide Fuel Fabrication Plant 


\section{LIST OF TABLES}

1.1 Reference Interim Storage Periods for the Three Fuel Cycle Modes

1.2 Distribution of Fissile Plutonium, MT - By $2000 \quad 1.16$

1.3 Gases Released During Reprocessing Mode III $\quad 1.17$

2.1 Summary of Non-Gaseous Reactor Waste Volumes 2.26

2.2 Characteristics of Unirradiated LWR Fuel Assemblies 2.32

2.3 Chemical Composition of the Reference LWR Fuel Assembiy 2.33

2.4 Chemical, Radiochemical, and Thermal Properties of Irradiated Reference LWR Assembly at Three Cooling Times 2.35

2.5 Reference LWR Fuel Assembly Weight Distributions at Various Appearance Rates

2.6 Summary of Solid Wastes Volumes from Spent Fuel Basins 2.42

2.7 Typical Plutonium Nitrate Specifications 2.53

2.8 Composition of Liquid High Level Waste Basis: 378 Liter/ MTHM, 25 GWd/MTHM, 35 MW/MTHM, SGR $=1.0$ for MOX Content; No $\mathrm{Xe}, \mathrm{Kr}, 0.1 \% \mathrm{I}, \mathrm{Br}, 8 \% 3 \mathrm{H}, 0.5 \% \mathrm{Pu}, 0.5 \% \mathrm{U}, \mathrm{A} 11 \mathrm{~Np}$, Am, Cm 2.59

2.9 Composition of High Level Waste Basis: $25 \mathrm{GWd} / \mathrm{MTHM}, 35 \mathrm{MW} /$ MTHM, SGR $=1.0$ for MO Content No Xe, $\mathrm{Kr}, 0.7 \% \mathrm{I}, \mathrm{Br}, 8 \%$ $3 \mathrm{H}, 0.5 \% \mathrm{Pu}, \mathrm{U}, \mathrm{A} 11 \mathrm{~Np}, \mathrm{Am}, \mathrm{Cm}$

2.10 Properties of Intermediate Level Waste Solution After Neutralization

2.11 Estimated Composition of Low Level Liquid Wastes

2.12 Noble Gas Fission Products Available in Fuel Reprocessing

2.13 Solid Wastes From Fuel Reprocessing Operations $\quad 2.68$

2.14 Summary of Solid Waste from Fuel Reprocessing $\quad 2.70$

2.15 Properties of Metals and Selected Elements Contained in Fuel Assembly Wastes

2.16 Radioactivity Content in Reference Fue1-Assembly Metal Waste as a Function of Long-Term Cooling

2.17 Fission Product and Actinide Content of LWR Fuel for a "Throwaway" Fuel Cycle

2.18 Properties of High-Level Waste from Processing of LWR Reference Fuel Compared with. Properties of "Throwaway" Fue 1

2.19 Radiation from High Level Waste Generated by Processing of Spent $\mathrm{UO}_{2}$-Bearing LWR Fue 1 
2.21 Properties of Plutonium from LWR-UO 2 Fuel

2.80

2.22 Isotopic Content and Radiations from LWR Plutonium

2.23 Mixed Oxide Fabrication Plant Plutonium Feed

2.24 Amounts and Activities of Plutonium-Contaminated Waste from Mixed-Oxide Fuel Fabrication

2.25 Volumes and Contamination Categories of Residues from Decommissioning of Light Water Reactors

2.26 Contaminated Waste from Dismantling a 1500 MTU/year Fue 1 Reprocessing Facility

2.27 Contaminated Waste from Dismantling a 300 MTHM/year MixedOxide Fabrication Facility

3.1 Characteristics of the Mod-Low Energy Growth Case

3.2 Projected Nuclear LWR 0perating Capacity

3.3 Projected Accumulation of Uranium Ore Tailings

3.4 Materials Consumed, Produced, and Stockpiled for LWR Power

3.8

3.5 LWR Fuel Fabricated

3.8

3.6 Shipments of Plutonium by Truck to Fabrication Plants for LWR Pu-Recycte Fue 1

3.9

3.7 Fresh Fuel Shipments by Truck to LWRs

3.9

3.8 Predicted Distribution of LWR Spent Fuel Reprocessing Among U.S. Facilities in the Near Term

3.9 Comparison of Reprocessing Requirements and Activities

3.10

3.10 Shipments of Spent LWR Fuel to Reprocessing Plants

3.11 Projected Accumulation of Solidified LWR High-Level Wastes at Fuel Reprocessing Plants Before Shipment

3.12 Containers of 10-yr-01d LWR High-Level Waste Shipped

3.13 Projected Accumulation of Solidified LWR High-Level Wastes at a Federal Repository

3.14 Projected Accumulation of LWR Cladding Wastes at a Federal Repository

3.15 Projected Accumulation of Fission Product Tritium from LWR Fue 1

3.16 Projected Accumulation of Fission Product Iodine from LWR Fuel

3.17 Projected Accumulation of Noble Gas Fission Products from LWR Fuel

3.18 Projected Accumulation of ${ }^{14} \mathrm{C}$ from Spent LWR Fuel

3.19 Projected Accumulation of Beta-Gamma Wastes at Surface Burial Grounds 
3.20 Projected Accumulation of Plutonium Alpha Wastes at a Federal Repository 
INTRODUCTION

AND EXECUTIVE SUMMARY 
INTROOUCTION

AND EXECUTIVE SUMMARY

This document describes technologies for managing radioactive wastes from commercial nuclear power. It is directed specifically at wastes associated with what is known as "the back end of the LWR fuel cycle," i.e., activities related to handing of spent fuel after it is removed from light-water-cooled reactors (LWRs). The LWRs are currently the predominant reactor type in the commercial U. S. nuclear power industry.

The document characterizes the technologies and classifies their state of availability. It is not a decision or program document. It is strictly a baseline or reference document, technical in nature, and designed to serve as a sourcebook of information on the technologies of radioactive waste management. It is a bridge between past and future activities to develop technology for managing radioactive wastes; i.e., it describes the current status of technology and provides a basis for future action. It is assumed that the technologies to be adopted must be operable within the applicable radiation safety regulations.

\section{ORIGINS AND FUNCTIONS OF THE DOCUMENT}

This document is an outgrowth of a need for technical alternatives in preparation of an environmental statement and a request from the Joint Committee on Atomic Energy for a comprehensive report on options for managing radioactive wastes. It is also a step in ERDA strategy for fulfilling its responsibilities concerning development of commercial radioactive waste management technology. The document is responsive to the JCAE request for a discussion of options; it simultaneously provides baseline information and data for formulation of ERDA program plans and preparation of environmental impact statements. Other documents will address R\&D plans; still others will address environmental impacts.

The basic purpose of this document is to provide government, industry, and the public a convenient, comprehensive and non-evaluative description of the technologies to be considered in actions such as preparation of environmental impact statements or selection of ERDA programs concerned with managing wastes from the back end of the commercial LWR fuel cycle. A document of this type is needed because there are in fact numerous alternative technologies for each aspect of radioactive waste management. This compilation of information helps assure that all alternatives are considered, and that all participants in actions to make selections have a common information base. To preserve its role as a source document, this report makes no recommendations, makes no comparative assessments 
and program selections are future actions to be derived from the contents of this document and public discussion of the alternatives.

BACKGROUND FOR THE TECHNOLOGY ADDRESSED

Spent LWR fuel contains fissionable uranium and plutonium in concentrations that are potentially of commercial interest. To make use of these materials, the fuel would be processed to recover the uranium and plutonium; these materials would then be fabricated into fuel elements containing mixed oxides of uranium and plutonium (Mox fuel elements) which would be recycled to reactors.

If uranium and plutonium are recovered and recycled, the back end of the LWR fuel cycle is said to be closed. One alternative to this mode of operation for the back end of the fuel cycle is to regard the spent fuel as material to be stored indefinitely or discarded; this is known as the "throwawal fuel cycle. Other alternatives involve recycle of one or the other of the fuel materials, e.g., recycle of uranium and storage of plutonium.

Radioactive materials in the back end of the fuel cycle become wastes when they are to be discarded. In their initial form, the wastes occur as a variety of solid, liquid, and gaseous materials; these are called "primary" wastes.

The primary wastes may undergo treatment prior to final disposition. For example, liquids can be converted to solids, and combustible materials can be burned in order to reduce their volume. In general, such operations are known as "treatment technologies"; there are numerous alternative specific concepts for each type of treatment.

Treatment of primary wastes produces what are known as "secondary" wastes which consist of the treated primary wastes plus any other wastes that result from the treatment process itself. Combustion, for example, generates off-gases that may be filtered prior to discharge; the spent filters, in addition to the residue from combustion of the primary wastes, become part of the secondary wastes.

In general, the treatment operations take a broad spectrum of primary waste materials and convert them to a few secondary waste types in forms suitable for transportation, handling, and final disposition. Quantities and characteristics of the secondary wastes will depend on which treatment technologies are used, which fuel cycle mode (e.g., throwaway or closed) is used, and what use is made of logistic factors such as holdup times prior to treatment. 
A single, unique characterization of commercial radioactive waste management is therefore not possible. Specific fuel cycle conditions and waste management technologies must be defined from among the alternatives. This document identifies and characterizes the waste management technology alternatives; these can be regarded as alternative "building blocks" from which complete waste management systems can be assembled.

In addition to waste treatment there are three other basic waste management functions: interim storage, transportation, and final isolation or disposal. Alternatives for each are discussed in this document. The terminology is used as follows:

- Storage is "interim" when the waste is being held with anticipation of subsequent waste management action such as treatment or transportation. An example of interim storage is tank storage of liquid wastes prior to solidification.

- Transportation is movement of materials from one site to another.

- "Final isolation or disposal" is the terminology used for the alternatives for final disposition of the wastes. "Disposal" refers specifically to alternatives that offer little or no chance for reversibility. "Final isolation" refers to alternatives that isolate the wastes from mankind and the biologic environment by placing them in stable geologic media.

Some of the isolation alternatives involve disposal concepts; i.e., the wastes would be put into geologic isolation using emplacement techniques not intended to permit reversibility. Other isolation alternatives involve "final storage," which isolates the wastes from the biologic environment by using emplacement techniques that do offer opportunity for reversibility, i.e., retrieval.

Two types of geologic isolation storage can be distinguished: "provisional geologic storage," which uses emplacement techniques and monitoring operations that permit retrieval with methods and rates essentially the same as those used for emplacement, and "permanent geologic storage" from which the wastes could be retrieved using excavation and mining techniques. Repositories operated for provisional storage could be converted to permanent storage by backfiling and sealing. 
This document discusses four basic types of media that can be used for geologic isolation by storage or disposal: shallow continental geologic formations, deep continental geologic formations, the sea floor, and ice sheets. It also describes two other irreversible disposal alternatives: ejection to space and transmutation, which involves bombarding the waste materials with nuclear particles or radiation in order to convert them to other isotopes. The latter two alternatives can be used only for selected waste constituents which would have to be separated from the rest of the materials in the waste that contains them.

In summary, alternatives for the back end of the LWR fuel cycle consist of options for the fuel cycle mode and options for technologies used for treatment, interim storage, transportation, and final isolation or disposal of wastes. This document describes the alternative waste management technologies and their current status. It is a technical basis for future programs, public discussion, and environmental impact statements.

\section{SCOPE OF THE DOCUMENT}

This document describes alternative technologies for all steps of management of all wastes for the back end of the LWR fuel cycle, including wastes from the reactors and wastes produced by decommissioning fuel cycle and waste management facilities. Technologies being developed or used in other nations are included.

The report also includes description of LWR fuel cycle alternatives, description of wastes, and projection of waste quantities. In practice, waste quantities and types, and the waste properties, will depend on many things, including the operating history of the reactors; the length of time the spent fuel is held in storage; the mode of operation of the back end of the fuel cycle (e.g., throwaway or closed); the technology, if used, for processing the spent fuel; the technology used for waste treatment and the length of time wastes are held in interim storage. The descriptions of wastes and projection of waste quantities that are included here are estimated on the basis of known characteristics of the technologies and anticipated operating practice in the industry.

For purposes of illustrating the effect of technology and fuel cycle mode on waste quantities and properties, the report also includes overview characterizations of three alternative fuel cycle modes: operating without spent fuel processing, recycle of uranium coupled with storage of plutonium, and recycle of both uranium and plutonium. In all three cases, use of current waste management technology is assumed. 
The descriptions of waste management technologies given in this document are, for the expert professional, highly condensed. Readers interested in details may consult the references or authors. References have been used extensively but without attempt to provide exhaustive compilation of the waste management literature. The references were selected to provide access to additional literature and information.

\section{STATUS OF THE TECHNOLOGY}

A major purpose of this report was to characterize waste management technology in terms of its state of readiness for commercial use. Another purpose was to determine if there are any areas where needed waste management technology is missing, i.e., not now available or under development. The cutoff date for characterizing the status of technologies was September 1,1975 .

The status of technologies is characterized and classified as commercialized, available, or under development. Commercialized technology is in routine use with radioactive materials for industry purposes at economic scale. Technology is "available" if its status is such that design and construction of a full scale commercial installation can be initiated; design verification tests might be required. The status of technologies under development can range from early-on concept testing in the laboratory to nearly available.

The information contained in this document shows that all technologies needed to manage radioactive wastes from the back end of the commercial LWR fuel cycle are commercialized, available, or under development; there are no gaps. Management of radioactive wastes from all options for the back end of the LWR fuel cycle can be accomplished using commercialized or available technology as defined above. Technologies for managing wastes from LWR reactors are fully commercialized. Technologies for treatment, interim storage, and transportation of wastes from fuel cycle operations such as fuel processing are commercialized, or ready for commercial-scale design and proof-testing, or can readily be implemented by adaptation of commercial practice for management of nonradioactive wastes.

The available technologies for final disposition of wastes are burial grounds and provisional storage in deep continental geologic formations. Stable geologies expected to be suitable for deep geologic isolation are known, technologies for site exploration and site selection are available, and design principles for waste repositories are known. Repository designs and qualification procedures will be specific to the site being considered; they can be developed as necessary when candidate sites are identified. 
The technologies under development provide alternatives to existing technology. Implementation of the developing technologies would be expected to provide benefits such as reduced environmental impacts, simplified procedures, and reduced costs in comparison with existing technology. Comparative assessments of existing and developing technologies can be made as information from the development work becomes sufficient for such evaluations.

\section{DOCUMENT STRUCTURE}

This document is structured to reflect the four basic waste management technologies of treatment, interim storage, transportation, and final isolation or disposal. Volume 1 includes, in addition to the Introduction (Executive Summary) and a Technical Summary, background information on the LWR fuel cycle alternatives, descriptions of waste types, and projections of waste quantities. Volume 1 also contains the overview characterizations of alternative LWR fuel cycle modes.

Volume 2 describes alternative waste treatment technologies. Volume 3 describes alternatives for interim storage and transportation. Volume 4 describes final isolation and disposal alternatives. The Appendices, Volume 5 , provide supporting information, with emphasis on continental and sea floor geologies. 


\section{TECHNICAL SUMMARY}

This is a technically oriented summary of this document, which describes alternatives for managing radioactive wastes from reactors, spent fuel storage basins, fuel reprocessing plants, and mixed-oxide fuel fabrication plants in the fuel cycle for light-water-cooled commercial reactors (LWR's). In commonly used terminology, the document describes waste management alternatives for the back end of the commercial LWR fuel cycle.

This document characterizes the technologies and classifies their status; it is not a decision or assessment document. It is a digest of technical information on waste management alternatives which is expected to serve as a basis for future decisions, assessments, and environmental impact statements. It is assumed that technologies to be adopted must be operable within the applicable radiation safety regulations. Because of its focus on the back end of the commercial LWR fuel cycle and its role as a reference document, the document does not:

- address pre-fission waste management issues

- address management of noncommercial (e.g., Defense) wastes

- address environmental impact issues

- select a preferred commercial waste management system

- estimate and compare costs

- estimate and compare safety and risks.

The scope of this document does include:

- identification and characterization of wastes from the back end of the commercial LWR fuel cycle

- projection of waste quantities

- identification and description of alternative technologies for treatment, interim storage, and transportation of wastes

- identification and description of alternatives for final storage and disposal

- overview characterization of three alternative fuel cycle and waste management systems:

- operation without fuel reprocessing ("throwaway" fuel cycle)

- recycle of uranium, storage of plutonium, and use of available waste management technology

- recycle of uranium and plutonium; use of available waste management technology.

These characterizations illustrate comparison of alternative LWR fuel cycle modes operated with the same waste management technology. Technologies which are not now ready for application but which show promise of economic, environmental impact, or operational benefits are 
candidates for research and development and detailed assessment of their effects on fuel cycle and waste management characteristics and impacts.

The alternative waste management technologies are discussed in terms of four basic waste management activities:

- Treatment, which converts the wastes from their as-generated form to forms needed for handling, transportation, and final disposition of the wastes. As-generated wastes are termed "primary wastes"; wastes that emerge from treatment operations are "secondary wastes."

- Interim storage, which provides retention of primary and secondary wastes while they are in man's environment and subject to subsequent management activities such as treatment or transportation.

- Iransportation, which is applied to movement of waste materials between sites.

- Final isolation or disposal, which provides final disposition of wastes. The basic alternatives are isolation in geologic media or elimination of the wastes from existence on earth.

Anticipated waste types, quantities, and characteristics for the commercial LWR fuel cycle are summarized in Figure 1. Actual waste quantities will depend on the specific technologies used in fuel cycle operations and waste management. Values given in Figure 1 are representative of current practice. Waste types and radioactivity characteristics shown in Figure 1 are expected to be generally representative of primary wastes generated by the commercial LWR fuel cycle.

Alternatives for the fuel cycle and waste management can be summarized as follows:

\section{FUEL CYCLE OPERATIONS}

Characteristics and quantities of wastes produced in the back end of the LWR fuel cycle will depend on technologies and logistics used for fuel cycle and waste management operations. Overview characterizations were developed for three basic alternatives, each of which was assumed to use available waste management technology:

- No recycle of uranium or plutonium.

- Uranium recycle only (plutonium is stored).

- Recycle of uranium and plutonium.

Waste management requirements for these alternatives differ in detail. The two recycle options are, within the framework of assumptions used, similar with respect to impacts on waste management: both require fuel reprocessing and its comparatively strong impact on waste quantities and characteristics. Recycle of plutonium in addition to uranium involves 


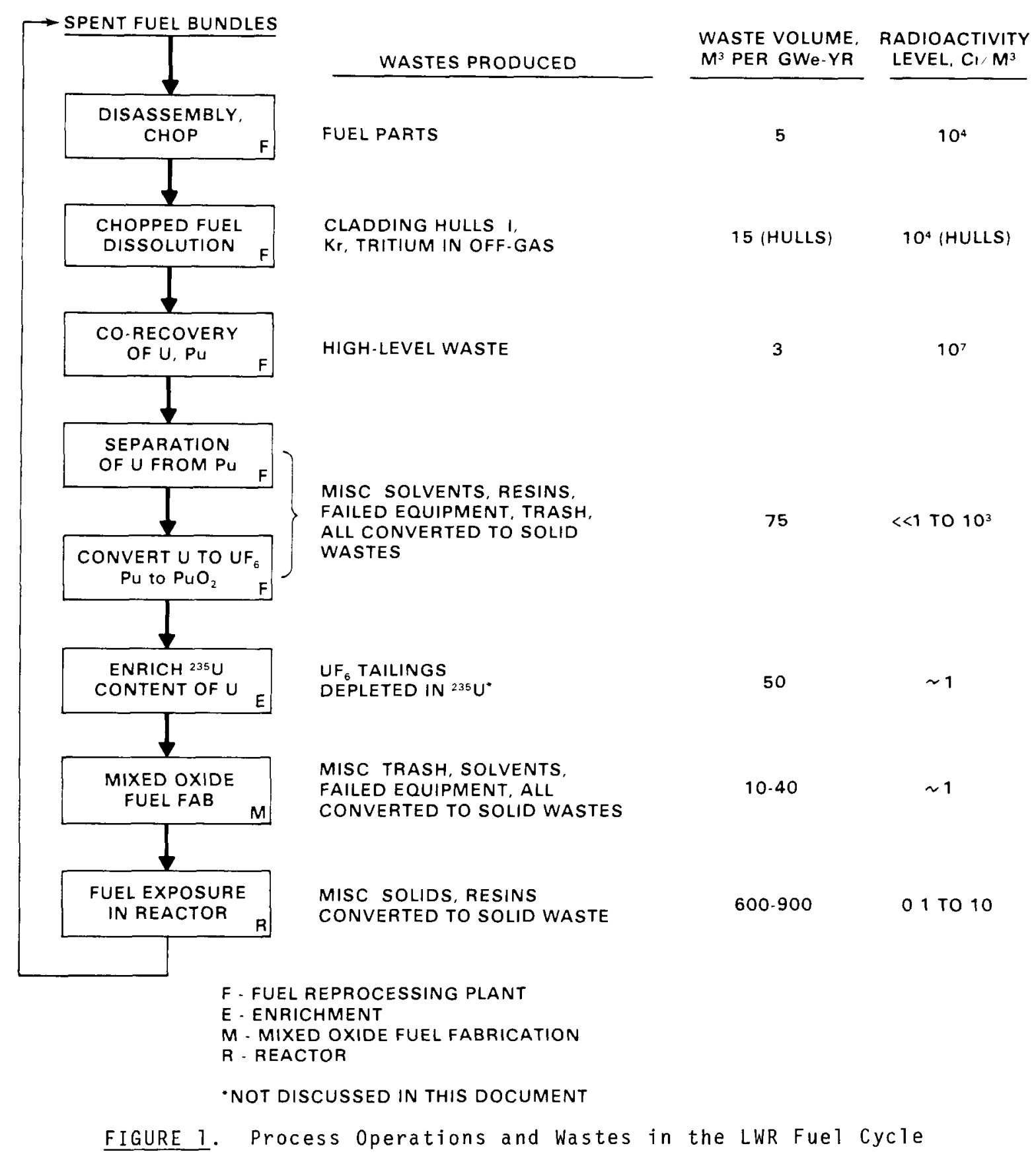


addition of mixed-oxide fuel fabrication plants to the fuel cycle; such operations have minor effect on waste quantities. The "throwaway" fuel cycle (no recycle of plutonium or uranium) minimizes waste quantities but maximizes inventories of long-lived alpha particle-emitting nuclides in the wastes. Detailed comparative assessments of these alternatives have not been made and are not within scope of this document.

IRRADIATED FUEL

The technology is available and in use for interim storage and transportation of irradiated LWR fuel. If the irradiated fuel becomes a waste, i.e., if the uranium and plutonium in spent fuel are not returned to the fuel cycle, then the fuel assemblies can be stored or managed as a waste, e.g., by placing them in containers and filling the void space with metal. Such technology is available but has not been used.

CHOP-LEACH FUEL BUNDLE RESIDUES

The chop-leach fuel bundle residues are solid wastes comprising short lengths of fuel cladding, fuel bundle support rods, poison rods, massive end fittings, fuel support grids, assorted springs, and spacer elements. Between 0.05 and $0.5 \%$ of the original fuel material remains with these wastes as an insoluble residue. The available technology is to store these wastes without treatment. The small amount of chop-leach fuel bundle residue wastes generated in the U.S. to date, at the Nuclear Fuel Services plant, was packaged in steel containers and placed in shallow geologic isolation (burial grounds).

Advanced technology is being developed to decontaminate and/or consolidate these wastes by mechanical compaction, by melting, or by chemical reaction.

\section{HIGH-LEVEL LIQUID WASTE}

High-level liquid waste (HLLW) is generated in the first solvent extraction cycle of nuclear fuel reprocessing facilities. Because HLLW can contain over $99.9 \%$ of the nonvolatile fission products and more than $50 \%$ of the actinide activity in the wastes from the back end of the fue 1 cycle, significant amounts of research, development, and engineering resources have been applied to this waste.

No LWR fuel cycle HLLW has yet been generated in the United States except for a small amount generated at the Nuclear Fuel Services plant at West Valley, New York, during the years 1966-1972. That waste is now in storage. Present regulations require that when more commercial HLLW is generated in the U.S. it must be converted to a stable, dry solid within five years after fuel reprocessing. 
Technology exists to convert the HLLW to a calcine powder or a glass. ERDA wastes, which differ chemically from LWR fuel cycle wastes and have lower levels of radioactivity, have been calcined routinely at the Idaho National Engineering Laboratory since 1963. A production-scale facility for converting HLLW to glass, under construction at Marcoule, France, is scheduled to begin operation in 1977. Several alternative methods for converting HLLW to a glass are being developed in the U.S. within ERDA programs.

\section{NON-HIGH-LEVEL LIQUID WASTES}

This classification includes a wide variety of waste types. Some plant wastes, such as laundry and decontamination solutions, are common. But the category also includes wastes specific to certain plants, such as acid etch solutions from a mixed-oxide fuel fabrication plant or alkaline solvent wash solutions from a fuel reprocessing plant. Thus the non-high-level liquid waste category encompasses a broad spectrum of radioactive liquid wastes varying widely in chemical and radioactive content.

Because of the diversity of non-high-level liquid waste types and because the goal is usually to clean large volumes so that the water can be released as a plant effluent, a sequence of treatment processes is usually required. The treatments are relatively conventional technology. In addition to evaporation, which is the most commonly used treatment technology, treatments can include reverse osmosis, flocculation, precipitation, filtration, and ion exchange. The technologies are all available, and most are currently being used in the nuclear industry.

Certain non-high-level liquid wastes, such as waste solvent from a reprocessing facility, are flammable. Technology is available for the incineration of these wastes.

IMMOBILIZATION OF NON-HIGH-LEVEL WASTES

Virtually all nuclear fuel cycle operations generate liquid or solid wastes requiring immobilization prior to transportation and storage. Many alternative technologies are currently in use to immobilize these wastes. The alternative technologies include the use of absorbents and the incorporation of the wastes in concrete, asphalt or urea-formaldehyde resin.

Absorbents have been used widely in both the chemical and nuclear industry to immobilize liquids for transportation and disposal. Some of the typical granular or powdered absorbent materials include vermiculite, silica gels, plaster of paris, and various clays. The absorbent method, properly applied, will entrap the waste liquid so that no free liquid exists within the bulk material. 
Incorporation of radioactive wastes in cement or concrete has been a common practice for many years. The optimum proportions of cement and waste vary with the type of waste to be solidified. Maximum waste contents for the solidified products are typically $75 \mathrm{wt} \%$ for solid waste or $33 \mathrm{wt} \%$ for aqueous solutions or slurries.

Commercialized technology is available for the immobilization of a wide variety of wastes in asphalt, or bitumen, including neutralized evaporator concentrates, sludges, ion exchange media, and incinerator ashes. Both batch and continuous processes are in use, particularly in Europe.

Systems for immobilizing reactor wastes in urea-formaldehyde have been marketed commercially since 1972 .

COMBUSTIBLE SOLID WASTES

Combustible solid radioactive wastes include a large variety of items such as paper, rags, plastic sheeting, protective clothing, gloves, rubber shoes, wood, organic ion exchange resins, filter aids, etc. Much of the waste material is collected as general trash, which usually consists of a mixture of combustible and noncombustible items. Therefore, treatment options generally include sorting prior to treatment of the wastes.

Waste compositions vary depending on the operations involved. General trash, or non-glove box waste, includes mainly cellulosic materials such as paper, wood, cardboard, absorbent cotton, cotton clothing, and rags. Usually these materials burn readily to release water vapor and carbon dioxide. Glove box-generated wastes, on the other hand, contain chiefly rubber or plastic materials since cellulosic materials are mostly excluded from glove box operations.

Various treatment technologies are available for combustible wastes. They range from simple storage in boxes or steel drums to compaction, encapsulation in concrete, and incineration.

Compaction or baling is a mechanical operation for reducing the volume of the waste. For a typical combustible waste, a volume reduction of 5to 10-fold can be expected. Shredding of the waste before compacting is sometimes done to increase the volume reduction ratio.

Some combustible wastes have been immobilized by mixing with concrete. An example of this type of operation is the incorporation of dewatered ion exchange resin in cement.

The incineration of combustible waste is simple in principle but requires special considerations when applied to radioactive materials. The most important of these considerations have been associated with the 
off-gas cleanup system. A number of alternative incineration systems are being developed and evaluated in the U.S. These systems include simple single-chamber units, fluidized beds, moving grates, and rotary kilns. The operational modes include excess air incineration, controlled air incineration, and acid digestion.

NONCOMBUSTIBLE SOLID WASTES

The primary constituent of these solid wastes is metal, but other noncombustibles such as glass and concrete are also present. Incidental quantities of combustible material such as grease, plastic, and floor sweepings may also be present with the noncombustible waste.

Examples of items that become noncombustible wastes are inoperable and obsolete process equipment such as pumps, process vessels, piping, and laboratory or process glove boxes. These large items present a unique waste management problem due to size and, in some cases, high radiation levels. Small items also in this waste category include filters, broken glassware, and shielding material.

The smaller noncombustible solid waste items are often associated with combustible materials. As an example, plant maintenance activities such as replacement of a process valve will contaminate plastic, rags, and other combustible items, thus requiring a prepackaging sorting or segrega. tion operation.

The steps in management of large noncombustible waste items are decontamination, disassembling, and packaging. Commercialized technology is available for these steps. Decontamination usually includes chemical flushing with several different reagents but may also include mechanical activities. Disassembling may be done by sawing or mechanical cutting or tearing, as well as cutting with torches or electric arc. Packaging can be done either with or without crushing or mechanical compaction.

Advanced alternatives being developed for the future are directed toward decreasing the final volume of these wastes and decreasing the individual mechanical operations required in their treatment. These alternatives include melting and dissolution.

\section{GASEOUS WASTES}

Gaseous wastes include radioactive noble gases, iodine, tritium and carbon-14. Treatment technology is available for the noble gases and iodine, and is being developed for tritium and carbon-14. The technologies being developed for tritium and carbon-14 are to meet a possible future need; their present release rates do not require treatment under present regulations. 
Two technologies are available to collect noble gases from off-gas effluents. One is the cryogenic treatment of the entire off-gas stream followed by distillation of the resultant liquified air for purification of the noble gas fraction. This technology is currently used at the Idaho Chemical Processing Plant (ICPP). The second technique is collection by liquid fluorocarbon absorption. This technology is presently being offered commercially for capture of noble gases released from light water reactors.

At present, captured noble gases are stored in pressurized gas cylinders. Development is currently underway on encapsulating noble gases in a sodalite-zeolite matrix. The advantage of the zeolite encapsulation is that long-term storage of noble gases does not depend on the integrity of pressure vessels.

Iodine can be removed from effluent off-gas streams by suing one of many available technologies which include caustic scrubbing, chemisorption by metal-loaded absorbents, mercuric nitrate-nitric acid scrubbing, and iodox scrubbing. The choice of technique depends on the nature of the off-gas stream to be treated and the desired final product form of the captured iodine.

DECONTAMINATION AND DECOMMISSIONING OF RETIRED FACILITIES

Facilities contaminated in fuel cycle operations can become a major waste quantity upon retirement. Three alternatives for decommissioning contaminated facilities have been identified in Regulatory Guide 1.86 of the Nuclear Regulatory Commission. The alternatives are protective storage, entombment, and dismantling.

Protective storage is often referred to as mothballing. In this decommissioning alternative the facility is prepared to be left in place safely for an extended period which might range from decades to two or three centuries. Potentially mobile radioactive materials are removed from the site. All operational systems and support utilities are placed in a nonoperation mode. A continuous surveillance program is established.

Entombment involves all the decommissioning steps of protective storage but in addition provides for sealing all contaminated facility components in a high-integrity structure. Such contaminated components might include the pressure vessel and internals of a light water reactor or the major processing vessels of a reprocessing facility.

The dismantling alternative involves removing from the facility site all radioactive components and materials which exceed the criteria for unrestricted release. Once all the radioactivity is gone, all restrictions on the site are removed. This mode of decommissioning may be applied 
immediately after facility retirement or following a period of protective storage to allow decay of short-lived radionuclides.

All three of the decommissioning alternatives have been employed. For example, four reactors at Hanford and the Fermi reactor in Michigan have been placed in protective storage and are currently in this status. The Hallam nuclear power facility near Hallam, Nebraska, has been entombed. After shutdown in 1968 the reactor at Elk River, Minnesota, was dismantled and the reactor site was returned to unrestricted use. Other facilities have also been subjected to these decommissioning technologies.

\section{INTERIM STORAGE OF WASTE}

There are several points during the operational sequence of an integrated waste management program at which interim storage should or can be provided for various waste forms. The interim storage may be a holding, or surge, point between operations, as is the case with interim liquid storage of both high-level and intermediate-level wastes. Interim storage may also be a holding point for final solid waste products prior to final isolation or disposal.

Interim storage facilities are designed to minimize radiation exposures to man and to provide confinement of the waste for as long as necessary. At the end of the interim storage period for solid wastes, the waste containers must be capable of being retrieved and transported to future treatment or storage sites, preferably without need for repackaging. Consideration must also be given to protecting the waste from accidental intrusion, vandalism, and other adverse acts.

Interim storage has been used for wastes representative of all of the wastes from the back end of the LWR fuel cycle, either commercially or in ERDA facilities. The storage technologies include tank storage of liquid wastes, water basin storage of spent fuel elements, and warehouse and other engineered surface storage of solid wastes. Retrievable surface storage of solidified high-level wastes has been investigated but not implemented.

\section{IRANSPORTATION}

Transportation of nuclear material is required between operating facilities in the nuclear fuel cycle. These transportation steps include movement of spent nuclear fuel from the reactors to reprocessing facilities, movement of nuclear waste from a reprocessing facility to a Federal repository, and movement of recovered plutonium, all of which must be done within the Department of Transportation regulations.

Transportation of Spent Fuel

The technology and hardware to transport spent light water reactor fuel is in use. Truck casks and rail casks are presently available. Most of 
these casks will accept PWR or BWR spent fuel with a slight change of the casks internals.

\section{Iransportation of Waste Forms}

The nuclear waste forms that require transportation include solidified high-level waste, chop-leach fuel bundle residues, and non-high-level solid wastes.

To date no solidified high-level waste has been generated by the commercial sector of the industry; therefore, none has been shipped. Conceptual designs are available for heavily shielded shipping casks to transport this waste form. These casks will be similar to currently available spent fuel casks.

Also to date, no chop-leach fuel bundle residues have been required to be shipped offsite. Thus no shipping containers specifically designed for these wastes are presently available. The wastes can, however, be shipped using conventional radioactive shipping container technology.

Non-high-level waste is generated at all back end fuel cycle facilities. To accommodate the various waste forms in this category, several waste transportation containers and casks have been developed, licensed, and are commercially available today. Special non-high-level waste forms may be generated that require new casks, but these new casks can be developed with existing technology.

Plutonium is separated from spent fuel at a reprocessing facility. The separated plutonium is then shipped to a fuel fabrication plant.

By regulation, all plutonium shipped after June 1978 will be in a solid form. Small quantities of plutonium are now being shipped routinely. Advanced plutonium cask designs are presently being developed to accommodate the larger quantities of plutonium that will require transportation in a mature industry. These developments would also be available for wastes containing plutonium.

FINAL ISOLATION AND DISPOSAL

There are two basic alternatives for final management of wastes generated by the commercial LWR fuel cycle: 1) geologic isolation and 2) elimination from existence on earth. Geologic isolation, that is, placement in geologic formations, offers two options: storage, which provides for retrieval of wastes after emplacement, and disposal, which uses emplacement techniques based on anticipation that the wastes would not be retrieved.

Two elimination alternatives have been defined: extraterrestrial ejection by rocket, and transmutation, in which nuclides are bombarded by nuclear particles or radiation with the objective of efficiently 
converting the bombarded nuclides to new species that will decay more quickly and/or emit less hazardous radiation.

The elimination options can be used only for selected waste components. The separations technology needed has not been developed.

The fundamental concept for geologic isolation is emplacement of wastes in geologic media expected, because of their stability, to maintain isolation for as long as necessary. Geologic isolation could be further augmented if the goelogic medium has capability to retard nuclide migration.

Four basic geologic environments have been identified as candidates for isolation of radioactive wastes: the sea floor, ice sheets, formations under the continents at depths isolated from the biosphere, and shallow continental geologic formations used as burial grounds.

With present technology, opportunities to use these geologic isolation alternatives can be summarized as follows:

- For ice sheets, additional geologic and meteorologic data are needed.

- Disposal in geologic formations in the sea floor is being investigated. The technical information base is at present insufficient, but all information available tc date is supportive of the concept.

- Emplacement in burial grounds, i.e., shallow geologic formations, has been used in the past and is anticipated for the future. Past use of this concept has not fully utilized a systematic approach to isolation in shallow geologic formations; practice is being improved.

- Numerous concepts for disposal in deep geologic formation (i.e., emplacement without anticipation or retrieval) have been defined. Most concepts are feasible with current technology, but long-term post-emplacement stability has not been evaluated.

- Deep continental geologic formations suitable for disposal or permanent storage have been identified. Procedures and technology for selecting specific repository sites are available, and conventional engineering practice can be used to design repository systems.

Geologic storage or disposal relies on the geologic medium to serve as a stable barrier that keeps the wastes isolated. The geologic barrier can be augmented by selecting waste forms and engineered structures that contribute to the stability of the system and, in storage systems, provide capability for waste retrieval.

Design of geologic isolation repositories is specific to the site, geologic medium, and characteristics of the wastes to be emplaced. Factors considered in the design of waste handling facilities and emplacement configurations include size and shape of the waste containers; heat and 
radiation emissions from the waste; chemical, thermal, mechanical, and radiation interactions between the waste and the geologic medium; and requirements for operational safety. Repositories can be excavated using conventional mining technology.

Repositories can be initially designed for "provisional" geologic storage; i.e., they can be designed for waste retrieval using methods and rates essentially the same as those used for waste emplacement. Such repositories can also, after a period of operation during which data are taken and evaluations are made to test long-term stability, be converted to "permanent" geologic storage by backfilling and sealing. 
1.0 ALTERNATIVES FOR THE BACK END OF THE LWR FUEL CYCLE 
○

• 


\subsection{ALTERNATIVES FOR THE BACK END OF THE LWR FUEL CYCLE}

The LWR fuel cycle can be operated to include recovery of uranium and plutonium from spent fuel so that these energy resources can be formed into new fuel elements and recycled to the power reactors. The back end of the fuel cycle can also be operated so that neither of these materials is recovered and recycled or so that either of them is recycled. Additional options can be defined when alternative technologies for fuel cycle operations and waste management are considered.

There are, therefore, numerous alternatives for the back end of the LWR fuel cycle. The technologies used and the materials recycle scheme that is selected will influence the quantities and types of wastes generated. Holdup times (e.g., storage time for spent fuel prior to reprocessing) will also influence waste quantities to be managed at any time and logistical factors such as capacity of waste storage facilities. Consequently, waste management requirements are highly dependent on how the back end of the fuel cycle is operated.

This section provides an overview characterization of waste management for three representative fuel cycle options. In each case, use is made of available waste management technology. Technologies and operating modes that differ from those used for these examples would be expected to produce different waste quantities and waste management logistics.

\subsection{FUEL CYCLE OPTIONS}

The three basic fuel cycle operating modes considered are:

Mode I. No Recycle of Uranium or Plutonium. This fuel cycle option is often referred to as the "throwaway" fuel cycle. In this option neither uranium or plutonium is recycled. The spent fuel would be managed as a waste.

Mode II. Uranium Recycle 0nly. In this version of the fuel cycle, spent fuel would be reprocessed to separate uranium and plutonium from the fission products, but only the uranium would be recycled. The plutonium oxide product from the reprocessing facility would be placed in storage. The uranium hexafluoride product from the reprocessing operation would be sent to an enrichment facility so that the enriched uranium could be fabricated into uranium oxide fuel and recycled back to light water reactors.

Mode III. Recycle of Plutonium and Uranium. In this full recycle option the spent nuclear fuel, following a brief interim storage period at the reactor, is transported to a nuclear fuels reprocessing facility. Here the spent fuel is processed into three major fractions: the high-level waste, the uranium product, and the plutonium product. The uranium product is converted to uranium hexafluoride, and the plutonium is converted to plutonium oxide. The uranium product is introduced to a uranium enrichment facility. The plutonium 
oxide is sent to a fabrication plant, where it is blended with natural uranium and fabricated into plutonium and uranium mixed-oxide fuel. The resultant enriched uranium from the enrichment facility is sent to the fabrication facility, where it is fabricated into uranium oxide fuel, and subsequently both the mixed-oxide fuel and the uranium oxide fuel are both recycled to light water reactors. The high-level waste is solidified by the commercial reprocessor and given over to Federal custody for management.

\subsection{WASTE MANAGEMENT FOR THE FUEL CYCLE OPTIONS}

The three fuel cycle operating modes will in part yield similar wastes. In particular, reactor operations will not differ; reactor wastes will therefore be essentially the same for each fuel cycle mode. There will, however, be differences in radiological composition, physical characteristics and quantity of some of the other fuel cycle wastes.

The differences in radiological composition result because in Mode $I$, the "throwaway" fuel cycle, all of the uranium and plutonium becomes waste. About 200 times the amount of uranium and plutonium normally expected in the high-level waste from fuel cycle Mode III, full recycle operation, would be discarded with the spent fuel assemblies. On the other hand, the nonplutonium transuranic content of the Mode III wastes will be higher than in the modes in which plutonium is not recycled. This means, for instance, that the neutron emission rate from the Mode III high-level waste is higher than from Mode II high-level waste. Details of the differences in radiological composition of the wastes from the three fuel cycle operating modes are given in Tables 2.17 to 2.22 in Section 2.4.3.

\subsubsection{Waste Management Systems for the Fuel cycle Options}

Figures 1.1 to 1.5 show waste management systems that can be established for each of the three fuel cycle operating modes using available technology described in this document. As previously noted, the systems shown are examples. The systems shown are feasible and representative of current technology, but there is no intent to imply that they are optimum systems for the fuel cycle options.

Mode I. Figure 1.1 shows a reference waste management system for Mode I, or the "throwaway" fuel cycle. For this operating mode the only operating components in the back end of the fuel cycle are the reactors and one or more interim storage repositories for the spent fuel assemblies. Each such repository, consisting of a water basin, packaging and possible final storage or disposal facilities, would service a large number of reactors. The reactor operators would ship their spent fuel directly to these facilities instead of to a reprocessing plant.

At the repository the fuel would be stored for several years in a water basin to allow decay in the radioactive heat generation rate sufficient to 

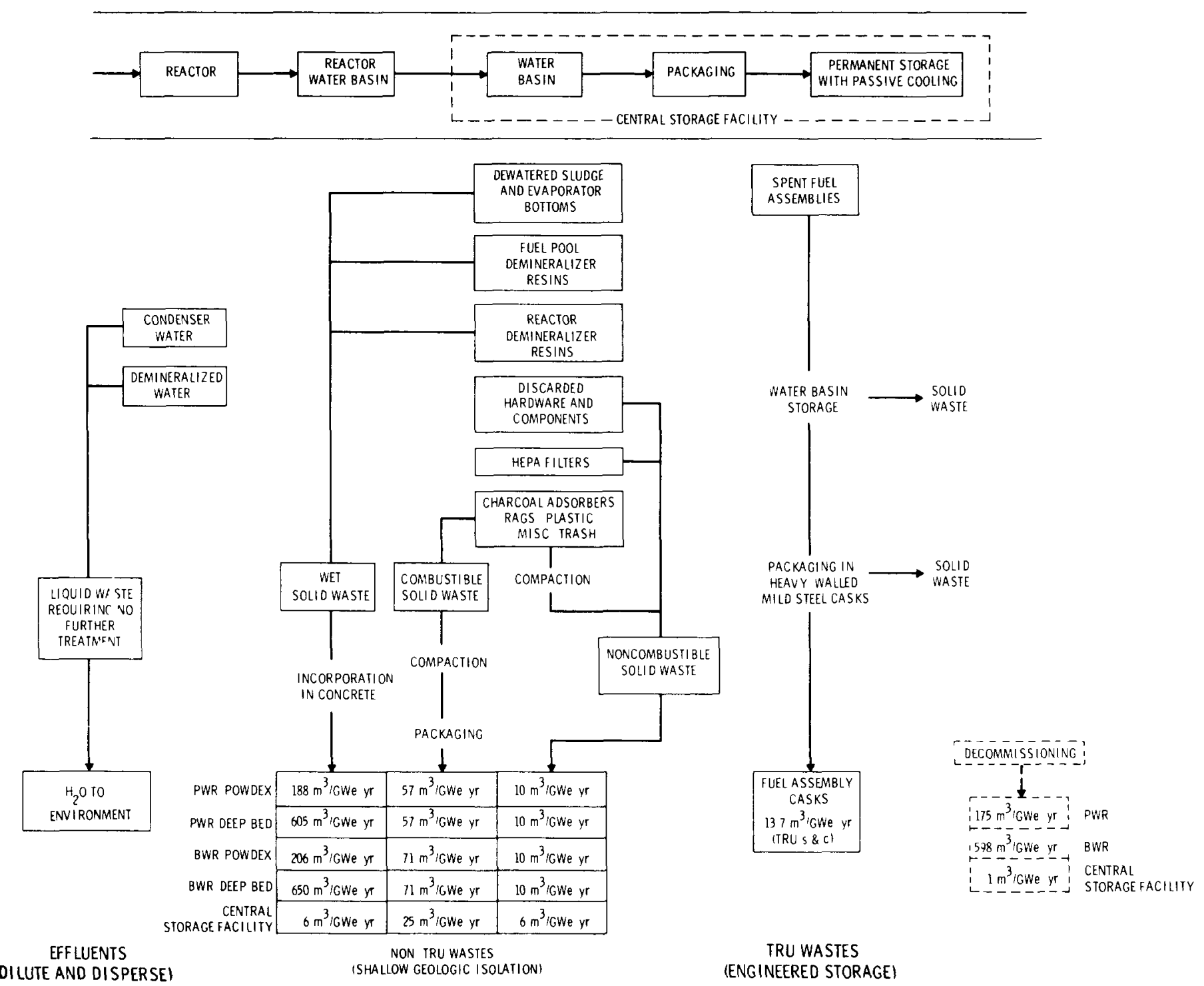

FIGURE 1.1. Origin, Treatment and Disposition of Radioactive Wastes from a Power Reactor (Mode I) 
minimize heat removal problems in subsequent final storage or disposal. Wastes resulting from operation of water basin storage facilities are discussed in Section 2.3. Techniques for packaging the spent fuel elements are described in section 17.3. For this characterization, it was assumed that the fuel assemblies would be packaged in mild-steel containers in groups of four, surrounded by a high-thermal-conductivity metal filler to maintain the fuel temperatures as low as possible. It also was assumed that the fuel would be stored in engineered surface or near-surface facilities using passive cooling. Such storage procedures are described in section 17.4. The fuel containers would subsequently be transferred to deep geologic storage.

The reactor operating wastes are treated in a conventional manner as shown in Figure 1.1. The wet sludges, resins, etc., would be incorporated in concrete and the dry wastes would be compacted and packaged before shipment to shallow geologic isolation (burial grounds). The waste volumes vary significantiy, depending on the reactor type and the method of condensate treatment. A detailed description of reactor wastes is given in section 2.2.

Mode II. In Mode II fuel cycle operation the spent fuel is reprocessed and the uranium is recycled through enrichment and fuel fabrication. Plutonium, considered to be a waste or byproduct in this operating mode, would be converted to oxide and sent to a storage facility. Figures 1.2 and 1.3 show reference waste management systems for the two back end-of-the-fuel-cycle components of Mode II operation, i.e., the reactors and fuel reprocessing plants.

Wastes from reactors would be managed using methods the same as those described for Mode I.

Operation of the reprocessing plant generates a diverse mixture of wastes, as shown in Figure 1.3. This figure shows the major reprocessing plant sources for the various waste categories and the treatment methods for these wastes. More details on these wastes and their compositions are given in section 2.4. If the waste treatment generates secondary wastes, as is the case, for example, for vitrification of high-level waste, the volume of the secondary wastes has been factored into the overall waste volumes. About $70 \%$ by volume of the reprocessing plant wastes are TRU-contaminated; it is assumed that these wastes will ultimately be placed in deep geologic storage repositories.

Iodine was assumed to be trapped and removed from the off-gas, but noble gases, tritium and carbon-14 were assumed to be released in the gaseous plant effluents, as is current practice. Process water was assumed to be vaporized and released as part of the gaseous plant effluents. 

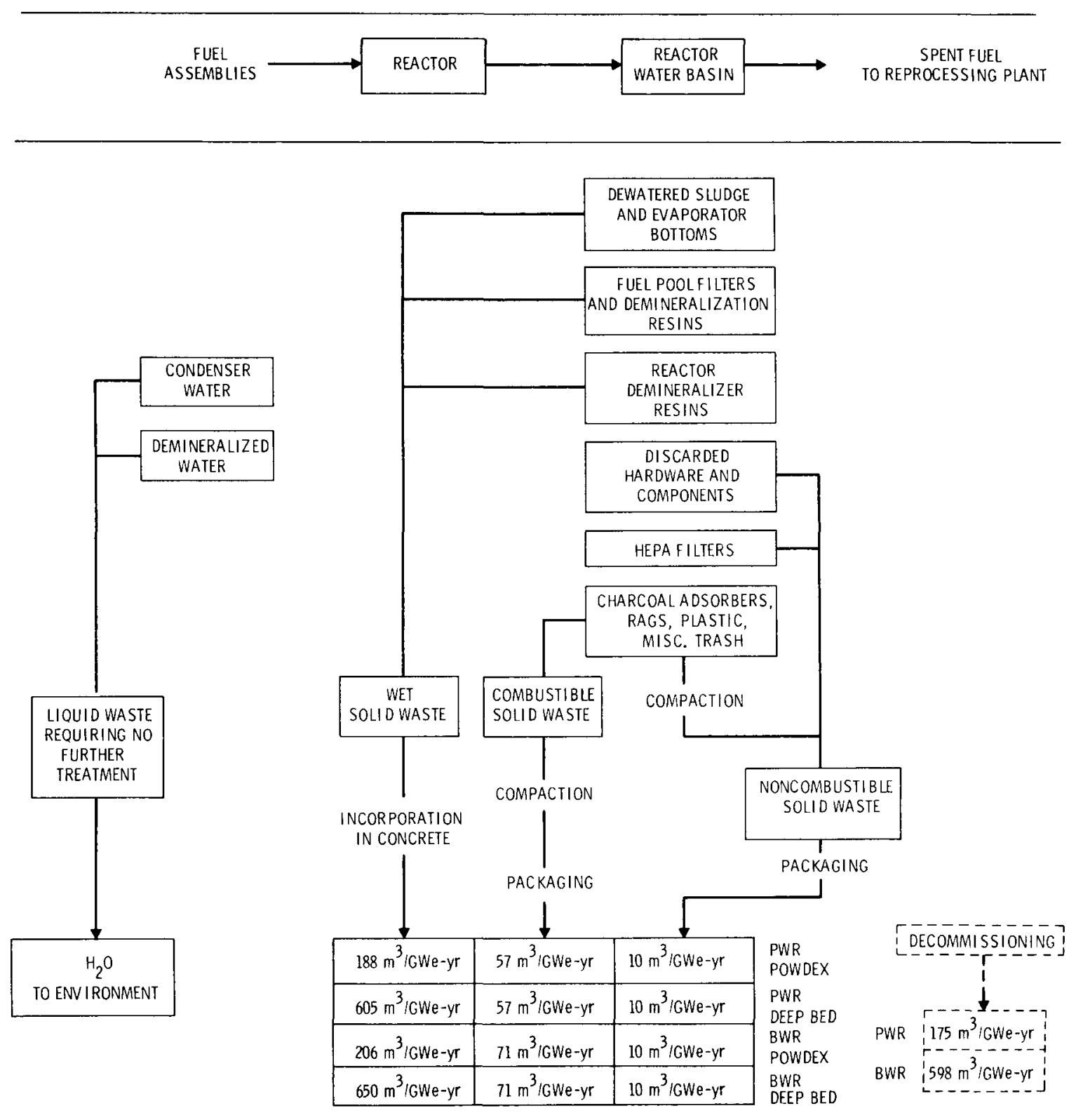

EFFLUENTS

(DI LUTE AND DISPERSE)

NON-TRU WASTES

(SHALLOW GEOLOGIC ISOLATION)

(NON - TRU)

FIGURE 1.2. Origin, Treatment and Disposition of Radioactive Wastes from a Power Reactor (Modes II and III) 


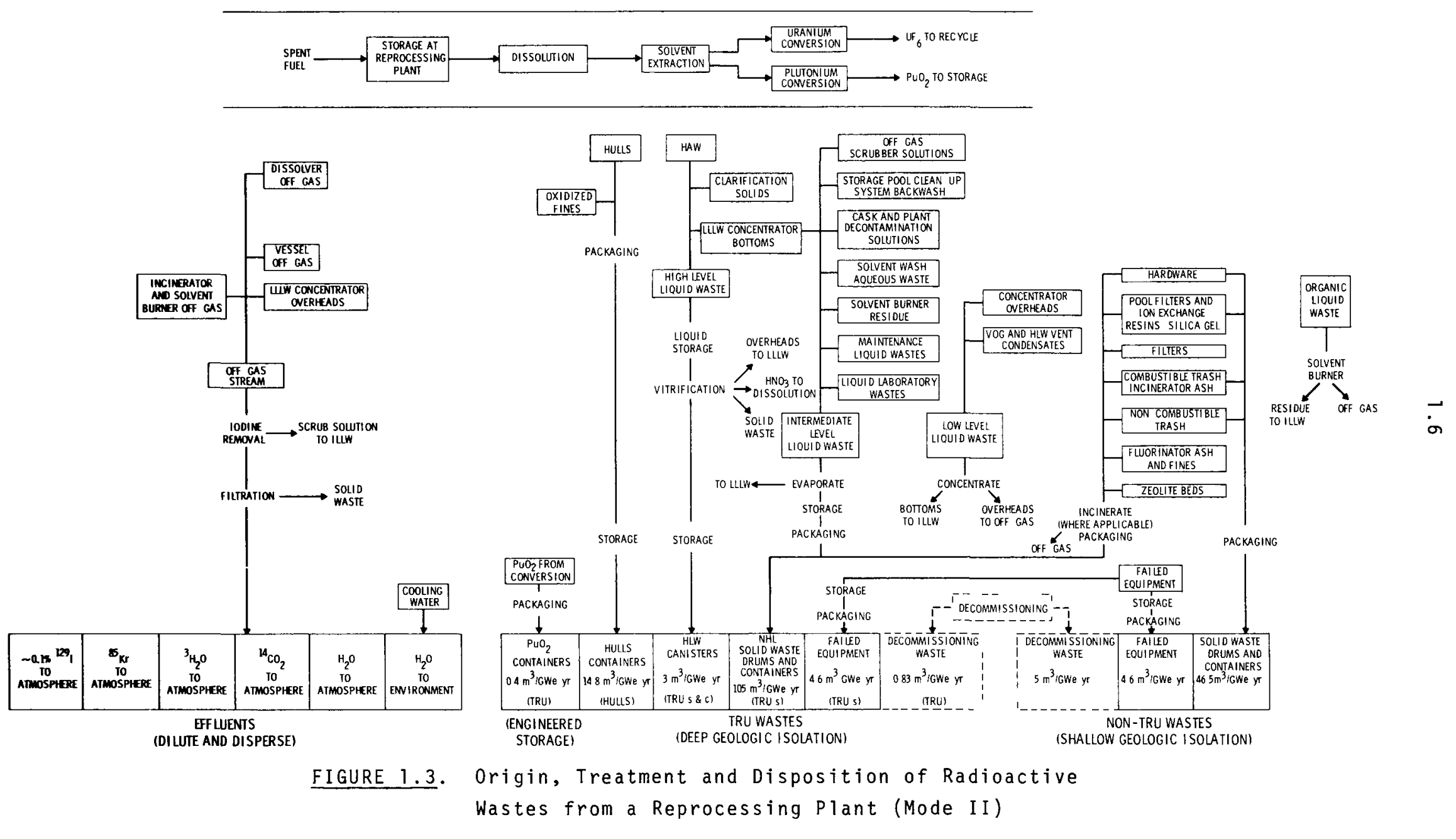


The plutonium was assumed to be stored in about $5-\mathrm{kg}$ batches in steel containers designed to prevent criticality. As in the case of spent fuel elements, interim engineered storage was assumed, to be followed, if appropriate, by deep geologic storage.

Mode III. As shown in Figure 1.4, the reprocessing plant wastes for Mode III operation are identical to those of Mode II operation except that the $\mathrm{PuO}_{2}$ product is now shipped to a mixed-oxide (MOX) fuel fabrication plant instead of being packaged and shipped to a Federal repository. Mode III operation generates additional wastes because of Mox fuel fabrication.

Figure 1.5 shows the major sources of wastes in a Mox fuel fabrication plant. Further information on these wastes is given in Section 2.5. A11 of the operating wastes from MOX fuel fabrication plants must be considered potentially TRU-contaminated, and are therefore shown being sent ultimately to deep geologic isolation or the equivalent.

\subsubsection{Impact of Fuel Cycle Options on Waste Generation}

The quantities and characteristics of wastes generated in the back end of the LWR fuel cycle are, as previously noted, sensitive to the technologies and logistics of the fuel cycle. This section outlines the impact of fuel cycle modes on waste quantities and characteristics.

The three fuel cycle modes described in Section 1.2 .1 were used to compare alternatives for the back end of the LWR fuel cycle. To describe the operating modes completely it is also necessary to define the cooling times, i.e., interim storage periods, at various stages in the cycle. In practice, the cooling times are expected to vary somewhat, and these variations can have important effects on waste characteristics. The cooling times used can even affect the selection of specific waste management technologies.

Although cooling times are an important logistics parameter, a thorough analysis of the effects of all of the possible combinations is beyond the scope of this document. One set of representative cooling times was selected for each operating mode, as shown in Table 1.1 .

TABLE 1.T Reference Interim Storage Periods for the Three Fuel Cycle Modes

\begin{tabular}{|c|c|c|c|c|c|}
\hline Case & $\begin{array}{l}\text { Spent Fuel } \\
\text { Cooling } \\
\text { Period, } \\
\text { years } \\
\end{array}$ & $\begin{array}{l}\text { Extent of } \\
\text { Recycle }\end{array}$ & $\begin{array}{l}\text { HLLW } \\
\text { Cool ing } \\
\text { Period, } \\
\text { years } \\
\end{array}$ & $\begin{array}{c}\text { Interim } \\
\text { Solid Waste } \\
\text { Cooling } \\
\text { Period, } \\
\text { years } \\
\end{array}$ & $\begin{array}{c}\text { Interim Hulls } \\
\text { Cooling } \\
\text { Period, } \\
\text { years } \\
\end{array}$ \\
\hline Mode I & & None & -- & -- & -- \\
\hline Mode I I & 5 & U & 1 & 5 & 6 \\
\hline Mode III & 5 & $\mathrm{U}, \mathrm{Pu}$ & 1 & 5 & 6 \\
\hline
\end{tabular}




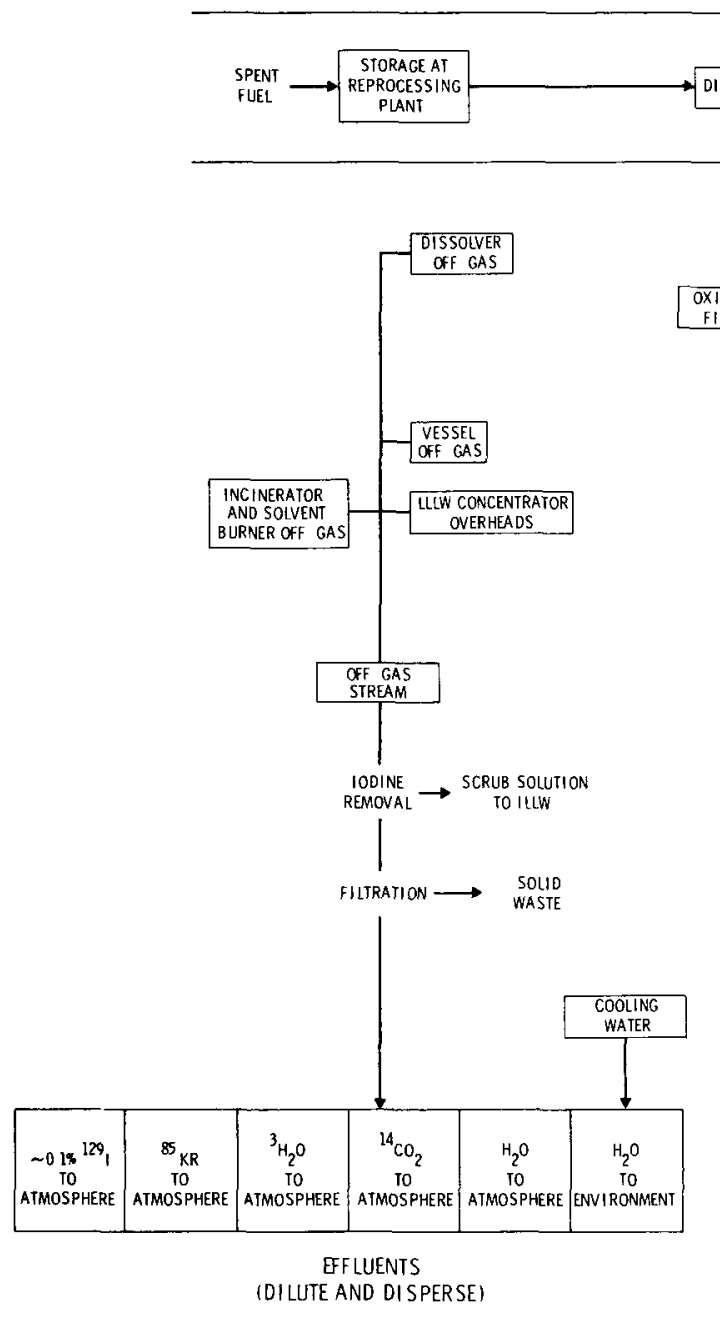

$\longrightarrow$ DISSOLUTION
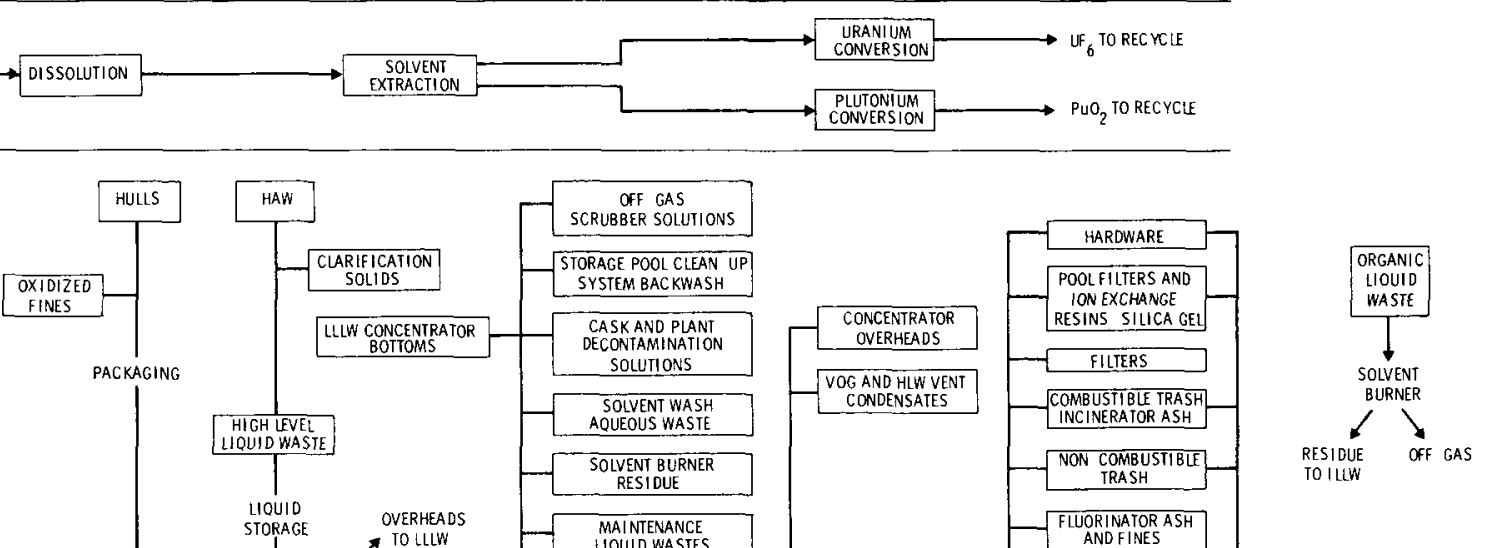

FIGURE 1.4. Origin, Treatment and Disposition of Radioactive

Wastes from a Reprocessing Plant (Mode III) 


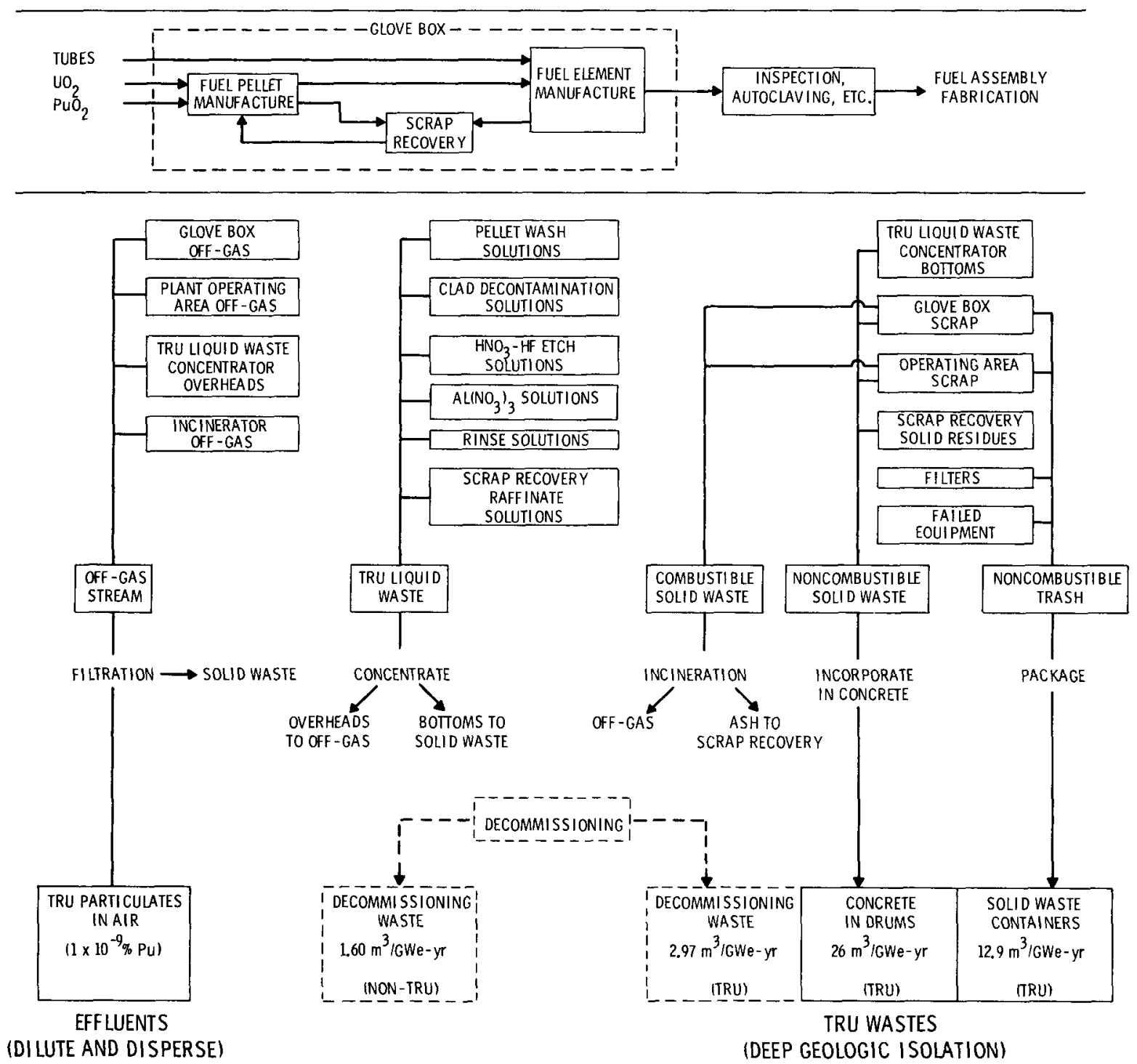

FIGURE 1.5. Origin, Treatment and Disposition of Radioactive Wastes from a MOX Fuel Fabrication Plant (Mode III) 
None of these cases will necessarily describe the LWR fuel cycle as it finally evolves since the spent fuel cooling time, recycle configuration, and waste management technology will change with experience and with the development of commercial reprocessing and waste treatment technology. This approach to the case description was selected because it allows separation of key variables in order to test their impacts on waste generation rates, design of facilities, and selection of final storage or disposal concepts.

Methodology. These characterizations were based on the moderate electrical (low nuclear growth projections in WASH-1139-(75). Projections of waste quantities are not the same as those given in section 3 of this report primarily because of differences in assumed fuel burnups. The range of projections given here and in section 3 is expected to span the alternatives for LWR fuel cycle operations; use of Section 3 values in these analyses would reflect expected alternative limits for waste quantities and characteristics.

The computer code NUFUEL (1) was used to generate the mass flows and material inventories in the LWR fuel cycle for the years 1975 through 2000 for each case analyzed. The mass flows from NuFUEL and waste generation coefficients from fuel cycle component diagrams (Figures 1.1 to 1.5) were used to accumulate waste inventories through year 1999 and to calculate flows in the waste streams in the year 2000. The various waste streams were categorized as follows: TRU-Shielded and Cooled (High-Level Waste), TRU-Shielded (but not cooled), Tru (not shielded or cooled), Hulls, and Non-TRU. These categories are shown in parenthesis on each component diagram. The non-TRU wastes are expected to be placed in shallow geologic isolation (burial grounds). All TRU waste forms are expected to be placed in deep geologic isolation.

The ORIGEN computer code ${ }^{(2)}$ was used to calculate the radiological properties of the spent fuel and high-level and hulls waste streams for each fuel cycle configuration. Low-exposure first-and second-discharge fuel was treated explicitly for each reactor in an attempt to accurately quantify the spent fuel compositions during this LWR growth period. First-recycle plutonium was used for LWR mixed oxide fuel since it was observed from the mass flows that the breeder reactor system utilized sufficient LWR plutonium to preclude significant amounts of multiple recycle in LWRs prior to year 2000 .

The ORIGEN files were accumulated and decayed to represent the radiological properties of spent fuel and waste inventories through the year 1999 and mass flows of these materials in year 2000. The inventories and properties of the spent fuel waste streams thus calculated were used in the case comparisons given in the following sections. 
Impact of Recycle Options

Modes I, II and III are equivalent with respect to fuel cycle delay times but vary with respect to fuel materials recycie. These variations were investigated to determine the effect of recycle fuels on the types and quantities of wastes from the LWR fuel cycle.

Implications of Restricted Recycle. In Modes II and III, spent fuel is reprocessed, and uranium and plutonium (Mode III) or uranium only (Mode II) are recycled to decrease the amount of fresh uranium required to fuel the LWR economy. In Mode I no fuel materials recycle is employed. The effect on uranium demand is shown in Figures $1.6,1.7$ and 1.8 which project mass flows through 1999 and in the Year 2000. The total $U_{3} 0_{8}$ demands through Year 2000 are $1.95,1.79$ and $1.54 \mathrm{million}$ short tons of $\mathrm{U}_{3} \mathrm{O}_{8}$ for Modes $\mathrm{I}$, I I and III respectively. Mode I does not provide separated plutonium; it therefore precludes development of the fast breeder reactor.

Waste volumes. The waste inventories for each of the recycle modes are shown in Figures $1.6,1.7$ and 1.8. There are no significant differences in waste volumes for Modes II and III; in Mode I several effects of operation are apparent. Engineered storage of packaged spent fuel elements is required before deep geologic isolation. The volume of packaged spent fuel is significantly less than the volume of TRU wastes from reprocessing and mixed oxide fabrication. However, the volume of non-TRU wastes is only slightly less than with Modes II and III because the reactor is the primary source of this waste category.

Materials Processed in Year 2000. To highlight differences between the fuel recycle modes, certain indices were selected to characterize the reprocessed spent fuel and the high-level liquid waste solidified during the year 2000. Specific activity (curies/unit throughput) and neutron source strength (neutrons/sec/unit throughput) were selected to compare the degree of shielding required during transport and processing steps. The heat load (watts/unit throughput) was selected to compare cooling requirements, and the toxicity index per unit throughput was selected as a firstorder indicator of the relative risk involved in handling and transporting these materials. For comparison, similar indices were calculated for spent fuel packaged in Mode I since no reprocessing or solidification takes place in this fuel cycle configuration.

In Figure 1.9, Modes I, II, and III are compared in terms of materials processed in the Year 2000. The differences between Modes II and III are due to higher concentrations of transuranics in plutonium recycle fuels. Mode $I$ is significantly different due to the 10 -year cooling period before packaging as compared to 5 -year cooling before reprocessing in Modes II and III. 


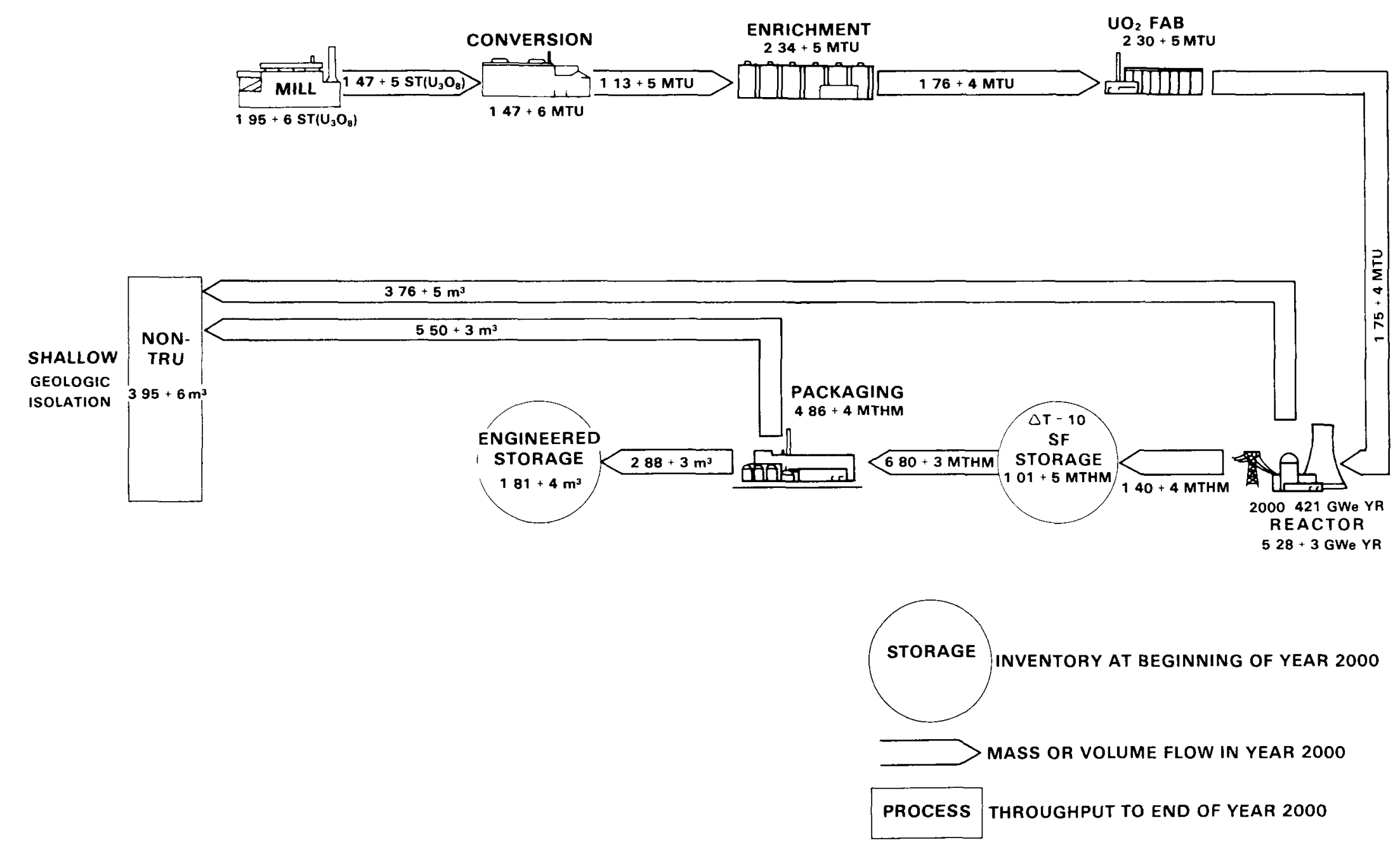

FIGURE 1.6. Mode I - 10 Year Spent Fuel Cooling, Then Engineered Storage 


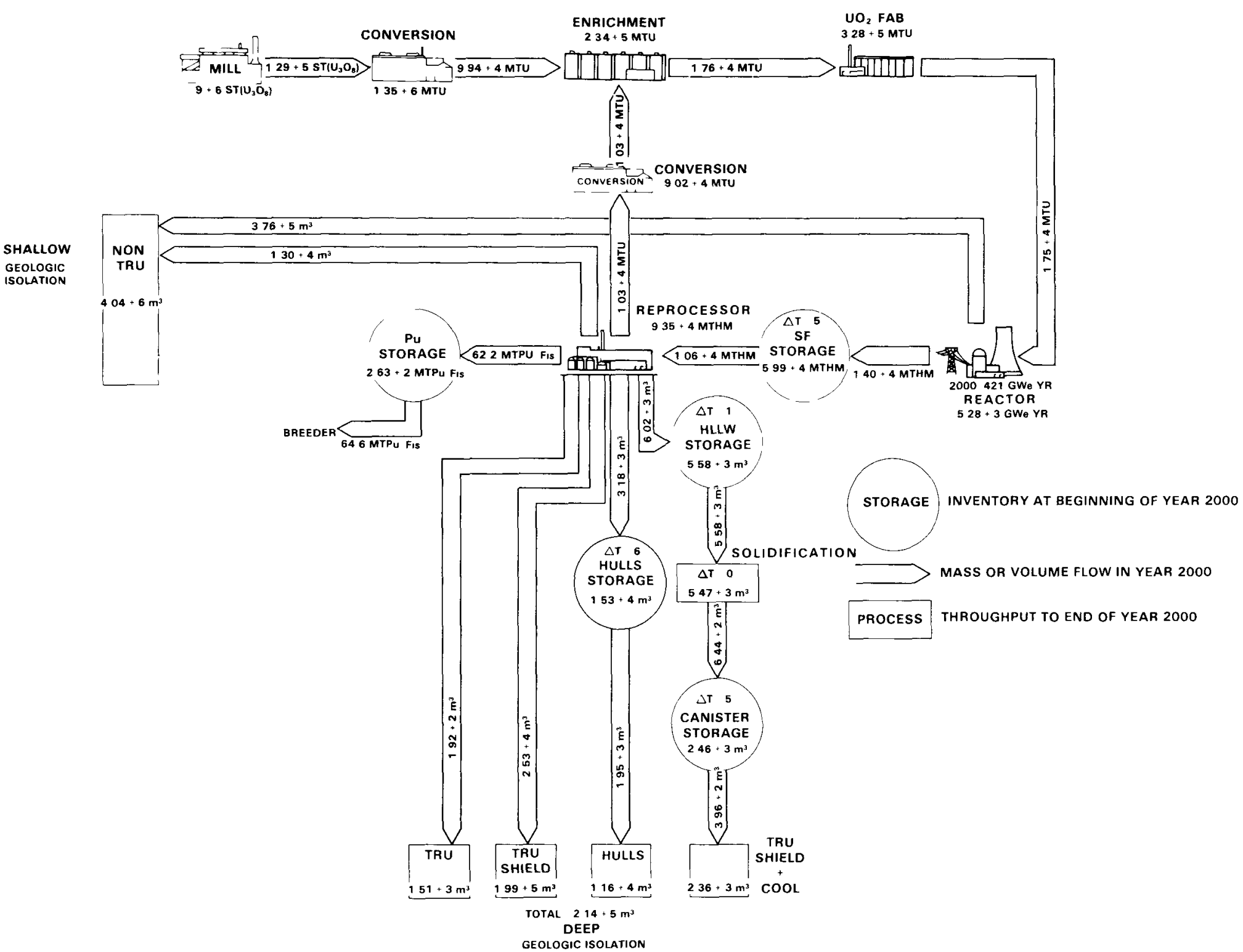

FIGURE 1.7. Mode II - 5 Year spent Fuel Cooling, 1 Year HLLW Cooling - U Recycle Only 


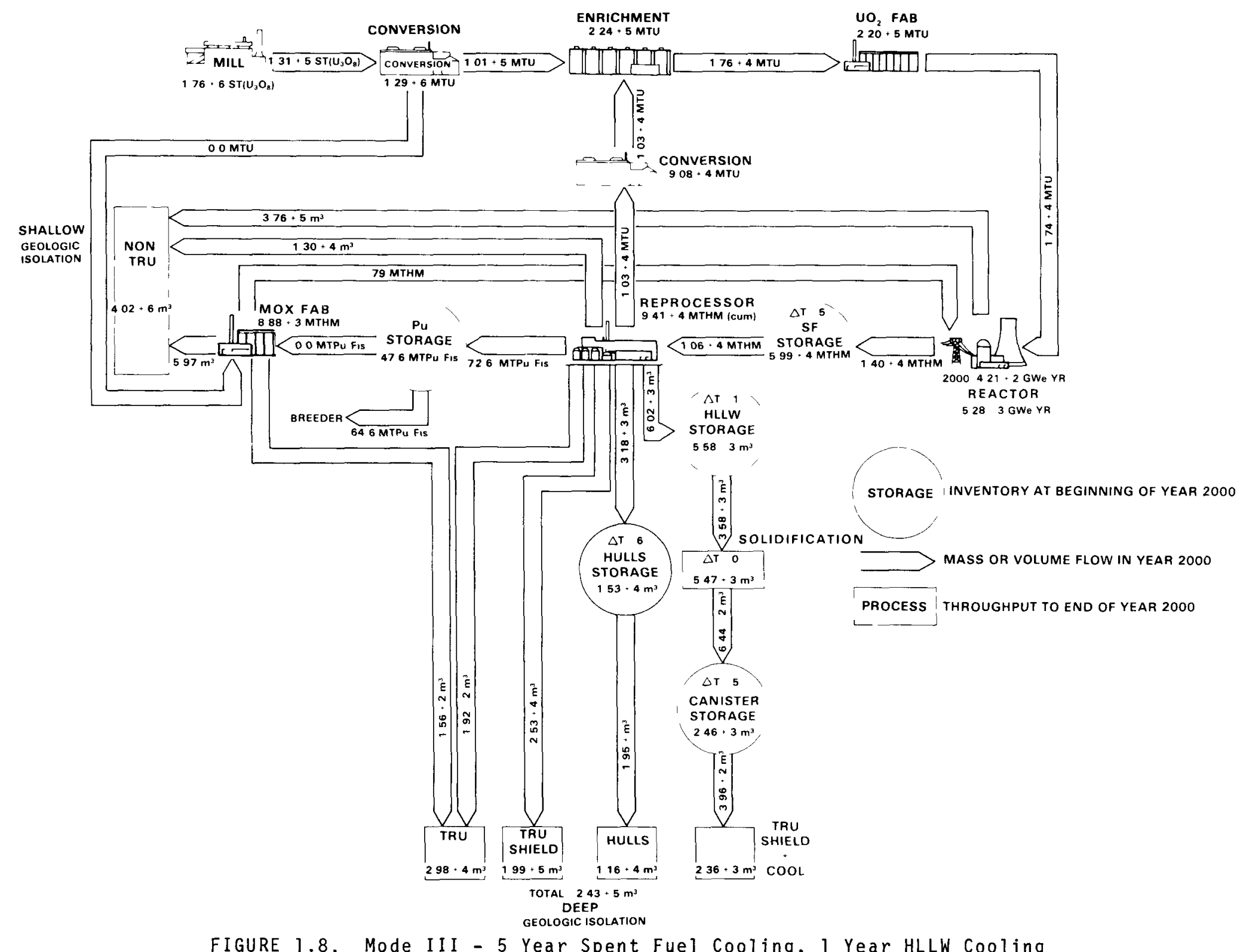



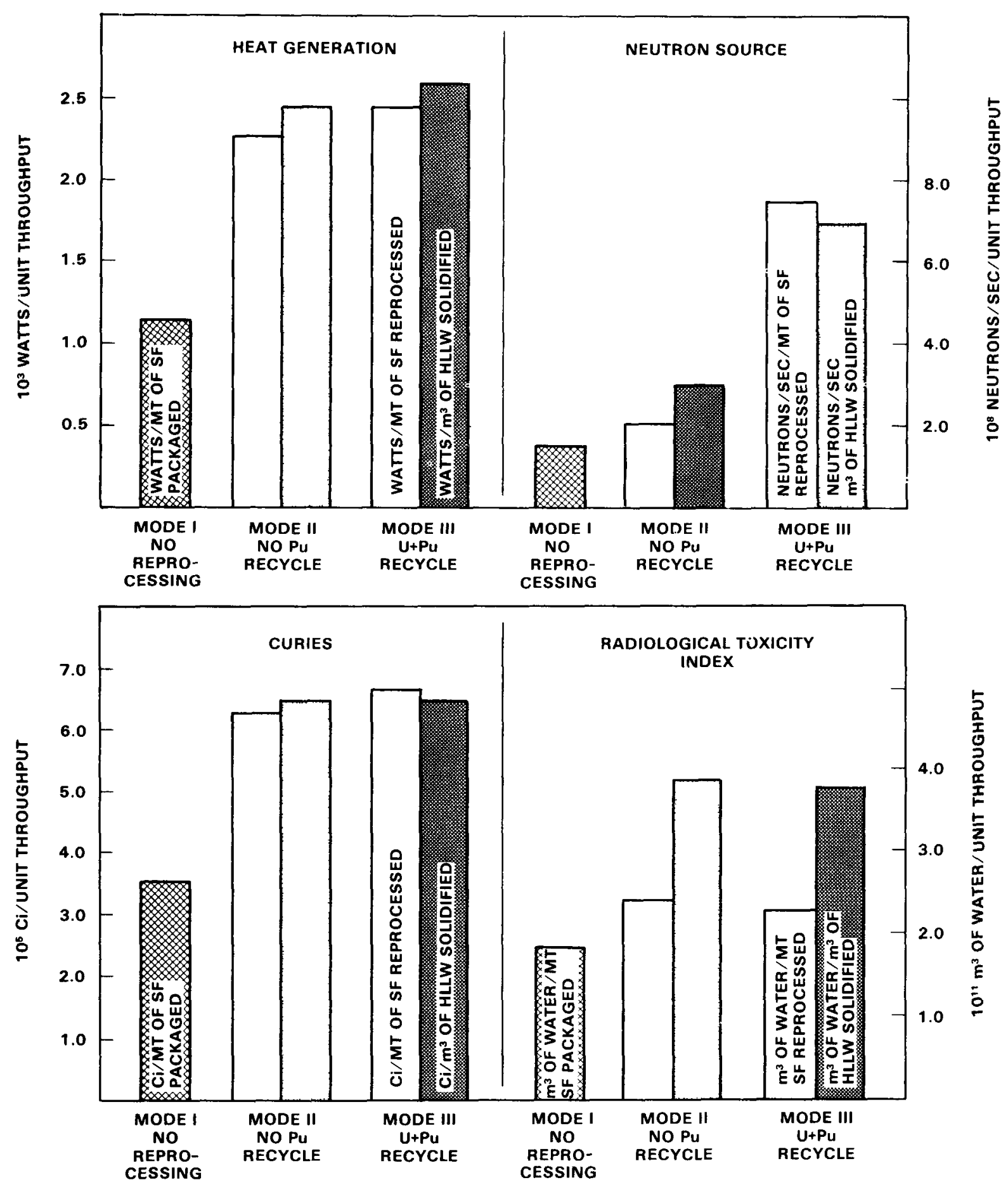

FIGURE 1.9. Modes Compared in Terms of Materials Processed in the Year 2000 


\section{Utilization of Plutonium}

Distributions of fissile plutonium at the beginning of the Year 2000 for Modes I, II and III are given in Table 1.2. In Mode I, all the plutonium remains in spent fuel form in residues in the spent fuel cooling facilities, or in engineered storage residues. In Mode II, roughly half of the plutonium recovered from reprocessing residues is placed in plutonium storage, the balance being used for fast-breeder reactors. In Mode III, where plutonium is recycled, about 111.6 MT (12.7\%) more plutonium than used in Mode II is ultimately utilized in the LWR system. Mixed oxide fuel fabrication from LWRs produces more plutonium for deep geologic inventories than do highlevel wastes. Plutonium-bearing wastes from LMFBR fabrication and reprocessing are not shown in these comparisons.

TABLE 1.2 Distribution of Fissile Plutonium, MT - By (a) 2000

\begin{tabular}{lccr} 
& Mode I & Mode I I & Mode I I \\
\cline { 2 - 2 } In Spent Fue & & & \\
Inventories & 625.9 & 373.1 & 431.7 \\
To LWR & 0 & 0 & 273.2 \\
To FBR & 0 & 242.5 & 242.5 \\
In Pu Storage & -- & 260.9 & 36.5 \\
In HLLW & -- & 0.3 & 0.3 \\
In Solidified HLW & $253.0(b)$ & 2.3 & 2.4 \\
In TRU Wastes from LWR & & & \\
MOX Fab. & -- & 0 & 4.1
\end{tabular}

a. Beginning-of-year

b. Packaged Spent Fuel in Engineered Storage

\section{RADIOACTIVE AIRBORNE RELEASES}

Airborne releases from reactors are the same for each fuel cycle mode. There are, however, significant gaseous releases during reprocessing, and these releases therefore differ for Mode $I$ in comparison with Modes II and III. Table 1.3 lists the airborne releases from reprocessing for Mode III; since these gases are produced via fission and activation, the corresponding quantities for Mode II are expected to be approximately the same. In Mode I, however, reprocessing does not occur and these gases are simply packaged with the spent fuel and sent to the engineered storage facility. 


\subsection{7}

TABLE 1.3 Gases Released During Reprocessing - Mode III

\begin{tabular}{|c|c|c|c|}
\hline & Mass, grams & $\mathrm{Ci}$ & $\begin{array}{c}\text { Toxicity Index, } \\
m^{3} \text { of water } \\
\end{array}$ \\
\hline Tritium & $2.24 \times 10^{3}$ & $2.18 \times 10^{7}$ & $7.27 \times 10^{9}$ \\
\hline Carbon & $6.09 \times 10^{6}$ & $2.71 \times 10^{5}$ & $3.39 \times 10^{8}$ \\
\hline Krypton & $2.35 \times 10^{7}$ & $5.38 \times 10^{8}$ & -- \\
\hline Iodine $(a)$ & $2.06 \times 10^{3}$ & 2.86 & $4.76 \times 10^{7}$ \\
\hline Xenon & $4.09 \times 10^{8}$ & -- & -- \\
\hline
\end{tabular}

a. Assumes Iodine decontamination factor of $10^{-3}$.

\section{REFERENCES}

1. Computer Program NUFUEL for Forecasting Nuclear Fuel Requirements and Related Quantities, WASH-1348, USAEC, October, 1974.

2. M. J. Bell, ORIGEN--The ORNL Isotope Generation and Depletion Code, ORNL-4628, 0ak Ridge National Laboratory, Oak Ridge, TN, May 1973. 
0 0 
2.0 LWR FUEL CYCLE WASTES 
○

0 


\section{$2.0 \quad$ LWR FUEL CYCLE WASTES}

This section describes the LWR fuel cycle and the wastes it can generate. There are several fuel cycle alternatives ranging from no recycle of uranium and plutonium in spent fuel to maximum recycle of both of these fuel material resources. Waste generation will in practice depend on recycle mode, fuel cycle operations technology and logistics, and waste management technology. The descriptions of the fuel cycle and waste types given in this section encompass the broadest range of operating conditions and waste management consequences expected for the back end of the LWR fuel cycle.

\subsection{DESCRIPTION OF THE LIGHT WATER REACTOR (LWR) FUEL CYCLE (1)}

The LWR fuel cycle is the system of operations and facilities for the preparation, utilization, and reconstitution of LWR fuel. The main operations involve 1) mining of ore, 2) milling, i.e., ore concentration and purification, 3) conversion of $U_{3} O_{8}$ to $\left.U F_{6}, 4\right)$ enrichment, 5) conversion of enriched $U F_{6}$ to $\mathrm{U0}_{2}, 6$ ) fuel fabrication, 7) irradiation in a reactor, and 8) reprocessing. Transportation of materials between the facilities where these operations are carried out and collection and storage of wastes are also considered parts of the fuel cycle. The fuel cycle is illustrated in the diagram of figure 2.1. closing the fuel cycle, that is, providing for operation of reprocessing plants and recycle of plutonium into LWR fuel as mixed oxides of plutonium and uranium (MOX), increases the uranium utilization by recovery of unused fissile ${ }^{235} \mathrm{U}$ and the fissile plutonium formed from ${ }^{238} \mathrm{U}$.

2.1.1 Mining $(1-3)$

A major portion of domestic uranium ore is found in New Mexico, Wyoming, Colorado, and Utah. Domestic uranium mines have the capacity to produce about 8 million metric tons* (MT) of ore per year. The assay of uranium ore averages about $0.2 \%$ or $2 \mathrm{~kg}$ of $\mathrm{U}_{3} \mathrm{O}_{8}$ per MT of ore. Two methods, open pit mining and underground mining, are used to produce most of the uranium in the United States.

Underground mining typically involves service buildings, hoisting and truck loading facilities, a mine waste pile, a flow of water pumped to surface drainage from underground sumps, shops, warehouse, changehouse, and office. Underground openings may extend laterally to a mile or so. Solid wastes (primarily nonradioactive) may accumulate in volumes equal to the volume of processed ore.

Open pit mining, on the other hand, typically involves a large open excavation, large piles of earth and rock overburden resulting from the excavation, a network of operating roads and yards, and a flow of mine water pumped into the local surface drainage. The site may include shops, warehouse,

*A metric ton is $1000 \mathrm{~kg}$, or $2204.61 \mathrm{~b}$. 


\section{2}

office, changehouse, and an assortment of heavy earth-moving equipment. The ore body may lie at various levels from 30 to 140 meters (m) below the surface in readily friable rock strata. The stripping ratio, that is, the volume of overburden to volume of ore body, may average about 30 to 1 . Wastes produced by mining are distributed in gaseous, solid, and liquid materials.

Airborne radioactive effluents such as uranium-bearing dusts and radon and its decay products are released to the atmosphere when an ore body is exposed and broken up during mining operations. The concentrations of airborne

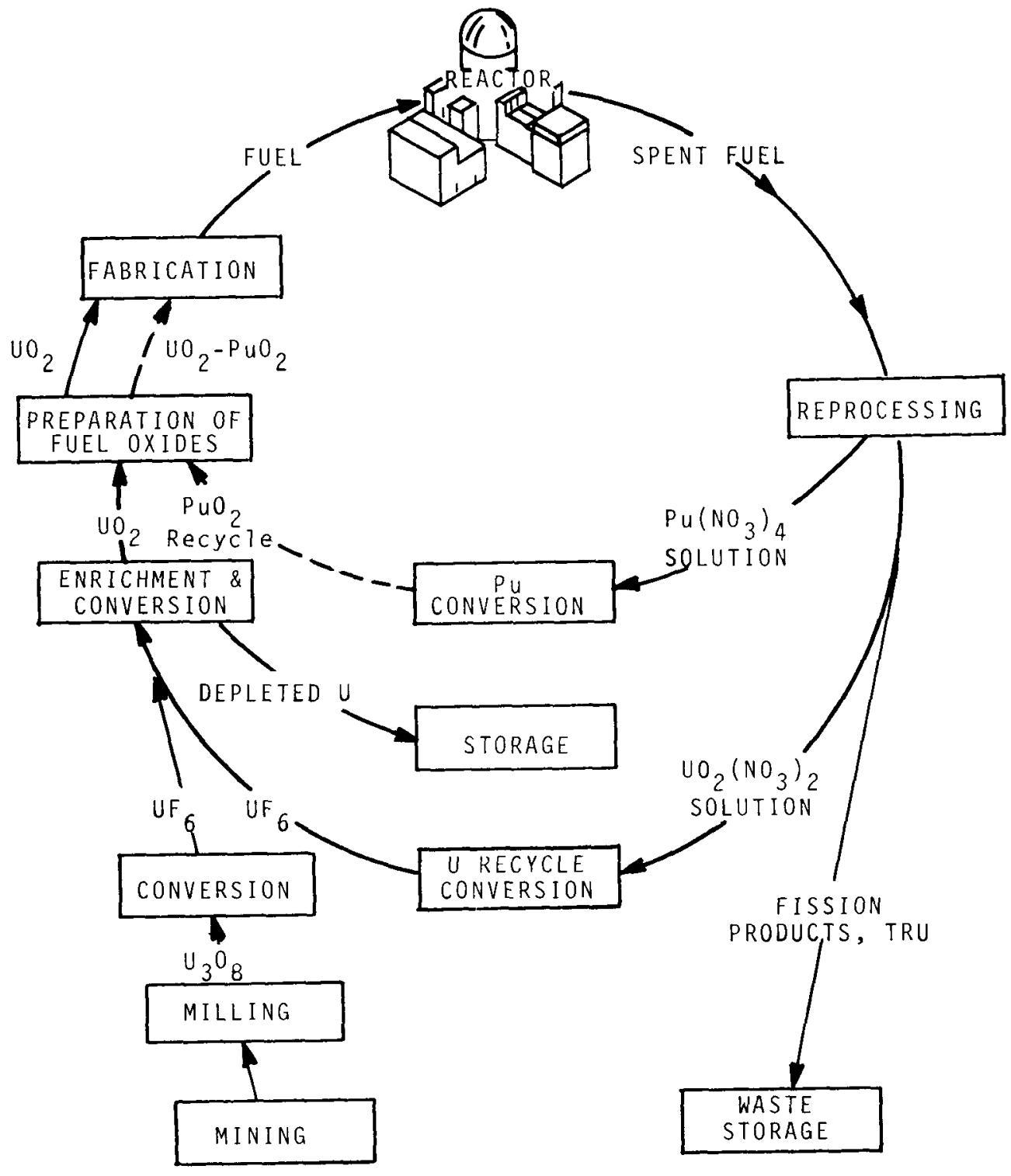

FIGURE 2.1. The LWR Fuel Cycle $\mathrm{e}^{(4)}$ 
radionuclides in unrestricted areas, at 1 east $600 \mathrm{~m}$ from the point of release, however, are expected to be below the limit of detection.

The primary solid waste material produced by mining is the barren rock and earth overburden, most of which may ultimately be disposed of as backfill. The small quantity of uranium and its decay products originally contained in the earth overburden may thus be returned to the ground as part of the backfill material.

The largest 1 iquid waste stream from open pit mining operations is mine drainage water. Mine drainage water frequently carries suspended solids, silicates, and trace uranium ore from the pit area. Dissolved and suspended uranium and its decay products, equivalent to several curies per 1000 MWeyear, * are dissolved and suspended in mine drainage water. (1) The wastewater is treated in settling pond operations by seepage and evaporation as it recycles into the hydrosphere.

Projections of the amounts of ore mined and mine tailings produced for U. S. LWRs are listed in Section 3.2 .

2.1.2 Milling $(1-3,5)$

A uranium mill extracts uranium from the ore by mechanical and chemical processing of the mineral into a semi-refined product, commonly called "yellowcake," which contains 70 to $90 \% \mathrm{U}_{3}{ }^{0} 8$. About 20 mills are operating in the United States with a total annual capacity of 17,000 MT of $\mathrm{U}_{3} 0_{8}$. Uranium mills are usually located near the source of ore; typically a uranium mill is located in an arid, isolated region of the western states.

Two methods are employed for uranium milling operations in the U. S.: the acid and the sodium carbonate leach process. The choice depends upon the characteristics of the ore being processed. Most of the ores are suited to the acid leach process which produces about $80 \%$ of all yellowcake. The basic steps in the acid leach process include:

1. Ores are crushed and blended, then wet ground in a rod or ball $\mathrm{mill}$, and transferred as a slurry to leaching tanks.

2. The ore is contacted with sulfuric acid solution and an oxidizing reagent to leach the uranium from the ore. The residues (tailings) are washed, and the product liquor is pumped to solvent-extraction units.

3. In the solvent-extraction step, the uranium is purified and concentrated.

*1000 MWe-year is the power generated by a reactor with a capacity of 1000 MWe, operating for a calendar year. Since, in actual practice, reactors are not operated continuously, a time of 1.25 to 1.55 years might be required for a reactor of 1000 MWe capacity to produce the power of 1000 MWe-year. 
4. The uranium is precipitated with ammonia and transferred as a slurry.

5. The concentrate is centrifuged to thicken and separate it from residual 1 iquids.

6. The concentrate is calcined and pulverized.

7. The powdered yellowcake is packaged in $0.2-m^{3}$ drums for shipment. The milling operation produces wastes in gaseous, liquid, and solid form.

The gaseous medium is air which normally carries radioactive gases and particulate solids away from the operation. Uranium and uranium decay products $\left({ }^{230} \mathrm{Th}\right.$ and $\left.{ }^{226} \mathrm{Ra}\right)$ are released from ore piles, the tailing retention system, and the ore crushing-grinding ventilation system in the form of dust. Natural uranium is released from the yellowcake drying and packaging operations as entrained solids. Radon gas is released from the leach tank vents, ore piles, tailings retention system, and the pulverization exhaust system. The concentrations of airborne radioactive particulate solids released into the environment from processing operations are limited by dust collection systems.

Liquid wastes from mills consist of solutions containing spent chemicals from the grinding, leaching, and washing operations. Since concentrations of ${ }^{226} \mathrm{Ra}$ and ${ }^{230} \mathrm{Th}$ may be above the limits specified by regulation, dispersal of this material to the environment is prevented. The neutralized waste liquor is stored in a tailings retention pond to prevent discharge into the surface water system and to minimize percolation into the ground.

Solid wastes (tailings) from mills are composed mostly of sandstone and clay particles. They contain traces of waste chemicals, and mine waste. These solid waste tailings may contain about $85 \%$ of the radioactive materials originally in the ore. The management of these tailings piles has received increased attention to limit the local inhalation of gaseous ${ }^{222} \mathrm{Rn}$, the radioactive decay product of ${ }^{226} \mathrm{Ra}$, to prevent the fines of these tailings from becoming airborne, and to prevent the runoff of tailings into surface streams.

2.1.3 Uranium Hexafluoride Production and Uranium Enrichment $(1,3,6)$

The $U_{3} 0_{8}$ concentrate extracted from the ore must be converted to the volatile compound uranium hexafluoride (UF ${ }_{6}$ ) for enrichment by the gaseous diffusion process. Two processes differing only in the head-end are used for $U_{6}$ production. Roughly equal quantities of UF feed to the enrichment plants are produced by each method. The dry hydrofluor process results in retention of impurities in either volatile compounds or as solid ash. The wet solvent extraction method separates impurities by extracting the uranium values in an organic solvent, leaving other constituents in the aqueous phase.

The dry hydrofluor process consists of these typical operations: 
1. pre-process handling, weighing, sampling, and storage

2. fluidized-bed reduction of the $\mathrm{U}_{3} \mathrm{O}_{8}$ to $\mathrm{UO}_{2}$ by cracked ammonia

3. fluidized-bed hydrofluorination with anhydrous $H F$ to form a crude $U F_{4}$

4. fluidized-bed fluorination with elemental fluorine to form crude $U F_{6}$

5. fractional distillation to form refined $U_{6}$.

In this process the impurities are separated from the product by taking advantage of relative differences in volatility.

The wet solvent extraction method consists of the following operations:

1. pre-process handling, weighing, sampling, and storage

2. digestion in hot nitric acid

3. countercurrent solvent extraction with tributylphosphate (TBP) in hexane

4. stripping of uranium as uranyl nitrate into an aqueous solution

5. calcining to $\mathrm{UO}_{3}$

6. fluidized-bed reduction to $U_{2}$ with cracked ammonia

7. hydrofluorination in a two stage countercurrent reactor to $\mathrm{UF}_{4}$ using anhydrous $\mathrm{HF}$

8. fluorination to $U F_{6}$ by reaction with elemental fluorine.

The two methods differ mainly in that the wet process starts with a solvent extraction step to purify the ore concentrate before fluorination, whereas the dry process converts the concentrate to UF 6 in fluidized-bed reactor stages and as a final step purifies the UF 6 by fractional distillation.

The wastes from the two methods of $U_{6}$ production differ substantialiy. Hydrofluor process wastes appear in both the gaseous and the solid states, whereas wet solvent extraction process wastes are primarily liquids.

The more contaminated liquid wastes, the raffinate from the solvent extraction process, are held in sealed ponds; only treated coolant and dilute scrubber solutions combined with all other clear water effluents are released. The 12-month average concentration of radioactive materials measured in the raffinate may be about $10 \%$ of the limits for natural uranium and ${ }^{226}{ }^{2} a^{*}$ in water effluents released to an unrestricted area. The raffinate liquid is held indefinitely in ponds; it is not directly released to the environment, but about $1.4 \times 10^{7} 1$ iters of water per 1000 MWe-year is expected to evaporate to the environment from such ponds. The radioactive components of the raffinate, ${ }^{226} \mathrm{Ra},{ }^{230} \mathrm{Th}$, and uranium isotopes, are in nonvolatile form, and are therefore expected to accumulate in the pond.

*Corresponds to $\sim 3 \times 10^{-6} \mu \mathrm{Ci}{ }^{226} \mathrm{Ra} / 1$ iter and $3 \times 10^{-3} \mu \mathrm{Ci}$ natural uranium/ liter. (7) 
Solid wastes from the hydrofluor process are a nonvolatile ash comprising iron, calcium, magnesium, copper, and other nonvolatile fluorides. The quantity of ash produced by hydrofluorination is about 40 MT/1000 MWe-year. (1) The ash is continually removed from the process and reacted with fresh fluorine to recover the uranium, thus minimizing uranium concentrations in the wastes. The final ash residue, containing traces of thorium and protactinium, is packaged and shipped to a licensed commercial waste burial site. The total activity involved is about $0.28 \mathrm{Ci} / 1000$ MWe-year. No similar volume of solid ash waste is produced by wet solvent extraction fluorination.

Commercial plants using each process, hydrofluor and wet solvent extraction, have been built and operated with capacity to process at least 5000 MTU/year, at a single plant, into uranium hexafluoride. To meet domestic requirements, the industry currentiy produces about $20,000 \mathrm{MT}(8)$ of uranium as hexafluoride annualiy.

Uranium hexafluoride prepared by the processes described above is used in isotopic enrichment operations, performed to increase the concentration of the fissile ${ }^{235} \mathrm{U}$ isotope in the uranium. Isotopic enrichment of uranium is necessary to provide fuel for a light-water moderated nuclear reactor. The concentration of $235 \mathrm{U}$ in natural uranium is about $0.7 \%$ and the required content for the current generation of reactors is 2 to $4 \%$. About $116,000 \mathrm{kilo-}$ grams (kg) of separative work units (SWU) are required to prepare enough uranium for the production of 1000 MWe-year of power. A separative work unit is a measure, expressed in mass units, for example, kilograms, of the effort expended to separate a quantity of uranium of a given assay into two components, one having a higher percentage of ${ }^{235} \mathrm{U}$ and one (tails) having a lower percentage.

Gaseous diffusion is the technology developed in the U. S. for performing the enrichment operation. The gaseous diffusion process is based on the principle that the rate at which a gas moves through a small hole is related to the speed, and therefore to the masses, of the gas molecules. The enrichment of uranium is accomplished by applying this principle to use of a porous barrier through which the gas molecules diffuse. This effect is multiplied by using a large number of successive barriers, or stages, called a cascade.

In addition to the enriched $U F_{6}$ product, the gaseous diffusion plants produce a UF 6 stream depleted in $235 \mathrm{U}$, called "tails." The selection of a tails assay, that is, the ${ }^{235} \mathrm{U}$ content, determines how an enrichment plant will be operated, the separative work involved, and, ultimately, the amounts of ore that will be mined to sustain a given power production schedule. The depleted uranium in the "tails" of the enrichment operation may have a $235 \mathrm{U}$ content of 0.2 to $0.3 \%$. This material is stored for future uses at the enrichment plants as solid UF 6 in cylinders or as $U F_{4}$ in drums. 
The radioactive component of gaseous wastes from the enrichment operation consists of airborne uranium, estimated at about $0.7 \mathrm{~kg} / 1000$ MWe-year, (1) and does not produce needs for shipping or storage under current standards.

Liquid wastes from enrichment that contain radioactivity (uranium) include liquid wastes from process cleanup operations (containing fluorides, nitrates, and iron) and liquid wastes from auxiliary production facilities (containing fluorides, nitrates, chlorides, iron, and ammonia). The quantity of uranium in liquid effluents supporting the production of 1000 MWe-year of power has been estimated at about $10 \mathrm{~kg}$. (1)

Solid wastes generated during enrichment come from liquid effluents from process cleanup operations, and are collected in holding ponds. The sludge collected in this manner contains soil runoff from groundwater, small quantities of precipitated metals, various suspended solids, and a detectable amount of radioactivity. The amount of solids attributable to the plant operations is less than 1 MT/1000 MWe-year. This is classified as a nonhighlevel, nontransuranic solid waste and is disposed of by burial onsite. Metallic equipment and scrap are also generated.

2.1.4 Fuel Fabrication $(1,3,9-11)$

In a fuel fabrication plant, the following main operations might be carried out:

- $U F_{6}$ is converted to $\mathrm{UO}_{2}$.

- Pellets of the $\mathrm{UO}_{2}$ are formed and sintered to the desired density.

- The pellets are loaded into Zircaloy tubes.

- The tubes are fitted with end caps which are then welded into place.

- The tubes (fuel elements) are assembled into fixed arrays to be handled as fuel assemblies.

An additional operation consists of recovery of uranium from scrap and material failing to meet specifications. The special characteristics of mixed oxide $\left(\mathrm{UO}_{2}-\mathrm{PuO}_{2}\right)$ fuel fabrication plants are described in section 2.5 .

Ten commercial plants licensed by the AEC (now the Nuclear Regulatory Commission, NRC) are presently capable of performing all or part of the fuel fabrication operations. Three of the plants use enriched UF 6 as feed material and produce completed light water reactor fuel assemblies. Four other plants use enriched $U F_{6}$ as feed material for producing $U_{2}$ powder or $U 0_{2}$ pellets. The other three plants use $\mathrm{UO}_{2}$ powder or $\mathrm{UO}_{2}$ pellets as feed material and produce completed fuel assemblies.

Assuming the feed material for the plant is enriched $U F_{6}$, received in cylinders from the gaseous diffusion plant, the process steps involved in the currently predominant ammonium diuranate (ADU) process are as follows: 
1. UF 6 is heated and transferred as a gas to a hydrolysis reactor.

2. Hydrolysis results from the interaction of the gaseous UF 6 with water forming a $\mathrm{UO}_{2} \mathrm{~F}_{2}$ solution.

3. Precipitation of ADU is accomplished by adding ammonium hydroxide.

4. The ADU siurries are concentrated by centrifuging or filtering.

5. The ADU is dried by heating.

6. The dried ADU is calcined to $U_{2}$ powder in a reducing atmosphere (hydrogen and nitrogen).

Mechanical operations involve the following major steps:

1. pretreatment of $\mathrm{UO}_{2}$ powder by comminution, compaction, and granulation to desired consistency

2. pelletizing

3. sintering of the pellets

4. grinding to finished dimensions

5. washing and cleaning the pellets

6. loading the pellets into metal tubes and welding the end caps

7. assembling finished fuel elements to form complete fuel assemblies.

Much of the off-specification material, revealed by the frequent testing and inspection procedures, can be recycled into the fabrication line. However, some of this material must be processed through a scrap recovery cycle involving the following principal steps:

1. dissolution of the uranium in nitric acid, forming uranyl nitrate

2. purification of the uranium through solvent extraction

3. precipitation of a hydrated uranium oxide with ammonium hydroxide and hydrogen peroxide

4. conversion to $U_{3} 0_{8}$ by drying and

5. reduction to $\mathrm{UO}_{2}$ powder.

The recovered uranium is returned to the main powder-pellet production system after step 4 or 5 of the scrap recovery cycle.

Cleanup of both 1 iquid and gaseous waste streams generates some solid wastes requiring management operations. Process off-gases from the UF 6 conversion and scrap recovery dissolution operations are passed through scrubber solutions, demisters, and then through a high-efficiency particulate air (HEPA) filter before release to the atmosphere. Exhaust air from enclosures, equipment, and areas where $\mathrm{UO}_{2}$ powder is handled is drawn through HEPA filters before release. Off-gases from incineration of miscellaneous combustible wastes are treated by a scrubber-demister or a bag filter followed by a HEPA filter.

Although the thorium decay products of uranium are separated from the uranium product at the milling plant, the ${ }^{234}$ Th decay product of $238 \mathrm{U}$, with a half-life of 24 days, grows back. The activity released from liquid raffinate 
holding ponds is estimated at about $20 \mathrm{mCi} / 1000$ MWe-year from uranium, $10 \mathrm{mCi} /$ 1000 MWe-year from ${ }^{234} \mathrm{Th}$, and $10 \mathrm{mC} / 1000$ MWe-year from ${ }^{234} \mathrm{~Pa}$.

Solid radioactive wastes of the fabrication plant consist mainly of contaminated $\mathrm{CaF}_{2}$. Water from the effluent air scrubber systems contains most of the fluoride released during operation. The combined liquid effluent from the $U F_{6}$ to $\mathrm{UO}_{2}$ conversion process and the scrap recovery operations is treated with lime to form a calcium fluoride precipitate. The $\mathrm{CaF}_{2}$ is filtered from the waste stream, and the water is released to a holding pond or lagoon. The calcium fluoride precipitate filtered from the liquid waste stream is buried in onsite trenches that are then backfilled. The total quantity produced is estimated at about 26 MT/1000 MWe-year. The 26 MT has a volume of about 8.4 $\mathrm{m}^{3}$. The $\mathrm{CaF}_{2}$ solids buried onsite contain about $0.06 \mathrm{Ci}$ of uranium/1000 MWeyear.

2.1.5 Irradiation In Reactor $(12,13)$

At the reactor, fresh-fuel assemblies may be temporarily stored, inspected, and tested prior to use. The assemblies are placed in the reactor core, and each is burned at a specific power and for a total burnup that may be the result of a complex decision process aimed at overall economic optimization. The decision process may include factors such as fraction of core to be replaced (typically $1 / 5$ to $1 / 3$ annually), fuel composition and design, uranium enrichment, physical relocation of assemblies, and length of subsequent operating cycles. (12) Upon removal from the core, an assembly may be stored outside the core region for 10 days, then removed to the reactor fuel storage pool and stored for 120 to 180 days before shipping. Wastes formed at the reactor include solid byproducts of the cleanup of reactor liquid streams and miscellaneous solids, described in Section 2.2, and also spent fuel, described in section 2.3. Discarded reactor components constitute a waste stream also described in Section 2.2.

\subsubsection{Reprocessing of Irradiated Fuel}

Reprocessing of irradiated fuel recovers usable fissile material from spent reactor fuel elements. During the operation of a reactor, the buildup of fission products and depletion of fissile material requires that the operator replace between one-fifth and one-third of the fuel assemblies annually and redistribute the other partially spent fuel in the reactor core. The

* Specific power, commonly expressed in units of thermal megawatts per metric ton of uranium (MW/MTU), represents the rate at which energy is extracted from the fuel, and the burnup, commonly expressed in thermal megawatt-days per metric ton of uranium (MWd/MTU), represents the total energy extracted. For Mox fuel, the unit of fuel is a metric ton of heavy metal (MTHM), i.e., a metric ton of $(U+P u)$. 
discharged fuel elements contain about one-third of the ${ }^{235} u$ that was in the fuel prior to irradiation, and the fissile plutonium that was produced from ${ }^{238} U$ during irradiation. The recovered uranium can be recycled in reactorreload fuel after addition of ${ }^{235} U$ to replace the spent fraction, and the plutonium can be stored or used in LWR reload fuel or as fuel in fast breeder reactors. Details of the reprocessing operation are described in section 2.4 and projections of the reprocessing load and fuel processed are given in Section 3.

\subsubsection{Transportation}

The flow of materials between facilities of the nuclear fuel cycle, diagrammed in Figure 2.1, briefly indicates the various types of materialstransport situations that may arise in a complete LWR fuel cycle. These various transportation activities are detailed in Section 22. Also, projections of shipments are given in Section 3.2, including fresh fuel shipments by truck to reactors, shipments of plutonium by truck to fabrication plants, spent fuel shipments to reprocessing plants, and shipment of 10-year-old high-level waste and transuranic (TRU) contaminated material in containers that may have held these wastes from 5 to 10 years.

\subsubsection{Alternative Fuel Cycles}

The LWR fuel cycle shown previously in Figure 2.1 can be changed in several ways, resulting in significant differences in waste management requirements. spent fuel from the reactor contains a modest concentration of fissile isotopes $\left({ }^{235} \mathrm{U},{ }^{239} \mathrm{Pu}\right.$, and $\left.{ }^{241} \mathrm{Pu}\right)$ and a significant concentration of fertile $235 U$ material $\left(238_{U}\right)$. The spent fuel may, as shown in Figure 2.1 , be transported to a reprocessing plant at which the fissile values are extracted and purified for reuse. Alternatively, spent fuel can be treated as waste and transported directly to a waste storage or a federal repository (i.e., "throwaway" fuel cycle). Further, plutonium that has been isolated by reprocessing of spent LWR fuel can be fabricated into mixed oxide (MOX) fuel for LWR, stored for other uses (e.g., fast reactor fuel), or treated as waste. The alternative fuel cycles are shown in Figure 2.2.

The impact of the alternatives on waste management is shown in Figure 2.3. The impact on reactor wastes of the alternative fuel cycles is minimal and will not be detailed. The composition of the spent fuel, however, is influenced by the fuel cycle mode. Because the "throwawa" fuel cycle does not include reprocessing, $200-t i m e s$ the amount of uranium and plutonium normally expected in the high-level waste from the reprocessing plant will be discarded in the spent fuel assembly. On the other hand, the lack of plutonium fuel in this fuel cycle option reduces significantly the transuranic* (TRU) content of the

*Transuranics are, by proposed regulation, (14) all elements with atomic numbers greater than 92, for example, Np, Pu, Am, Cm. 


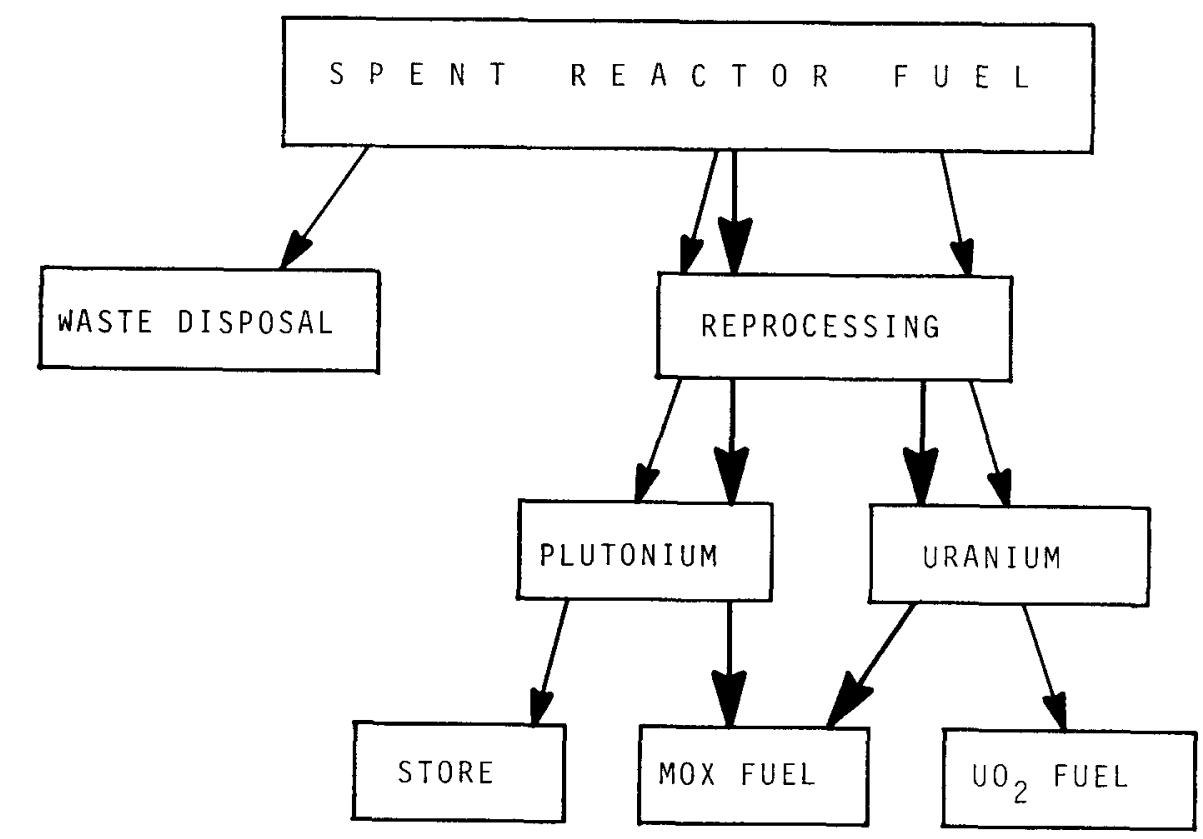

$\longrightarrow$ REFERENCE FUEL CYCLE

alternative fuel cycle

FIGURE 2.2. Alternative Fuel Cycles
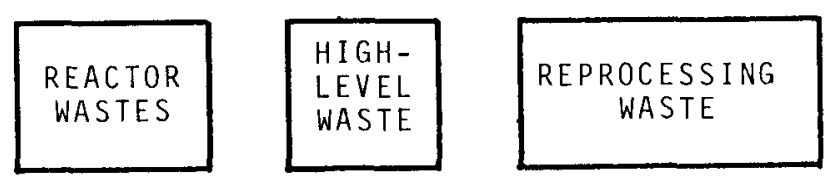

OPTION

\begin{tabular}{lr}
\hline "THROWAWAY" & $x$ \\
URANIUM RECYCLE & $x$ \\
U-PU RECYCLE (REFERENCE) & $x$ \\
\hline & \\
a. As intact fuel assemblies. \\
b. Includes plutonium.
\end{tabular}

FIGURE 2.3. Waste Sources from Alternative Fuel Cycles 
spent fuel. The alternative of reprocessing spent fuel to recover the unused $235 U$ and isolation of plutonium for storage (rather than recycle in Mox elements) is a fuel cycle alternative that generates high-level waste and other reprocessing plant wastes but no waste from Mox fabrication. The highlevel waste produced in this alternative is similar to the waste formed by processing of mixtures of $\mathrm{UO}_{2}$ and MOX fuel except that there is a lower transuranium content and a corresponding reduction in the neutron emission rate. Additional descriptions of fuel cycle alternatives are given in sections 2.3 and 2.4 . 


\section{REFERENCES}

1. U. S. Atomic Energy Commission, Directorate of Licensing, Fuels and Materials, Environmental Survey of the Uranium Fuel Cycle, WASH-1248, Apri1 1974 .

2. E. A. Youngberg, "Uranium Exploration, Mining, and Milling," Education and Research in the Nuclear Fuel Cycle, D. M. Elliott and L. E. Weaver, editors, University of OKlahoma Press, Norman, OK, 1972.

3. U.S. Environmental Protection Agency, Office of Radiation Programs, Field Operations Division, Environmental Analysis of the Uranium Fuel Cycle, Part I - Fuel Supply, EPA-520/9-003-B, October 1973.

4. Adapted from U.S. Atomic Energy Commission, Division of Reactor Development and Technology, Liquid Metal Fast Breeder Reactor Program Plan, Element 8 Fuel Recycle, Second Edition, WASH-1108, December 1972.

5. M. B. Sears, R. E. Blanco, R. C. Dahlman, G. S. Hill, A. D. Ryon, and J. P. Witherspoon, Correlation of Radioactive Waste Treatment Costs and the Environmental Impact of Waste Effluents in the Nuclear Fuel Cycle for Use in Establishing "As Low As Practicable" Guides - Milling of Uranium Ores, ORNL-TM-4903, Vo1. 1, Oak Ridge National Laboratory, Oak Ridge, TN, May 1975 .

6. R. W. Levin, "Conversion and Enrichment in the Nuclear Fuel Cycle," Education and Research in the Nuclear Fuel Cycle, D. M. Elliott and L. E. Weaver, editors, University of Oklahoma Press, Norman, OK, 1972.

7. Code of Federal Regulations, Title 10-Atomic Energy-Part 20, Appendix B.

8. U. S. Atomic Energy Commission, Office of Industry Relations, The Nuclear Industry 1974, WASH-1174-74, U. S. Government Printing Office, 1974.

9. I. Thomas, "Fuel Fabrication," Education and Research in the Nuclear Fuel Cycle, D. M. Elliott and L. E. Weaver, editors, University of Oklahoma Press, Norman, OK, 1972.

10. W. H. Pechin, R. E. Blanco, R. C. Dahlman, B. C. Finney, R. B. Lindauer, and $J$. P. Witherspoon, Correlation of Radioactive Waste Treatment Costs and the Environmental Impact of Waste Effluents in the Nuclear Fuel Cycle for Use in Establishing "As Low As Practicable" Guides - Fabrication of Light-Water Reactor Fuel from Enriched Uranium Dioxide, ORNL-TM-4902, 0ak Ridge National Laboratory, Oak Ridge, TN, May 1975.

11. W. S. Groenier, R. E. Blanco, R. C. Dahlman, B. C. Finney, A. H. Kibbey, and J. P. Witherspoon, Correlation of Radioactive Waste Treatment Costs and the Environmental Impact of Waste Effluents in the Nuclear Fuel cycle for Use in Establishing "As Low As Practicable" Guides - Fabrication of Light-Water Reactor Fuels Containing Plutonium, ORNL-TM-4904, Oak Ridge National Laboratory, Oak Ridge, TN, May 1975. 


\subsection{4}

12. L. W. Lau, Elements of Nuclear Reactor Engineering, Gordon and Breach Science Publishers, New York, NY, 1974.

13. A. F. Veras, "In-Core Fuel Management at Commonwealth Edison Company," Education and Research in the Nuclear Fuel Cycle, D. M. Elliott and

L. E. Weaver, editors, University of OKlahoma Press, Norman, OK, 1972.

14. 39 FR 32921, published September 12, 1974. 


\subsection{WASTES FROM REACTORS}

Based on the state of technological development and of commercial construction activity and commercial intentions, light water reactors of the boiling water reactor (BWR) type and pressurized water reactor (PWR) type are expected to provide a major portion of all nuclear power produced in the U. S. through at least the year 2000. Most of the radioactive wastes generated in power production by 1 ight water reactors will remain in the spent fuel, and be collected not at the reactor site, but at the fuel reprocessing facility when the spent fuel is disintegrated by chopping and leaching processes. A minor portion, however, will normally be present for potential release at the reactor site. This radioactivity results from neutron activation of structural materials near the core, corrosion products and chemical additives, fission of tramp uranium on the surfaces of fuel cladding, and failure of a small fraction $(0.25 \%)$ of fuel cladding that results in release of constituents* of irradiated fuel into the primary coolant system. All soluble radioactivity that becomes available for potential release at the LWR site is originally introduced into either the primary coolant or the fuel storage pool coolant. Minor portions of these liquids spread to various parts of the LWR plant by leakages, and therefore radioactivity appears in various waste streams of the LWR plant.

The present discussion is limited to the liquid waste streams. operations to remove radioactivity and both dissolved and suspended solids are applied to all these liquid streams before either recycle for use at the plant or discharge. The byproducts of the operations on liquid streams, therefore, will contain most of the radioactivity from the LWR site requiring waste management operations such as shipment and storage. These byproducts are in the form of wet solids. Also, some of the radioactivity at the LWR site will be incorporated in dry wastes of miscellaneous form and composition. $(1,2)$

Some radioactivity from the reactor site, including noble gases, tritium, and minor amounts of other isotopes, is dispersed to the environment in amounts and concentrations limited by current regulations. These wastes represent no demand at this time for further waste management operations and are therefore not considered here. The general flow patterns of radioactive wastes in a boiling water reactor (BWR) and in a pressurized water reactor (PWR) are diagrammed in Figures 2.4 and 2.5 .

In summary, in addition to the accumulation of miscellaneous dry solid wastes, an important determinant of the origin and nature of wastes emerging from reactors is the management of internal waste streams, the cleanup

\footnotetext{
*Mainly gaseous and volatile constituents; a minute fraction of the oxide fuel is water-soluble, and the penetration of water into a failed element is unlikely except during reactor shutdowns.
} 


\subsection{6}

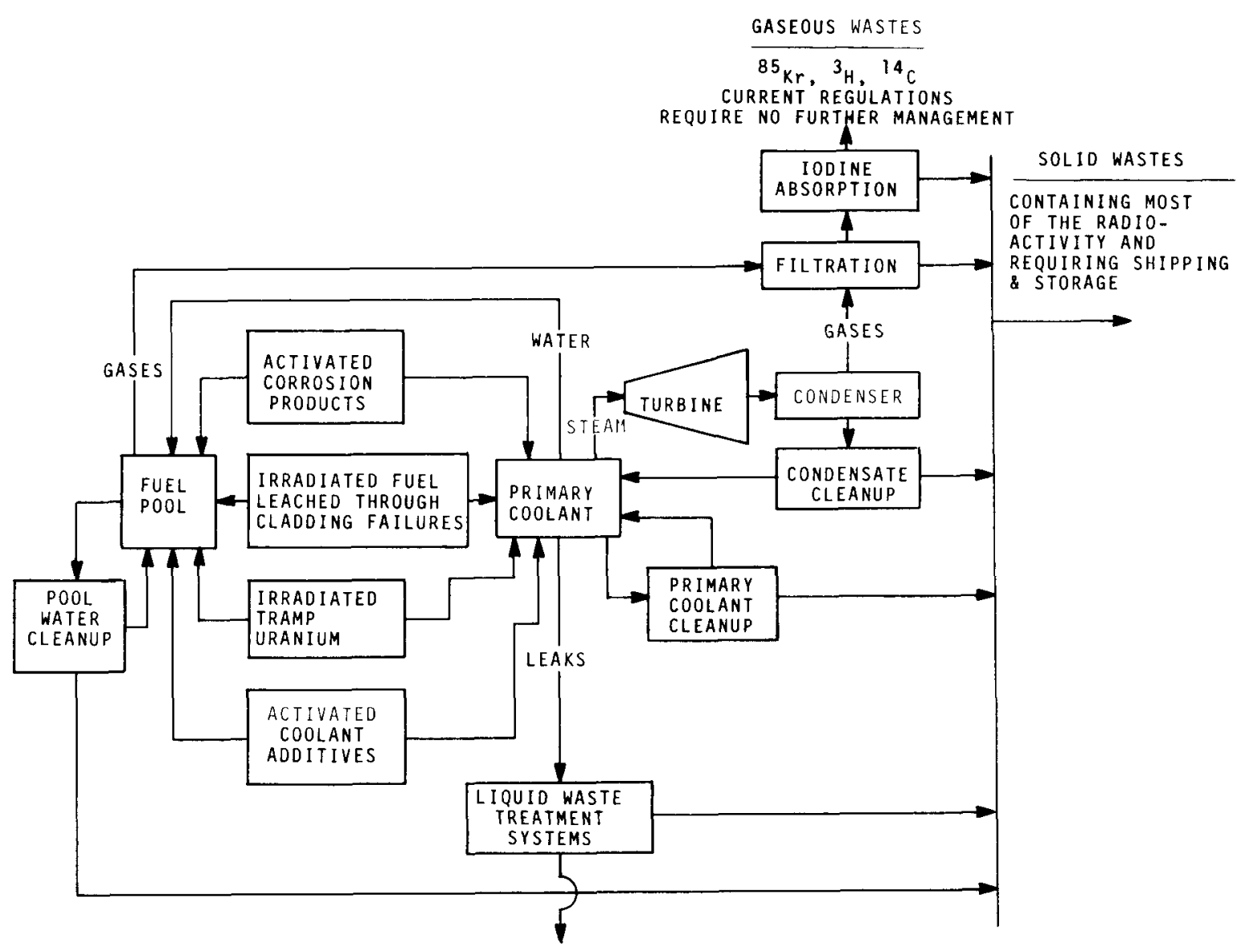

LIQUIO WASTES REQUIRING NO FURTHER MANAGEMENT

FIGURE 2.4. Typical Flow Pattern of Radioactive Wastes in the BWR System 


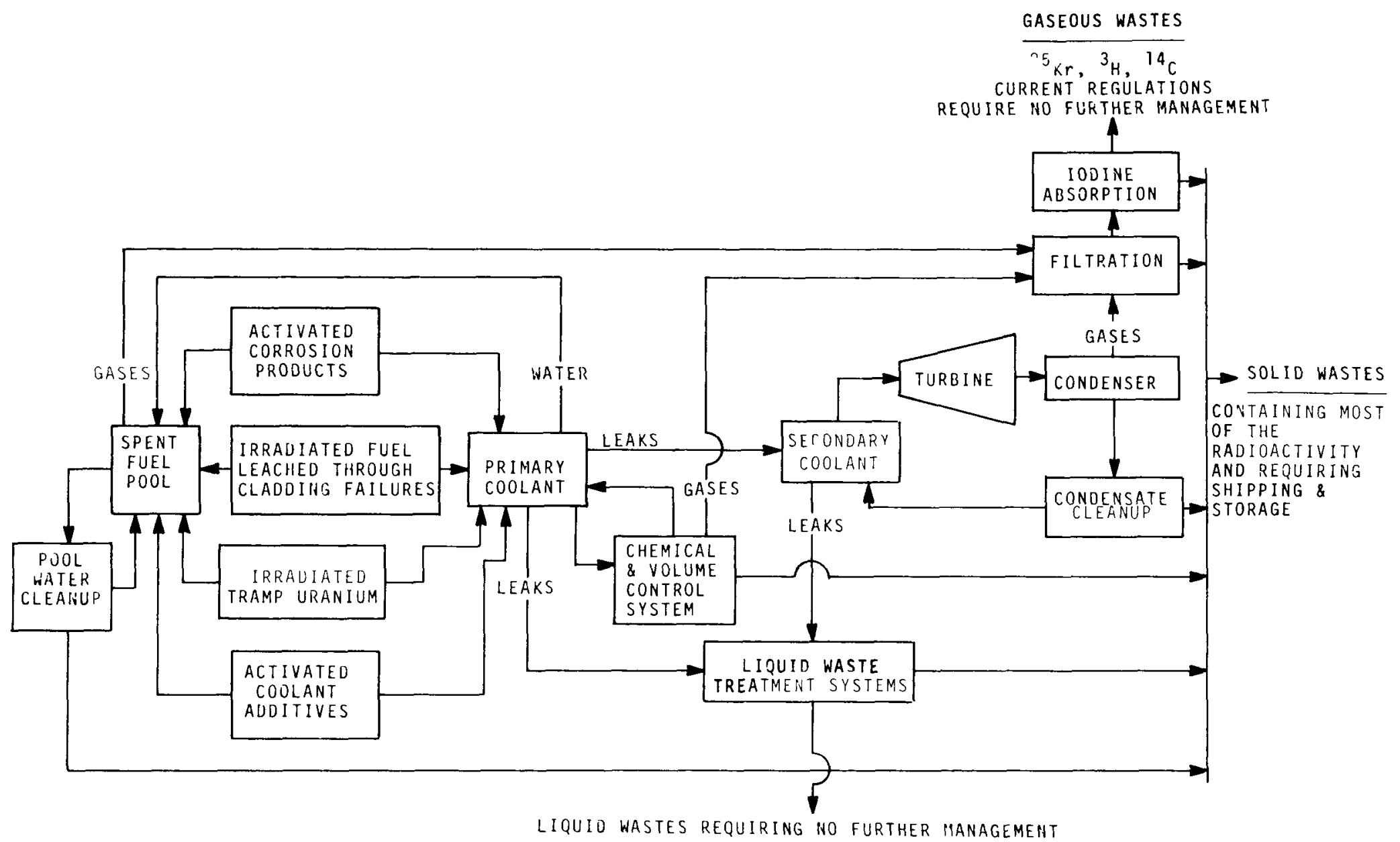

$\stackrel{\sim}{\nu}$

FIGURE 2.5. Typical Flow Pattern of Radioactive Wastes in the PWR System 
operations applied to them, and the wet solids resulting from these

operations. Therefore, the management of internal liquid streams and the cleanup operations applied to them are described below.

\subsubsection{Management and Cleanup Operations on Internal LWR Liquid Streams}

The processes applied to liquid reactor streams and producing wet solid wastes are filtering, demineralizing (ion exchange), evaporating, and (less commonly) centrifuging and reverse osmosis. (1-5) Prior to these processes, the various streams in a light water reactor are classified and segregated or collected according to their radioactivity and dissolved solids content in order to combine waste streams having similar characteristics and requiring similar treatment. Streams of low dissolved solids content ("clean" wastes) can be purified directly by demineralization. On the other hand, streams of high dissolved solids content ("dirty" wastes) are unsuitable for demineralization; they are treated by evaporation, producing a bottoms slurry that is concentrated in solids, and a purified, overhead stream that can be purified further by demineralization. Reverse osmosis has been suggested for use in reducing the dissolved solids content of laundry wastes before discharge. (1) The reject stream from reverse osmosis would be concentrated in both dissolved and suspended solids. Centrifugation, to dewater some of these wet solids, has been used less than the simpler process of settling and decantation, but will probably be used more widely in the future. An outline of the general management scheme is shown in Figure 2.6. These operations are detailed in Section 10 .

\subsubsection{Management of Primary Coolant}

Radioactivity enters the wet wastes through the direct processing of primary coolant or of other streams containing primary coolant because of various transport processes and leakage. For the wet wastes, therefore, the radioactivity level and the care in management will increase generally in proportion to the concentrations of primary coolant that they normally contact. The origin of some of the characteristics of these wastes can be inferred from the following general description of primary coolant management in BWRs and PWRs.

In a BWR, primary coolant water is converted to steam by heat from the fuel elements in the core. The steam expands through a turbine and then is condensed. The condensed steam is processed through the condensate cleanup system, collected, and returned to the reactor for reuse. A separate side stream of primary coolant is continuously withdrawn and processed through the reactor cleanup system (demineralizers) and returned to the reactor vessel. Both cleanup systems removed suspended solids and ionic impurities from the primary coolant. The materials collected by the demineralizers are removed periodically by chemical regeneration or by replacement of resins. The liquid 


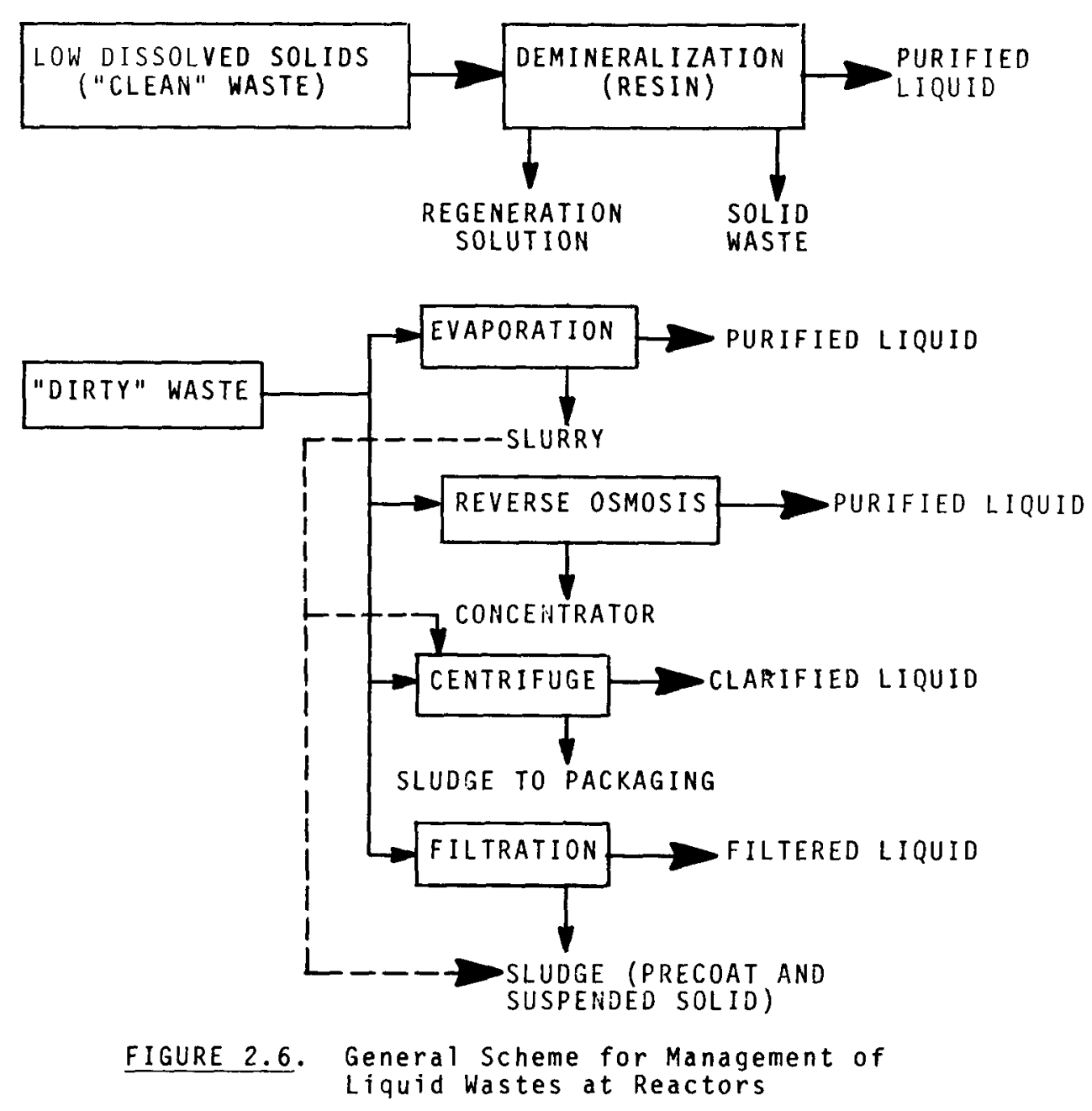


wastes are processed in the liquid waste treatment system, and the ion exchange resins are transferred to the solid waste treatment system and prepared for offsite shipment.

Liquid leakage occurring through valve stems, pump seals, and flanged connections is collected in drains and routed to the appropriate liquid waste treatment systems. Additional sources of liquid wastes are: the liquid streams needed to sluice (transfer), backwash, regenerate, and rinse demineralizer resins; wastewater from the laundry, personnel showers, laboratory drains, and decontamination areas; and water collected in equipment drains and floor drains.

In a PWR, primary coolant water circulates through the reactor core, where it removes the heat from the fuel elements. The pressurized primary coolant water flows from the core into the steam generator, where heat is transferred from it to the secondary coolant water, forming steam. The steam expands through the turbine and is then condensed and returned to the steam generators. The primary coolant water flows back to the reactor core.

The primary coolant is continuously purified by passing a side stream through filters and demineralizers in the chemical and volume control system. The purity of the primary coolant must be maintained to reduce corrosion, to prevent fouling of heat surfaces, and to keep releases to the environment to a low level.

Chemicals are added to the primary coolant to inhibit corrosion and/or improve fuel economy. Lithium hydroxide is added for pH control to reduce corrosion. Boron is also added to the primary coolant as a neutron absorber (shim control). At a later stage, boron is removed from the primary coolant, if adjustment of concentration is necessary, through the chemical and volume control loop (shim bleed). The shim bleed is processed through an evaporator, and the boron in the evaporator bottoms is either reused or packaged as solid waste. The evaporator distillate may be recycled to the reactor coolant system as makeup water or discharged to the environment.

By leakage through valve stems and pump shaft seals, some primary coolant escapes into the containment and into the auxiliary buildings. A portion of the leakage evaporates, and the remainder is collected in drains to be processed through the liquid waste treatment systems.

Leakage of primary coolant into the secondary coolant in the steam generator is the only source of radioactivity in the secondary coolant system. Water or steam leakage from the secondary system adds significant amounts to the liquid and gaseous radwaste treatment systems. In a secondary system maintained by blowdown, * the radioactivity introduced into that system will

\footnotetext{
*Blowdown is the removal of a portion of the recirculating cooling water con-
} taining concentrated dissolved salts to prevent their buildup in the system. 
eventually appear in solids used to treat streams that collect leaks from the secondary system. However, in a secondary system maintained by

demineralization, the radioactivity introduced to that system will eventually be borne on the resins of that demineralizer.

\subsubsection{Typical Waste Management Schemes and Solid Waste Generation Rates}

Flow sheets for liquid waste management at LWRs are not standardized. Considering waste generation rates, it is convenient to classify light water reactors into four main types: ${ }^{7)}$ BWRs and PWRs that treat the condensate with deep bed demineralizers and BWRs and PWRs that treat the condensate with powdered-resin filter-demineralizers. Figures 2.7 through 2.10 illustrate simplified schemes for liquid waste management and solid waste generation rates to be expected for these four types. The activity levels are based on an assumed cladding failure of $0.25 \%$ *

\subsubsection{Summary of Reactor Waste Volumes}

The reactor waste volumes 1 isted in Figures 2.7 through 2.10 are summed according to primary waste type and listed in Table 2.1.

\subsubsection{Reactor Component Wastes}

Replacement of and maintenance on reactor components (e.g., control rod guides, instruments, control rods, support plates, etc.) produce waste that is radioactive because of activation products formed during service within the high neutron flux region of the reactor. The activation products are an inherent part of the solid metal structures in which they were generated and thus become available contamination only upon deterioration of the very highly corrosion-resistant metals. The metallic components are usually sufficiently radioactive to require shielding for disposal and may need to be cut or compacted to fit into modest sized containers. Burial in commercial facilities is the probable disposition since this waste constitutes a non-TRU, intermediate level $\beta-\gamma$ waste with little or no mobile, radioactive contamination. Data on quantities or properties estimated for a 1000 MWe reactor are not available.

*This cladding failure percentage indicates that $0.25 \%$ of the total thermal power of the reactor is produced in fuel rods that have developed cladding defects. The percentage of total fission products, contained in irradiated fuel, that escape into the primary coolant would be several orders of magnitude lower. 


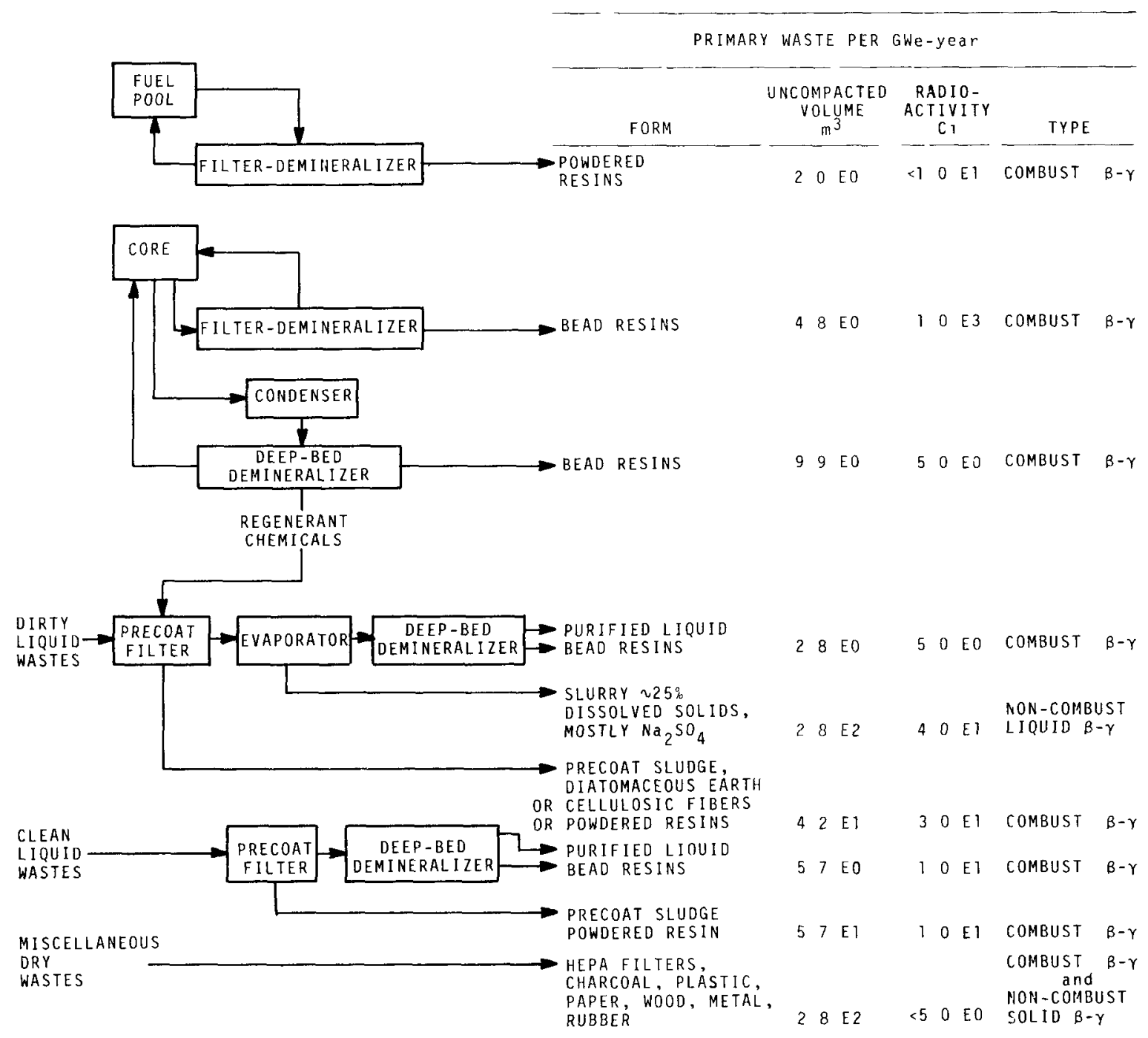

FIGURE 2.7. Sources and Characteristics of Non-Gaseous Wastes from 1-GWe BWR with Deep-Bed Condensate Cleanup 
PRIMARY WASTE PER GWe-year

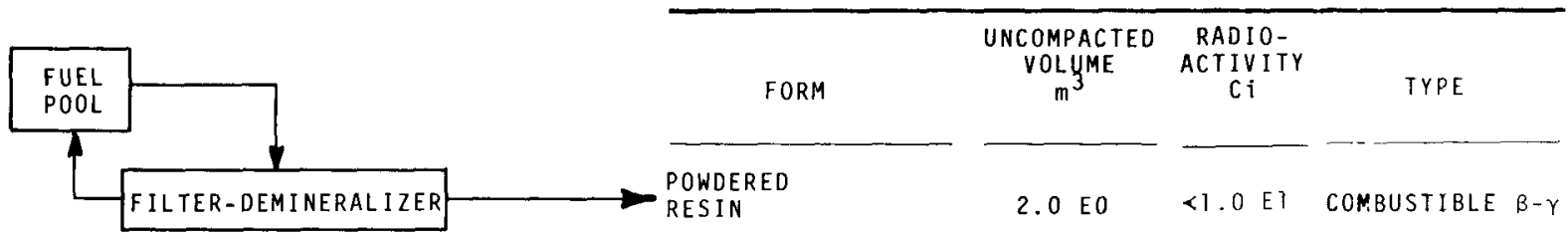

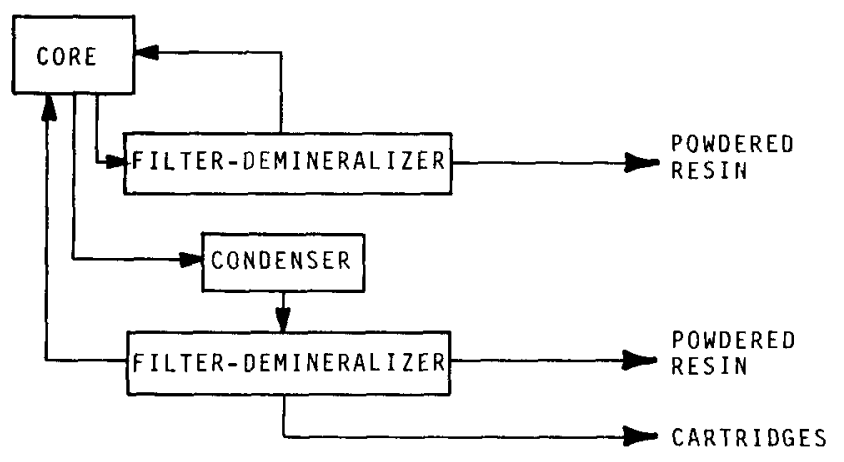

4.8 E0 1.1 E3 COMBUSTIBLE B Y

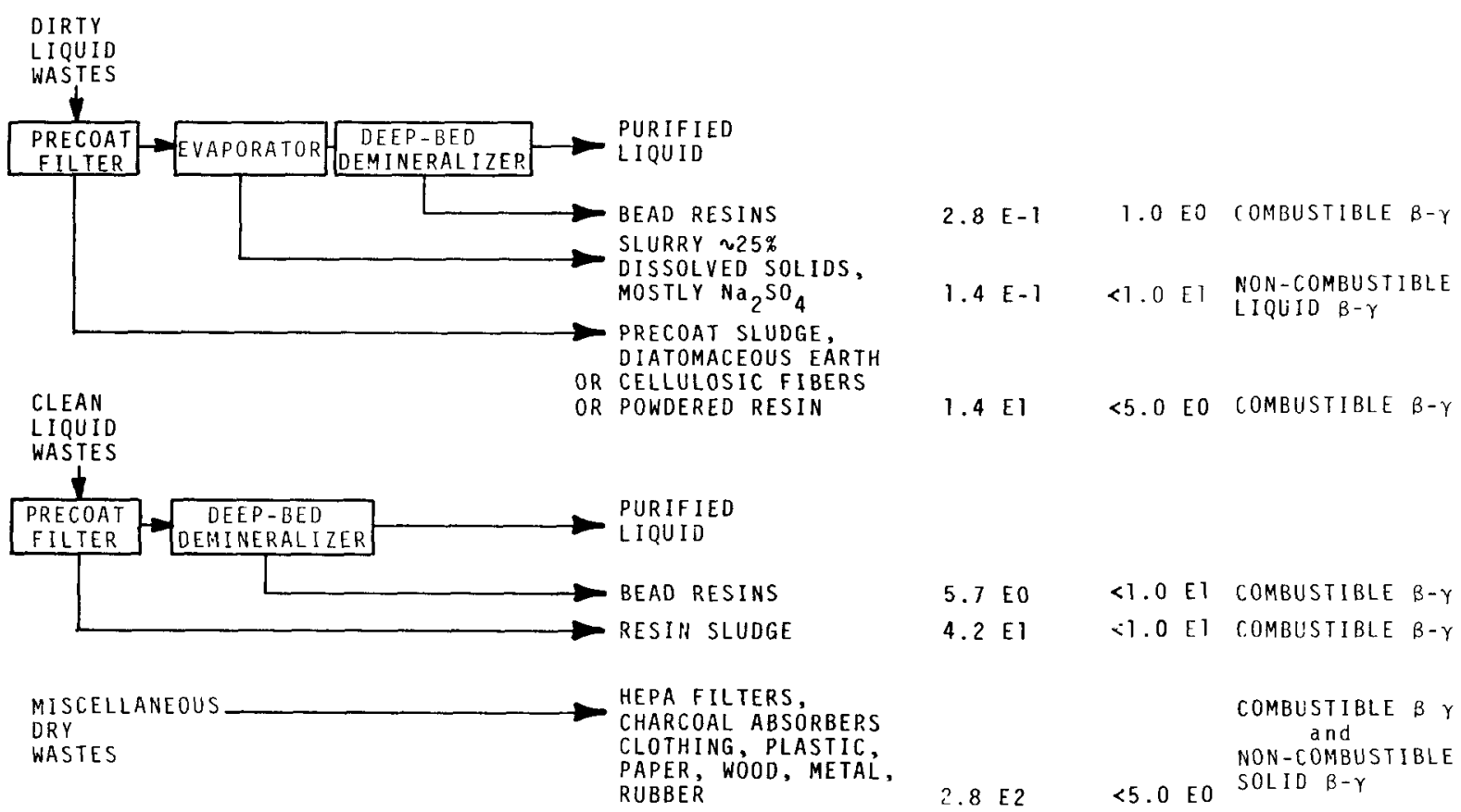

FIGURE 2.8. Sources and Characteristics of Non-Gaseous Wastes from 1-GWe BWR with Powdered Resin Condensate Cleanup 


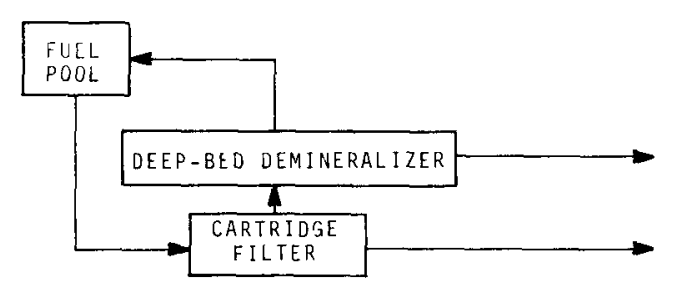

\begin{tabular}{|c|c|c|c|}
\hline \multicolumn{4}{|c|}{ PRIMARY WASTE PER GWe-year } \\
\hline FOR:I & $\begin{array}{c}\text { UNCOMPACTED } \\
\text { VOL UME } \\
\mathrm{m}^{3}\end{array}$ & $\begin{array}{c}\text { RADIO- } \\
\text { ACTIVITY } \\
\text { Ci }\end{array}$ & TYPE \\
\hline BEAD RESINS & $1.4 \mathrm{EO}$ & $5.0 E 0$ & COMBUSTIBLE $B-Y$ \\
\hline $\begin{array}{l}\text { FILTER } \\
\text { CARTRIDGES }\end{array}$ & $1.4 E-1$ & $5.0 \mathrm{EO}$ & COMBUSTIBLE $B-\gamma$ \\
\hline
\end{tabular}

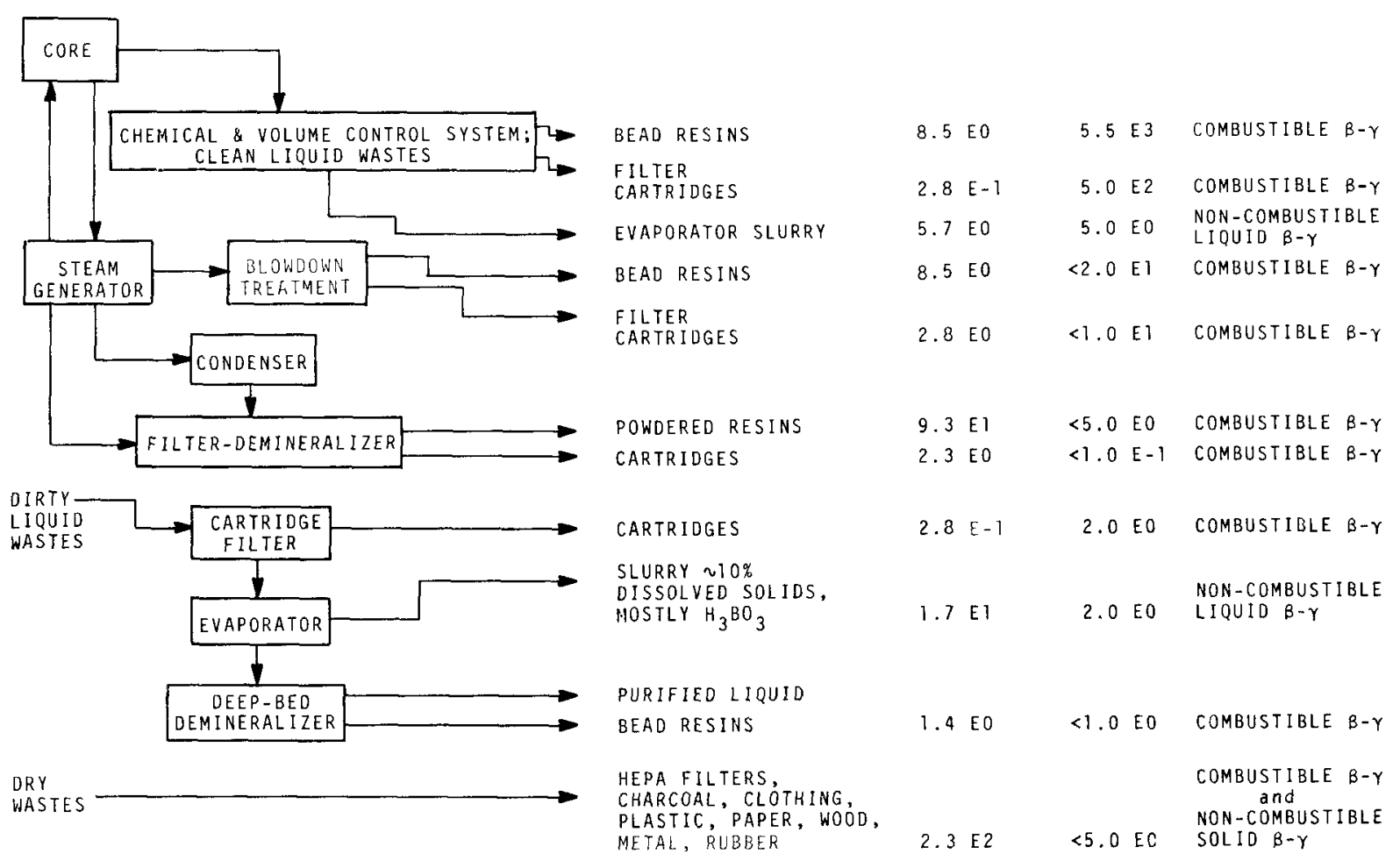

FIGURE 2.9. Sources and Characteristics of Non-Gaseous Wastes from T-GWe PWR with Powdered Resin Condensate Cleanup 


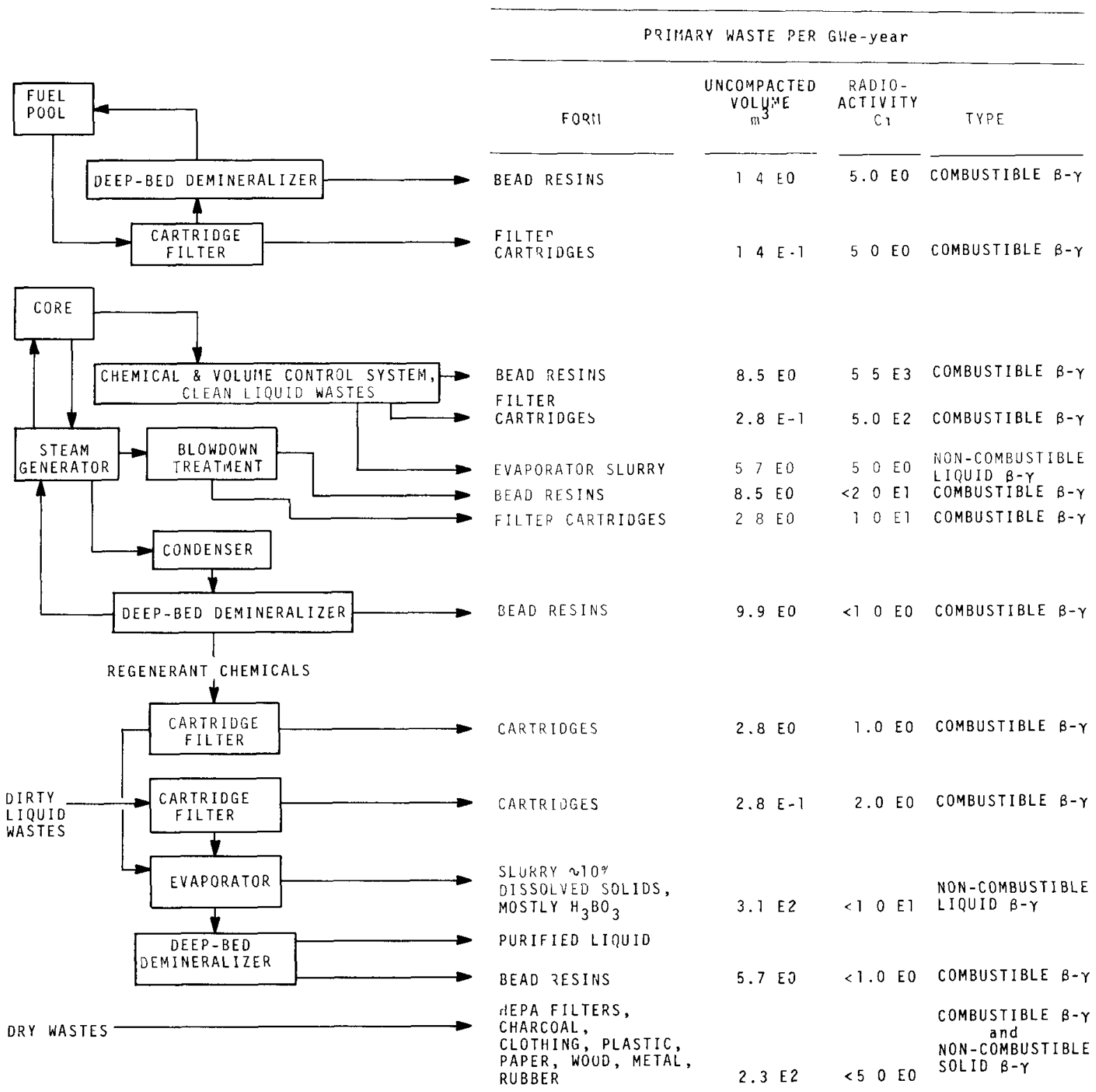

FIGURE 2.10. Sources and Characteristics of Non-Gaseous Wastes from 1 GWe PWR with Deep-Bed Condensate Cleanup 
TABLE 2.1. Summary of Non-Gaseous Reactor Waste Volumes (a)

\begin{tabular}{|c|c|c|c|c|}
\hline \multirow[b]{2}{*}{ Primary Waste Type } & \multicolumn{4}{|c|}{ Amounts in ${ }^{3} \mathrm{~m} / 1000$ MWe-year } \\
\hline & $\begin{array}{c}\text { BWR } \\
\text { Deep-Bed } \\
(b)\end{array}$ & $\begin{array}{c}\text { BWR } \\
\text { Powdered } \\
\text { Resin (c) }\end{array}$ & $\begin{array}{c}\text { PWR } \\
\text { Deep-Bed }\end{array}$ & $\begin{array}{c}\text { PWR } \\
\text { Powdered } \\
\text { Resin }\end{array}$ \\
\hline Combustible $\beta-\gamma$ & $351(d)$ & $392(e)$ & $223^{(f)}$ & $301(f)$ \\
\hline Non-Combustible Solid $\beta-\gamma^{(g)}$ & 57 & 57 & 46 & 46 \\
\hline Non-Combustible Liquid $\beta-\gamma(h)$ & 280 & 0.14 & 317 & 23 \\
\hline
\end{tabular}

a. Derived from Reference 7 ; all volumes on uncompacted basis.

b. Deep-bed demineralizer used for condensate cleanup.

c. Powdered resin filter-demineralizer used for condensate cleanup.

d. Resins + aqueous filter sludges (assumes combustible precoats) $+80 \%$ of miscellaneous dry wastes.

e. Resins + aqueous filter cartridges + filter sludges $+80 \%$ of miscellaneous dry wastes.

f. Resins + aqueous filter cartridges $+80 \%$ of miscellaneous dry wastes.

g. $20 \%$ of miscellaneous dry wastes.

h. Evaporator slurries. 


\section{REFERENCES}

1. U. S. Atomic Energy Commission, Directorate of Regulatory Standards, Final Environmental Statement Concerning Proposed Rule Making Action: Numerical Guides for Design Objectives and Limiting Conditions for Operation to Meet the Criterion "As Low As Practicable" for Radioactive Material in LightWater-Cooled Nuclear Power Reactor Effluents, Vo1. 1, WASH-1258, July 1973.

2. A. H. Kibbey and H. W. Godbee, A Critical Review of Solid Radioactive Waste Practices at Nuclear Power Plants, ORNL-4924, Oak Ridge National Laboratory, 0ak Ridge, TN, March 1974.

3. U. S. Environmental Protection Agency, Office of Radiation Programs, Technology Assessment Division, Environmental Analysis of the Uranium Fuel Cycle, Part II - Nuclear Power Reactors, EPA-520/9-73-003-C, November 1973.

4. K. H. Lin, Use of I on Exchange for the Treatment of Liquids in Nuclear Power Plants, ORNL-4792, Oak Ridge National Laboratory, Oak Ridge, TN, December 1973.

5. J. 0. Blomeke and F. E. Harrington, Management of Radioactive Wastes at Nuclear Power Stations, ORNL-4070, Oak Ridge National Laboratory, Oak Ridge, TN, January 1968.

6. H. W. Godbee, Use of Evaporation for the Treatment of Liquids in the Nuclear Industry, ORNL-4790, Oak Ridge National Laboratory, Oak Ridge, TN, September 1973.

7. C. R. Cooley, compiler, Commercial Alpha Waste Program Quarterly Progress Report January-March, 1975, HEDL-TME-75-87, Hanford Engineering Development Laboratory, Richland, WA, October 1975. 


\subsection{WASTES FROM SPENT FUEL STORAGE FACILITIES}

A spent fuel storage facility (pool) offers a number of services, including storage, cooling (usually by transfer of heat to the environment through a secondary cooling system and heat exchanger, e.g., an evaporative cooling tower), shielding, inspection, and control of radioactive materials released from both intact and failed fuel. $(1,2)$ pools will be a source of both wet and dry solid wastes that will require shipping, storage, and associated management operations. These wastes consist mainly of the byproducts of operations used to remove radioactive materials introduced into the pool water by both intact and failed fuel.

Pools are presently located at Federal sites including the Savannah River Plant, the Idaho National Engineering Laboratory, and the Hanford Plant. These pools are associated with both government-owned reactors and fuel reprocessing plants. Other pools are located at nuclear power stations and commercial fuel reprocessing plants. Although commercial plants are not reprocessing fuel at present, the fuel pools at both the Nuclear Fuel Services (NFS) Plant* and Midwest Fuel Reprocessing Plant (MFRP)** are already used for storage of spent fuel assemblies, and the pool at Barnwell Nuclear Fuels Plant (BNFP) ${ }^{+}$is expected to be put into service before reprocessing begins. ( 3 ) In addition to the above locations, independent pools, not associated with any other nuclear facility, have been proposed to alleviate the lack of storage space for fuel presently being discharged from operating nuclear power stations, but for which storage capacity is rapidiy diminishing. Several design studies are under way in an attempt to substantially increase the capacity of existing water basins.

The following sections discuss the characteristics of spent fuel, the operations of fuel pools, and finally the wastes emerging from these operations.

\subsubsection{Description of Spent Fuel}

Light-water reactor fuel assembliestt are composite units made of fuel elements ${ }^{+t}$ in a geometric cluster and held together by end pieces and a number of element spacers. BWR and PWR fuel assemblies differ significantly, but the basic component of each is the fuel element. A fuel element of either type is a long section of metal tubing filled with ceramic pellets of uranium dioxide

\footnotetext{
*West Valley, NY.

**General Electric Co., Morris, IL.

${ }^{\dagger}$ Allied-General Nuclear Services, Barnwell, SC.

t十"Fuel Assembly: A grouping of fuel elements which is not taken apart during the charging and discharging of a reactor core--Fuel Element, The smallest structurally discrete part of a reactor or fuel assembly which has nuclear fuel as its principal constituent." (7)
} 
or mixed uranium-plutonium dioxide and closed at both ends (see figure 2.11). The BWR ${ }^{(4)}$ cladding tube is typically larger $(\sim 1.4-\mathrm{cm}$ diam) and the finished element longer ( $\sim 400 \mathrm{~cm}$ ) than the PWR element. A typical fuel loading is $\sim 3$ $\mathrm{kg}$ of heavy metal in the oxide form per BWR fuel element. A PWR fuel element, ${ }^{(5)}$ on the other hand, has cladding with a $1-\mathrm{cm}$ diam and a $380-\mathrm{cm}$ length. A typical PWR fuel loading is $22 \mathrm{~kg}$ of heavy metal per element.

Differences between completed BWR and PWR fuel assemblies are even more noticeable. In the BWR assembly (Figure 2.12), the fuel elements are arranged in a 7- $x$ 7-element square array, but advanced fuels are to contain $8 \times 8$ arrays of $1.25-\mathrm{cm}$ diam elements. $(4,6)$ The total fuel-loading is $2200 \mathrm{~kg}$ of heavy metal for an average 64-element BWR fuel assembly. The individual elements are secured by upper and lower tie-plates and spacer-grids at intervals along the element cluster. The entire assembiy is covered by a thin Zircaloy sheet-metal box called a fuel channel. The fuel channel is normally reused following withdrawal of an assembly. The total weight of a completed BWR fuel assembly is typically $\sim 280 \mathrm{~kg}$ (excluding fuel channel). It has a $14-x 14-\mathrm{cm}$ cross section and is $4.5 \mathrm{~m}$ long.

The PWR assembly (Figure 2.13) contains 264 fuel elements in a square $(17 \times 17)$ array of locations, some of which are occupied by reactivity-control rods,* instrumentation, * and burnable-poison elements. $(5,9)$ An average fuel loading for a complete PWR assembly is $2460 \mathrm{~kg}$ of heavy metal. A PWR assembly has no cover or coolant channel, being secured by top and bottom nozzle fixtures and spring-clip grids spaced along the length of the element cluster. A completed PWR fuel assembly weighs $2670 \mathrm{~kg}$, has a cross section of $22 \times 22$ $\mathrm{cm}$, and is about $4 \mathrm{~m}$ long.

\subsubsection{Properties of Spent Fuel}

For purposes of describing compositions of waste streams, the physical differences in BWR and PWR fuel assemblies and the imbalance of numbers of the two types of reactors in the industry are synthesized into a hypothetical "reference LWR" fuel-assembly. Table 2.2 characterizes the reference assembly. Table 2.3 details the chemical composition. The oxide fuel would be contained in a square array with $2.57 \mathrm{~kg}$ of heavy metal per element. Total weight of this reference assembly is set at $454 \mathrm{~kg}$. The reference LWR fuel assembly contains fuel-cladding tubes that are made of Zircaloy with Zircaloy end plugs. Top and bottom assembly tie-plates or nozzle fixtures will be fabricated from type 304 stainless steel. Element-spacing fixtures will be of Inconel. The fuel pellets are $U_{2}$ or $(U, P u) 0_{2}$.

\footnotetext{
*Control rods and in-core instrumentation are not part of a PWR assembly and are removed from the array prior to reactor discharge.
} 


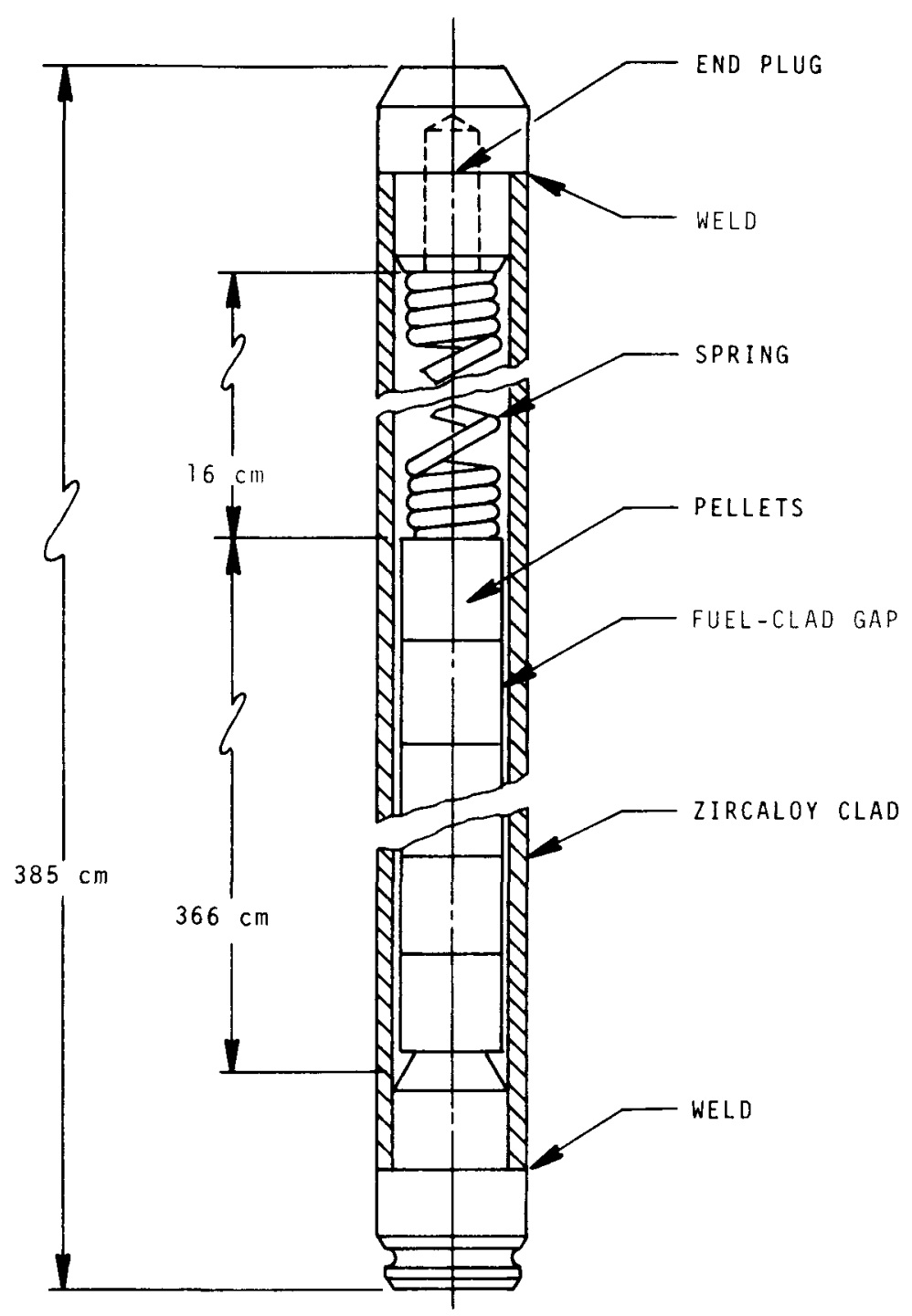

FIGURE 2.11. Typical PWR Fuel Element

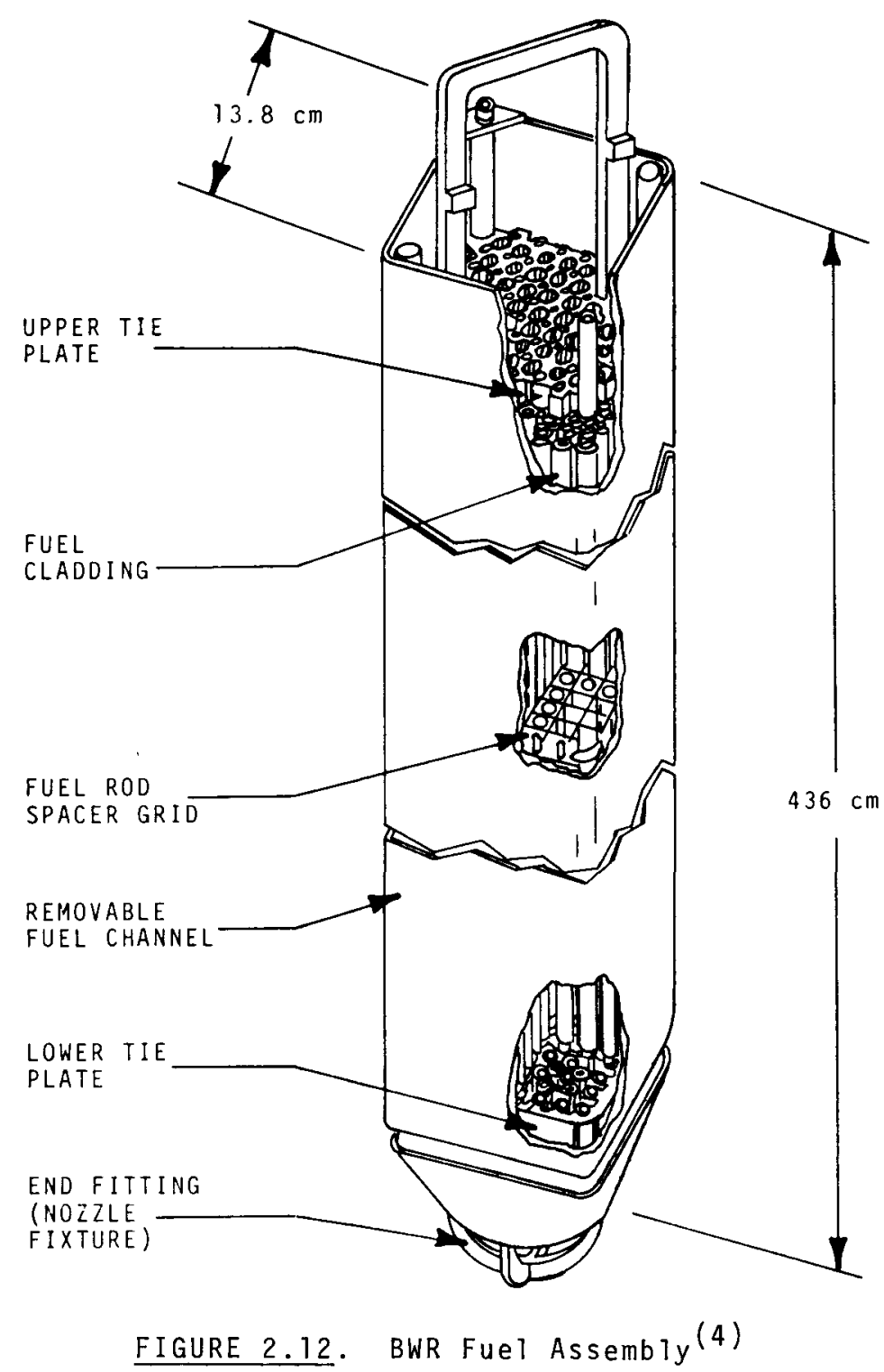




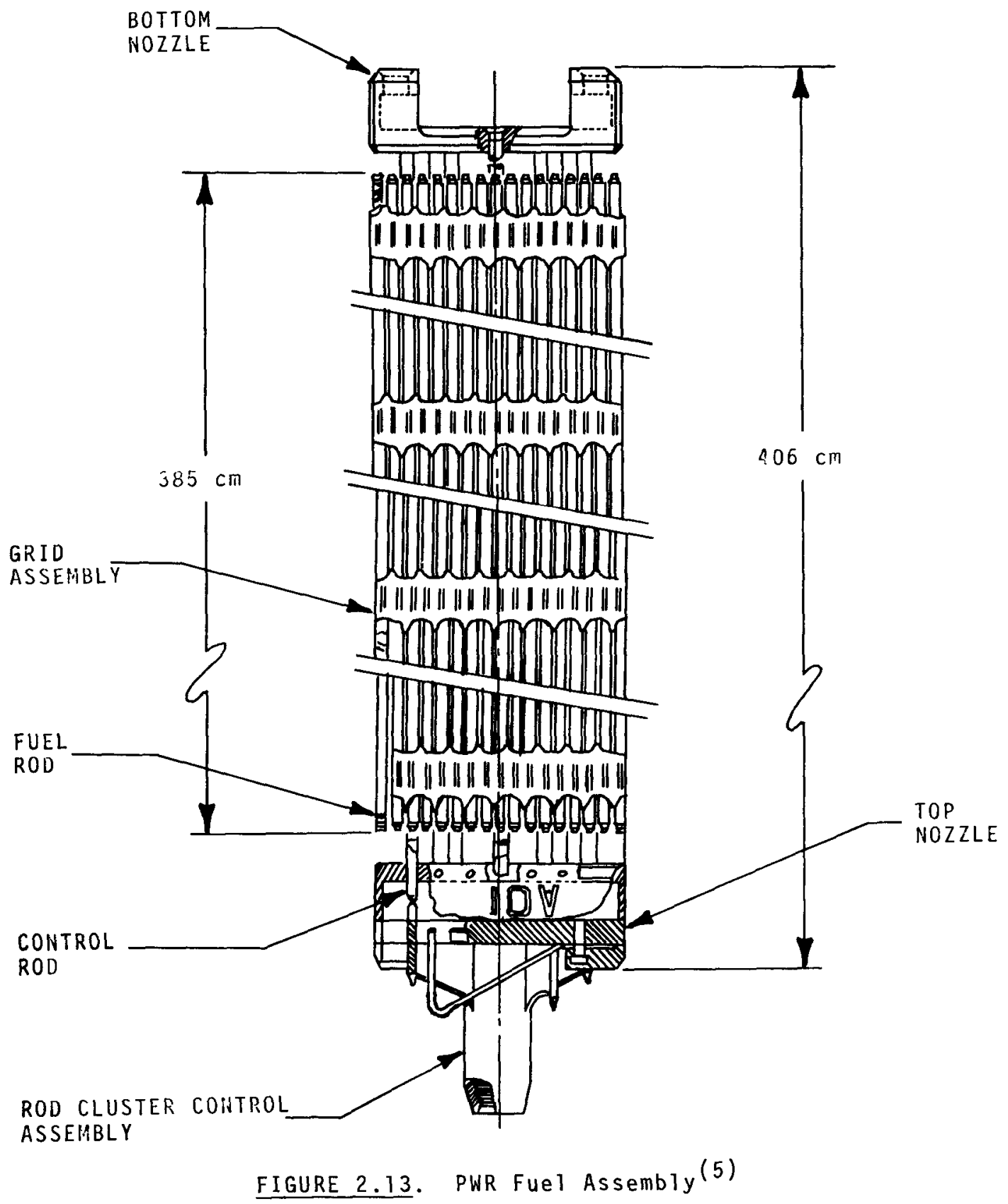


TABLE 2.2. Characteristics of Unirradiated LWR Fuel Assemblies

\begin{tabular}{|c|c|c|c|}
\hline & PWR ${ }^{(5)}$ & $B W R{ }^{(4)}$ & $\begin{array}{c}\text { "Reference" } \\
L W R(g)\end{array}$ \\
\hline Overall assembly length, m & 4.059 & 4.470 & ---- \\
\hline Cross section, $\mathrm{cm}$ & $21.4 \times 21.4$ & $13.9 \times 13.9$ & $-\ldots-1$ \\
\hline Fuel element length, m & 3.851 & 4.064 & ----- \\
\hline Active fuel height, m & 3.658 & 3.759 & $3.70^{(\mathrm{e})}$ \\
\hline Fuel element OD, $\mathrm{cm}$ & 0.950 & 1.252 & $1.16^{(e)}$ \\
\hline Fuel element array & $17 \times 17$ & $8 \times 8$ & $121^{(e)}$ \\
\hline Assembly total weight, $\mathrm{kg}$ & 668.6 & 279 & 454.32 \\
\hline Uranium/Assembly, $\mathrm{kg}$ & 461.4 & 188.7 & $311.4^{(h)}$ \\
\hline $\mathrm{MO}_{2} /$ Assembly, $\mathrm{kg}$ & 523.4 & 214.1 & 353.28 \\
\hline Zircaloy/Assembly, $\mathrm{kg}$ & $129.7^{(a)}$ & $56.7^{(b)}$ & 89.55 \\
\hline Hardware/Assembly, kg & $15.5^{(c)}$ & $8.2^{(d)}$ & $11.485^{(f)}$ \\
\hline Total metal/Assembly, $\mathrm{kg}$ & 145.2 & 64.9 & 101.03 \\
\hline
\end{tabular}

a. Includes Zircaloy control-rod guide thimbles.

b. Includes Zircaloy fuel-element spacers.

c. Includes $10 \mathrm{~kg}$ SS nozzles, $5.5 \mathrm{~kg}$ Inconel-718 grids.

d. Includes SS tie-plates, negligible amount of Inconel springs.

e. Specified only to estimate fuel content of each element of $2.57 \mathrm{~kg}$ heavy metal.

f. Includes $9 \mathrm{~kg}$ SS end pieces, $2.5 \mathrm{~kg}$ Inconel-718 spacers.

g. Based on discharges of fuel from PWR and BWR reactors with installed capacity ratio of 2 PWR: 1 BWR, using the same burn-up and fuel

assemblies of advanced GE and Westinghouse design (Reference 4,5).

The reference fuel assembly produces a metallic stream comparable to processing of a mix of PWR and BWR fuel.

$h$. $k g$ of heavy metal $(U+P u)$. 
TABLE 2.3. Chemical Composition of the Reference LWR Fuel Assembly (As Fabricated)

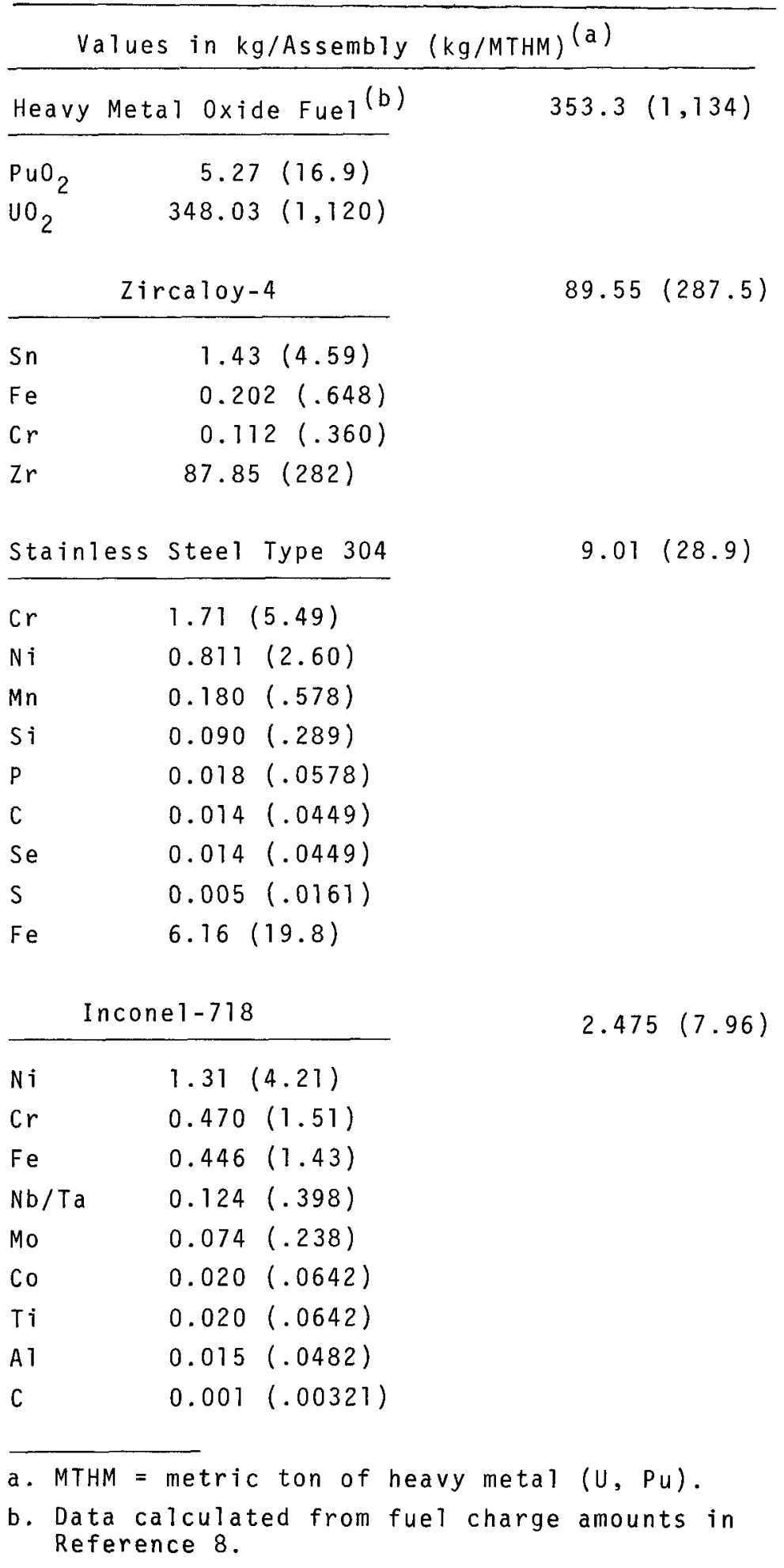


After irradiation at 35 MW/MTHM specific power and 25,000 MWd/MTHM burnup, in the core of a LWR, a spent-fuel assembly will have a total thermal power of 640 kilowatts $(\mathrm{kW})$. After 120 days cooling the heat generation rate has decayed to $8.4 \mathrm{~kW}$ per assembly. These data are shown in Table 2.4. A detailed list of fission products, actinide elements, and metallic construction elements, together with the anticipated radiations for various cooling times is also shown in Table 2.4. The spent-fuel assemblies will have a beta-gamma radiation dose rate at discharge of $>10^{6}$ Roentgen/hour (R/hr) at the most radioactive surface.

For the purposes of this document, it is assumed that the LWR spent-fuel assemblies contain no leaking and/or ruptured fuel elements. Thus, it is assumed that, except for emission of heat and radioactivity, the assemblies are physically unaltered from their fabricated conditions. It is recognized that a modest fraction of assemblies will contain leaking elements and that these require special handing. This impact on the overall waste management processes described in these sections is assumed to be small.

\subsubsection{Quantities of Spent Fuel}

It is assumed that a LWR will generate 45.6 MTHM of spent fuel in the production of 1000 MWe-year of power.* Based on the reference LWR fue 1 assembly containing $311.4 \mathrm{~kg}$ of heavy metal, 147 spent-fuel assemblies will be discharged for each 1000 MWe-year. A 1500-MTHM/year fuel reprocessing plant will process about 4800 of the reference assemblies each year, or 16 assemblies per day for 300 days. This rate is equal to fuel output from 33,000 MWe-year power generation by LWRs. Table 2.5 gives the weight distributions of the reference LWR assembly at various appearance rates.

\subsubsection{Characteristics and Operations of Reactor Pools}

A typical 21000 MWe reactor pool can store as much as $12 / 3$ reactor cores, i.e., about 100 to 250 MTHM of fuel.** During storage, much of the activity associated with short-lived isotopes will decay. The presence of short-lived activity distinguishes reactor pools from the pools both at fuel reprocessing plants and independent locations. At some reactors, assemblies are transferred from core positions to storage in the pool via a canal that joins the core and the pool. Thus, in this transfer, primary coolant mixes with pool water and the pool water can become contaminated. Radioactivity can be introduced into a reactor pool from mixing with primary coolant, from leaching of fuel from assemblies with failed cladding, and from shedding of deposits from the surfaces of assemblies.

*Based on 25,000 MWd/MTHM burnup as currently apparent in spent fuel and an efficiency of 0.32 MWe/MWth.

**PWR core, 89 MTHM; BWR core, 138 MTHM. $(4,5)$ 
TABLE 2.4. Chemical, Radiochemical, and Thermal Properties of Irradjated Reference LWR Assembly at Three Cooling

Element

Fission products $(d)$

$H(e)$
$G e$
$A S$
$S e$
$B r$
$B r$
$K r$
$R b$
$S r$
$Y$
$Z r$
$\mathrm{Zr}$
$\mathrm{Nb}$
$\mathrm{Mo}$
$\mathrm{TC}$
$\mathrm{Ru}$
$\mathrm{Rh}$
$\mathrm{Pd}$
$\mathrm{Ag}$
$\mathrm{Cd}$
$\mathrm{In}$
$\mathrm{Sn}$
$\mathrm{Sb}$
$\mathrm{Te}$
$\mathrm{I}$
$\mathrm{Xe}$
$\mathrm{CS}$
$\mathrm{Ba}$
$\mathrm{La}$
$\mathrm{Ce}$
$\mathrm{Pr}$
$\mathrm{Nd}$
$\mathrm{Pm}$
$\mathrm{Sm}$
$\mathrm{Eu}$
$\mathrm{Gd}$
$\mathrm{Tb}$
$\mathrm{G}$

Grams/Assemb 1 y

Curies/Assembly

Light elements $(f)$

\begin{tabular}{|c|c|}
\hline 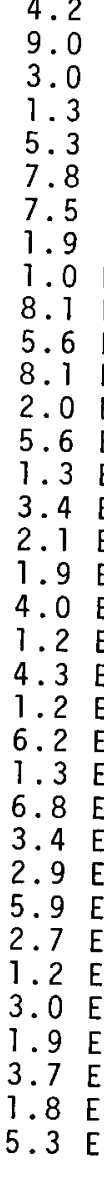 & $\begin{array}{ll}2 & E \\
0 & E \\
0 & E \\
3 & E \\
3 & E \\
8 & E \\
5 & E \\
9 & E \\
0 & E \\
1 & E \\
6 & E \\
1 & E \\
0 & E \\
6 & E \\
3 & E \\
4 & E \\
1 & E \\
9 & E \\
0 & E \\
2 & E 1 \\
3 & E C \\
2 & E 2 \\
2 & E 1 \\
3 & E 3 \\
8 & E 2 \\
4 & E 2 \\
9 & E 2 \\
9 & E 2 \\
7 & E 2 \\
2 & E 3 \\
0 & E 1 \\
9 & E 2 \\
7 & E 1 \\
3 & E 1 \\
3 & E-\end{array}$ \\
\hline & \\
\hline
\end{tabular}

$1.7 \mathrm{ET}$

$1.5 \mathrm{El}$

$9.1 \mathrm{EI}$

2. 0 ET

2.3 E3

$1.8 \mathrm{E} 2$

$6.9 \mathrm{E} 3$

2.0 E 1

2. 1 E3

8.8 E 4

1.2 E2
Curies/Spent-Fuel Assembly

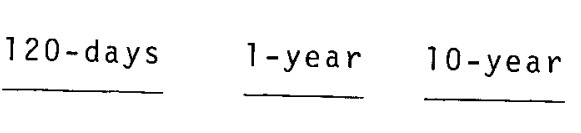

$1.6 \mathrm{E2}$

$9.7 \mathrm{El}$

(-

$9 . \overline{\mathrm{E}}-2$

$2.1 \mathrm{E3}$

$1.6 \mathrm{EO}$

$7.0 \mathrm{E} 4$

1.0 E5

1.4 E5

2.5 E5

3. 4 EO

2. 0 E 5

2.0 E 5

$3.1 E-2$

$1.8 \mathrm{E} 4$

$6.5 \mathrm{EI}$

$5.0 \mathrm{E}-1$

8.0 E2

2. $6 \mathrm{E} 3$

9.0 E 3

$1.0 \mathrm{ET}$

$6.0 \mathrm{E}]$

6.8 E4

2.5 E 4

9.0 E2

2.9 E5

2.6 E5

1. 0 E2

3.4 E 4

$3.4 \mathrm{El}$

$3.0 \mathrm{E} 3$

2.7 EO

1.1 E2

- -

9. $0 \overline{\mathrm{E}}-2$

9.

9. $0 \mathrm{E}-2$

$2.0 \mathrm{E} 3$

1. $8 \mathrm{E}-4$

1.9 E4

2. 1 E 4

1.0 E4

2. 2 E4

$3 . \overline{\mathrm{EO} O}$

8.7 E 4

8.7 E 4

3. 1 E-2

$9.3 \mathrm{E3}$

9.3 EO

1.5 E-2

2.2 E2

$2.2 \mathrm{E3}$

$1.5 \mathrm{E} 3$

$8.5 \mathrm{E}-3$

4. $0 \mathrm{E}-6$

6.0 E4

2.4 E 4

$1.5 \mathrm{E}-3$

$1.4 \mathrm{E} 5$

1.4 E5

2. $0 \mathrm{E}-3$

2.8 E 4

$3.4 \mathrm{E} 1$

2.6 E 3

$1.9 \mathrm{EO}$

7.1 E0

1. $1 \mathrm{E} 3$

4.7 E-6

]. $3 \mathrm{E} 4$

1. $3 \mathrm{E} 4$

$\begin{array}{ll}6.0 & E-1 \\ 2.9 & E-2\end{array}$

$3 . \overline{\mathrm{E} 0} 0$

$1.8 \mathrm{ET}$

$1.8 \mathrm{ET}$

$3.1 \mathrm{E}-2$

$1.1 E O$

$5.0 \mathrm{E}-1$

-.-

$1.9 \mathrm{E}-1$

2.2 E2

$5.6 \mathrm{E} 1$

8. $4 \mathrm{E}-3$

2. $2 \mathrm{E} 4$

2. 0 E- 4

4.7

4.7 El

$7 \mathrm{E}$

$2 . \overline{\mathrm{E} 3}$

$3.1 \mathrm{EI}$

$1.2 \mathrm{E} 3$

-..
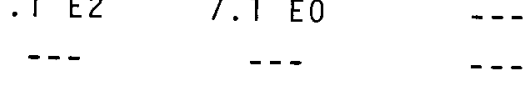

$\underline{\underline{1.7 \quad E 6}} \quad \underline{\underline{6.5 \quad E 5}} \underline{\underline{7.4 \quad E 4}}$

$2.5 \mathrm{E}-1$

$-.$.

- -

$--$

$4.9 E 2$

$1.7 \mathrm{E3}$

2.2 E 3

$2.8 \mathrm{E} 3$

$7.9 \mathrm{El}$

$2.8 \mathrm{E} 3$

$1.8 \mathrm{E} 3$
2. $5 \mathrm{E}-1$

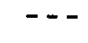

$--$

1.1 EO

$9.9 \mathrm{E}]$

1.8 E3

$1.6 \mathrm{E3}$

$7.9 \mathrm{EI}$

2. 0 E2

$1.5 \mathrm{E} 2$
$2.5 E-1$

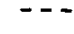

$--$

$5.4 \quad E-2$

$1.6 \mathrm{E} 2$

$4.5 \mathrm{E} 2$

$7.4 \mathrm{El}$

$2.4 \mathrm{E}-2$

$4.2 \mathrm{E}-3$ 
TABLE 2.4. (contd)

Element

Light elements $(f)$

Mo
Tc
Sn
Sb
Te

Grams/Assembly

Curies/Assembly

Transuranics $(d)$
$7.9 \mathrm{ET}$

5. 0 E3

2. $9 \mathrm{E} 2$

$1.1 \mathrm{E2}$

$5.5 \quad E 3$

Grams/Assemb $1 y$

Curies/Assemb $1 y$

Total grams/Assembly $(\mathrm{g})$

Total curies/Assembiy

Thermal watts/Assembly

Fission products

Light elements

Transuranics

Total $\underline{\underline{5.5} \mathrm{ES}}$

$\underline{1.1 \quad E 5}$
Curies/Spent-Fuel Assembly

Grams/

Assembly (b) 120-days 1-year 10-year

$7.6 \mathrm{El}$

$1.2 \mathrm{E}-1$

1. 3 E3

8. 5 E 1

4.9 EO

$1.0 \quad E 5$

$1.5 E-3$

$1.5 E-3$

2. $0 E-3$

1. $9 \mathrm{E} 3$

2. $0 \mathrm{E}-3$

7.4 E 3

$5.8 \mathrm{E} 3$

$3.5 \mathrm{E3}$

$1.4 \mathrm{E3}$

$3.6 E-3$

2. $0 E-3$

$7.9 E-2$

$1.6 \mathrm{E3}$

$3.3 E 2$

$1.4 \mathrm{E} 2$

- -

$2.7 \quad E 4$

- - -

-.-

$\underline{1.1 E 4} \quad \underline{1.2 E 3}$
4. 3 ET

8.2 E4

2. 3 E2

$3.1 E 4$

$4.3 E T$

7.9 E4

3.2 E2

1.6 E4

4. 3 E T

$5.2 \mathrm{E} 4$

$1.2 \mathrm{E3}$

$5.5 \mathrm{E3}$

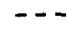

$1.1 \quad E 5$

$95 \mathrm{E}$

$\frac{9.5 E 4}{\ldots-}$

$1.8 E$

$\underline{7.6 \quad E 5}$

$\underline{1.3 \quad E 5}$
$7.1 E 3$

$2.9 \mathrm{E3}$

$2.2 \mathrm{E} 2$

$1.5 \mathrm{E} 2$

$5.9 \mathrm{El}$

$8.7 \mathrm{EO}$

$1.2 \quad E 3$

$6.6 \mathrm{E} 2$

$3.1 \mathrm{E} 2$

$8.4 \quad E 3$

$3.6 \quad E 3$

$5.4 \quad E 2$

Total neutrons

$n / \sec -A \operatorname{semb} l y$

a. Based on recycle core loading of $70 \% \cup 0$ fuel and $30 \%$ MOX fuel, $25,000 \mathrm{MWd} / \mathrm{MTHM}$ burnup and $35 \mathrm{MW} / \mathrm{MTHM}$ specific power.

b. For 8.4 E3 read $8.4 \times 10^{3}$ or 8400 ; for $4.0 \mathrm{E}-1$ read $4.0 \times 10^{-1}$ or 0.40 .

c. Load at l-year cooling.

d. Contained in oxide fuel.

e. As tritium assuming $170.3 \mathrm{Ci} / \mathrm{assembly}$ at discharge.

f. Contained in metallic assembly components.

g. Excludes $3.38 \mathrm{E} 5 \mathrm{~g} \mathrm{UO} \mathrm{O}_{2}$ and $6.7 \mathrm{E} 2 \mathrm{~g}$ oxygen from PuO ${ }_{2}$. See Table 2.2 for mass summaries. 
TABLE 2.5. Reference LWR Fuel Assembly Weight Distributions at Various Appearance Rates

A11 Weights in Metric Tons Per

\begin{tabular}{|c|c|c|c|c|}
\hline & Assemb $1 y$ & 1 MTHM & GWe-year & 1500 MTHM \\
\hline Assemblies, No. & $-1-$ & $-3.21-$ & $-147-$ & $-4817-$ \\
\hline U-Pu weight & 0.3114 & 1 & 45.6 & 1500 \\
\hline 0xide fuel weight & 0.3533 & 1.13 & 51.9 & 1702 \\
\hline Zircaloy weight & 0.0896 & 0.288 & 13.2 & 432 \\
\hline Hardware weight & 0.0115 & 0.037 & 1.69 & 55.4 \\
\hline Total weight & 0.4544 & 1.46 & 66.8 & 2189 \\
\hline
\end{tabular}

$\frac{\text { 2.3.5 Characteristics and Operations of Pools at Fuel Reprocessing Plants and }}{\text { Independent Locations }}$

The capacity of storage pools at reprocessing plants varies from 90 MTHM at the Midwest plant to an estimated 360 MTHM at the Barnwell plant. (3) The data for a "typical" 1500 MTHM/year reprocessing plant has been reduced to ح250 MTHM, based on 800 "reference LWR" assemblies.

The general set of operations carried out at fuel reprocessing plants and independent locations that will result in introduction of radioactivity into the pool and ultimately in generation of wastes requiring shipping and storage, are outlined as follows. On receipt, a shipping cask containing spent fuel is inspected and monitored for exterior radioactivity. If the cask is not contaminated, it is washed outside the plant. However, if the cask is contaminated, it will be washed inside the plant and the contaminated liquids routed to the waste treatment system. The cask is then transferred to a decontamination pit where the cask is vented, and the gases are routed through a filtered exhaust system. If the cask coolant* is found to be contaminated, it is pumped to the waste treatment system, and the interior of the cask is flushed. The cask is then transferred to a separate cask-unloading pool where the fuel assemblies are transferred to storage canisters (Figure 2.14). To avoid stresses on assemblies, they are transferred to storage positions by moving canisters rather than individual assemblies. The loaded canisters are placed in racks for storage.

The lid is replaced on the unloaded cask, the cask rinsed with clean water as it is removed from the cask unloading pool, and drained, if it is the drycavity type. The cask is then transferred back to the decontamination pit for

*The Allied-General Nuclear Services spent-fuel cask is designed for use without an internal coolant; personal communication, R. Keely (AGNS) to M. Steindler (ANL). 


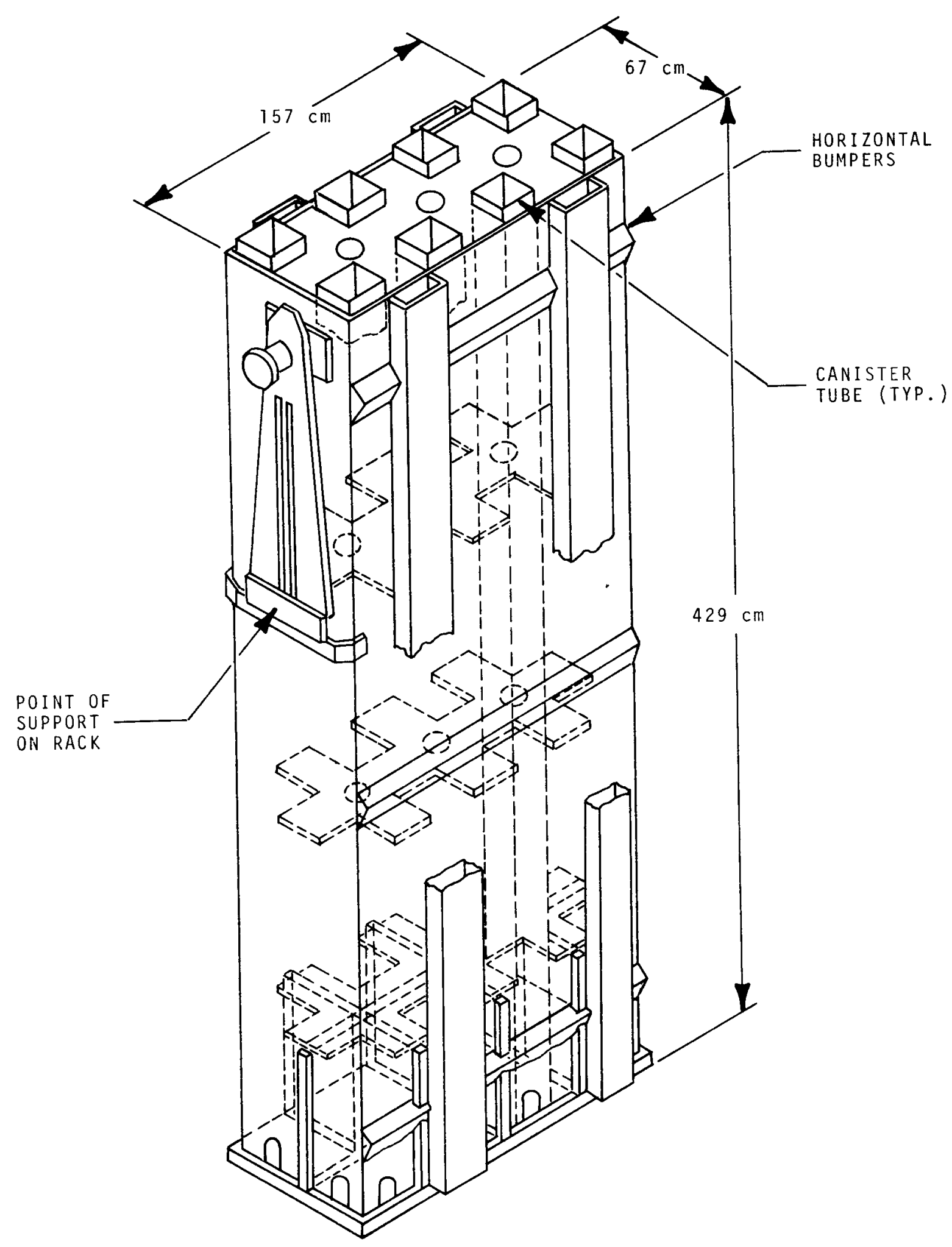

FIGURE 2.14. Fuel Storage Canister 
inspection and additional decontamination. Finally the cask is removed and remounted on the transport vehicle and shipped from the plant site.

At pools associated with commercial reprocessing plants, where there is no communication with primary reactor coolants, and short-lived isotopes have decayed before fuel is introduced to the pool, the chance of radioactive contamination is less than at reactor pools. Probably the most important source of contamination of reprocessing plant storage pools is shedding of the deposit of radioactive materials on the surface of fuel elements. These deposits consist of activated corrosion products and the components of failed fuel. The major corrosion products will be ${ }^{58} \mathrm{Co},{ }^{60} \mathrm{Co}$, and ${ }^{54} \mathrm{Mn}$. The major fission products expected are ${ }^{134} \mathrm{Cs},{ }^{137} \mathrm{Cs},{ }^{106} \mathrm{Ru}-{ }^{106} \mathrm{Rh},{ }^{95} \mathrm{Zr}-{ }^{95} \mathrm{Nb},{ }^{124} \mathrm{Sb}$, ${ }^{144} \mathrm{Ce},{ }^{129} \mathrm{I}$, and ${ }^{137} \mathrm{I}$. One other source of contamination of these pools is contaminated coolant from shipping casks.

\subsubsection{Waste-Generating Operations and Magnitude of Waste Streams}

The operations that generate wastes requiring shipping and storage are mainly filtration and ion exchange. These are done to maintain clarity of the water for observing underwater operation and storage conditions, and to keep radiation levels sufficiently low to avoid excessive exposure of operating personne1. These operations are designed to remove dirt, corrosion products, and radioactive material from the pool water. Filtration may be carried out using porous stainless steel elements in stainless steel housings. A typical ion exchange bed will consist of mixed resin, containing both anion and cation resins and an acid and a caustic regeneration system.

The atmosphere of the pool system is conditioned typically by a ventilation and air conditioning system of $2.8 \times 10^{3} \mathrm{~m}^{3} / \mathrm{min}$ capacity. Also, an exhaust system for venting shipping casks and the hoods that are placed over leaking fuel assemblies will have a capacity of $2.8 \mathrm{~m}^{3} / \mathrm{min}(100 \mathrm{cfm})$ and be equipped with HEPA filters and iodine absorbers.

The wastes that emerge from these cleanup operations are associated with changing and charging pool water filters, ion exchangers, and iodine absorbers, and with waste treatment and packaging. Thus they will consist of wet solids, including spent resins and filter sludges, and miscellaneous dry solids, including HEPA filters, charcoal or silver zeolites (at reactor pools), clothing, plastic, paper, wood, metal, and rubber (Figures 2.15 and 2.16). Estimates of the waste volume generated from fuel storage pools are shown in Table 2.6. 


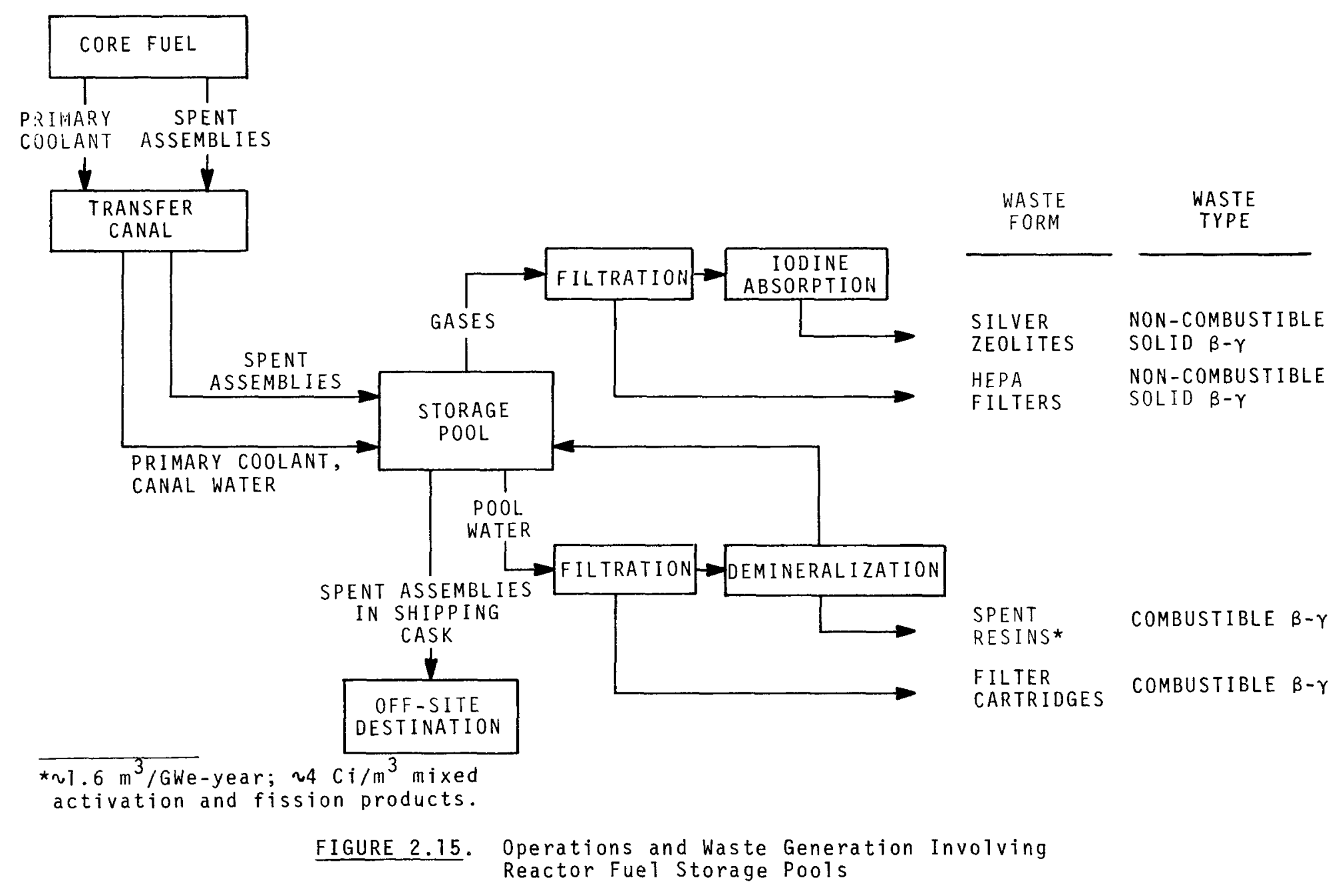


2.41

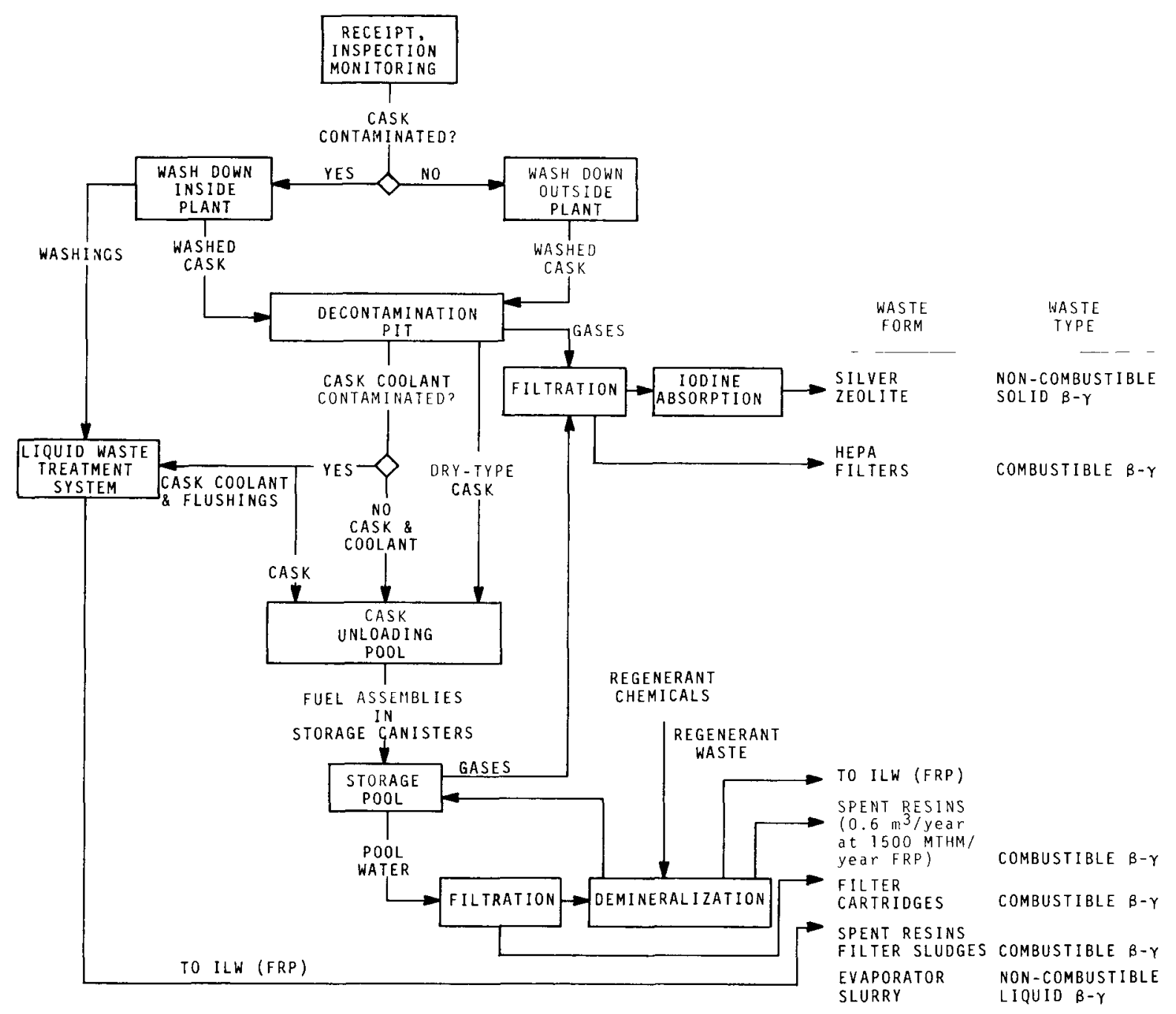

FIGURE 2.16. Operations and Waste Generation Involving Fuel Storage Pools at Reprocessing Plants and Independent Locations 
TABLE 2.6. Summary of Solid Wastes Volumes from Spent Fuel Basins(a)

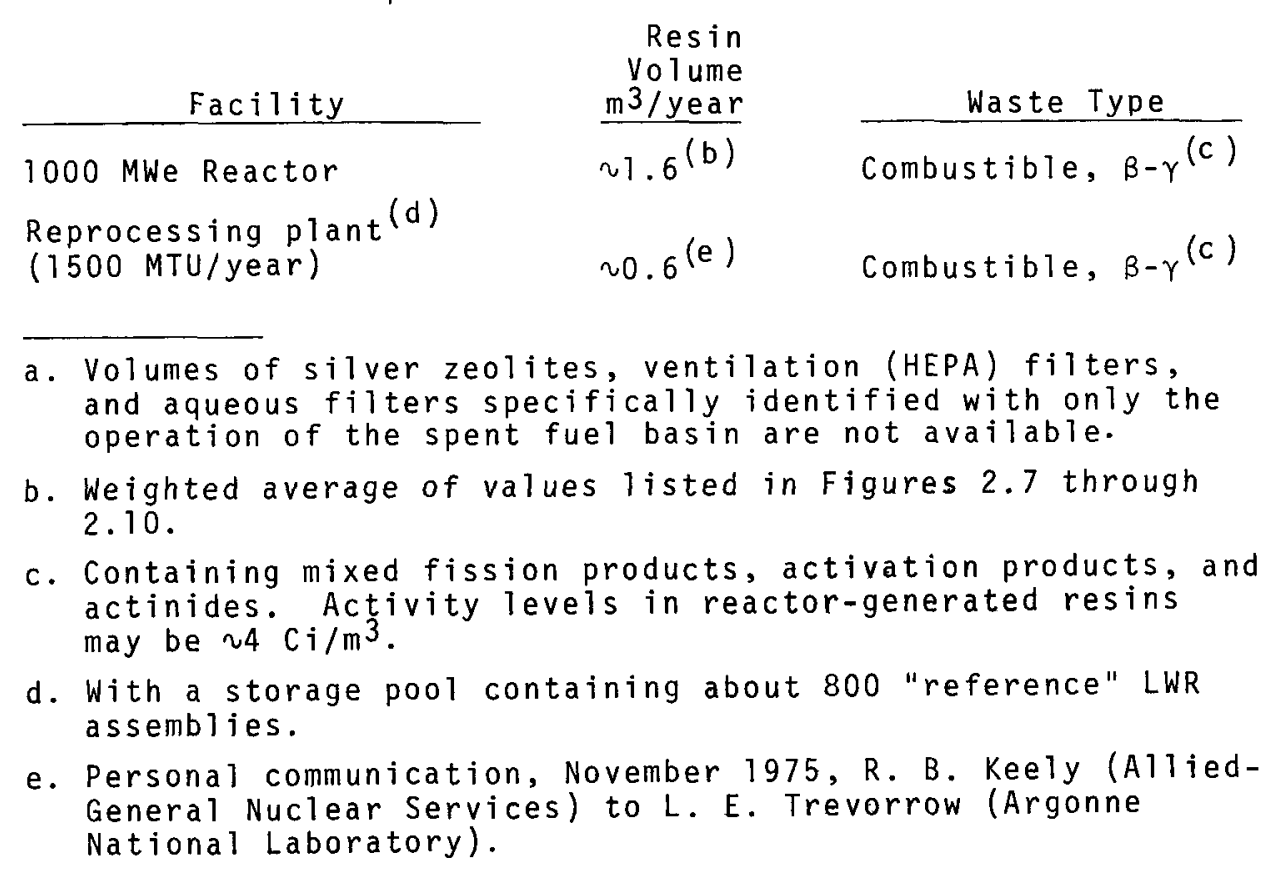

\section{REFERENCES}

1. Allied-General Nuclear Services, Barnwell Nuclear Fuel Plant, Final Safety Analysis, DOCKET 50-332, pp. 4-11.

2. United States Atomic Energy Commission, The Safety of Nuclear Power Reactors and Related Facilities, WASH-1250, pp. 1-39, July 1973.

3. United States Energy Research and Development Administration, LWR Spent Fuel Disposition Capabilities, 1975-1984, ERDA-25, March 1975.

4. General Electric Co., Standard Safety Analysis Report, Vol. 2, BWR/6.

5. Westinghouse Corp., Reference Safety Analysis Report, Vol. II, RESAR-3S, July 1975.

6. F. Judge, H. Williamson, and D. Weiss, "General Electric Fuel Performance Update," Trans. Amer. Nucl. Soc., Vol. 20, pp. 249-250, April 1975.

7. USA Standard Glossary of Terms in Nuclear Science and Technology, United States of America Standards Institute, New York, NY, 1967.

8. C. W. Kee, ORIGEN Code, PWR-U Equilibrium and Pu-Recycle Fuel, 25,000 MWd/ MTHM Burnup, 35 MW/MTHM Specific Power; Program Output, Oak Ridge National Laboratory, 0ak Ridge, TN, 0ctober 1975, private communication from J. 0. Blomeke (ORNL) to M. J. Steindler (ANL), 1975.

9. W. P. Tiler and L. R. Katz, "Evolution of Westinghouse PWR Leading Up to the 3000-MW(th) Reactor Mode1," Trans. Amer. Nucl. Soc., Vol. 20, pp. 1317, April 1975 . 


\subsection{WASTES FROM FUEL REPROCESSING PLANTS}

Most of the radioactivity in nuclear wastes is generated in processes which disassemble the reactor fuel and separate uranium, plutonium, and the fission products. Plutonium and uranium are segregated to recover their fissile values for reuse in the nuclear fuel cycle. The wastes are isolated to insure their long-term containment.

For the purposes of this document, the reprocessing plant operations start with the receipt of spent fuel at the reprocessing plant and terminate with the formation and packaging for shipment of plutonium dioxide and uranium hexafluoride. Described here, in brief detail, is a generic reference process. The process description emphasizes the behavior and formation of waste streams rather than the behavior and transport of the products. Fuel reprocessing technology for plants in existence or under development is based on the aqueous reprocessing by methods known as the Purex processes. A reference Purex process flow sheet for a $1500-$ MTHM per year reprocessing plant $(1-3)$ is therefore used.

\subsubsection{Process 0utline and Sources of Waste}

The "head end" process steps include 1) the receipt of fuel in shielded casks at the plant, 2) the storage of fuel for sufficient time to allow decay of radioactivity to levels used as criteria for the reprocessing operations, 3) disassembly of fuel assemblies and chopping of fuel elements into modestsized pieces, 4) the leaching of the fuel from the cladding by nitric acid, and 5) the preparation of the acidic feed solution for the solvent-extraction separations process.

The Purex process steps are 1) solvent extraction which effects the separation from fission products and partition of uranium and plutonium, 2) purification of uranium and plutonium to separate these products from the small quantity of residual fission products, and 3 ) conversion of uranium to $\mathrm{UF}_{6}$ and plutonium to $\mathrm{PuO}_{2}$. In addition, the waste management operations stemming from general plant operations, such as maintenance, decontamination, supporting analytical services, the general recycle and makeup plant liquids and reagents, and other such activities, are included. Figure 2.17 identifies the various steps in the reference process.

2.4.1.1 Head End Operations (Figure 2.18)(1-3)

Head end operations in the fuel reprocessing plant consist of washing of the casks to remove external radioactivity and transfer of the fuel assemblies from the cask into the pool racks for storage. The cask decontamination solutions, the pool water cleanup backwash and regeneration solutions, and spent pool water filters and resins constitute a portion of the waste streams from the head end. After sufficient cooling, the fuel assemblies are chopped and the fuel fragments treated with nitric acid to produce a solution of spent 
SOLVENT

EXTRACTION

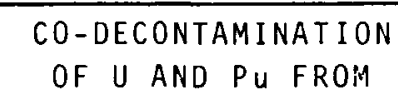

OF U AND PU FROM

FISSION PRODUCTS

\section{PARTITION}

PURIFICATION

AND PRODUCT

FORMATION

U

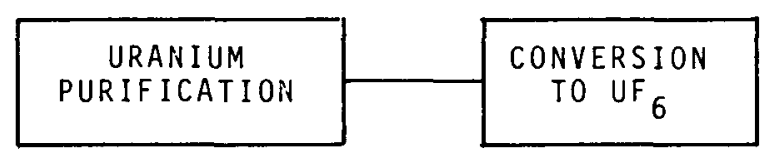

PURIFICATION AND PRODUCT FORMATION

$\mathrm{Pu}$

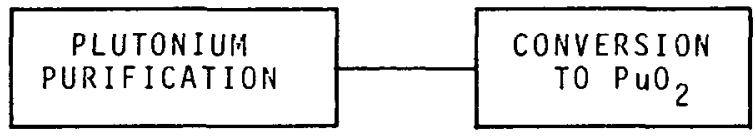

PROCESS

SUPPORT

GENERAL PLANT AND PROCESS SUPPORT

FIGURE 2.17. Reprocessing of LWR Fuel 


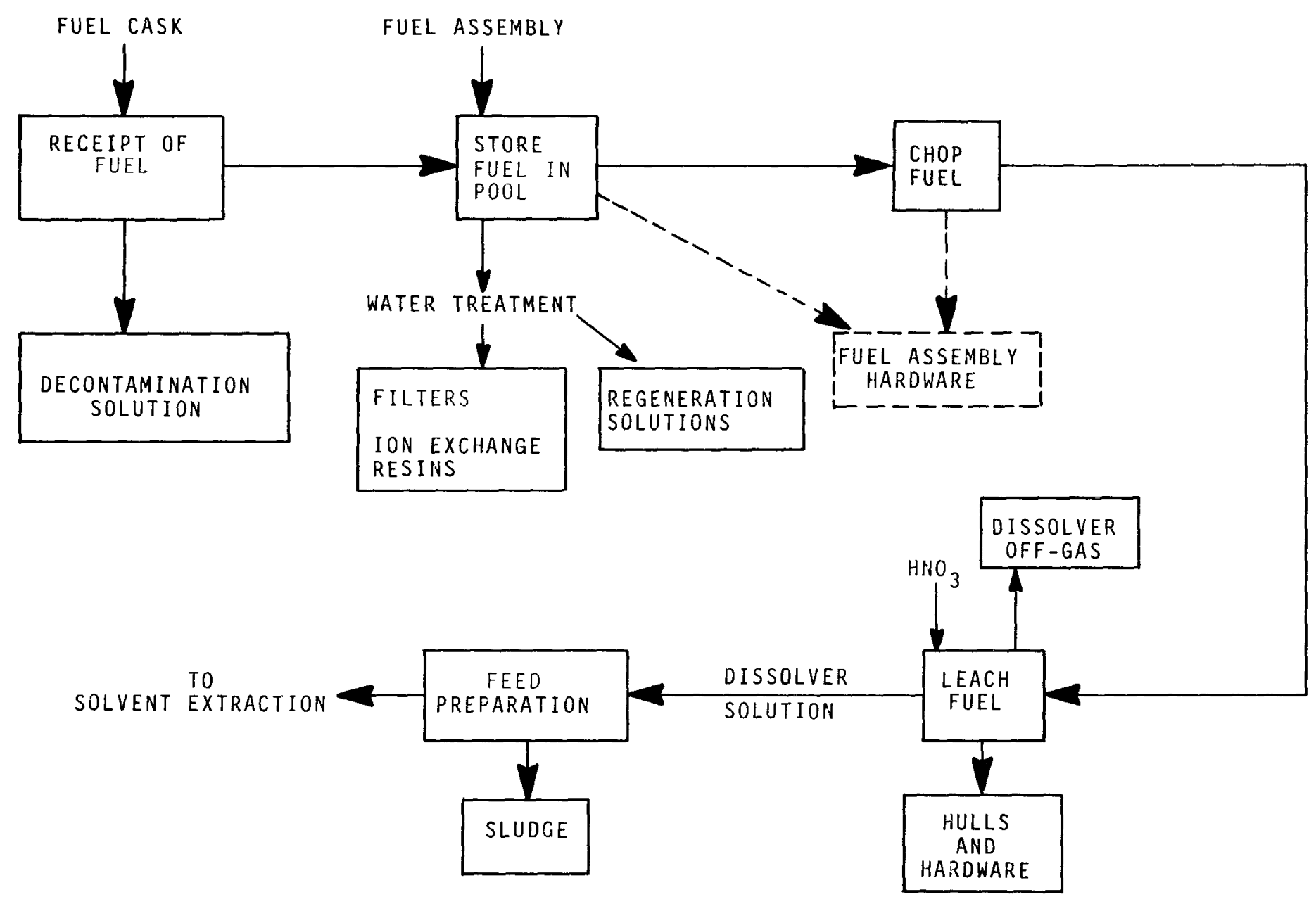

FIGURE 2.18. Waste Generation Flow Sheet for Fuel Reprocessing

I. Head-End 
fuel and a waste stream of cladding hulls and other metallic fuel components. The dissolver off-gas contains noble gas, tritium, and iodine fission products. The feed solution for solvent extraction is prepared by clarification of the dissolver solution to remove suspended solids. These solids, in the form of a sludge of insoluble radioactive materials, are part of the head end waste.

In the reference process, fuel is received from the reactors in shielded casks shipped either by rail or by truck. The receiving operations consist largely of examination of the cask and, if necessary, decontamination of its exterior. The cask is then introduced into the fuel pool, where the top is removed and individual spent fuel assembijes (see Section 2.2) are withdrawn from the cask and placed in storage racks. These are underwater procedures. Section 2.3 discusses fuel-pool wastes.

Following acceptable decay, a fuel assembly is introduced into the main portion of the reprocessing plant and disassembled. Some disassembly, e.g., removal of the shroud, may be done while the assembly is at the reactor, in the pool, or prior to the chopping. Disassembly to remove end hardware by unbolting, sawing, or shearing would remove massive metal from the fuelcontaining portion, thus effecting a 10 to $15 \%$ reduction of metal waste mass. $(2,3)$ Alternatively, the whole assembly could be chopped, reducing the number of waste types and the number of separate operations. (1) In the reference case described here, all metallic components of the fuel assembiy are assumed to constitute a single waste stream of hulls and hardware.

After chopping in a mechanical shear, the fuel pieces are dropped into a dissolver vessel. In the dissolver, the chopped pieces of fuel $(1$ to $8 \mathrm{~cm}$ long) are treated with concentrated nitric acid* bringing into solution most of the oxide fuel and leaving the Zircaloy, stainless steel, and Inconel essentially unattacked. In the dissolution, the noble gas fission products, some of the fission product iodine, and some of the tritium** are introduced into the vapor space above the dissolver and, hence, the dissolver off-gas system (DOG).

Following the dissolution of the fuel, the resulting solution is clarified, generally in a centrifuge, to prepare the feed for the subsequent solvent extraction operations. The clarification of the dissolver solution produces a modest amount of insoluble, highly radioactive sludge which contains fission products and may be contaminated by plutonium and actinide elements.

\footnotetext{
* Possibly containing a suluble neutron poison such as Gd, B, or Cd salts. **Tritium distribution is shown in Figure 2.25.
} 


\subsubsection{Solvent Extraction Separation (Figure 2.19) $(1,4,5)$}

The co-decontamination and partition parts of the solvent extraction process effect transfer, initially, or uranium and plutonium into the organic phase leaving in the nitric acid solution small amounts of uranium and plutonium, and almost all of the fission product activity. This solution is the high-level waste. The partitioning portion of the flow sheet effects the separation of uranium and plutonium by selective transfer of plutonium into nitric acid. Subsequent transfer of uranium into a nitric acid phase completes the partitioning. The resultant three streams are the high-level waste in nitric acid, plutonium in nitric acid, and uranium in nitric acid. The waste streams from this portion of the reprocessing operation consist of the highlevel wastes, the vessel vent off-gases, the solvent cleanup residues, and the spent solvent combustion wastes.

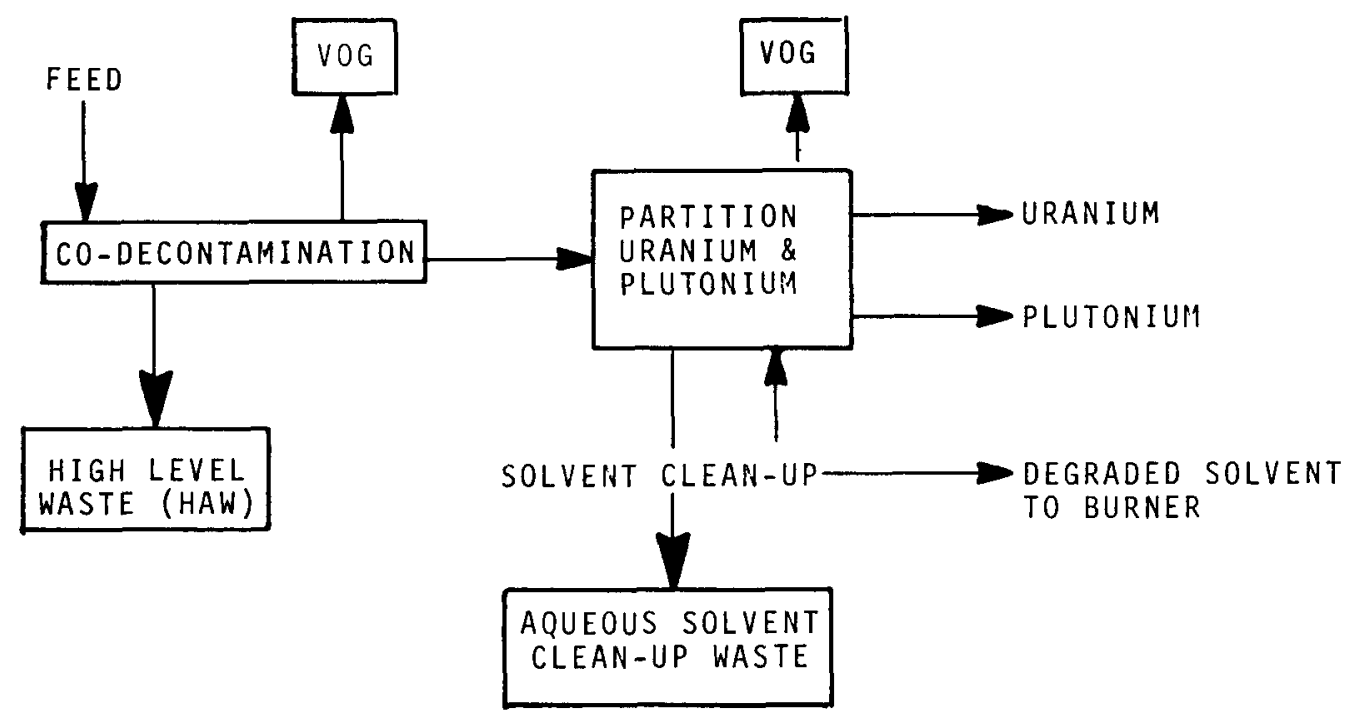

FIGURE 2.19. Waste Generation Flow Sheet for Fuel Reprocessing II. Solvent Extraction 
The aqueous solution from the feed clarification step is contacted with an organic solution of tributyl phosphate in normal dodecane. The apparatus used is either a centrifugal contactor or a pulse column. The solvent extraction conditions are adjusted to transfer uranium and plutonium into the organic phase with a minimum of transfer of the fission products. Separation of the organic phase from the aqueous phase effects the first separation of fission products from uranium and plutonium. This co-decontamination step removes from uranium and plutonium more than $99 \%$ of the fission products in the feed solution and produces the high-level liquid (HLLW) waste stream. During these operations, the vessel off-gas system (VOG) retains sufficient radioactivity to require treatment.

Following the co-decontamination step, the organic phase containing uranium and plutonium is contacted with nitric acid containing chemicals that effect transfer of plutonium back to the aqueous solution while uranium is maintained in the organic phase. Separation of the organic and aqueous phases produces a stream of nitric acid containing plutonium and an organic phase containing uranium. The final step in the partitioning is the stripping of uranium from the organic phase into nitric acid.

It is necessary to clean the organic extractant and solvent because the high radiation from the fission products, particularly in the co-decontamination step, results in decomposition products detrimental to the extraction operations. The solvent cleanup system employs a process in which the organic phase is treated alternately with a dilute $\mathrm{Na}_{2} \mathrm{CO}_{3}$ solution and with nitric acid to remove decomposition products. The waste stream from these steps is one of the components of the intermediate-level wastes described below. Also, extensive recycle of the solvent may result in a fraction of the solvent being no longer usable in extraction operations. This material can either be absorbed in a solid or can be burned. The reference flow sheet employs the combustion of spent solvent. The residues from the treatment of the off-gas from burning of spent solvent also constitute a waste stream to be described below.

\subsubsection{Uranium Purification and Conversion (Figure 2.20$)^{(1,2)}$}

The uranium purification process involves solvent extraction, using the same general technology as applied in the co-decontamination and partitioning steps. The wastes from these operations are largely solvent cleanup wastes 
and vapor treatment wastes from the vessel off-gas system. A final uranium purification step, consisting of contact of the uranium solution with silica gel, produces a waste stream of regenerant solution for the silica gel bed and, infrequently, the used silica gel. The conversion process to produce UF 6 from uranium in nitric acid consists of dehydration, denitration, and reduction steps followed by conversion of the oxide to the volatile uranium hexafluoride. The waste streams from these operations consist of off-gases which are largely not radioactive, solids from off-gas scrubbing, solids consisting of the fluorinator residue and fines in which the main portion of the radioactive contaminants can be found, and particulate filters.

The aqueous nitric acid solution of uranium obtained in the partitioning step contains not only uranium but sufficient fission products to require further decontamination before conversion to uranium hexafluoride. Uranium is further purified by repetition of the solvent extraction processes previously described for co-decontamination and partitioning. Nitric acid solutions of uranium are contacted under appropriate conditions with a solution of tributyl phosphate in normal dodecane to transfer uranium from the aqueous to the organic phase while leaving in the aqueous phase many of the fission product impurities. The aqueous phase then represents a waste stream containing fission products which will be combined with other fission product waste streams. Adjustment of conditions allows for the transfer of uranium back to a clean aqueous phase. Repetition of the transfer of uranium between aqueous nitric acid and organic tributyl phosphate solutions removes residual fission products and produces a uranium solution of sufficient purity to be used as feed for the conversion to uranium hexafluoride. A final cleanup of the uranium solution by contacting it with silica gel may be used in place of a cycle of solvent extraction to remove selected fission products.

The product of the purification of uranium is a concentrated solution of uranium in nitric acid. This solution is dehydrated to remove water and heated further to convert uranyl nitrate to uranium trioxide, which is reduced with hydrogen to form uranium dioxide. Uranium dioxide is converted to uranium tetrafluoride by gaseous hydrogen fluoride, and finally uranium tetrafluoride is converted to the volatile uranium hexafluoride using elemental fluorine. Several of these steps are carried out in large, fluidized-bed reactors in which gases are easily contacted with granular solids. The waste streams from these operations are generally of very modest radioactivity, largely because the feed uranium has been subjected to extensive purification. Nevertheless, waste streams include off-gases, off-gas cleanup wastes, the nonvolatile 


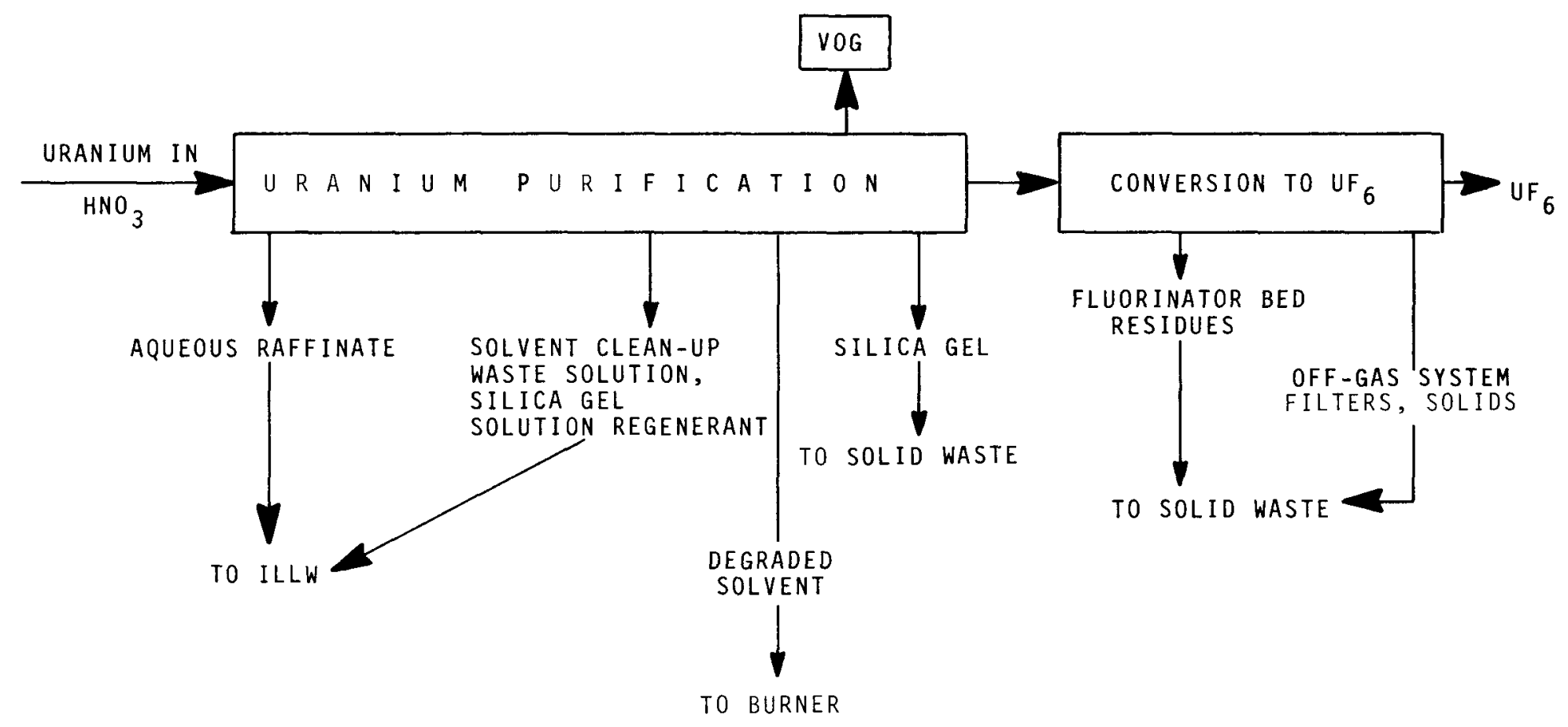

FIGURE 2.20. Waste Generation Flow Sheet for Fuel Reprocessing III. Uranium Purification and Product Formation 
residues from the fluorination step, and miscellaneous solids such as filters and bulk fluidized-bed inert material.

2.4.1.4 Plutonium Purification and Conversion (Figure 2.21$)^{(1,2)}$

Plutonium purification and conversion are carried out by solvent extraction of plutonium nitrate to remove residual fission products, followed by the conversion of plutonium nitrate to the insoluble oxalate that is calcined to the dioxide. The waste streams from these parts of the process contain relatively little fission products. The waste streams come from the solvent extraction steps, e.g., liquid waste streams from the solvent cleanup operations, and some solid wastes from the precipitation of wastes in the conversion step. The vessel off-gas systems for the purification of plutonium and operations in the conversion steps require filtration and some scrubbing and generate wastes of filters and scrubber residues.

The nitric acid solution of plutonium obtained in the partitioning operations is also not pure enough to be used directly for the conversion to plutonium dioxide. Two additional cycles of solvent extraction are employed to remove the residual fission products. The solvent extraction system is similar to that described previously and consists of a contact of the solution of plutonium with tributyl phosphate in normal dodecane. The transfer of plutonium into the organic phase effects a separation between plutonium and fission products. Subsequent scrubbing of the organic solution under appropriate conditions additionally purifies the plutonium in the organic phase. A change in extraction conditions results in transfer of plutonium from the organic phase to the aqueous phase. This transfer also effects an additional purification from fission products. Repetition of this procedure for a third plutonium cycle produces a nitric acid solution of plutonium (Table 2.7) of adequate purity to be used in the preparation of plutonium dioxide.

Plutonium nitrate solution is converted to solid plutonium dioxide by formation of an insoluble plutonium oxalate, subsequent filtration of the plutonium oxalate, and calcination of the oxalate to the oxide. The conversion of plutonium nitrate to plutonium dioxide generates relatively little waste since much recycle is normally done to ensure low losses of the valuable fissile plutonium. Scrap recovery involves use of fluoride for the dissolution of plutonium dioxide, and additional purification is needed to make the plutonium solution suitable for recycle. The solvent extraction purification used for scrap recycle produces a modest amount of waste, largely aqueous. other impurities also are present and are removed from aqueous waste solutions by precipitation with caustic. The major waste streams from the conversion of plutonium nitrate to plutonium dioxide, when carried out in conjunction with operations of the fuel reprocessing plant, are filter cakes from the caustic precipitation of impurities. Most of the aqueous solutions are recycled either 


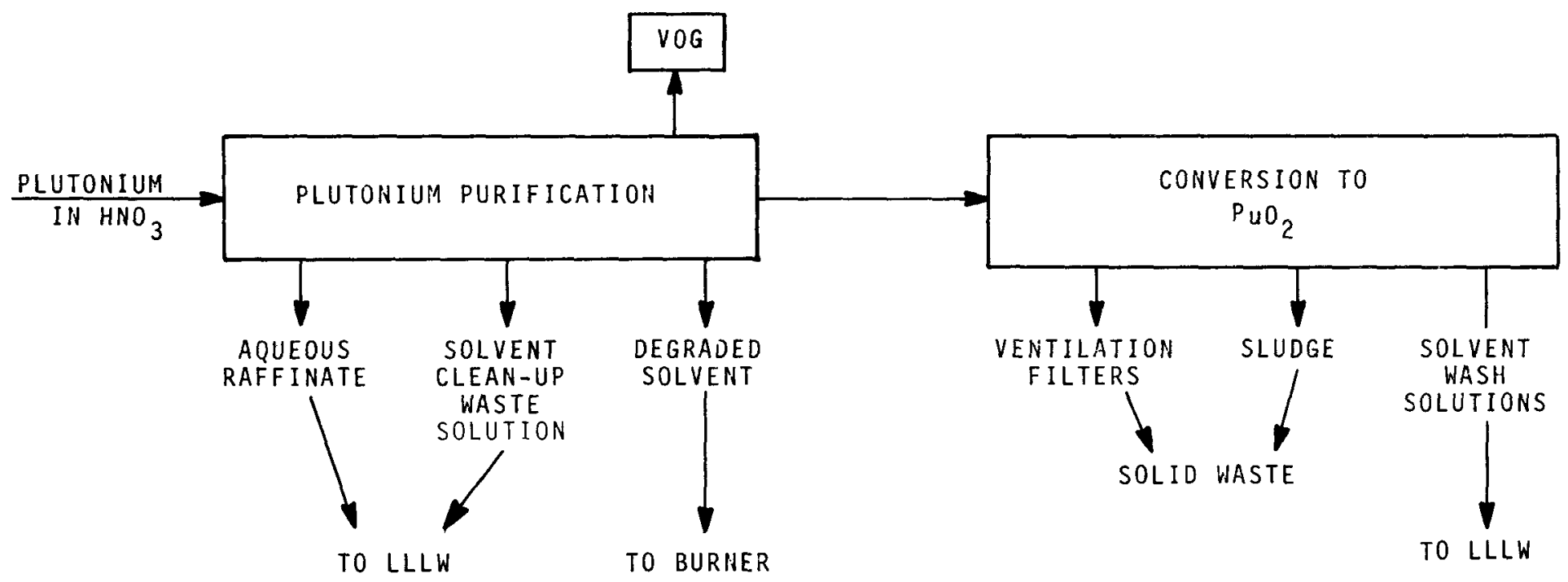

FIGURE 2.21. Waste Generation Flow Sheet for Fuel Reprocessing IV. Plutonium Purification and Product Formation 
within the conversion operations or into the solvent extraction portion of the separations plant. The vessel off-gas stream is scrubbed, producing aqueous solutions that also contain a modest amount of solids.

TABLE 2.7. Typical Plutonium Nitrate Specifications (1)

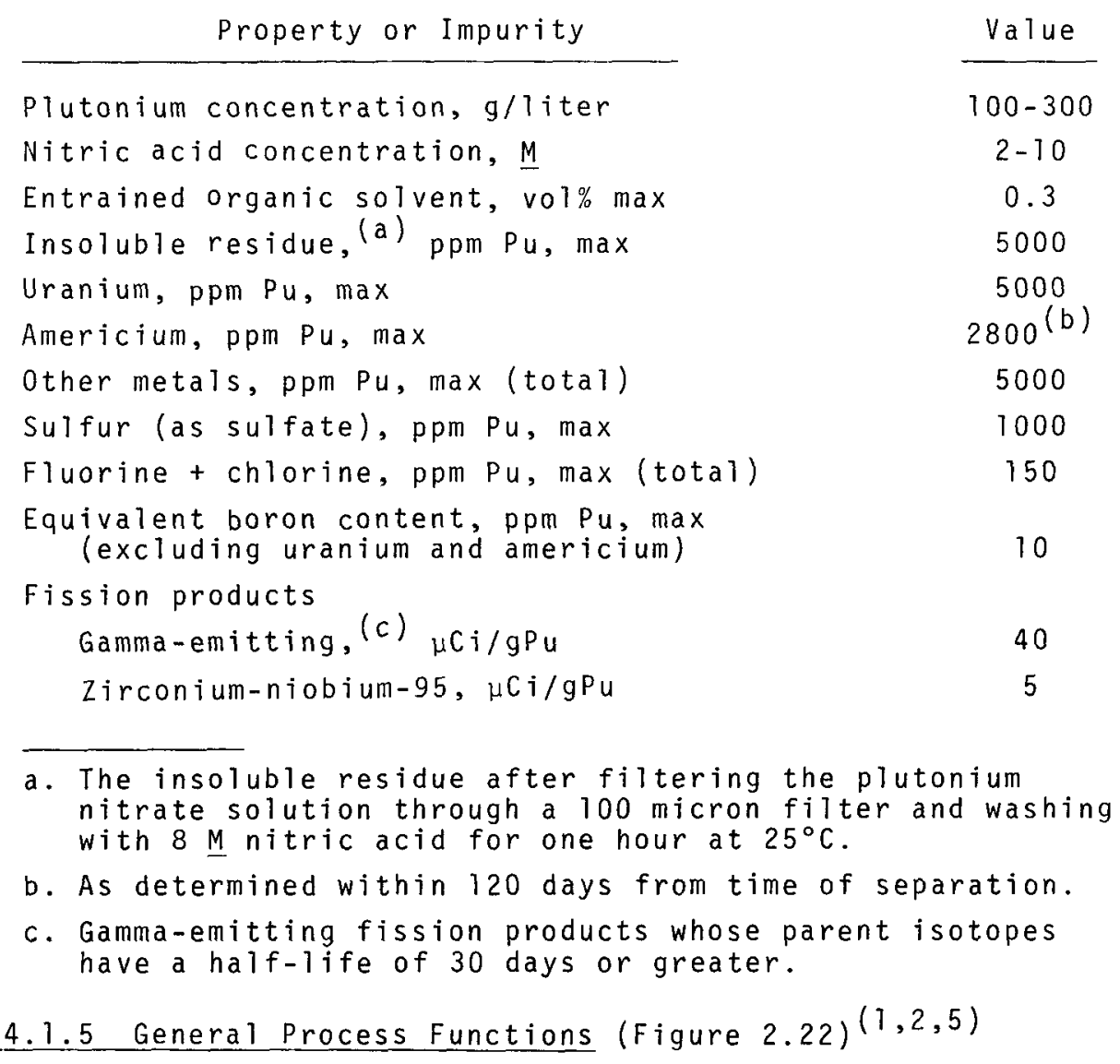

There are other operations carried out in the reprocessing plant not easily ascribable to any single portion of the process. These include general maintenance and maintenance of specific pieces of equipment, decontamination of areas and equipment, analytical services, and the recycle and preparation of reagents and solutions. The maintenance, testing, and replacement of facilities that reduce the radioactivity in effluents also generates waste streams. Maintenance involves broad, process-wide activities and generates waste streams that include filters, noncombustible trash, and some liquids. Analytical wastes are both liquid and solid, while decontamination solutions are mostly aqueous liquids that may include some organic materials. Combustible trash, spent equipment too large to be conveniently stored or disposed of in the standard 55-gal $\left(0.2 \mathrm{~m}^{3}\right)$ drum, and materials such as the vapors from concentrator operations are part of the wastes generated in plantwide operations. Each of these waste streams will be described in subsequent sections. 


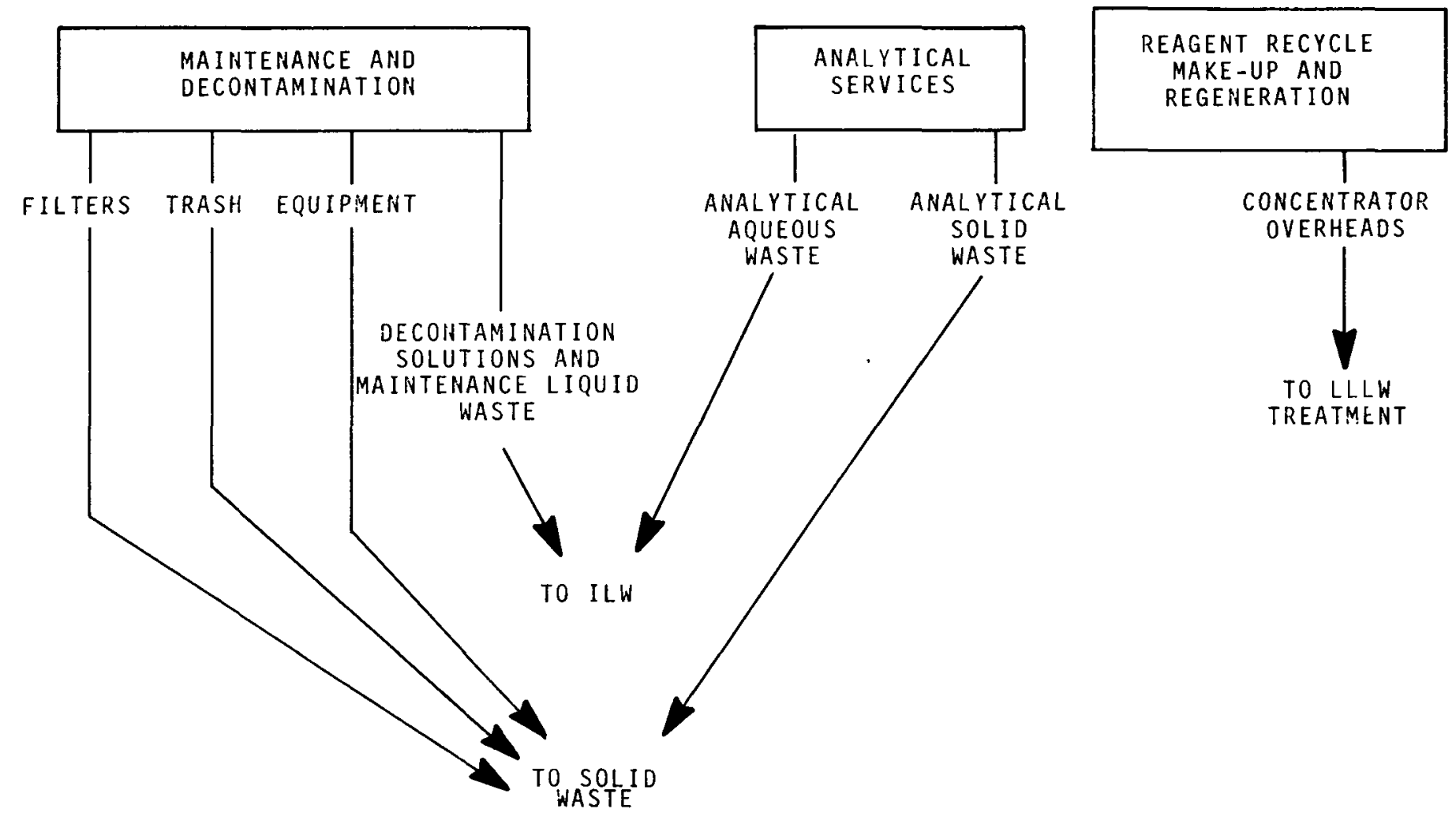

FIGURE 2.22. Waste Generation Flow Sheet for Fuel Reprocessing $\checkmark$. Process Support 
$\frac{2.4 .2 \text { Organization, and Descriptions of Waste Streams (Figures } 2.23 \text { and }}{2.24)(1,2,5)}$

Waste streams from reprocessing operations were arbitrarily divided into five categories. The high-level waste, as defined in the code of Federal Regulations, (7) consists of the raffinate from the first solvent extraction cycle. In normal practice, the low-level aqueous waste concentrator residues and the solids from the feed clarification step are added to the high level waste stream.

A second waste stream, called the intermediate-level liquid waste, contains the off-gas treatment system ( $D O G, V O G$ ) scrubber solutions. The intermediate-level waste stream also contains the pool water cleanup backwash and regeneration solutions, the cask and plant decontamination solutions, the solvent wash aqueous waste, the liquid waste generated by maintenance operations, and the liquid wastes generated by the laboratories. All of these constitute feed for the intermediate-level liquid waste treatment system.

A third waste stream is the low-level liquid waste system, which consists of the second and third uranium and plutonium cycle aqueous wastes, the condensed overhead stream from the concentrators, the condensed stream from the vessel off-gas system and the high-level waste vent system, the condensed overhead stream from conversion steps, and the aqueous stream from the plutonium purification in the conversion process. These waste streams constitute the feed to the low-level liquid waste processing operation described subsequently.

A fourth waste is the gaseous stream which is effluent from the off-gas treatment systems. The feed to the off-gas treatment systems consists of the dissolver off-gas stream, the general vessel off-gas stream, and other ventilation streams that are routed through chemical and physical retention systems in the off-gas treatment trains.

The last waste category is the solid waste. This stream includes hulls and assembly hardware, filters, failed equipment, zeolite, silica gel and resin beds, fluorinator ash and fines scrubber solids, and noncombustible trash. The reference plant processes convert all combustible TRU waste to ash, but volumes of unburned trash are given in subsequent tables. Hulls will be treated as a separate category.

$$
\text { 2.4.2.1 High-Level Waste }{ }^{(1-3)}
$$

The high-level waste (HLW) system receives initially the high-level aqueous stream from the co-decontamination of uranium and plutonium from the fission products contained in the dissolver solution. More than $99 \%$ of the fission products is present in this stream in relatively dilute form as generated in the co-decontamination solvent extraction step. The high-level waste from the co-decontamination contactor is evaporated to increase the concentration of fission products and to recover overhead both water and nitric 


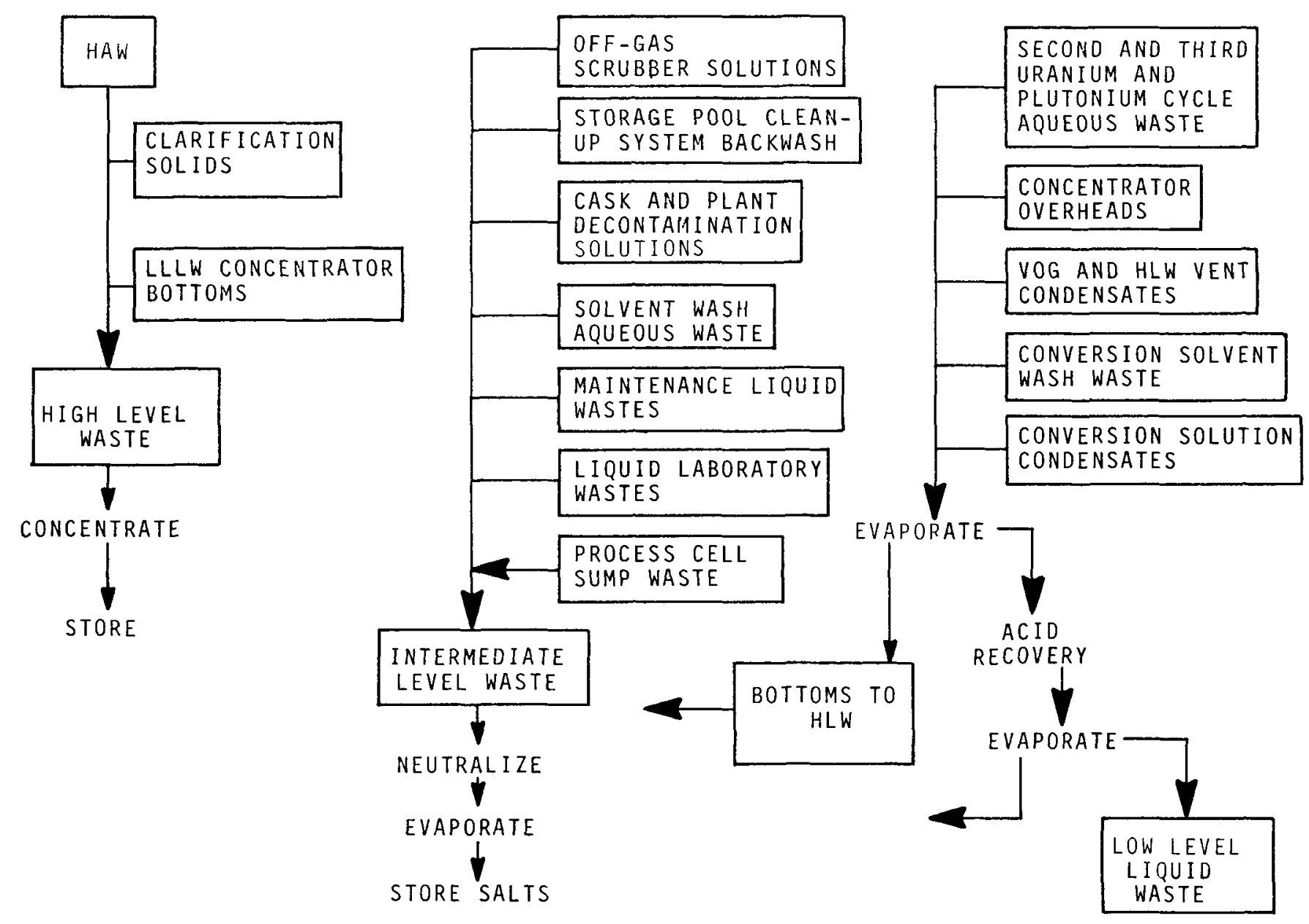

FIGURE 2.23. Waste Generated in Fuel Reprocessing Operations I. High Level, Intermediate Level, and Low Level Liquid Waste 


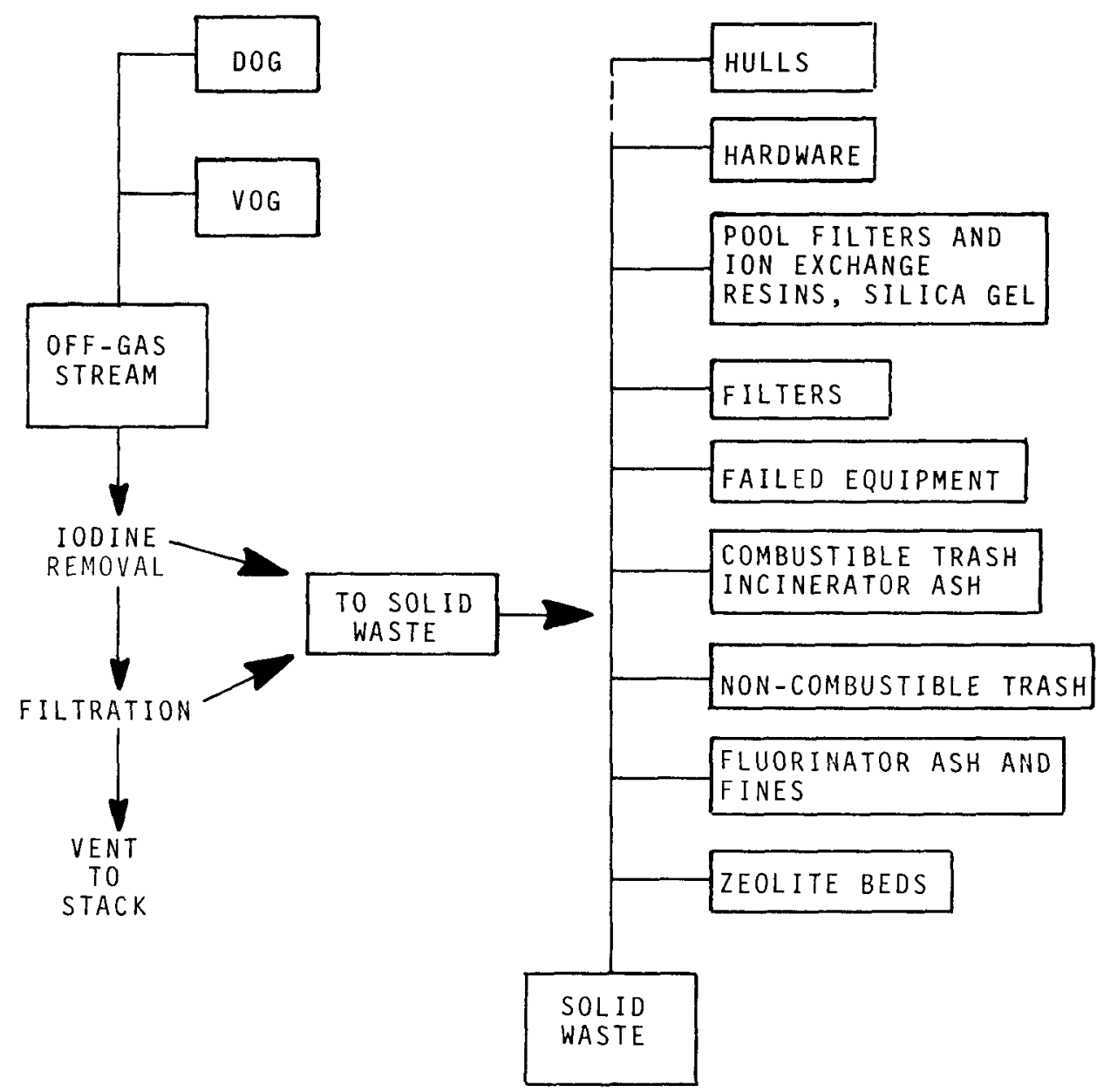

FIGURE 2.24. Waste Generated in Fuel Reprocessing Operations II. Gaseous and Solid Waste 
acid. The concentrated high-level waste in nitric acid is routed to cooled tanks for storage. There slurries are added from the centrifuge siudge formed in the feed preparation step and the residue left in the low-level liquid waste concentrator. Liquid HLW is stored in cooled, shielded tanks because of its heat and radiation emissions.

The composition of 1 iquid HLW as stored is shown in Table 2.8 and 2.9. The data $(6)$ are based on transfer of $99+\%$ of the fission products to the HLW; no noble gas fission products, $0.1 \%$ of the iodine, $8 \%$ of the tritium, $0.5 \%$ of the plutonium, and $0.5 \%$ (at 160 days cooling after discharge from reactor core) of the uranium are included. The fuel burnup is assumed to be 25,000 MWd/MTHM at a specific power of $35 \mathrm{MW} / \mathrm{MTHM}$. The data are shown for a solution with a waste volume ratio of $100 \mathrm{gal}$ (378 1 iters)* per MTHM. Although the HLW is produced at the rate of $\sim 5000$ liters/MTHM, the rate is strongly dependent on the details of the reprocessing plant flow sheet. Storage in concentrated form is contemplated for economic reasons, i.e., greater recycle of nitric acid and water. It is likely that a part of the constituents are in the form of suspended solids.

2.4.2.2 Intermediate-Level Wastes $(1-3,5)$

The intermediate-ievel waste (ILW) treatment system (see Figure 2.23) accepts the mercuric nitrate scrubber solutions from the dissolver off-gas and the vessel off-gas systems, incinerator scrubber solutions, the pool water cleanup backwash solutions, the aqueous solutions from cask and plant decontamination operations, the aqueous waste solutions from the washing of process solvent, HLW demister scrubber solutions, liquid wastes from laundry and laboratory operations, and process cell sump wastes. This group of wastes is neutralized and concentrated in an evaporator. The concentrated solution is transferred to a storage tank where salts gradually crystallize from the solution while the supernatant liquid is returned to the concentrator for additional boil-down. The ILW that is stored consists of the salt cake in a shielded tank. An alternative to storage of salt cake, but not included here, is to combine the ILW with the HLW prior to solidification.

The composition of the neutralized ILW solutions is described in Table 2.10 .

2.4.2.3 Low-Lever Liquid Waste $(1-3,5)$

The low-level waste treatment system of the reprocessing plant accepts the aqueous solutions from second and third cycle uranium and plutonium purification streams, the condensate from concentrators and vessel off-gas systems, relatively clean conversion solutions, and the aqueous wastes from the washing of solvent used in the recycle of plutonium in the conversion process.

*Interim storage at 600-1100 liters/MTHM may be practical (see Section 6.0). 
IABLE 2.8. Composition of Liquid High Level Waste(a) Basis: 378 Liter/MTHM, 25 GWd/MTHM, 35 MW/MTHM, SGR $=1.0$ for MOX Content; ${ }^{(b)}$ No $\mathrm{Xe}, \mathrm{Kr}, 0.1 \% \mathrm{I}, \mathrm{Br}, 8 \%{ }^{3} \mathrm{H},(\mathrm{C}) 0.5 \% \mathrm{Pu}$, $0.5 \% \mathrm{U}, \mathrm{All} \mathrm{Np}, \mathrm{Am}, \mathrm{Cm}$

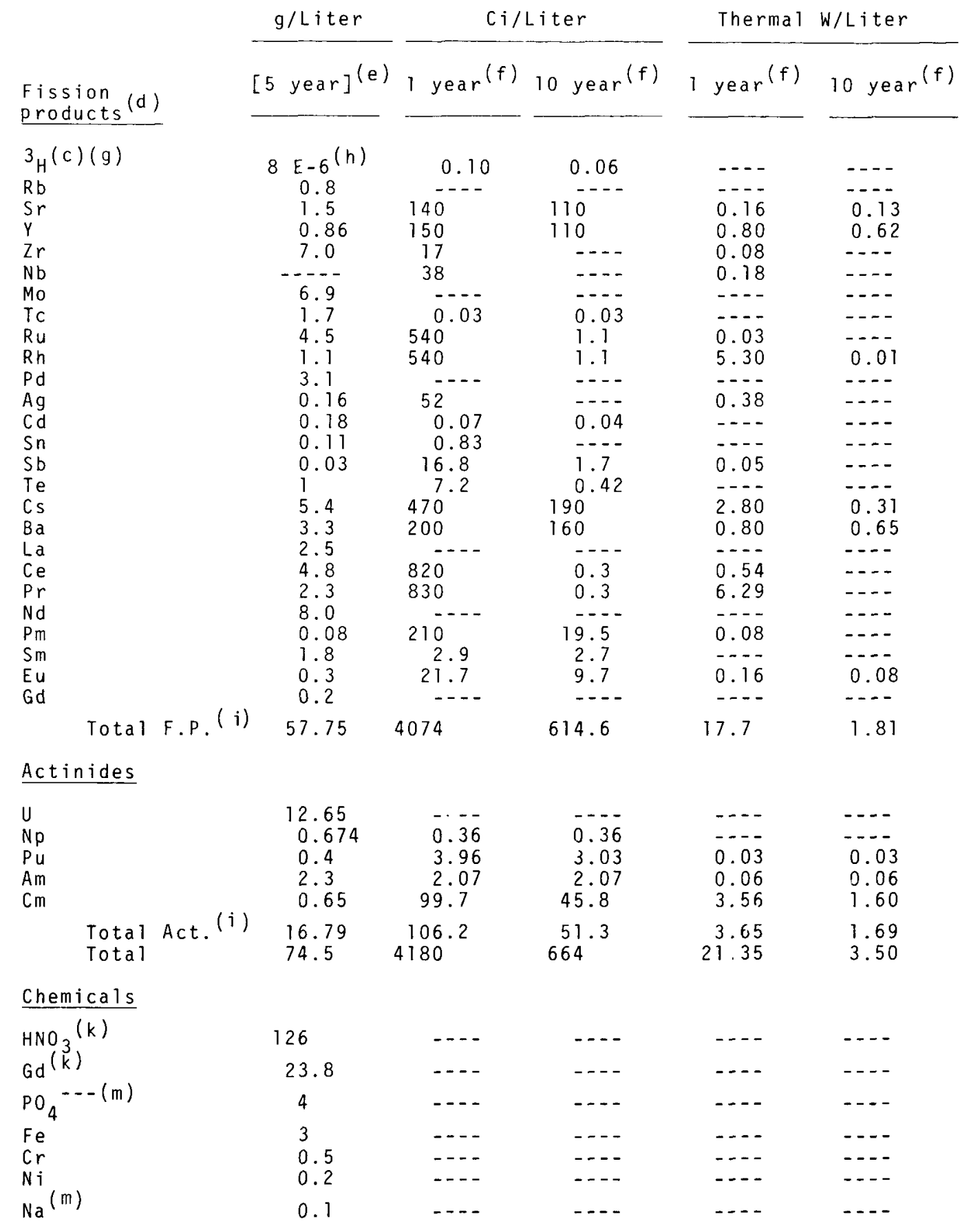


IABLE 2.9. Composition of High Level Waste (a)

Basis: 25 GWd/MTHM, 35 MW/MTHM, $S G R=1.0$ for MO Content $(b)$ No Xe, $\mathrm{Kr}, 0.1 \% \mathrm{I}, \mathrm{Br}, 8 \%{ }^{3} \mathrm{H},(\mathrm{C}) 0.5 \% \mathrm{Pu}$, $U, A 1] \mathrm{Np}, \mathrm{Am}, \mathrm{Cm}$

g/MTHM C) / MTHM

Thermal W/MTHM

Fission
products

$[5$ year $]$
$3 E-3^{(h)}$
$3.7 E 2$

$5.8 \mathrm{E2}$

$3.2 \mathrm{E} 2$

2. 6 E 3

2.6 E3

$6.5 \mathrm{E} 3$

$1.7 \mathrm{E} 3$

4. 3 E2

1. 2 E 3

$6.2 \mathrm{El}$

$6.8 \mathrm{El}$

4. 1 E 1

$1.1 \mathrm{EI}$

$3.8 \mathrm{E2}$

2. 0 E3

1.2 E 3

9.4 E2

$1.8 \mathrm{E} 3$

8.7 E2

3. 0 E3

$3 \mathrm{E}]$

$6.9 \mathrm{E} 2$

$1.1 \quad E 2$

Eu

$6.6 \mathrm{El}$

$\mathrm{Cl}_{\mathrm{C} / \mathrm{MTH}}$

.

- Thermal W/MTHM

Total F.P. (1)

$2.18 E 4$

\begin{tabular}{c}
1 year \\
\hline 4.0 El \\
5.4 E4 \\
5.5 E4 \\
6.4 E3 \\
1.4 E4 \\
$-1 .-$ \\
1.1 El \\
2.05 C5 \\
2.05 E5 \\
$-1 .-$ \\
2 E4 \\
2.5 E1 \\
3.2 E2 \\
6.4 E3 \\
2.7 E3 \\
1.8 E5 \\
7.7 E4 \\
3.7 E5 \\
3.1 E5 \\
- - \\
8.0 E4 \\
1.1 E3 \\
8.2 E3 \\
$\cdots-2$
\end{tabular}

$10 \operatorname{year}^{(f)} 1$ year

(f) 10 year $(f)$

Actinides

\begin{tabular}{|c|c|c|c|c|c|}
\hline $\begin{array}{l}U \\
\mathrm{~Np} \\
\mathrm{PU} \\
\mathrm{Am} \\
\mathrm{Cm}\end{array}$ & $\begin{array}{ll}4.8 & E 3 \\
2.5 & E 2 \\
1.5 & E 2 \\
8.7 & E 2 \\
2.4 & E 2\end{array}$ & $\begin{array}{lll}4 & \mathrm{E} & -2 \\
1.4 & \mathrm{E} 2 \\
7.5 & \mathrm{E} 3 \\
7.8 & \mathrm{E} 2 \\
3.8 & \mathrm{E} 4\end{array}$ & $\begin{array}{ll}3 & E-2 \\
1.4 & E 2 \\
1.1 & \text { E } 3 \\
7.8 & \text { E2 } \\
1.7 & \text { E4 }\end{array}$ & $\begin{array}{l}2 . \mathrm{E}-4 \\
1.9 \mathrm{E}-1 \\
9.7 \\
2.3 \mathrm{E} 1 \\
1.3 \mathrm{E} 3\end{array}$ & 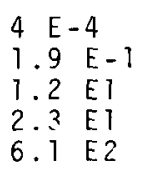 \\
\hline Total Act. (1) & 6.25 E3 & $4.02 E 4$ & $1.94 \mathrm{E} 4$ & i. $38 \simeq 3$ & $6.4 E 2$ \\
\hline Total & $2.82 E 4$ & $1.58 \mathrm{E} 6$ & $2.51 \mathrm{E5}$ & 8.07 E3 & $1.32 \mathrm{E} 3$ \\
\hline S.F. n/sec MTHM & & $3.64 \mathrm{Eg}$ & $2.49 \mathrm{E} 9$ & $\cdots$ & $\cdots$ \\
\hline \multicolumn{6}{|l|}{ Chemrcals } \\
\hline $\mathrm{HNO}_{3}(k)$ & $4.76 \mathrm{E} 4$ & --- & --- & ---- & --- \\
\hline$G d \quad(k)$ & $9 E 3$ & --- & --- & $\cdots--$ & --- \\
\hline $\begin{array}{l}\mathrm{PO}_{4} \equiv() \\
\mathrm{Fe}_{4} \\
\mathrm{Cr} \\
\mathrm{Na}_{\mathrm{Na}}(\mathrm{J})\end{array}$ & $\begin{array}{l}1.5 \mathrm{E3} \\
1.13 \mathrm{E3} \\
1.89 \mathrm{E2} \\
7.6 \mathrm{El} \\
3.8 \mathrm{E}]\end{array}$ & $\begin{array}{l}--- \\
--- \\
--- \\
--- \\
---\end{array}$ & $\begin{array}{l}--- \\
---- \\
---- \\
---- \\
----\end{array}$ & $\begin{array}{l}\cdots-- \\
\cdots-- \\
\cdots-- \\
\cdots-- \\
\cdots-\end{array}$ & $\begin{array}{l}---- \\
---- \\
--- \\
---- \\
----\end{array}$ \\
\hline
\end{tabular}

Footnotes follow on next page. 
Footnotes to Tables 2.8 and 2.9

a. Data from Reference 6 unless otherwise indicated.

b. Data from Reference 9. See Description of Fuel Assembly in Section 2.3; SGR = Self-Generating Ratio. Percentages apply to nuclide composition of fuel at 160 days after removal from core.

c. Reference 5 .

d. Selected fission products with significant mass, activity, or thermal power.

e. Based on mass of element after 5 year, 160 days cooling of waste after discharge from reactor core.

f. After cooling for indicated period following processing at 160 days, 1 year cooling corresponds to 1.4 year elapsed time from discharge from core.

g. Modified, for greater yield from ${ }^{239} \mathrm{Pu}$ fission, to $547 \mathrm{Ci} / \mathrm{MTHM}$ at discharge.

h. 11 E-6 read as $11 \times 10^{-6}, 5.8$ E2 read as $5.8 \times 10^{2}$, etc.

i. Total for all elements in the category, listed or not.

j. Spontaneous fission neutrons on $1 \mathrm{y}$; $>99 \%$ due to $\mathrm{Cm}$ and $\mathrm{Cf}$.

k. From Reference 10 , waste category $\mathrm{PW}-7 ; \mathrm{HNO}_{3}$ is $2 \mathrm{M}$ free acid. Gd added as a neutron poison.

i.. Sasad on Reference 1 flow sheet. 
TABLE 2.10. Properties of Intermediate Level Waste Solution After Neutralization

$$
\underline{\text { g/liter (a) }} \text { Ci/year kg/year (a) }
$$

Chemical Composition

$\mathrm{NO}_{3}^{-}$

$\mathrm{Na}$

$\mathrm{Hg}$

$\mathrm{Ca}, \mathrm{Mn}, \mathrm{SO}_{4}^{--}, \mathrm{Cl}$

$\mathrm{K}, \mathrm{Fe}, \mathrm{Ag}, \mathrm{F}$

Misc. Chem. (b)

Radioactivity

$u$

$\mathrm{Pu}$

(b)

Fission Products (d)

Physical Properties

Volume, 1 iter/year $(e, f)$

Solids (a)

Density (estimate)

Heat Generation (W/1)

$\begin{array}{ccc}400 & -- & 66,000 \\ 150 & -- & 24,750 \\ 15 & -- & 2,475 \\ 1 \text { each } & -- & 165 \text { each } \\ 0.5 \text { each } & -- & 82 \text { each } \\ \text { minor } & -- & --- \\ & & \\ 20 & -- & 3,300 \\ 0.05 & -- & 8.25 \\ 1.8 & 2300 & 297 \\ \text { trace } & 3300 & ----\end{array}$

165,000

97,000

1400

$0.01-0.1$

a. Based on $\sim 42 \%$ dissolved solids.

b. Oxalate, citrate, phosphate, acetate, ammonium, chromate, surfactants, detergents, etc.

c. Based on $2100 \%$ of iodine in this stream. $79 \%{ }^{129} \mathrm{I}$, $21 \% 127$ I by weight, and $98 \% 131$ I, $2 \% 129$ I by activity, at 320 days following discharge from reactor core.

d. Based on 2.2 Ci/MTHM. These values may be low by a factor of 10 or more, compared to values based on other estimates. Activity contributed primarily by fission product Ru, Rh, $\mathrm{Zr}$, and Nb.

e. Based on 1101 iters per MTHM, 1500 MTHM per year.

f. It is estimated that spent, combustible solvents, will be generated at a FRP at the rate of $0.01 \mathrm{~m}^{3} /$ MTU or $15 \mathrm{~m}^{3} / 1500$ MTU-year, (8) but the reference process includes combustion of the solvent.

This waste is concentrated in a general purpose concentrator or in a low level waste concentrator and the overheads from this operation are usually vented in vapor form directly to the stack. The very low concentration of radionuclides in this waste is shown in Table 2.11. The major contaminant is tritium, present as a dilute solution of HTO in $\mathrm{H}_{2} \mathrm{O}$. 


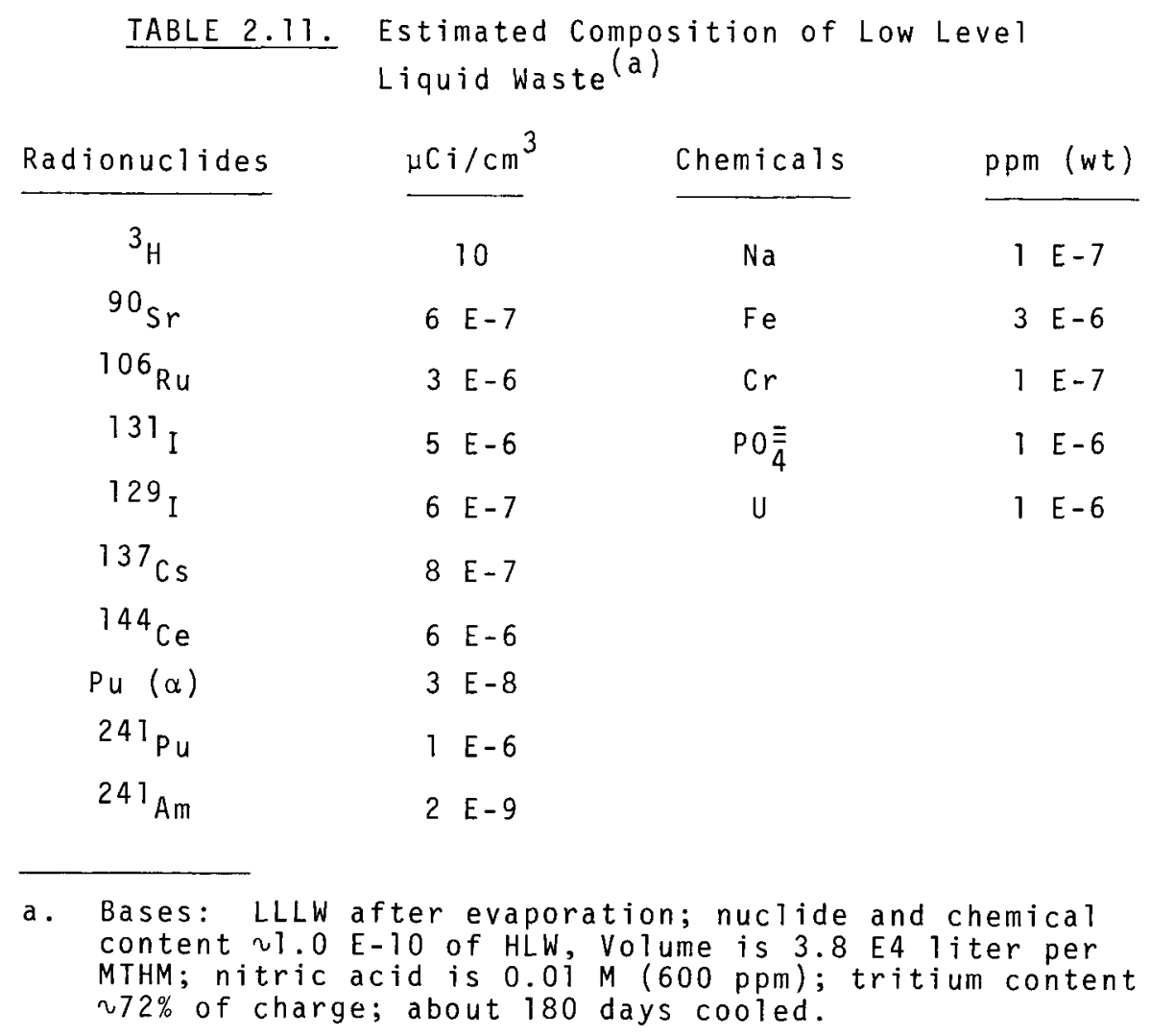

The distribution of tritium in the various reprocessing waste streams is based on assumptions illustrated in Figure 2.25. Data on the distribution of tritium in spent LWR fuel and processing waste streams is relatively incomplete. (5) The assumed distribution shows the majority of the tritium in the low level liquid waste stream which is in general agreement with experience. The data in Figure 2.25 are for no decay (cooling) following discharge of the reference fuel.

The residue remaining in the concentrator is transferred to the high level waste tanks for storage. No data are presented for this stream since further treatment of the contained waste is included in the description of high level waste.

2.4.2.4 Gaseous Waste ${ }^{(1-3,5)}$

The vapors from the dissolver off-gas system and the vessel off-gas system are passed through scrubbers of mercuric nitrate to remove iodine* from the off-gas stream. They are subsequently filtered for additional iodine removal in silver zeolite beds before final filtration through HEPA filters.

*Long-1ived ${ }^{129} \mathrm{I}$ is expected at the rate of $2 \times 10^{2} \mathrm{~g}\left(3 \times 10^{-2} \mathrm{Ci}\right) /$ MTHM or $3 \times 10^{5} \mathrm{~g}(50 \mathrm{Ci}) / 1500$ MTHM-year. 


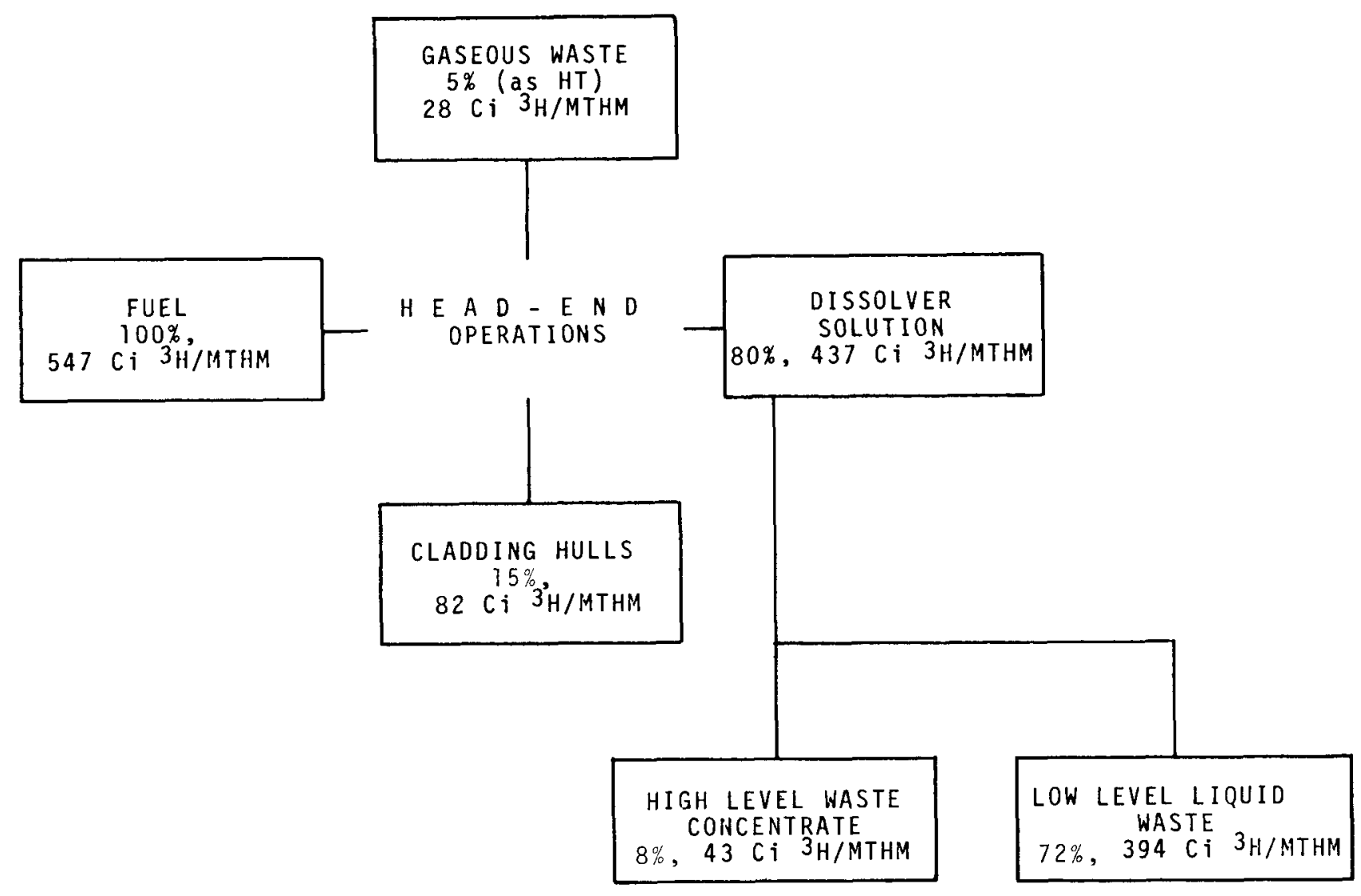

$\stackrel{n}{\text { on }}$

FIGURE 2.25. Distribution of Tritium in Fuel Reprocessing Wastes

$\left(100 \%{ }^{3}\right.$ H Assumes No Cooling of Reference Fuel) 
The treated gases are vented to the stack. The off-gas treatment system does not generate gaseous wastes that need to be retained. All the fission product krypton and xenon is discharged by this path. Table 2.12 shows the expected quantities of noble gas fission products. The filters and solid iodine absorbing materials are treated as a solid waste, and the iodine-containing scrubber solutions are treated in the intermediate-level waste treatment system. *

The presence of ${ }^{14} \mathrm{C}$ in LWR fuel is the result of the ${ }^{14} \mathrm{~N}(n, p){ }^{14} \mathrm{C}$ reaction with the nitrogen impurity in the fuel and, to a lesser extent, the reaction ${ }^{17} 0(n, \alpha){ }^{14} \mathrm{C}$ with the oxygen of the fuel ceramic. The carbon impurity in fuel represents a negligible source of ${ }^{14} \mathrm{C}$ since the ${ }^{13} \mathrm{C}(\mathrm{n}, \mathrm{\gamma}){ }^{14} \mathrm{C}$ reaction has a $10 \mathrm{w}$ cross section. Estimates of ${ }^{14} \mathrm{C}$ production in LWR fuel vary considerabiy and no definitive analyses have been reported. (15) Further, the movement of ${ }^{14} \mathrm{C}$ through the fuel cycle has not been defined. For the present discussion, it is assumed that $25 \mathrm{ppm}$ nitrogen impurity results in a ${ }^{14} \mathrm{C}$ production of $20 \mathrm{Ci} /$ 1000 MWe-year, and that a 11 of the ${ }^{14} \mathrm{C}$ will be found in the gaseous waste as $\mathrm{CO}_{2}{ }^{*}$ These data are equivalent to $0.4 \mathrm{Ci}{ }^{14} \mathrm{C}$ per MTHM and $660 \mathrm{Ci}{ }^{14} \mathrm{C}$ per year from a reprocessing plant with a 1500 MTHM/year throughput.

2.4.2.5 Solid Wastes $(1-3,17,18)$

The solid waste generated in fuel reprocessing comprises several streams. The hulls and fuel assembly hardware from head end operations are described in a subsequent section. A class of solid wastes consisting of wet solids includes filters used to filter the pool water, ion exchange resins used to purify the pool water, silica gel from the final stage of uranium purification, and the filter cake from the liquid waste treatment used in converting plutonium nitrate to plutonium oxide. The bulk of the $\mathrm{CaF}_{2}$ sludge from conversion process scrubbers is nonradioactive. Another source of solid wastes is the failed process equipment of varying size, normally at least partially decontaminated before removal from the process enclosures. Storage of large, contaminated equipment is in special containers or in a failed equipment vault. Additional sources of solid wastes include the noncombustible trash, the ash from the uranium fluorination, ventilation filters such as the HEPA filters, and the ash from combustors. ${ }^{\dagger}$

*If the ILW is to be combined with the HLW and calcined, mercury-containing scrubber solutions need to be handled separately, e.g., as a waste formed by sorbing the solution onto a solid.

** It is recognized that neither the anticipated chemistry of ${ }^{14} \mathrm{C}$ nor the behavior of $\mathrm{CO}_{2}$ would result in a single result as outlined.

the reprocessing plant is designed to burn solvent no loriger needed as well as some of the combustible radioactive wastes that are generated. 
TABLE 2.12. Noble Gas Fission Products Available in Fuel Reprocessing (a)

\begin{tabular}{lcc} 
& \multicolumn{1}{c}{$\mathrm{Kr}(\mathrm{d})$} & $\mathrm{Xe}$ \\
\cline { 2 - 2 } $\mathrm{g} /$ MTHM (b) & 250 & 4061 \\
$\mathrm{~kg} /$ year (a) & 375 & 6091 \\
$\mathrm{~m}^{3}$ (STP)/MTHM (c) & 0.066 & 0.678 \\
$\mathrm{~m}^{3}$ (STP)/year & 99 & 1017 \\
Ci/MTHM & & \\
90 days cooled & 6860 & 127 \\
120 days cooled & 6827 & 20 \\
I year cooled & 6543 & $10^{-5}$ \\
10 years cooled & 3652 & $\cdots$
\end{tabular}

MCi/1500 MTHM

1 year cooled

9.81

10 years cooled

5.48

W/MTHM

$\begin{array}{lrr}90 \text { days cooled } & 10.3 & 0.11 \\ 120 \text { days cooled } & 10.2 & 0.02 \\ 1 \text { year cooled } & 9.8 & -\ldots \\ 10 \text { years cooled } & 5.5 & \ldots\end{array}$

$\mathrm{kW} / 1500$ MTHM
1 year cooled
14.7
10 years cooled
8.2
$-\cdots$
$-\cdots$

a. Based on 25,000 MWd/MTHM, 35 MW/MTHM; MOX mixture based on self-generating ratio $=1.0$ using 30 wt $\%$ MOX at 4.98 wt \% Pu in natural uranium and $70 \%$ $3.3 \% 235 j$ in uranium; plant throughput 1500 MTHM/ year. 1 year cooled off-gas will also contain 26 Ci tritium per MTHM ( $5 \%$ of contained tritium in fuel) as HT, and $0.4 \mathrm{Ci} 14 \mathrm{C} /$ MTHM as $\mathrm{CO}_{2}$.

b. Estimated at 5 years cooled after processing 160 days following discharge from core.

c. Atomic weight of $\mathrm{Kr}=84.8, \mathrm{Xe}=134.2$.

d. Krypton will contain $\sim 6 \%{ }^{85} \mathrm{Kr}$. The total krypton will be $2120 \mathrm{ppm}$ of the total dissolver off-gas.

other solid wastes are the zeolite beds used to absorb iodine from the off-gas system, and the ash from incinerated combustible wastes. Most of these solid wastes are stored in relatively leak-free containers, particularly if it seems they might contain significant quantities of transuranium elements. 
Table 2.13 lists the solid waste streams expected from reprocessing operations, using the best data currently available. The magnitudes of volumes, mass, and contamination levels are closely related to the details of selected process steps, plant operation philosophy, and other factors. The data in Table 2.13 are restated in summary form in Table 2.14 for the reference 1500 MTHM/year plant. Selection of contamination designations for waste was based on the assumption that intermediate levels of beta-gamma contamination are usually associated with TRU contamination. Further, the burning of spent solvent at an estimated rate of $n 8 \mathrm{~kg} / \mathrm{hr}$, (14) produces a waste stream that is mixed with ILW salts and stored, while some combustible $L L$, non-TRU waste is reduced to a dry, solid ash.

$$
\text { 2.4.2.6 Hul1s and Fuel Assembly Hardware }(1-3,11-13,19)
$$

Chopped hulls are rinsed and removed from the dissolver after dissolution of the oxidic fuel by nitric acid. Massive end pieces and internal hardware are also part of this stream. Zircaloy fines generated by sawing and chopping are oxidized prior to mixing with the hulls stream. Tables 2.15 and 2.16 summarize the properties of the metallic waste in the hull stream. Data in these tables can be converted to other units (e.g., per GWe-year, per fue 1 assembly) using the conversion factors in the footnotes. The metallic waste is assumed to contain $0.05 \%$ of the initial fuel, * almost entirely in the form of unleached oxidic fuel in the cladding hulls. Further, the hulls are assumed to contain $15 \%$ of the tritium formed in the fuel. The volume of the metal waste is estimated based on an average bulk density of uncompacted hulls and hardware of $1 \mathrm{~g} / \mathrm{cm}^{3}$. Oxidized Zircaloy fines represent an insignificant mass or volume contribution to this stream. The metallic waste is packaged in containers of high integrity after being surveyed for excessive amounts of undissolved reactor fuel. Data in Tables 2.15 and 2.16 do not include fuel assembly channels. It is assumed that these are reused at the reactor and, when no longer serviceable, are discarded as a solid waste generated at the reactor. Amounts of fuel channel waste are estimated to be equivalent to 100 kg Zircaloy per MTHM or about 3.3 MT Zircaloy per 1000 MWe-year. (16) This waste may have a greater density than hulls and may represent a volume of $1 \mathrm{~m}^{3} /$ 1000 MWe-year.

\subsubsection{Alternative Fuel Cycles}

As described in Section 2.1, alternative fuel cycles have an impact on the nature of the waste generated in reprocessing operations. The "throwaway" fuel cycle produces a waste consisting of the entire fuel assembly. The fission product and actinide content of the assembly, listed in Table 2.17, differs from high-level waste generated in processing of the Mox reference fuel

\footnotetext{
*Early experience suggests that fuel contamination could be as high as $0.1 \% .(12)$
} 
TABLE 2.13. Solid Wastes From Fuel Reprocessing Operations

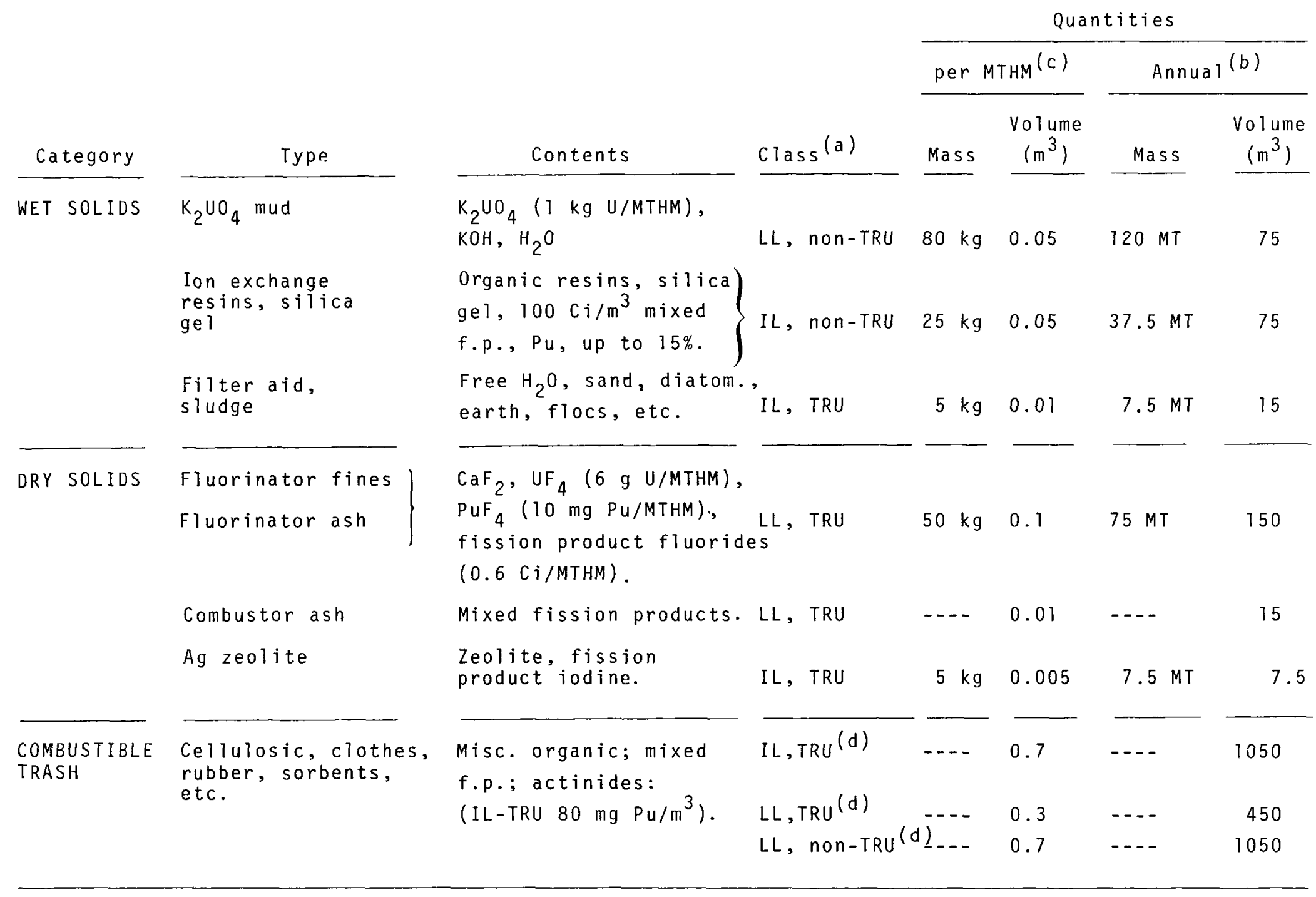


TABLE 2.13. (contd)

\begin{tabular}{|c|c|c|c|c|c|c|c|}
\hline \multirow[b]{3}{*}{ Category } & \multirow[b]{3}{*}{ Type } & \multirow[b]{3}{*}{ Contents } & \multirow[b]{3}{*}{$\operatorname{class}(a)$} & \multicolumn{4}{|c|}{ Quantities } \\
\hline & & & & \multicolumn{2}{|c|}{ per MTHM $(c)$} & \multicolumn{2}{|c|}{ Annual (b) } \\
\hline & & & & Mass & $\begin{array}{c}\text { Volume } \\
\left(\mathrm{m}^{3}\right)\end{array}$ & Mass & $\begin{array}{c}\text { Volume } \\
\left(\mathrm{m}^{3}\right)\end{array}$ \\
\hline \multirow{3}{*}{$\begin{array}{l}\text { NON- } \\
\text { COMBUSTIBLE } \\
\text { TRASH }\end{array}$} & \multirow{3}{*}{$\begin{array}{l}\text { Smal } 7 \text { equipment, } \\
\text { tools, glass }\end{array}$} & \multirow[t]{3}{*}{ Metals, ceramics. } & IL , TRU & $-\ldots$ & 0.7 & --- & 1050 \\
\hline & & & $L L, T R U$ & $-\ldots$ & 0.2 & $-\ldots$ & 300 \\
\hline & & & $L L$, non-TRU & $-\ldots$ & 0.1 & $\ldots$ & 150 \\
\hline \multirow[t]{2}{*}{ EQUIPMENT } & \multirow{2}{*}{$\begin{array}{l}\text { Process vessels, } \\
\text { apparatus }\end{array}$} & \multirow{2}{*}{$\begin{array}{l}\text { Metals, inorganic, } \\
\text { materials. }\end{array}$} & $I L, T R U$ & $\ldots$ & 0.1 & $-\ldots$ & 150 \\
\hline & & & $L L$, non-TRU & --- & 0.1 & --- & 150 \\
\hline \multirow[t]{3}{*}{ FILTERS } & \multirow{3}{*}{$\begin{array}{l}\text { HEPA, roughing } \\
\text { filters }\end{array}$} & \multirow{3}{*}{$\begin{array}{l}\text { Metal, glass, } \\
\text { organics. }\end{array}$} & IL , TRU & $\ldots$ & 0.06 & $-\cdots$ & 90 \\
\hline & & & LL, TRU & $\ldots$ & 0.1 & $-\ldots$ & 150 \\
\hline & & & $L L$, on-TRU & --- & 0.01 & --- & 15 \\
\hline
\end{tabular}

a. Class designation based on "200 mr/hr" cut-off for LL/IL and $10 \mathrm{nCi} P u / g$ for non-TRU/TRU. Class IL usually contains mixed fission products and, except for storage pool resins, will also be a TRU waste.

b. Based on 1500 MTHM/year plant capacity.

c. MTHM = metric ton of heavy metal $(U+P u)$.

d. Uncompacted, noncombusted form. 


$$
2.70
$$

TABLE 2.14. Summary of Solid Waste from Fuel Reprocessing

\begin{tabular}{|c|c|c|}
\hline & \multicolumn{2}{|c|}{$\begin{array}{l}\text { Annual Rate for } \\
1500 \mathrm{MTHM} / \text { year, in } \mathrm{m}^{3}\end{array}$} \\
\hline & TRU & non-TRU \\
\hline Combustible (trash)(a) & 1500 & 1050 \\
\hline Noncombustible solids & 1660 & 315 \\
\hline Slurries, sludges, resins & 15 & 150 \\
\hline \multirow[t]{2}{*}{ Filters } & 240 & 15 \\
\hline & $\sim 3400$ & 21500 \\
\hline
\end{tabular}

a. Uncompacted, noncombusted form. 
TABLE 2.15. Properties of Metals and Selected Elements Contained in Fuel Assembly Waste (a)

\begin{tabular}{|c|c|c|c|c|c|c|c|c|}
\hline & \multirow[t]{2}{*}{ Mass $(g)$} & \multicolumn{3}{|c|}{ Activity, $\mathrm{Ci}^{(\mathrm{b})}$} & \multicolumn{4}{|c|}{ Heat Generation, $w^{(b)}$} \\
\hline & & 120 day & 1 year & 10 year & 120 & day & 1 year & 10 year \\
\hline & $1 E 6$ & $2.7 \mathrm{E} 5$ & 1.1 E5 & 1.2 E4 & 1.5 & E3 & $5.8 \mathrm{E} 2$ & $8.6 \mathrm{El}$ \\
\hline Zircaloy $(g)$ & $8.9 E 5(f)$ & $\ldots$ & $-\ldots$ & --- &.- & - & $-\ldots$ & --- \\
\hline Stainless Steel & $8.9 \mathrm{E} 4$ & --- & $\ldots$ & $-\ldots$ & $\cdots$ & - & --- & -- \\
\hline Incone] & $2.5 \mathrm{E} 4$ & $\ldots$ & $\ldots$ & --- & $\cdots$ & & $-\ldots$ & $-\ldots$ \\
\hline$M n(d)$ & $1.8 \mathrm{E} 3$ & $1.7 \mathrm{E} 4$ & $9.8 \mathrm{E} 2$ & $5.0 E-1$ & 1.4 & E2 & $7.9 \mathrm{EO}$ & $4.1 E-3$ \\
\hline $\mathrm{Fe}^{(\mathrm{d})}$ & $6.8 \mathrm{E} 4$ & $2.2 \mathrm{E} 4$ & 1.8 E4 & $1.6 \mathrm{E} 3$ & 2.9 & ET & $2.3 E 1$ & 2.1 EO \\
\hline $\mathrm{CO}^{(\mathrm{d})}$ & $2.0 \mathrm{E} 2$ & $2.8 \mathrm{E} 4$ & 1.6 E4 & $4.4 \mathrm{E} 3$ & 4.3 & E2 & $2.5 \mathrm{E} 2$ & $6.8 \mathrm{El}$ \\
\hline$N i^{(d)}$ & $2.1 \mathrm{E} 4$ & $7.8 \mathrm{E} 2$ & 7.8 E2 & $7.3 \mathrm{E} 2$ & 1.6 & $E-1$ & $1.6 E-1$ & $1.5 E-1$ \\
\hline$S b^{(d)}$ & $8.4 \mathrm{E} 2$ & $5.7 \mathrm{E} 4$ & $3.5 \mathrm{E} 4$ & $3.3 \mathrm{E3}$ & 2.5 & $\mathrm{E} 2$ & 1.5 E2 & $1.4 \mathrm{El}$ \\
\hline$T e^{(d)}$ & $4.8 \mathrm{El}$ & $1.6 \mathrm{E} 4$ & $1.4 E 4$ & $1.4 E 3$ & 1.4 & El & 1.3 El & 1.3 EO \\
\hline Fission products $(c)$ & $3.4 \mathrm{El}$ & $8.4 \mathrm{E} 3$ & 3.2 E2 & $3.7 \mathrm{E} 2$ & 3.5 & El & $1.4 E 1$ & 1.1 EO \\
\hline TRU Elements $(c)$ & $2.7 \mathrm{El}$ & $5.4 \mathrm{E} 2$ & $4.7 \mathrm{E} 2$ & $2.9 \mathrm{E} 2$ & 6.0 & EO & $3.0 E 0$ & 1.5 EO \\
\hline$n / \sec$ & & $6.4 \mathrm{E} 6$ & $5.9 \mathrm{E} 6$ & $3.9 \mathrm{E} 6$ & - - & -- & - - - & $\ldots$ \\
\hline Totals/MTHM & $3.3 \mathrm{E} 5$ & $9.1 \mathrm{E} 4$ & $3.6 \mathrm{E} 4$ & 4.2 E3 & 5.0 & E2 & $2.0 \mathrm{E2}$ & $2.9 \mathrm{EI}$ \\
\hline Totals/MT hulls- & $1.0 \mathrm{E} 6$ & $2.8 \mathrm{E} 5$ & 1.1 E5 & $1.3 E 4$ & 1.5 & E3 & $6.0 \mathrm{E} 2$ & $8.9 \mathrm{El}$ \\
\hline
\end{tabular}

a. Based on data in Table $2 \dot{2}\}$ for the reference LWR fuel assembly, 25,000 MWd/MTHM burnup and 35 MW/MTHM specific power. $\{\dot{6}\}$

b. For cooling times indicated.

c. Based on residual fuel in cladding of $0.05 \%$.

d. Selected on the basis of significant activity fraction after more than

e. $1000 \mathrm{~kg}$ of metallic waste $\equiv 9.898$ fuel assemblies $\equiv 3.08$ MTHM. A 1500 MTHM/year plant generates $487 \mathrm{MT}$ of this metallic waste, or 14.8 MT of waste/1000 MWe-year. At an average density of 1 $\mathrm{g} / \mathrm{cm}^{3}$, the metallic waste from one day operation of the $1500 \mathrm{MTHM} / \mathrm{year}$ plant has a volume of $21.6 \mathrm{~m}^{3}$.

f. Includes from 90 to $900 \mathrm{~g}$ zirconium fines $(0.01$ to $0.1 \%$ of Zircaloy).

g. Includes $15 \%$ of the tritium, corresponding to $277 \mathrm{Ci} / \mathrm{MTHM}\left(239 \mathrm{Ci}^{3} \mathrm{H} / 1000 \mathrm{~kg} \mathrm{hulls}\right)$ at 1 -year cooling. 
TABLE 2.16. Radioactivity Content in Reference Fuel-Assembiy Metal Waste as a Function of Long-Term Cooling (a)

Fission products $(b)$

$C i / M T$ (metal waste)

Ci/MTHM (fuel)

Ci/GWe-year

Predominant fission products

Ci/MT (metal waste) (c)

$\mathrm{Se}$
$\mathrm{Zr}$
$\mathrm{Nb}$
$\mathrm{TC}$
$\mathrm{Pd}$
$\mathrm{Sn}$
$\mathrm{Sb}$
$\mathrm{CS}$

Activation products

Ci/MT (metal waste)

Ci/MTHM (fuel)

$\mathrm{Ci} / \mathrm{GWe}$-year

Predominant activation products

Ci/MT (metal waste) (c)
Cooling Periods

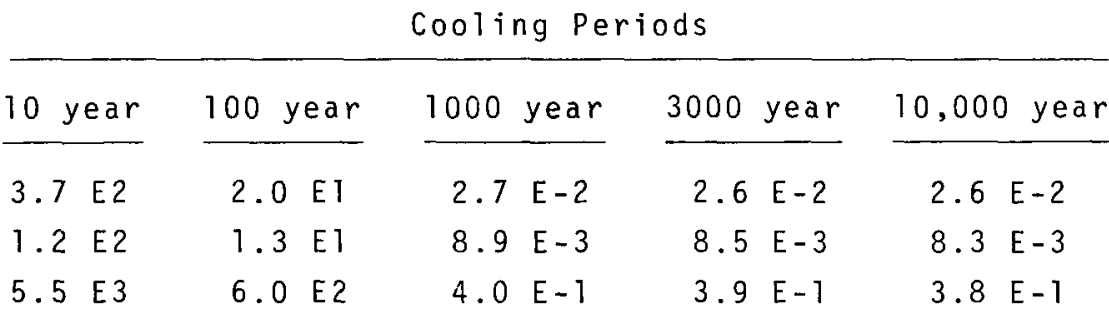

\begin{tabular}{|c|c|c|c|c|}
\hline$\ldots$ & $\ldots-$ & $4.5 E-4$ & $4.4 E-4$ & $4.1 \quad E-4$ \\
\hline$-\cdots$ & --- & $3.3 E-3$ & $3.3 E-3$ & $3.3 E-3$ \\
\hline--- & --- & $3.1 E-3$ & $3.1 E-3$ & $3.1 \quad E-3$ \\
\hline$\ldots$ & --- & $1.7 E-2$ & $1.7 E-2$ & $1.7 \mathrm{E}-2$ \\
\hline$-\cdots$ & ---- & $1.6 E-4$ & $1.6 E-4$ & $1.6 E-4$ \\
\hline--- & --- & $7.5 \quad E-4$ & $7.4 \quad E-4$ & $7.1 \quad E-4$ \\
\hline--- & ---- & $8.6 E-4$ & $8.5 E-4$ & $8.1 E-4$ \\
\hline$\ldots$ & $-\cdots$ & $5.3 E-4$ & $5.3 E-4$ & $5.3 E-4$ \\
\hline
\end{tabular}

$\stackrel{n}{N}$

$\begin{array}{llllllll}1.2 & \text { E4 } & 3.8 \text { E2 } & 7.9 & \text { EO } & 6.9 & \text { E0 } & 5.6 \text { E0 } \\ 3.9 & \text { E3 } & 1.2 \text { E2 } & 2.6 \text { E0 } & 2.2 \text { EO } & 1.8 \text { E0 } \\ 1.8 \text { E5 } & 5.7 \text { E3 } & 1.2 \text { E2 } & 1.0 \text { E2 } & 8.3 \text { E I }\end{array}$

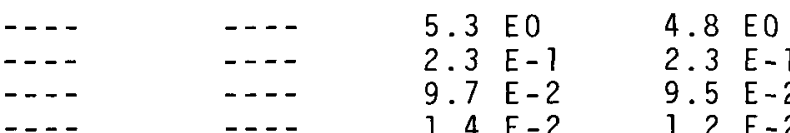

$4.5 \mathrm{EO}$

2. $3 E-1$

$9.1 E-2$

$7.0 \mathrm{E}-3$

$\begin{array}{llllll}--- & 1.4 & \mathrm{E}-2 & 1.2 \mathrm{E}-2 & 7.0 \mathrm{E}-3 \\ --- & -- & 1.9 \mathrm{E}-2 & 1.9 \mathrm{E}-2 & 1.9 \mathrm{E}-2\end{array}$


TABLE 2.16. (contd)

Cooling Periods

Actinides (b)

Ci/MT (metal waste)

Ci/MTHM (fuel)

Ci/GWe-year

Predominant actinides

Ci/MT (metal waste) ${ }^{(c)}$

$\mathrm{Pa}$
$\mathrm{U}$
$\mathrm{Np}$
$\mathrm{Pu}$
$\mathrm{Am}$
and actinides)

Gross totals (fission products,
tivation products, and actinides)

$\begin{array}{lllllll}\text { Ci/MT (metal waste) } & 1.3 E 4 & 4.4 E 2 & 1.3 E 1 & 9.2 \text { E0 } & 6.9 E 0 \\ \text { Ci/MTHM (fuel) } & 4.1 \text { E3 } & 1.4 E 2 & 4.4 \text { E0 } & 3.0 \text { E0 } & 2.2 \text { E0 } \\ \text { Ci/GWe-year } & 1.9 E 5 & 6.7 E 3 & 2.0 E 2 & 1.3 E 2 & 1.0 \text { E2 }\end{array}$

a. Based on reference fuel assembly (Tables $2.2,2.3,2.4$, and 2.5) and reactor performance of 25,000 MWd/MTHM burnup and 35 MW/MTHM specific power.

b. Based on $0.05 \%$ residual fuel with cladding.

c. Values for Ci/MT (metal waste) convertible by applying the following factors:

X $0.324=$ amount/MTHM (fue 1 )

$X 14.8=$ amount/GWe-year

X $487^{\circ}=$ amount $/ 7500$ MTHM (fuel). 
TABLE 2.17. Fission Product and Actinide Content of LWR Fuel for a "Throwaway" Fuel Cycle (a)

$\mathrm{Ci} / \mathrm{MTHM}^{(\mathrm{b})}$

g/MThM (c) 90 day 160 day 1 year 10 year 100 year 1000 year 3000 year

Fission

products

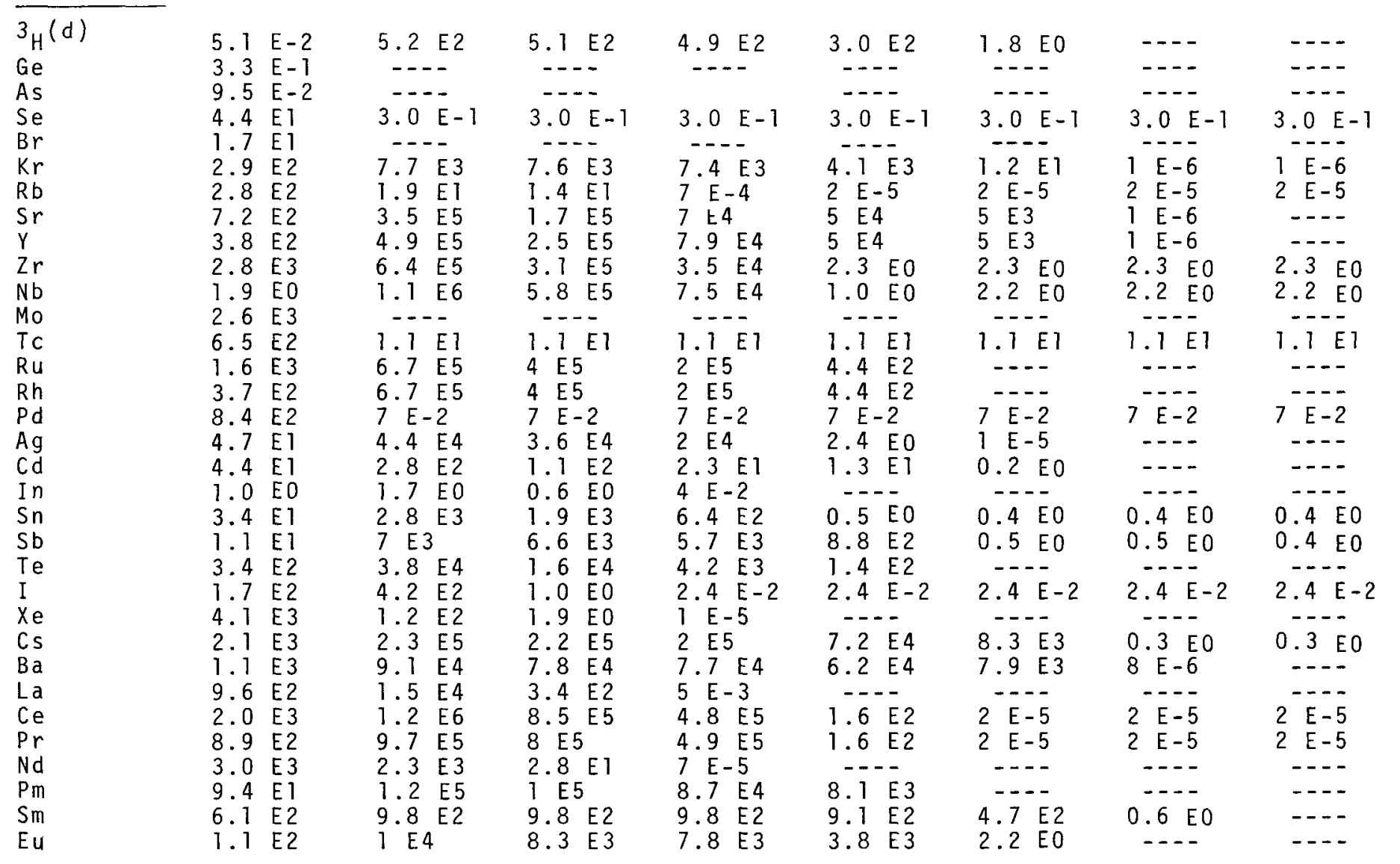


TABLE 2.17. (contd)

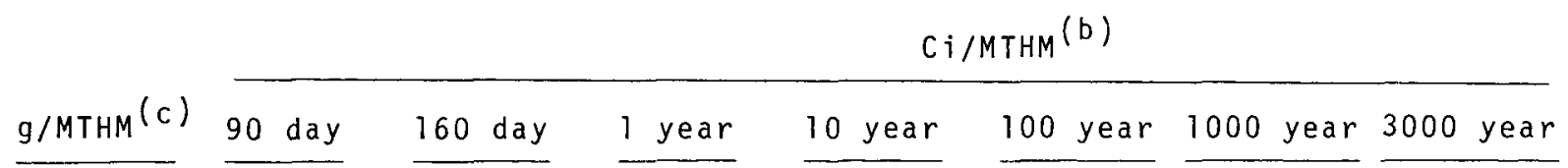

Fission

products (contd)

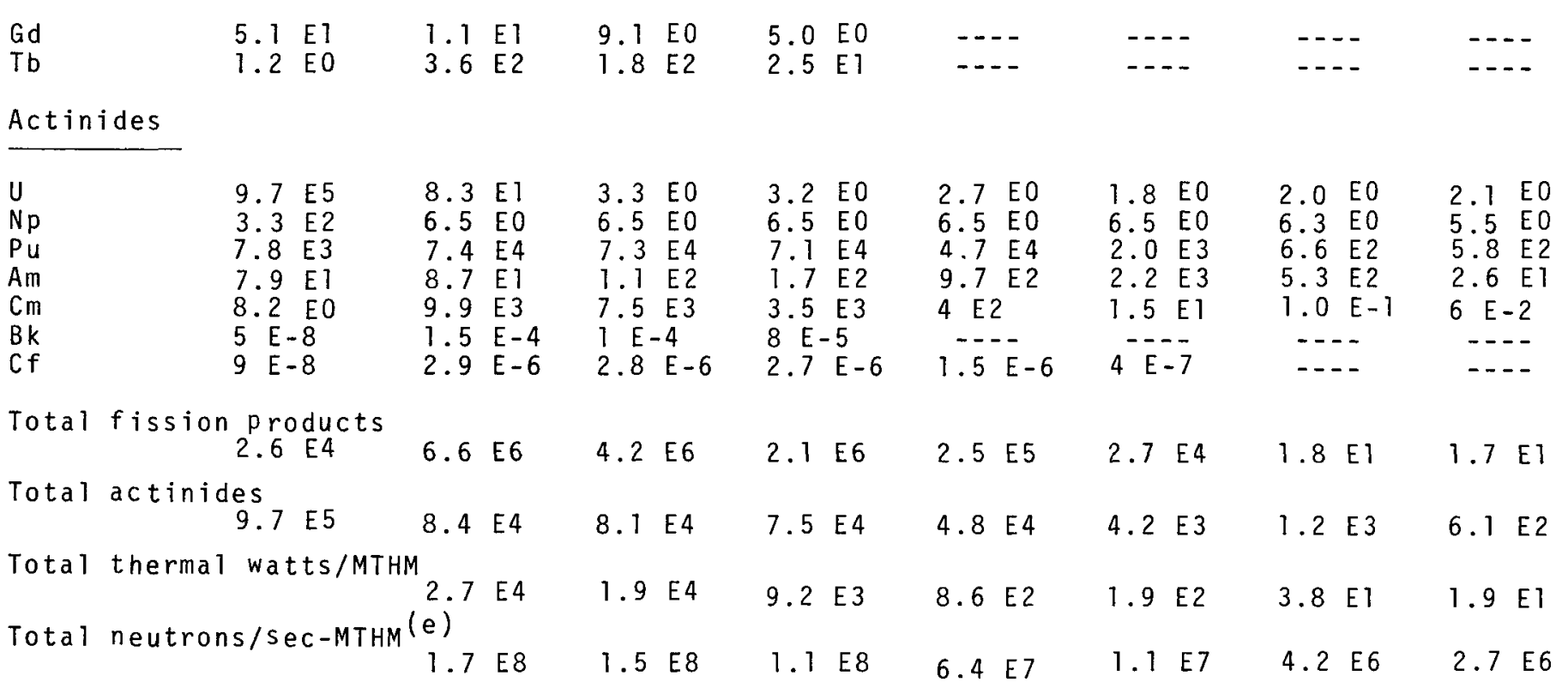

a. Basis: 25,000 MWd/MTHM, 35 MW/MTHM, initial 235 enrichment $3.3 \%$. Data from Reference 6 .

b. Curies of activity from the indicated elements, per metric ton of heavy metal in discharged fuel cooled for the times stated at column headings.

c. Based on element present after 1 year cooling.

d. Based on $523 \mathrm{Ci}{ }^{3}$ H/MTHM at discharge in fuel of 25,000 MWd/MTHM burnup and $\mathrm{T}_{1 / 2}=12.262$ year.

e. Includes $(\alpha, n)$ and spontaneous fission neutrons. 
largely because of the absence of initial plutonium in the "throwaway" fuel and of processes that remove the bulk of the uranium and plutonium from the spent fuel. Hence, the waste from the "throwaway" fuel cycle contains $970 \mathrm{~kg}$ of uranium per MTHM (with $1.22 \% 235$ U remaining) and $7.8 \mathrm{~kg}$ plutonium.

Table 2.18 compares the waste composition from LWR reference fuel processing and from the "throwaway" fuel cycle.

Another fuel cycle alternative requires the reprocessing of the $\mathrm{UO}_{2}$ fuel to segregate uranium, plutonium, and fission products but includes storage of plutonium rather than incorporation of plutonium into Mox fuel. This alternative generates all the types of reprocessing waste found in the reference fuel cycle but the composition of the wastes differs slightly from that found in the reference case. Table 2.19 contains summary data on the radiation from high-level waste obtained by reprocessing $U 0_{2}$ fuel. The differences between the LWR reference high-level waste (Table 2.9) and the $\mathrm{UO}_{2}$ reprocessing high-level waste are largely due to the actinide content of the former waste.

Data shown in Table 2.19 illustrate the activity, heat generation, and neutron emission from high-level waste from processing of $\mathrm{U}_{2}$ fuel for various cooling times. These data are similar to those in Table 2.17 except for the removal of $99.5 \% \mathrm{U}$ and $\mathrm{Pu}$. Comparable data for the LWR reference fuel cycle are shown in Table 2.9. Data in Table 2.20 illustrate more specifically the reduction in actinide content of the waste from processing of $\mathrm{UO}_{2}$ fuel.

Minor differences in the distribution of actinide isotopes will also be evident in all TRU wastes from reprocessing operations. The concentration of TRU contamination of non-high-level waste is not great enough to require new source term descriptions for treatment technologies. For a constant mass contamination level, TRU waste generated by processing only U $0_{2}$ fuel should show a reduction in curie level proportional to that shown for the fuel or high level waste. In all cases, the fission product spectrum is sufficiently similar so that no consequential differences in the wastes result from the processing of $\mathrm{U}_{2}$ fuel.

Conversion of plutonium nitrate to plutonium dioxide is common to the LWR reference fuel cycle and to the "uranium-only" fuel cycle, in which $\mathrm{PuO}_{2}$ is stored. Storage of $\mathrm{PuO}_{2}$ for prolonged periods may require close attention to the extent to which volatile and decomposable materials are removed from the dioxide on calcination. No significant differences are anticipated in technology for the conversion process. Storage of $\mathrm{PuO}_{2}$ is expected to be in small batches, e.g., $5 \mathrm{~kg} \mathrm{PuO}{ }_{2}$,* properly packaged and spaced for criticality and radiologic safety. Since the $5 \mathrm{~kg}$ batches will generate $\sim 40 \mathrm{~W}$ of thermal energy, large arrays may require forced cooling. The isotopic composition and

$\star 4.4 \times 10^{3} \mathrm{~g}$ of $\mathrm{Pu}$. 


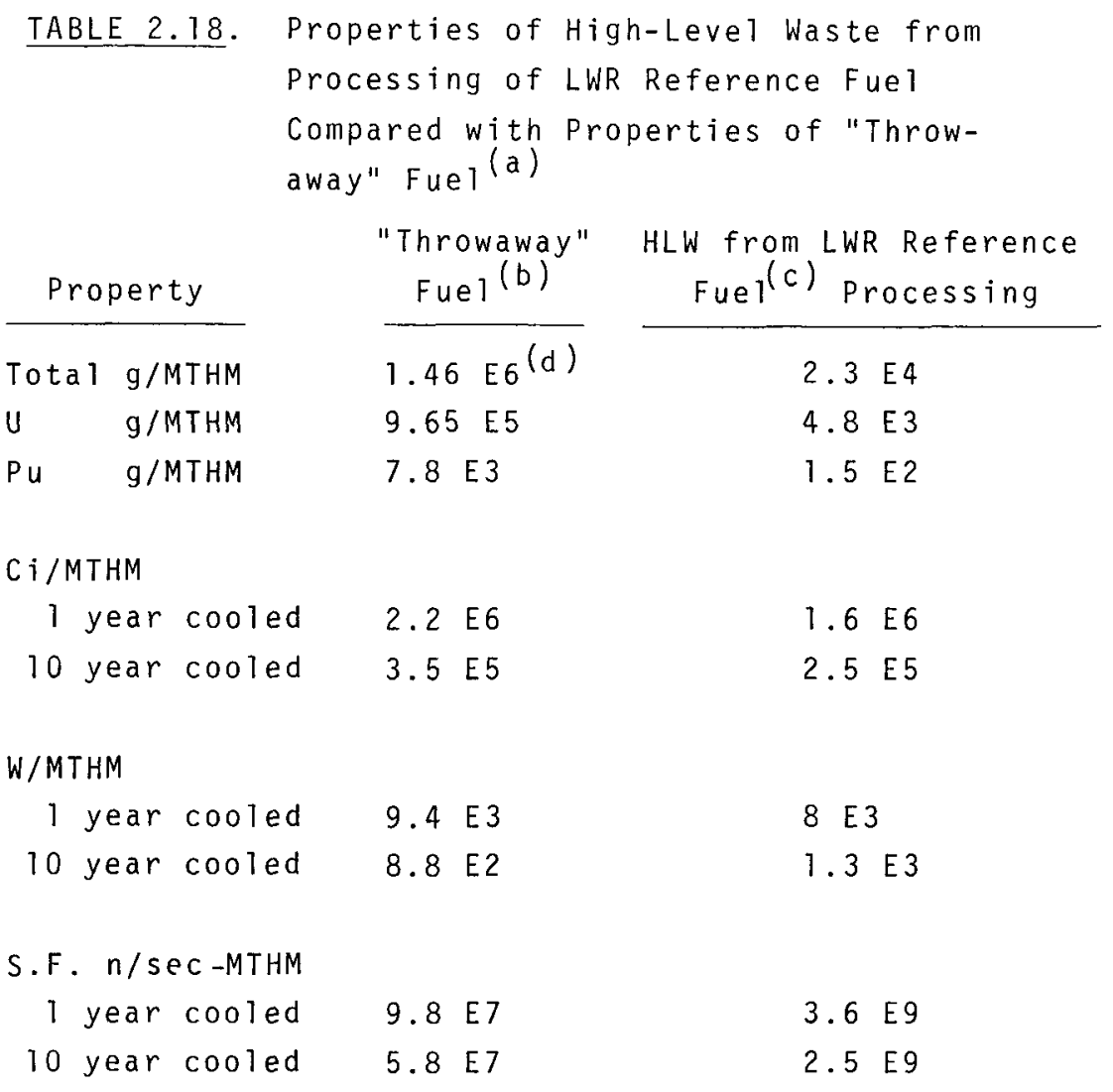

a. Both fuels at 25,000 MWd/MTHM, 35 MW/MTHM. (6)

b. Fuel fabricated from only enriched uranium.

c. Fuel fabricated from MoX (uranium and plutonium).

d. Includes metallic component of reference fuel. 
TABLE 2.19. Radiation from High Level Waste Generated by Processing of Spent $\mathrm{UO}_{2}$-Bearing LWR Fuel (a)

\begin{tabular}{|c|c|c|c|c|c|c|c|c|c|c|}
\hline \multirow[b]{2}{*}{ Source } & & \multicolumn{9}{|c|}{ Cooling Time } \\
\hline & & $160 \mathrm{~d}$ & 1.4 & $y$ & 10.4 & $y$ & 100 & $y$ & $1000 y$ & $3000 y$ \\
\hline \multicolumn{11}{|c|}{$\begin{array}{l}\text { Fission } \\
\text { Products: }\end{array}$} \\
\hline & Ci/MTHM & $4.2 \mathrm{E} 6$ & 1.5 & E 5 & 2.4 & E5 & 2.7 & E4 & $1.8 \mathrm{El}$ & $1.7 \mathrm{El}$ \\
\hline & W/MTHM & $1.8 E 4$ & 6.4 & E3 & 7.3 & E2 & 7.5 & E1 & $1.44 E-2$ & $1.42 E-2$ \\
\hline \multicolumn{11}{|c|}{ Actinides: } \\
\hline & $\mathrm{Ci} / \mathrm{MTHM}$ & $8 \mathrm{E} 3$ & 2.5 & E3 & 7.7 & E2 & 1.5 & E2 & $3.9 \mathrm{EI}$ & $1.5 \mathrm{El}$ \\
\hline & W/MTHM & $2.8 \mathrm{E} 2$ & 7.8 & E 1 & 1.9 & ET & 4.6 & EO & $1.1 \mathrm{EO}$ & $4.0 E-1$ \\
\hline & $n / \sec -M T H M(b)$ & $1.4 \mathrm{E} 8$ & 9.2 & E7 & 5.6 & E7 & 2.3 & E6 & $3.1 \mathrm{E} 5$ & $2.0 \mathrm{E} 5$ \\
\hline \multicolumn{11}{|l|}{ Total: } \\
\hline & Ci/MTHM & $4.2 \mathrm{E} 6$ & 1.5 & E6 & 2.4 & E5 & 2.7 & E4 & $5.7 \mathrm{El}$ & $3.2 \mathrm{El}$ \\
\hline & W/MTHM & $1.8 \mathrm{E} 4$ & 6.4 & E3 & 7.4 & E2 & 8.0 & El & $1.1 \mathrm{EO}$ & $4.0 \mathrm{E}-1$ \\
\hline
\end{tabular}

a. Based on 25,000 MWD/MTHM, 35 MW/MTHM, initial U-235 content is $3.3 \%$. The waste contains $0.5 \%$ of initial $U$ and $\mathrm{Pu}$, no tritium, $\mathrm{Xe}, \mathrm{Kr}$, and $0.1 \%$ of $\mathrm{I}$ and $\mathrm{Br}$. These percentages are applied to fuel at 160 days after removal from the reactor core.

b. Spontaneous fission neutrons only. 
selected radiation data for plutonium separated from LWR-U0 2 fuel is 1 isted in Table 2.21. The $2.2 \times 10^{6} \mathrm{n} / \mathrm{sec}$ and $1 \times 10^{-1} \mathrm{Ci}$ of gamma radiation, per $5 \mathrm{~kg} \mathrm{PuO} 2$, may require modest shielding. Table 2.22 summarizes data for various sources of plutonium.

TABLE 2.20. Actinide Content of High Level Waste from Processing of $\mathrm{UO}_{2}$ Fuel and of LWR Reference Fuel ${ }^{(a)}$

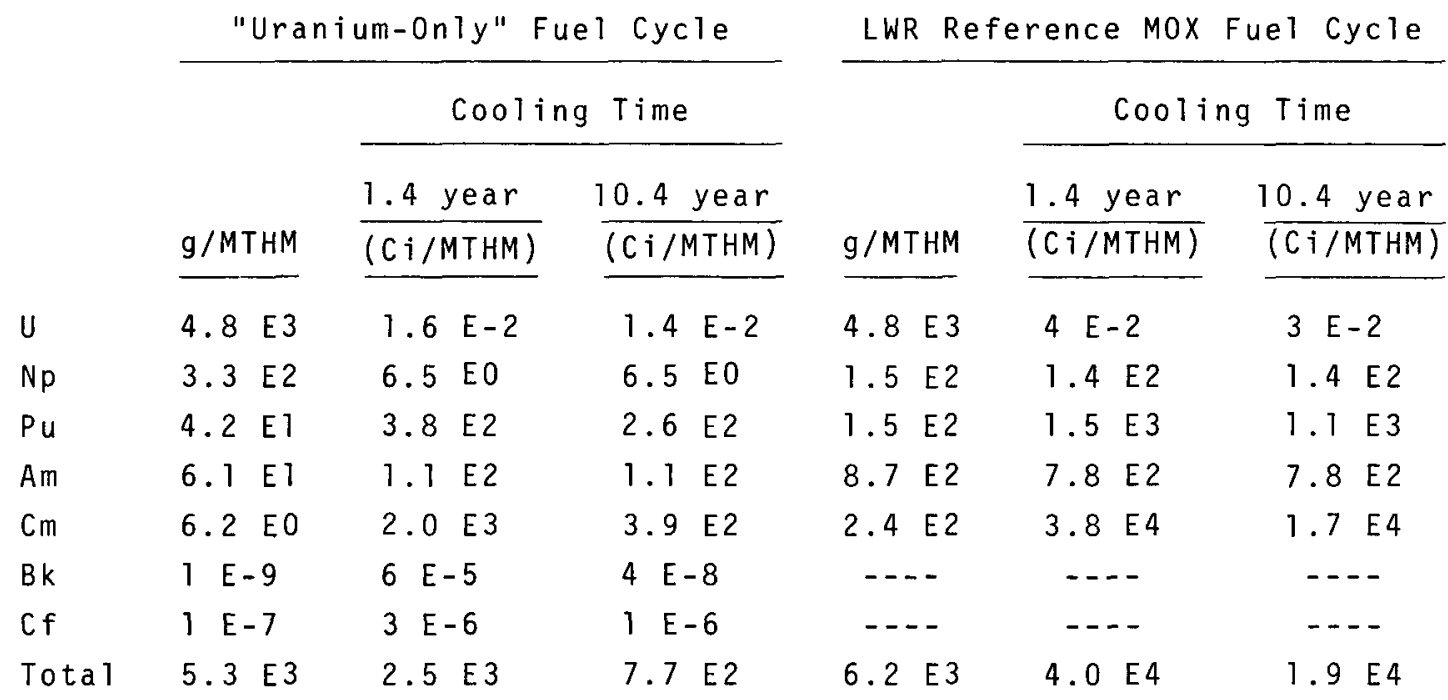

a. 25,000 MWd/HiHM, 35 MW/MTHM, $0.5 \%$ of initial U and Pu, $100 \%$ of a 11 other transuranic elements. The percentages apply at 160 days after discharge from reactor core.

\section{4 .4 Summary}

In summary, the generation of various waste streams in the reprocessing of spent reactor fuel has been described. The reference plant receives spent reactor fuel and produces plutonium dioxide and uranium hexafluoride. Various types of waste streams are generated in the reprocessing of the fuel and the purification of the final products. High-level waste is stored in liquid form, onsite, in tanks. Solids are stored in containers or are buried. Intermediate-level liquid wastes are subject to treatment and concentration to a crystalline solid, which is stored in tanks. Low-level liquid wastes are collected and evaporated to a vapor portion that is vented directly to the atmosphere and a concentrated residual liquid that is combined with the stored high-level wastes. The reference reprocessing plant discharges no liquid wastes. The off-gas treatment system scrubs reactive fission products such as iodine from the off-gases. It allows the complete venting to the stack of the noble gases, e.g., krypton, and of tritium and ${ }^{14} \mathrm{C}$ in the form of water vapor and $\mathrm{CO}_{2}$. 
TABLE 2.21. Properties of Plutonium from LWR-U0 2 Fuel (a)

\begin{tabular}{|c|c|c|c|c|c|c|}
\hline & ${ }^{238} \mathrm{Pu}$ & ${ }^{239} \mathrm{Pu}$ & $240 \mathrm{Pu}$ & $241 \mathrm{Pu}$ & ${ }^{242} \mathrm{Pu}$ & Total $(f)$ \\
\hline wt $\%$ & 1.03 & 65.30 & 22.49 & 9.01 & 2.17 & 100 \\
\hline$\alpha \mathrm{Ci} / \mathrm{g}$ & 17.4 & $6.15 \mathrm{E}-2$ & 0.227 & $2.58 E-3$ & $3.9 E-3$ & 0.27 \\
\hline$\beta C i / g$ & --- & --- & --- & 1.124 E2 & -- & 10.13 \\
\hline$\gamma C j / g(b)$ & $2 E-4$ & $4.7 E-6$ & -- & $2 E-4$ & -- & $2.5 E-5$ \\
\hline$n / \sec -g(c)$ & $2.8 \mathrm{E} 3$ & $2.2 E-2$ & $1.02 \mathrm{E} 3$ & $2.3 E-2$ & 1.73 E3 & $3 \mathrm{E} 2$ \\
\hline$n / \sec -g^{(d)}$ & $1.4 \mathrm{E} 4$ & 45 & $1.7 \mathrm{E} 2$ & $\sim 10$ & 210 & $2 \mathrm{E} 2$ \\
\hline Total $\mathrm{n} / \mathrm{sec}-\mathrm{g}$ & $1.7 \mathrm{E} 4$ & 45 & $1.2 E 3$ & 270 & $1.7 \mathrm{E} 3$ & $5 \mathrm{E} 2$ \\
\hline$w / g^{(e)}$ & 0.577 & $1.91 E-3$ & $7.07 E-3$ & $\alpha 7.99 \quad E-5$ & $1.15 E-4$ & $9.2 E-3$ \\
\hline & & & & $\beta 4.64 E-3$ & & \\
\hline
\end{tabular}

a. 25,000 MWD/MTHM, $35 \mathrm{MW} /$ MTHM, $7.826 \mathrm{~kg} \mathrm{Pu}$ discharged/MTHM. Initial $235 \mathrm{U}=3.3 \%$.

b. At $E>100 \mathrm{kev,} \alpha$ decay gamma only.

c. Spontaneous fission.

d. $(\alpha, n)$ on oxygen in $\mathrm{PuO}_{2}$.

e. Based on $Q_{\alpha}$ and $Q_{\beta}$.

f. Totals are sums of isotopic contribution in relation to their wt \% of elemental plutonium. 
TABLE 2.22. Isotopic Content and Radiations from LWR Plutonium

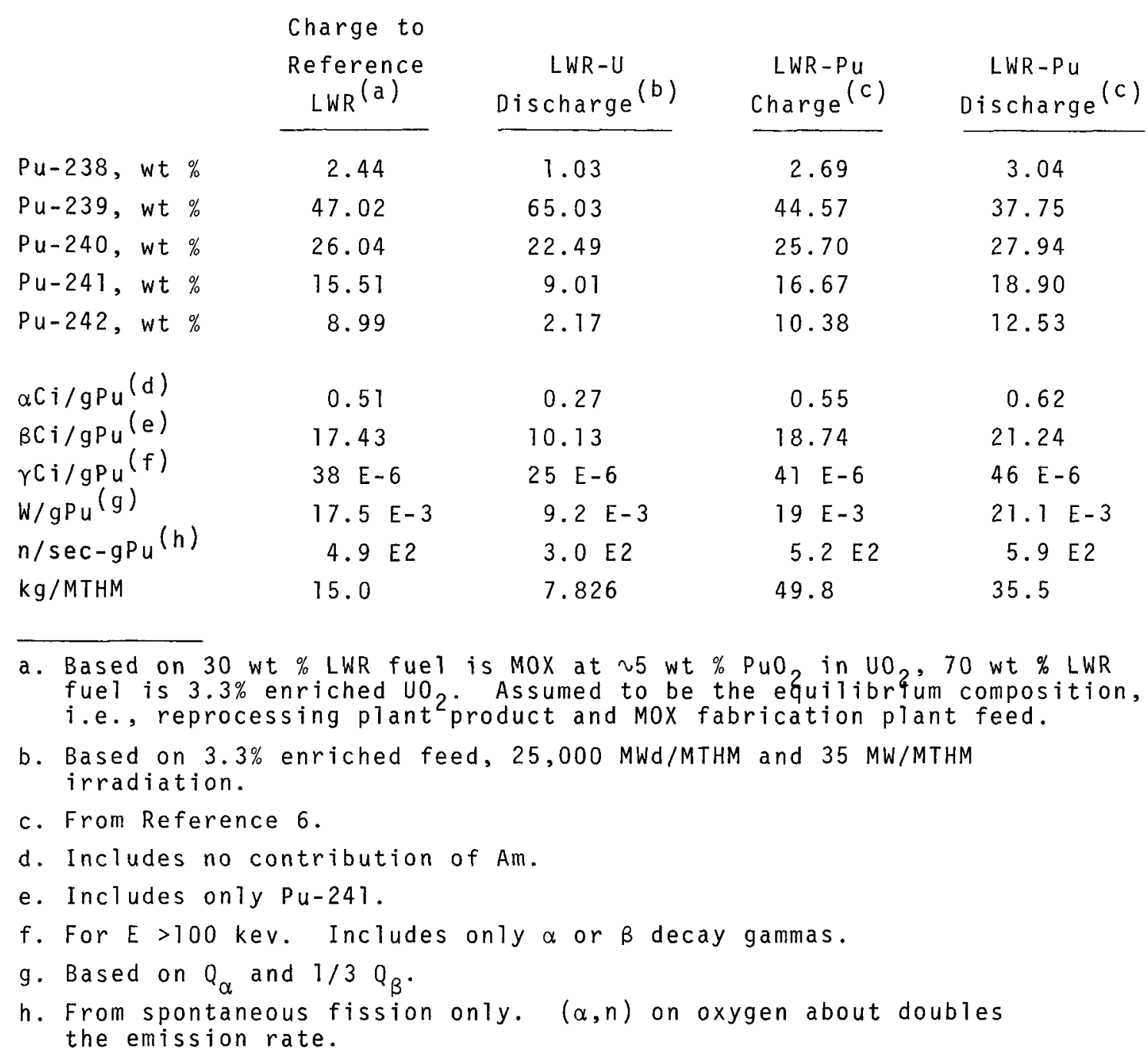




\section{REFERENEES}

1. Allied-General Nuclear Services, Barnwell Nuclear Fuel Plant: Final Safety Analysis, DOCKET 50-332, October 10, 1973.

2. General Electric Co., Midwest Fuel Recovery Plant, Final Safety Analysis Report, DOCKET 50-268, December 1970.

3. Nuclear Fuel Services, Inc., Final Safety Analysis Report, West Valley Reprocessing Plant, DOCKET 50-201, 1969.

4. E. R. Irish, Description of Purex Plant Process, United States Atomic Energy Commission Report, HW-60116, May 19, 1959.

5. B. J. Kullen, L. E. Trevorrow, and M. J. Steindler, Tritium and Noble Gas Fission Products in the Nuclear Fuel Cycle. II. Fuel Reprocessing Plants, United States Atomic Energy Commission Report ANL-8135, March 1975.

6. C. W. Kee, ORIGEN Code, PWR U-Equilibrium and Pu-Recycle Fue 1, 25,000 MWd/MTHM Burnup, 35 MW/MTHM Specific Power; Program 0utput, 0ak Ridge National Laboratory, Oak Ridge, TN, October 1975.

7. United States Nuclear Regulatory Commission, Title 10, Chapter 1, Code of Federal Regulations - Energy, Part 50 - Licensing of Production and Utilization Facilities, Appendix F - Policy Relating to the Siting of Fuel Reprocessing Plants and Related Waste Management Facilities, p. 50-28, April 20, 1975 .

8. C. R. Cooley, compiler, Commercial Alpha Waste Program Quarterly Progress Report July-December 1975, HEDL-TME 76-22, Hanford Engineering Development Laboratory, Richland, WA, to be published March 1976.

9. United States Atomic Energy Commission Directorate of Licensing, GESMO, Generic Environmental Statement on the Use of Recycle Plutonium in Mixed oxide Fuel in LWR's, United States Atomic Energy Commission Report, WASH-1327, Vol 1-4 (drafts), August 1974.

10. J. L. McElroy, K. J. Schneider, J. N. Hartley, J. E. Mendel, G. L. Richardson, R. W. Mckee, and A. G. Blasewitz, Waste Solidification Program Summary Report. Vol. II. Evaluation of WSEP High Level Waste Solidification Processes, United States Atomic Energy Commission Report, BNWL-1667, June 1972 .

11. N. M. Levitz, B. J. Kullen, and M. J. Steindler, Management of Waste Cladding Hulls. Part 1. Pyrophoricity and Compaction, United States Atomic Energy Commission Report, ANL-8139, February 1975.

12. B. Griggs, Feasibility Studies for Decontamination and Densification of Chop-Leach Cladding Residues, United States Atomic Energy Commission Report, BNWL-1820, July 1974. 
13. J. 0. Blomeke and J. J. Perona, Storage, Shipment, and Disposal of Spent Fuel Cladding, United States Atomic Energy Commission Report, ORNL-TM-3650, November 1972.

14. United States Atomic Energy Commission Directorate of Licensing, Environmental Statement-Barnwell Nuclear Fuel Plant, DOCKET 50-332, January 1974 .

15. P. J. Magno, C. B. Nelson, and W. H. Ellett, "A Consideration of the Significance of Carbon-14 Discharges from the Nuclear Power Industry," CONF-740807, p. 1047, 13th Air Cleaning Conference, August 1974.

16. R. Dillon, Battelle Northwest Laboratories, Private Communication, 1975.

17. E. D. North, Solid Waste Generation in Reprocessing Nuclear Fuels, Paper presented at the Fall AIChE meeting, Boston, MA, 1975.

18. R. B. Keely, "Description of Solid Wastes Expected from a Large Commercial Reprocessing Plant," Allied-General Nuclear Services, Private Communication, 1975.

19. R. B. Keely, Allied-General Nuclear Services, Private Communication, 1975. 


\subsection{WASTES FROM MIXED OXIDE FUEL FABRICATION PLANTS}

\subsubsection{Process Description}

Plutonium from the reprocessing plant is combined with natural uranium in the fabrication plant to produce mixed oxide LWR fuel (MOX). Plutonium is shipped to the plant as the dry oxide (see Table 2.23 for radiation properties) in sealed, overpacked containers (see section 22). The sealed containers are put into the glove boxes that are continually isolated from the plant atmosphere and the environment. Batches of uranium dioxide are transferred in similar fashion. Within the glove boxes, the following processes are performed.

1. blending of $\mathrm{PuO}_{2}$ and $\mathrm{UO}_{2}$ powders

2. cake-pressing of mixed-oxide-blend (MOX) powder

3. granulation and reblending of caked MOX

4. forming MoX granules into "green" pellets

5. high-temperature sintering of green pellets

6. finish grinding of sintered pellets

7. cleaning and inspection of finished pellets

8. loading finished pellets into fuel cladding tubes

9. fuel cladding decontamination and seal-welding.

At this point, the plutonium in the fuel is contained in sealed metal tubes that are outside the glove box enclosures. Subsequently, the fuel elements are subjected to the following additional routines by direct contact.

1. degreasing

2. fuel cladding etching and rinse

3. x-ray inspection of fuel pellet arrangement

4. autoclaving of fuel elements

5. fuel cladding leak-check and dimensional inspection

6. packaging, storage, and shipment.

The contaminated waste materials generated in these two operational areas range in transuranic (TRU), primarily plutonium, concentration from gross amounts to TRU-suspect concentrations. The latter wastes are classified as such by proposed regulations in 10CFR20 because they come from restricted areas of a TRU facility. (1) Table 2.24 shows a summary of characteristics of the waste streams. These wastes are identified and arranged by type in the following sections.

\subsubsection{Transuranic-Contaminated Combustible Solid Waste}

Combustible solids considered to be contaminated with transuranic elements are generated in two specific areas of a MoX fabrication plant (Figure 2.26). The first is in the operating area defined as restricted but not exposed to glove box interior atmospheres and/or effluents. (4) combustible materials $(5)$ 
TABLE 2.23. Mixed Oxide Fabrication Plant Plutonium Feed (a)

\begin{tabular}{|c|c|c|c|c|c|c|}
\hline & ${ }^{238} \mathrm{Pu}$ & ${ }^{239} \mathrm{Pu}$ & ${ }^{240} \mathrm{Pu}$ & $241 \mathrm{Pu}$ & ${ }^{242} \mathrm{Pu}$ & Total \\
\hline wt \% & 2.44 & 47.02 & 26.04 & 75.57 & 8.99 & 100 \\
\hline$\alpha C i / g(b)$ & 17.4 & $6.15 \mathrm{E}-2$ & 0.227 & $2.58 E-3$ & $3.9 E-3$ & 0.51 \\
\hline$\beta C i / g^{(c)}$ & $-\cdots$ & --- & --- & $7.724 \mathrm{E} 2$ & --- & 17.43 \\
\hline$\gamma \mathrm{Ci} / \mathrm{g}^{(d)}$ & $2 E-4$ & $4.7 E-6$ & --- & $2 E-4$ & -- & $38 E-6$ \\
\hline$n / \sec -g^{(e)}$ & $1.68 \mathrm{E} 4$ & 45.02 & $1.19 \mathrm{E} 3$ & 210 & 1.74 E3 & $9 E 2$ \\
\hline$w / g^{(f)}$ & 0.577 & $1.91 E-3$ & $7.07 \mathrm{E}-7$ & $4.64 E-3^{(g)}$ & $1.15 E-4$ & $17.5 \mathrm{E}-3$ \\
\hline
\end{tabular}

a. Derived from data of Reference 2 and based on discharge from the reference LWR with 30 wt $\%$ MOX fuel and 70 wt $\% 3.3 \%$ enriched UO fuel, 25,000 MWd/MTHM, 35 MW/MTHM, and an approximate self generation ratio ${ }^{2}$ (SGR) $\simeq 1.0$.

b. No Am included.

c. Only ${ }^{241} \mathrm{Pu}$ included.

d. at $E>100$ kev, decay gammas.

e. Spontaneous fission and $(\alpha, n)$ on oxygen in $\mathrm{PuO}_{2}$.

f. Based on $Q_{\alpha}$ and $1 / 3 Q_{\beta}$.

g. Beta power only. 
TABLE 2.24. Amounts and Activities of Plutonium-Contaminated Waste from Mixed-0xide Fuel Fabrication

Non-

Combustible Combustible HEPA

\begin{tabular}{ccc}
$\begin{array}{c}\text { Combustible } \\
\text { Solid(a) }\end{array}$ & $\begin{array}{c}\text { Combustible } \\
\text { Solid(a) }\end{array}$ & Filters (a) Liquid (b) \\
\hline
\end{tabular}

Waste volumes

$\mathrm{m}^{3} /$ MTHM in MOX

4.1

56

$1.9 E 3$

$m^{3} / 450$ MTHM in MOX $(d)$

Plutonium Mass

$\mathrm{g} / \mathrm{m}^{3}$ of waste

$\mathrm{g} / \mathrm{MTHM}$ in MOX

g/13.7 MTHM in MOX

g/450 MTHM in MOX

Pu Alpha Activity(e)

$\mathrm{Ci} / \mathrm{m}^{3}$ of waste
$\mathrm{Ci} / \mathrm{MTHM}$ in MOX
$\mathrm{Ci} / 13.7$ MTHM in MOX
$\mathrm{Ci} / 450$ MTHM in MOX

Pu Alpha-Beta

Activity (e)

$\mathrm{Ci} / \mathrm{m}^{3}$ of waste

540

$2.2 \mathrm{E3}$

500

$2.3 \mathrm{E} 3$

E4

$\mathrm{C} i / \mathrm{MTHM}$ in MOX

$3.1 E 4$

400

700

810

Ci/13.7 MTHM in MOX

E6
$5.4 E 3$

$1.8 \mathrm{E} 5$
0.3

0.06

4

0.8

140

27

Ci/450 MTHM in MOX
9.4 E3

E4

$3.2 \mathrm{E} 5$

$4 \quad E 5$

a. Values based on simple average of predictions found in References 3 and 4 .

b. Calculated from Reference 3 .

c. Represents MOX fraction of fuel for a GWe-year; $30 \%$ of a total 45.6 MTHM in enriched-U plus MOX fuels.

d. Represents MOX fraction of fuel for the 1500 MTHM-year case; $30 \%$ of a total 1500 MTHM in enriched-U plus MOX fuels.

e. Data based on "Reference" Pu activity of $0.5 \mathrm{Ci} / \mathrm{g}$ alpha and $18 \mathrm{Ci} / \mathrm{g}$ alpha plus beta. 


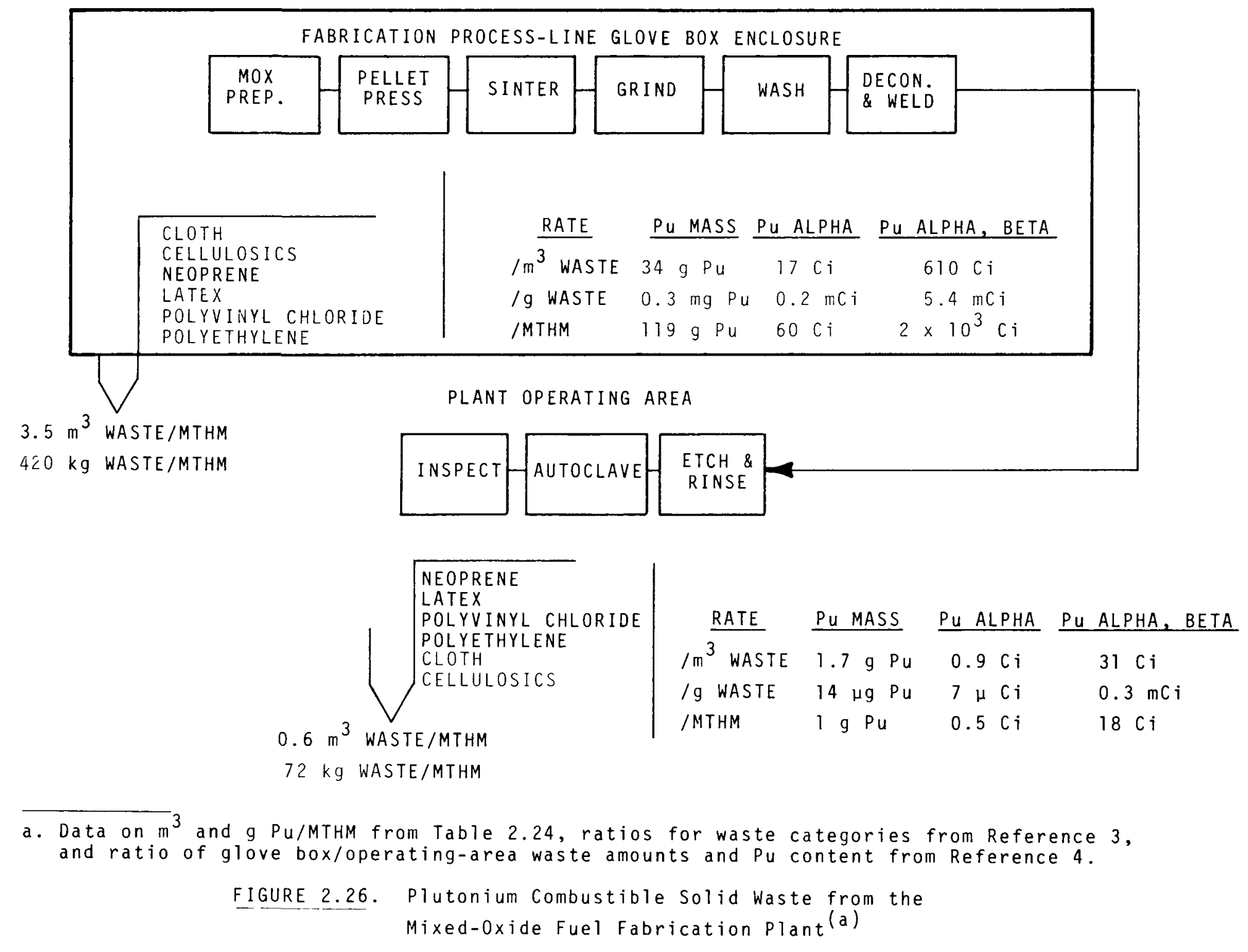


include neoprene and latex, polyvinyl chloride (PVC) and polyethylene plastics,* various types of cloth, and various types of paper (cellulosics). It has been estimated that this category of materials could have a transuranic activity of $7 \mu \mathrm{C} i$ (alpha) or $0.3 \mathrm{mC}$ (alpha, beta) per gram of waste (14 $\mu \mathrm{g} \mathrm{Pu/g}$ waste). $(3,4)$

Combustible materials that are exposed to glove box atmospheres and/or effluents comprise the second category of waste. This waste could also include neoprene, latex, PVC, polyethylene, various types of cloth, and cellulosics. The TRU content of this waste type is estimated to be $0.2 \mathrm{mC} i$ (a)pha) or $5.4 \mathrm{mCi}$ (alpha, beta) per gram of waste $(0.3 \mathrm{mg}$ Pu/g waste). $(3,4)$

It has been estimated that a 1500 MTHM-year Pu-recycle rate (450 MT of MOX, 22.4 MT of Pu) may result in the generation of $2 \times 10^{3} \mathrm{~m}^{3}\left(4 \mathrm{~m}^{3} /\right.$ MTHM) of combustible solid waste from mixed oxide fuel fabrication. $(4,6)$ on a 1000 MWe-year basis, $260 \mathrm{~m}^{3}$ of this type waste may be expected from the fabrication of 13.7 MT of MOX (30\% of 45.6 MTHM fuel). An estimated $15 \mathrm{Ci}$ (alpha) or 540 Ci (alpha, beta)/m $/ \mathrm{m}^{3}$ can be expected in TRU combustible solid wastes. ** Thus, on a 1000-MWe-year basis, $850 \mathrm{Ci}$ (alpha) or $1.7 \times 10^{3} \mathrm{~g}$ of Pu might appear with these wastes. This would represent a $0.25 \%$ plutonium loss.

\subsubsection{Transuranic Noncombustible Solid Waste}

Noncombustible wastes contaminated with transuranic elements typically also come from both plant areas (Figure 2.27). Noncombustibles that are not exposed to the glove box atmospheres or effluents are metal, glass, and mineral insulation material. $(4,5)$ It is estimated that the transuranic activity of this category of waste is in the same magnitude as the combustibie waste from this area, e.g., $1.5 \mu \mathrm{Ci}$ (alpha) or $54 \mu \mathrm{Ci}$ (alpha, beta) per gram of waste $(3 \mu \mathrm{g} \mathrm{Pu/g}$ waste). $(3,4)$

Noncombustibles that have been exposed to glove box atmospheres or effluents include metal transfer containers, metallic equipment, metal ductwork, and reject fuel-clad tubing. $(4,5)$ The estimated transuranic contamination levels approximate those for in-box combustibles, e.g., $0.1 \mathrm{mcj}$ (alpha) or $3.6 \mathrm{mCi}$ (alpha, beta) per gram of waste $(0.2 \mathrm{mg} \mathrm{Pu} / \mathrm{g}$ waste). $(3,4)$

Another noncombustible in-box waste is scrap or residual $\mathrm{PuO}_{2}$ or (U, $\mathrm{Pu})_{2}$. This material, which is likely to be recycled, could have TRU activities of $\sim 0.5 \mathrm{Ci}$ (alpha, beta)/g of the mixed oxides to $212 \mathrm{Ci}$ (alpha, beta)/g of $\mathrm{PuO}_{2},(3)$ an estimated potential of $2 \% \mathrm{Pu}$ loss. (8)

*Polyethylene and PVC plastics have been included with combustible solids despite their poor combustion characteristics. The quantities of this type waste are estimated to be $68 \mathrm{~kg} /$ MTHM of out-of-box and $950 \mathrm{~kg} /$ MTHM of in-box combustible wastes, based on a survey which showed plastics to be $20 \%$ of outof-box and $36 \%$ of in-box total solid waste. (5)

**Estimates from other reported data include: $10 \mathrm{Ci}$ (alpha)/m ${ }^{3}$ (Reference 3 ); $8 \mathrm{Ci}$ (alpha)/m (Reference 7); and $300 \mathrm{Ci} / \mathrm{m}^{3}$ (apparent Pu specific activity of $6.8 \mathrm{Ci} / \mathrm{g})($ Reference 4$)$. 


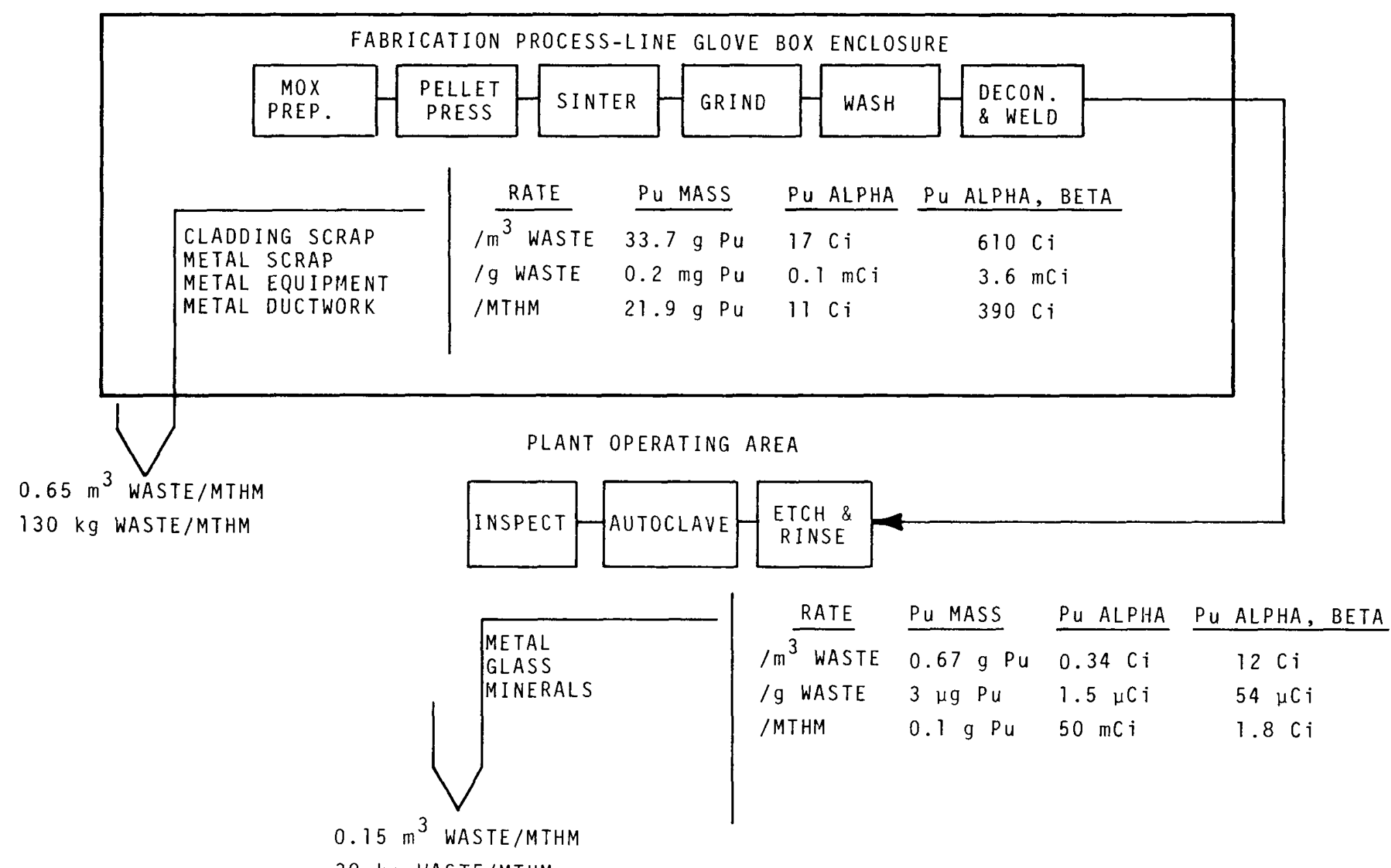

a. Data on $\mathrm{m}^{3}$ and $\mathrm{g}$ Pu/MTHM from Table 2.24, ratios for waste categories from Reference 3 , and ratio of glove box/operating-area waste amounts and Pu content from Reference 4.

FIGURE 2.27. Plutonium Noncombustible Solid Waste from the Mixed-oxide Fuel Fabrication plant (a) 
An important fraction of transuranics will be found in discarded highefficiency particulate air (HEPA) filters used in glove box ventilation systems. This noncombustible solid waste will be described separately in a subsequent section.

The estimated generation rate for noncombustible solids, excepting fuel scrap and HEPA filters, is $360 \mathrm{~m}^{3} / 1500$ MTHM-year, or $11 \mathrm{~m}^{3} / 1000$ MWe-year. For the 1000 MWe-year, the waste would be contaminated with $160 \mathrm{Ci}$ (alpha) or $2310 \mathrm{~g}$ of plutonium, representing a $0.05 \% \mathrm{Pu} 10 \mathrm{ss}$.

\subsubsection{Transuranic Liquid Waste}

Although the MOX fabrication process is essentially a dry operation, four steps do require a liquid for cleaning and decontamination. $(4,8)$ Figure 2.28 identifies these liquid streams. After finish grinding, Mox fuel pellets are washed with water. Due to the insolubility of transuranic oxides, contamination would result only from the suspension of fine particles in the wash water.

After pellets are loaded in fuel-cladding tubes, the resulting elements are subjected to decontamination (before or after final end-cap welding) and a subsequent degreasing procedure. Both the decontamination and degreasing fluids are suspect for TRU content. (1)

Prior to autoclaving, the elements are subjected to etching. Generated in this step are $\mathrm{HNO}_{3}$ - $\mathrm{HF}$ etching solutions, aluminum nitrate stop-etch solutions, and water used as a rinse, all TRU-suspect streams.

The generation rate for TRU-contaminated liquids for the 1500 MTHM Purecycle basis has been estimated to be $2.7 \times 10^{4}$ 1iters. For the 1000-MWeyear, 800 liters of liquid waste could be expected. Using an estimate of 0.4 Ci (a Tpha) or $14 \mathrm{Ci}$ (alpha, beta)/liter, TRU liquids might appear with activities of $315 \mathrm{Ci}$ (alpha) or $10^{4} \mathrm{Ci}$ (alpha, beta) per 1000 MWe-year. (3) This would amount to about $620 \mathrm{~g} \mathrm{Pu} / 7000$ MWe-year, or a plutonium loss of 0.09 .

Adding a scrap recovery system to the plant flow sheet, recycling scrap $\mathrm{PuO}_{2}$ and $(\mathrm{U}, \mathrm{Pu})_{2}$, would generate another TRU-contaminated liquid stream. (6) This liquid would appear in the form of an acidic raffinate from a solventextraction step. Extensive recycling to reduce plutonium losses is likely to be practiced.

The reference fabrication plant uses evaporation to eliminate liquid wastes. The resulting solid residue is dried and would be removed as a noncombustible TRU waste, or would be recycled to aqueous recovery and purification operations. Hence the amounts of TRU (plutonium) waste shipped from the fabrication plant will depend to some extent on the specific recycle and recovery operations practiced. 


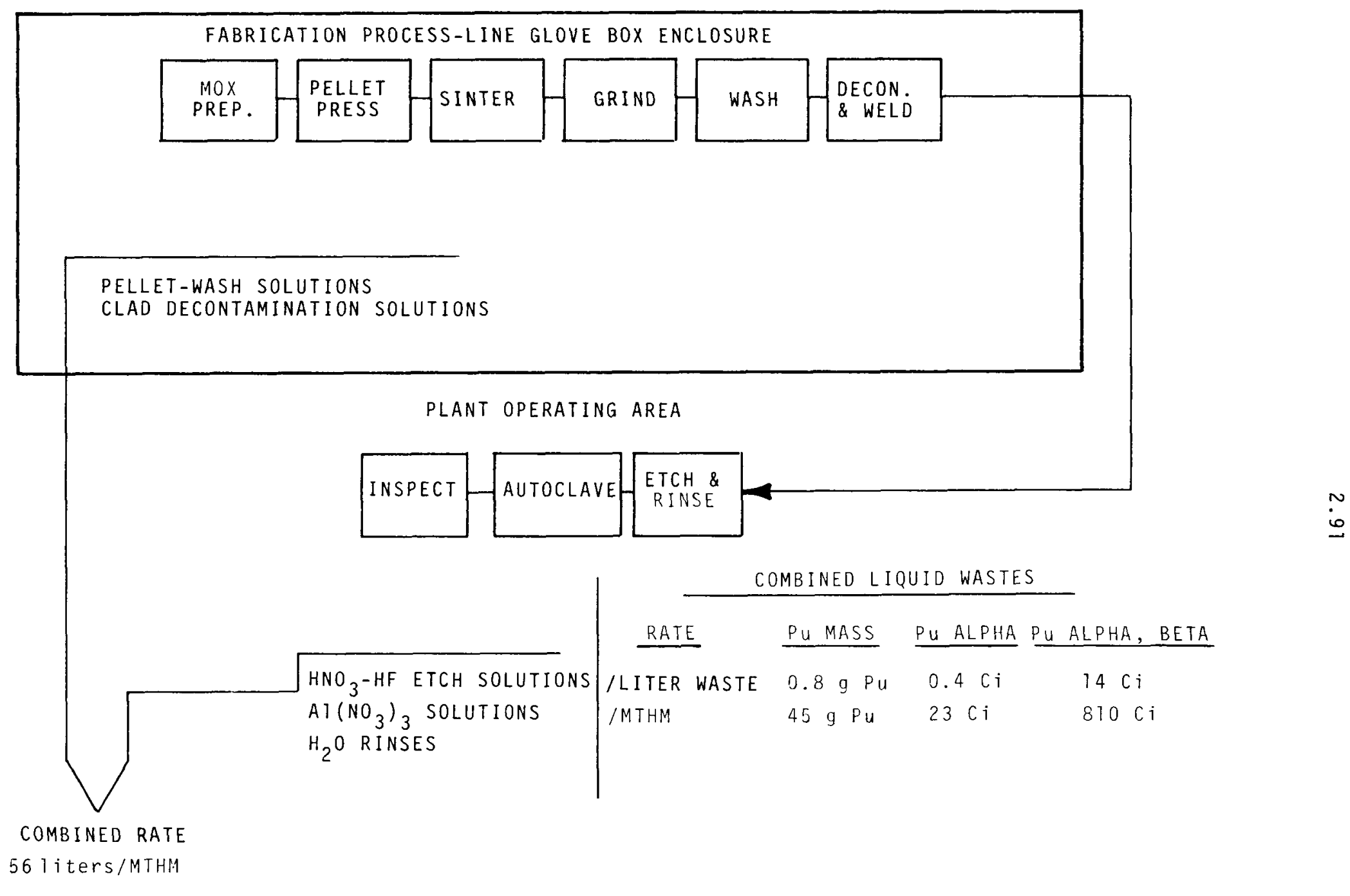

a. Based on data from Reference 3 .

FIGURE 2.28. Plutonium Liquid Waste from the Mixed-0xide Fuel Fabrication Plant (a) 


\subsubsection{HEPA Filter Waste (Figure 2.29)}

The mixed oxide fabrication processes within the glove boxes will generate particles of $\mathrm{PuO}_{2}$ and $(U, \mathrm{Pu})_{2}$ powder. A portion of these particles will become entrained in the ventilation flow. High-efficiency air (HEPA) filters are used to clean this air stream before discharge to the atmosphere. Hence filter media become contaminated with TRU material, and, when replaced, HEPA filters are a relatively high-volume solid waste at a MOX fabrication plant. Estimated data for a comparable MOX production facility set an average trans uranic concentration in spent HEPA filters at $125 \mathrm{Ci}$ (alpha) or $4.5 \times 10^{3} \mathrm{Cj}$ (a)pha, beta) $/ \mathrm{m}^{3}$. (3)

Filters in the ventilation exhausts from operational areas outside glove box enclosures also will constitute TRU-contaminated solid waste. Transuranic concentration in these HEPA filters is expected to be much less than that for glove box ventilation filters.

For the 1500 MTHM-year fabrication basis, it is estimated that HEPA filter wastes are generated at a rate of $140 \mathrm{~m}^{3} /$ year, or $4 \mathrm{~m}^{3} / 1000$ MWeyear. $(3,4)$ In this waste, transuranic contamination would amount to $9 \times 10^{3}$ Ci (alpha)/1500 MTHM-year or $260 \mathrm{Ci}$ (a1pha)/1000 MWe-year. For the 1000 MWeyear, these activities represent $520 \mathrm{~g} \mathrm{Pu}$, or a plutonium loss of $0.08 \%$. 


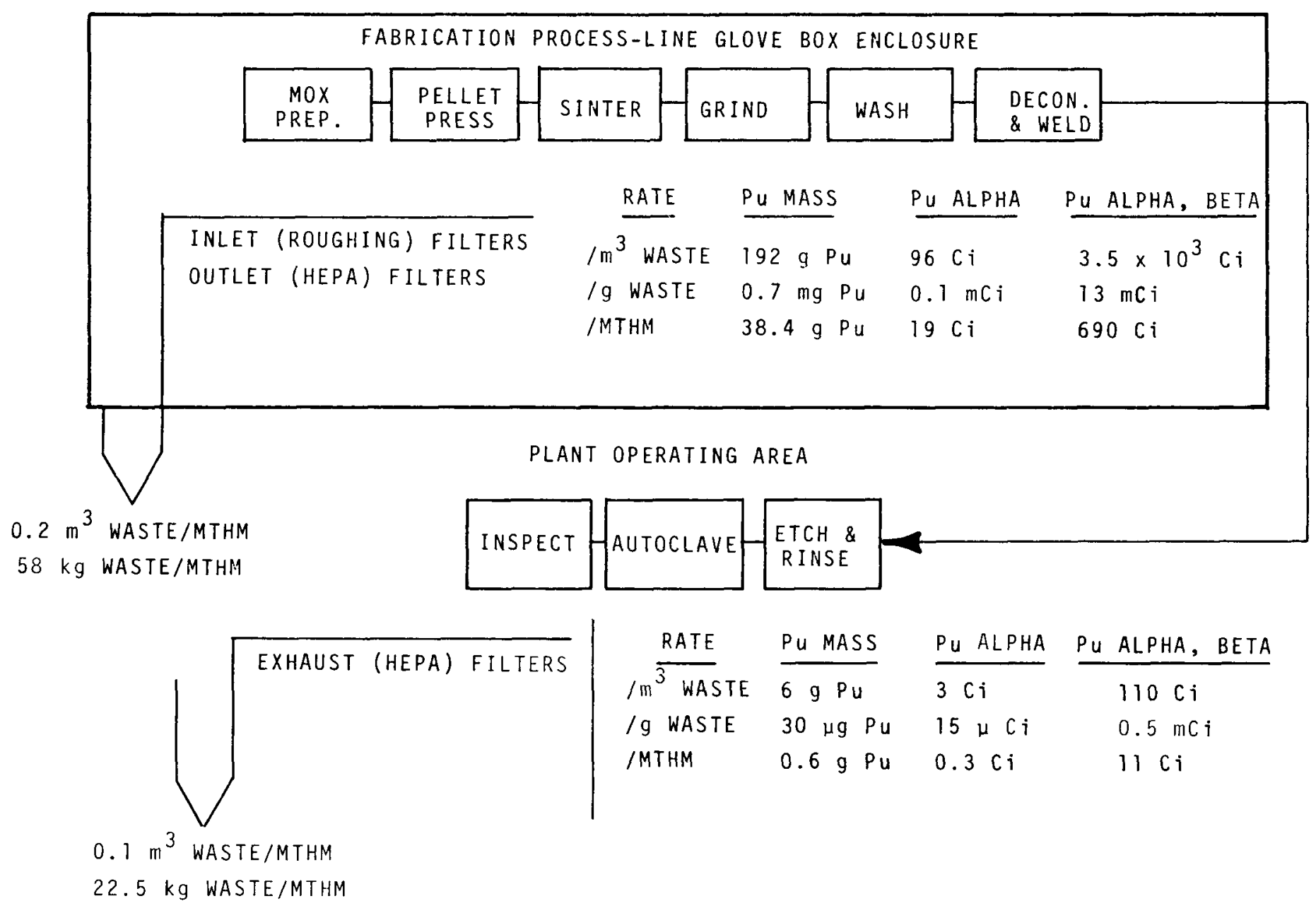

a. Data on $\mathrm{m}^{3}$ and $\mathrm{g}$ Pu/MTHM from Table 2.24, ratios for waste categories from Reference 3 , and ratio of glove box/operating-area waste amounts and Pu content from Reference 4.

FIGURE 2.29. Plutonium ventilation-filter vaste from the Mixed-oxide Fuel Fabrication Plant (a) 


\section{REFERENCES}

1 Transuranic Waste Disposal, Federal Register, Vol. 39, No. 178, pp. 32921-32923, September 12, 1974.

2. C. W. Kee, ORIGEN Code, PWR U-Equilibrium and Pu-Recycle Fuel, 25,000 MWd/ MTU Burnup, 35 MW/MTU Specific Power, 0ak Ridge National Laboratory, Private Communication, October 1975

3. C. R Cooley, Commercial Alpha Waste Program Progress Report July-December 1975, HEDL-TME 76-22, Hanford Englneering Development Laboratory, Richiand, WA, to be published March 1976.

4. DOCKET 70-1257, Final Environmental Statement-Mixed Oxide Fabrication Plant, Exxon Nuclear Company, June 1974.

5. E. B. Fowler et al., Transuranic Waste Research and Development Program, Los Alamos Scientific Laboratory, United States Atomic Energy Commission Report, LA-5281-MS, May 1973.

6. DOCKET 70-1432, Recycle Fuels Plant-License Application, Westinghouse Nuclear Fuel Division, July 1973.

7. H. H. Van Tuyi et al., A Survey of Alpha Waste Generation and Disposal as Solids in the U. S. Nuclear Fuel Industry, Battelle Pacific Northwest Laboratories, United States Atomic Energy Commission Report, BNWL-B-34, December 1970.

8. W. S. Groenier et a1., Correlation of Radioactive Waste Treatment Costs and the Environmental Impact of Waste Effluents in the Nuclear Fuel cycle for Use in Establishing "as Low as Practicable" Guides-Fabrication of Light-Water-Reactor Fuels Containing Plutonium, Dak Ridge National Laboratory, United States Atomic Energy Commission Report, ORNL-TM-4904, May 1975. 


\subsection{WASTES FROM DECOMMISSIONING OF FUEL CYCLE FACILITIES}

Materials resulting from the decontamination and decommissioning (D\&D) of fuel cycle facilities must be included in any complete waste management scheme for the fuel cycle. In addition, $D \& D$ is receiving increased attention because of its importance to arriving at a complete assessment of nuclear power economics. D\&D operations and results are detailed in Section 15 of this report. The characterization of materials emerging from decommissioning, i.e., the identity of materials, their volume, and the contamination levels associated with them, are the concern of the present section.

The commercial fuel cycle facilities expected to contribute to D\&D wastes are the fuel reprocessing plants, mixed-oxide fuel fabrication plants, reactors, fuel storage basins, and facilities for interim storage of transuranium wastes. Although experience obtained in the D\&D of first-generation reactors (1) and a number of contaminated ERDA facilities (1) indicates that generic techniques are available, experience on D\&D of facilities representative of the commercial fuel cycle is not available. The recent conference on $D \& D(1)$ summarized present experience.

Three modes of decommissioning are presently considered rather generally by the nuclear industry, although a consistent nomenclature is apparently not in common use. These three modes are described in section 15 of this report. The choice of mode and decontamination operations might be made on the basis of such factors as the type of facility, the type and level of contamination, location of the facility, and the cost/risk ratio of applying the alternative modes to the particular facility. All modes involve decontamination by treatment with liquids to remove radioactivity from surfaces, with the resultant generation of contaminated liquids requiring additional waste treatment (e.g., volume reduction) operations. The mode that most requires planning for subsequent waste management, i.e., dismantiing, is the one that involves shipping of residual materials to storage.

Since experience in D\&D of modern commercial fuel cycle facilities is not available, conceptual studies of decommissioning of reference plants are the only bases at present for discussion of materials type, volume, and associated contamination levels. Several such conceptual studies are in progress, and the results are expected to be published in 1976. One study of the D\&D of LWRs is expected to be published soon; (2) the only prepublication data available are presented in preliminary form in Table 2.25. An independent study of the decommissioning of LWRs is also expected to be initiated soon. (3) Some factors involved in the decommissioning of facilities for interim storage of transuranium wastes are discussed in section 20 of this report, but quantitative estimates are not available at this time. A 
TABLE 2.25. Volumes and Contamination Categories of Residues from Decommissioning of Light Water Reactors $(a, b)$ volume $\left(\mathrm{m}^{3}\right)(\mathrm{c})$

\begin{tabular}{ccc}
$\begin{array}{c}\text { Reactor } \\
\text { Type }\end{array}$ & $\begin{array}{c}\text { Non- } \\
\text { radioactive } \\
\text { Materials }\end{array}$ & $\begin{array}{c}\text { Radioactive } \\
\text { Materials }\end{array}$ \\
\cline { 2 - 2 } & 36,700 & 23,900 \\
PWR & 29,800 & 7,000
\end{tabular}

\footnotetext{
a. 1000 MWe capacity.

b. Reference 2, data to be published in a study of decommissioning by the Atomic Industrial Forum.

c. Includes plant components, building materials, and a relatively small contribution from decommissioning wastes probably in the form of evaporator bottoms.
}

discussion of the criteria for decommissioning of a mixed oxide facility has been presented, (4) and the decommissioning of a fuel reprocessing plant has been discussed in terms of standards. $(5,6)$ Results of a conceptual study of the decommissioning of a mixed oxide fuel fabrication plant and a fuel reprocessing plant are also expected to be avajlable in 1976; (3) prepublication results are summarized in Table 2.26 and Table 2.27 .

In summary, the waste materials emerging from D\&D operations are expected to fall into the general categories of metallic process components, building materials, and decontamination solutions or the residues from volume reduction operations on the solutions. Although few quantitative results are presently available, the area of $D \& D$ is beginning to receive attention, and additional quantitative estimates are expected soon. 
TABLE 2.26. Contaminated Waste from Dismantling a 1500 MTU/year Fuel Reprocessing Facility (a)

Process Building and Waste Tank Galleries

Equipment

Volume $\left(\mathrm{m}^{3}\right)$

Weight (MT)

Avg fission product

contamination $\left(\mathrm{C} i / \mathrm{m}^{3}\right)$

$\%>10 \mathrm{nCi} / \mathrm{g} \mathrm{TRU}(\mathrm{b})$

Stainless steel liners

Volume $\left(\mathrm{m}^{3}\right)$

Weight (MT)

Avg fission product

contamination $\left(\mathrm{C} i / \mathrm{m}^{3}\right)$

$\%>10 \mathrm{nCi} / \mathrm{g} \mathrm{TRU}(\mathrm{b})$

Concrete

Volume $\left(\mathrm{m}^{3}\right)$

Weight (MT)

Avg fission product

contamination $\left(\mathrm{C} i / \mathrm{m}^{3}\right)$

$\%>10 \mathrm{nCi} / \mathrm{g} \mathrm{TRU}(\mathrm{b})$

Total shipping volume
Liquid Waste Storage Tanks

$\begin{array}{cc}2,000 & 1100 \\ 1,600 & 910 \\ 0.04 & 1.4 \\ 20 & 0 \\ 31 & 130 \\ 245 & 1000 \\ 3 & 3.2 \\ 7 & 0 \\ 594 & \\ 1,400 & -- \\ 14 & -- \\ 43 & \\ 6,510 \mathrm{~m}^{3} ;, 090 \mathrm{~m}^{3}=>10 \mathrm{nCi} / \mathrm{g} & \mathrm{TRU}\end{array}$

a. Reference 3 .

b. Nanocuries per gram of transuranic waste, essentially plutonium.

TABLE 2.27. Contaminated Waste from Dismantiing a 300 MTHM/year Mixed-Oxide Fabrication Facility (a)

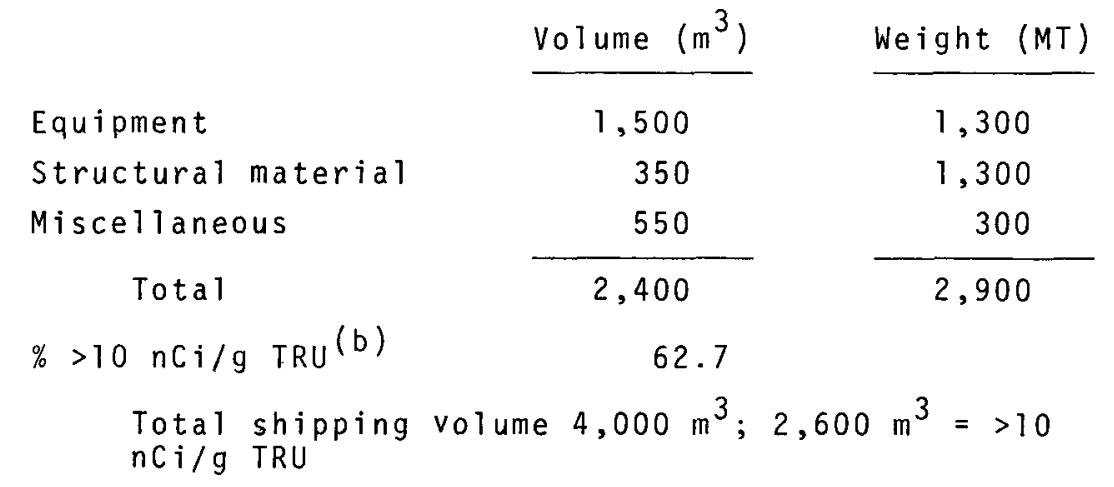

a. Reference 3 .

b. Transuranic waste-essentially plutonium. 


\section{REFERENCES}

1. U. S. Energy Research and Development Administration and Aerojet Nuclear Company Waste Management Program Division, Proceedings of the Conference on Decontamination and Decommissioning (D\&D) of ERDA Facilities, CONF750827 , September 1975.

2. Personal Communication, November 1975, from J. Davis, Atomic Industrial Forum to L. Trevorrow, Argonne National Laboratory.

3. Personal Communication, November 1975, from L. D. Williams and C. E. Jenkins, Battelle Northwest Laboratories to L. Trevorrow, Argonne National Laboratory.

4. D. A. Waite and C. E. Jenkins, "Development of Disposition Criteria Derivation Methodology for Commercial Fuel Cycle Facilities, " in Proceedings of the First Conference on Decontamination and Decommissioning (D\&D) of ERDA Facilities, CONF-750827, p. 47, September 1975.

5. R. B. Chitwood, "Decontamination and Decommissioning of Licensed Fuel Reprocessing Plants," in Proceedings of the First Conference on Decontamination and Decommissioning of ERDA Facilities, CONF-750827, p. 59, September 1975 .

6. H. B. Graham, "Status of ANSI Standards on Decommissioning of Nuclear Reprocessing Facilities," in Proceedings of the First Conference on Decontamination and Decommissioning of ERDA Facilities, CONF-750827, p. 23, September 1975. 
3.0 PROJECTIONS OF LWR FUEL CYCLE QUANTITIES 
-

- 


\subsection{PROJECTIONS OF LWR FUEL CYCLE QUANTITIES}

\subsection{BASIC ASSUMPTIONS}

Projections of waste quantities and associated management activities for the LWR fuel cycle are presented here to indicate the future requirements for waste management facilities and services to be provided by Federal and commercial organizations.

Quantities of, characteristics of, and management requirements for wastes from the LWR fuel cycle will depend on total energy production and growth, the penetration of total energy production by electrical energy, and the fraction of electrical energy produced by light water reactors. The United States Energy Research and Development Administration Office of Planning and Analysis periodically prepares forecasts, based on extrapolation of recent trends in operation, construction, and planning of nuclear power plants, in the form of sets of probable conditions or reference cases. (1) Uncertainties and trends in the demand for power in general and in the conditions affecting nuclear power growth in particular have recently necessitated frequent revision of projections. Thus the projections presented here differ somewhat from those in a detailed study issued in 1974. (2) Moreover, the most probable reference case has been revised from a moderately high growth case in early 1975 to a moderately low growth case in late 1975. This latter case is the basis for projections presented here.

\subsubsection{Total Electric and Nuclear Capacities}

The power-growth case used here assumes a moderately low growth of electrical energy, the delay of spent fuel reprocessing until late calendar year 1978, and the delay of plutonium recycle until calendar year 1981. The kilowatt-hour production in this case grows at $6.0 \%$ per annum through 1985 and then declines to a $5.4 \%$ per annum growth through the year 2000 . Table 3.1 lists projections of total electrical generating capacity and total installed nuclear capacity by year.

\subsubsection{Bases for Projections of Electric Operating Capacity, Materials Flows, and Waste Generation Involving LWRS}

Projections of parameters have been selected to characterize the LWR fuel cycle in the period 1975 through 2000. The assumptions upon which these projections are based are collected in this section. Tables of projections are presented in Section 3.2. These parameters include LWR operating capacity (Table 3.2), the flow and accumulation of primary wastes, and the flow of various other materials necessary to the operation of a complete LWR fuel cycle. 
TABLE 3.1. Characteristics of the Mod-Low Energy Growth Case

\begin{tabular}{ccc} 
Year & $\begin{array}{c}\text { Total Electric } \\
\text { Generating Capacity, } \\
\text { GWe }\end{array}$ & $\begin{array}{c}\text { Total Installed } \\
\text { Nuclear Capacity, (a) } \\
\text { GWe }\end{array}$ \\
\hline 1973 & 436 & 18.4 \\
1980 & 620 & 76.0 \\
1985 & 800 & 185.0 \\
1990 & 1040 & 340.0 \\
2000 & 1750 & 800.0
\end{tabular}

a. Includes all types of reactors. See Table 3.2 for projections of operating capacity for LWRS only.

Assumptions basic to the projections have been previousiy described, (2) and are briefly summarized here. The ratio of PWRs to BWRs $=2: 1$. Plant factors are $40 \%$ during the pre-operational period between fuel loading and commercial operation, $65 \%$ during the first two years of commercial operation, $70 \%$ for years 3 through 15 , and following the 15 th year, deciline at 2 percentage points per year to a minimum of $40 \%$. Uranium is recycled as soon as material can be returned through normal fuel cycle timing. plutonium is recycled beginning with $25 \%$ of the reactors in $1981,50 \%$ of reactors in 1982 , $75 \%$ of reactors in 1983 , and without constraint in following years except that sufficient plutonium is withheld for use in FBRs.

The burnup of fuel at discharge determines several factors of importance to waste management, including the composition, thermal power, and gamma power of high-level waste. Average burnup at discharge and power level during irradiation will differ slightly for BWRs and PWRs and will increase somewhat during the period 1975 to 2000. Much of the planning for an LWR fuel cycle has been done on the basis of a fuel burnup of 33,000 MWd/MTHM. This burnup level is expected to be characteristic of future LWR fuel, but the average burnup will be lower for fuel discharged to the present, now in storage, and slated for processing between 1975 and 2000. With this expectation, data on isotopic composition, thermal power, and gamma power associated with highlevel waste and with cladding hulls presented in Sections 2.3 and 2.4 are based on a burnup of 25,000 MWd/MTHM and a specific power of 35 MW/MTHM. Calculations of projections, however, are presently available only for a burnup of 33,000 MWd/MTHM, and these numbers are the basis for the projections presented in Section 3.2. Since higher burnup will increase the amounts of longer-lived radioisotopes to be found in waste, these projections will be conservative in that estimates of activities associated with the wastes will tend to be high. 
Plutonium recycle in the PWR assumes self-sustaining recycle that uses a mixture of assemblies containing either enriched uranium (PWR-U) or plutonium mixed with natural uranium (PWR-PU). These assemblies are assumed to be shipped and reprocessed together, such that the plutonium product, and wastes, will be blended. At steady state: 1) 1.2 atoms of fissile plutonium replace 1.00 atom of $235 \mathrm{U}$ in the plutonium-fueled assemblies; 2 ) $32.4 \%$ of the assemblies in the reactor are fueled with plutonium; and 3 ) the plutonium used in the plutonium-fueled assemblies has an initial fissile content of $61.3 \%$ and a fissile content at discharge of $55.4 \%$. The plutonium produced in the enriched uranium elements $(70.64 \%$ fissile) is blended with the product of the plutonium elements $(55.4 \%$ fissile) to prepare the plutonium for the next refueling ( $61.3 \%$ fissile). LWR fuel is assumed to be reprocessed after a postirradiation decay time of 150 days.

The accumulations of ore tailings from milling uranium ores (Table 3.3 ) are based on the assumption that $95 \%$ of the uranium is extracted from ores that assay $0.2 \%$ uranium, and that the unrecovered $5 \%$ and al 1 radioactive daughters remain with the tailings. The volume of tailings is estimated on the basis of $0.264 \mathrm{~m}^{3}$ being formed per kilogram of recovered $\mathrm{U}_{3} 0_{8}$. The requirements for mining of uranium are based upon a tails assay in uranium enrichment of $0.2 \%{ }^{235} \mathrm{U}$ and al lows for the recycle for reenrichment of uranium that contains greater than $0.4 \% 235 U$.

The annual production of fissile materials (Table 3.4 ) is defined as the annual quantity stockpiled following reprocessing. The quantities in the columns labeled "used" are the annual quantities withdrawn from this stockpile.

The projected annual loads of fuel fabrication plants (Table 3.5) includes total heavy metal. The shipment load for plutonium recycle in light water reactors (Tables $3.6,3.7$ ), on the other hand, includes only those portions of the fuel assemblies that are fueled with mixed oxide.

The projected fuel reprocessing schedule (Tables 3.8-3.10) differs slightly from the moderately-low growth case in that reprocessing begins on a small scale in 1977 rather than in 1978.

High-level wastes (Tables 3.11-3.13) are those aqueous raffinates resulting from the operation of the first cycle solvent extraction system, or equivalent, and the concentrated wastes from subsequent extraction cycles, in a facility for reprocessing irradiated reactor fuels. These wastes contain virtually all of the nonvolatile fission products, several tenths wt $\%$ of uranium and plutonium originally in the spent fuels, and all the other actinides formed by transmutation of the uranium and plutonium in the reactors. Present regulations call for these wastes to be solidified within 5 years after they are generated and for the resultant stable solids to be shipped to a federal repository within 10 years after the liquids are generated. (3) 
In the characterization of these wastes, reprocessing flow sheets were assumed that minimized, wherever possible, additions of chemicals which might be particularly troublesome in subsequent waste management operations, specifically, sodium and sulfate ions. Product losses are taken as 0.05 wt\% of the Pu to the LWR cladding; 0.1 wt\% of the $P u$ and $U$ to the aqueous raffinates; * and $0.01 \mathrm{wt} \%$ of the $P U$ and $U$ to the solvent during stripping (which ultimately appears in the solvent regenerants).

The actual volumes of high-level waste will depend on many factors that must be resolved through actual operating experience. Although waste management economics will tend to force the final volumes toward smaller values, additional wastes arising from maloperations, equipment decontamination, etc., will tend to increase them. Similarly, possible future requirements for higher quality waste products (less leachable in water, more radiationresistant) may also result in higher volumes of waste per ton of fuel processed. In view of these possibilities, an upper limit volume for solidified high-level waste of $0.06 \mathrm{~m}^{3}$ per MTHM processed (based on waste in the form of oxides with minor additions of $\mathrm{NaOH}$ or $\mathrm{B}_{2} \mathrm{O}_{3}$ to prevent volatilizing of some components) is used in calculating volumes of solidified high-level waste.

Although solidification of commercial high-level waste has not as yet been practiced, packaging concepts include the use of steel canisters $20.3 \mathrm{~m}$ in diam by $23 \mathrm{~m}$ long. As many as 12 such canisters (each containing $0.2 \mathrm{~m}^{3}$ of 10-year-old solidified waste) could be shipped by rail in a single iron- or lead-shielded cask. $(4,5)$

Projections on cladding wastes (Table 3.14) are based on volumes of the residual Zircaloy and stainless steel cladding and structural components of the fuel assemblies that remain after the fuel cores have been dissolved. Many of the assumptions used to construct projections are based on an earlier study of cladding wastes. (6) In addition to neutron-induced isotopes, their main source of radioactivity, the cladding is assumed to contain 0.05 wt\% of the actinides and $0.05 \mathrm{wt} \%$ of the fission products originally in the spent fuel. Although cladding may be compacted for storage, the volumes are presented here on an uncompacted basis.

Shipments and accumulations of fission product tritium (Table 3.15 ), 1 year after its separation from spent fuel at reprocessing plants, are based on the assumptions that this tritium is recovered in water at a concentration of $200 \mathrm{Ci} / 1$ iter and is then immobilized as $\mathrm{Ca}(\mathrm{OH})_{2}$, which is shipped, probably by motor freight, to a repository for long-term storage. Most of the fission product tritium contained in spent fuel will accumulate in the low-level

*This level of residual contamination is adequate for projections, similar to the 33,000 MWd/MT burnup. Calculations for Section 2.4 assumed 0.5 wt\% $U$ and 0.5 wt\% Pu in high-level waste. 
aqueous waste of the fuel reprocessing plant (Table 2.10). Within present regulations, this tritium can be released to the environment by discharging the low-level waste to surface streams, depending on site characteristics, or by vaporizing it into the atmosphere. However, in the future, the separation of tritium from spent fuel may be required, either before fuel dissolution or from low-level aqueous waste after the normal sequence of Purex operations. The necessity and feasibility of separating and storing tritium is currently being debated. Although a number of separation schemes have been examined, and some have received some development work, technology for collection is not ready for commercial application. The projected accumulations of fissionproduct tritium presented here, therefore, illustrate a set of possible options rather than current practice.

Projections on the accumulation of fission product iodine (Table 3.16) are based on the assumption that $99.9 \%$ of the iodine is recovered at the reprocessing plants, converted to $K I$, also as an example rather than an indication of most probable practice, and stored for 1 year before shipment to a repository or to a disposal site.

Current regulations permit the release of noble gases at the fuel reprocessing plant, but a requirement that noble gases be collected in the future and stored is currently being debated. The basic collection technology is available, but the feasibility of quantitative collection and storage, on the scale expected for commercial fuel reprocessing, has not been demonstrated. Therefore, the projections presented here (Table 3.17) are only an illustration of the option of collecting and storing the noble-gas fission products. For the projected accumulation of noble-gas fission products, it is assumed that the mixed krypton and xenon isotopes are packaged in standard 50-1iter gas cylinders at a pressure of $156 \mathrm{~kg} / \mathrm{cm}^{2}$, stored for 7 year at the reprocessing plant, and then shipped by rail to a repository for long-term storage. An individual shipment is assumed to consist of six gas cylinders.

Carbon-14 is produced in LWR fuel by the action of neutrons on ${ }^{14} \mathrm{~N}$, a constituent of the nitrogen impurity in the oxide fuel. The projections 1 isted in Table 3.18 are based on the assumption that a nitrogen impurity of $25 \mathrm{ppm}$ is present in oxide fuels. As in the cases of tritium and noble gases, the questions of necessity and feasibility of collecting and storing ${ }^{14} \mathrm{C}$ released from spent fuel at the reprocessing plant have not been resolved. The projections of accumulated ${ }^{14} \mathrm{C}$, therefore, represent only the results of a possible option in its management.

Projections of beta-gamma solid wastes are based on the generation of 1100,2300 , and $450 \mathrm{~m}^{3}$ per metric ton of plutonium processed at fuel preparation, fabrication, and reprocessing plants, respectively. In addition, the accumulations include $113 \mathrm{~m}^{3} /$ year of waste from each installed 1000-MW LWR. 
For the projections of Table 3.19, no allowance is made for their volume reduction by compaction or other methods. The volumes are the sums of combustible and noncombustible wastes.

Table 3.20 presents projections of plutonium alpha (TRU, low $\beta-\gamma$ ) wastes assuming they are shipped and accumulated at a repository 1 year following their generation. Volumes are based on the generation of $283,566, a n d 113 \mathrm{~m}^{3}$ of waste per ton of plutonium processed in fuel preparation, fabrication, and reprocessing plants, respectively. The average concentration of plutonium (1\% ${ }^{238} \mathrm{Pu}, 59 \%{ }^{239} \mathrm{Pu}, 24 \%{ }^{240} \mathrm{Pu}, 12 \%{ }^{241} \mathrm{Pu}, 4 \%{ }^{242} \mathrm{Pu}$ ) in the wastes is taken as $9 \mathrm{~g} / \mathrm{m}^{3}$ before treatment for volume reduction. The volumes 1 isted are the sums of combustible and noncombustible wastes.

Accumulations of alpha-beta-gamma (TRU, intermediate-1evel $\beta-\gamma$ ) solid wastes (Table 3.21) were constructed on the basis of $283 \mathrm{~m}^{3}$ of such waste being generated per metric ton of plutonium recovered from spent fuels at reprocessing plants and $i t$ is also assumed that $0.025 \%$ of the fission products in the spent fuels is present. The volumes listed are the sums of combustible and noncombustible wastes.

\subsection{PROJECTIONS}

The projections are presented in Tables 3.2 through 3.21 as annual amounts and also, for some factors, as accumulated amounts for succeeding years from 1975 through 2000. Tabulations for some factors cover a period later than 1975-2000 because of the delayed initiation of the operation from which they are derived, e.g., fuel reprocessing, plutonium recycle, and highlevel waste solidification.

TABLE 3.2. Projected Nuclear LWR Operating Capacity (a)

\begin{tabular}{lr} 
Year & GWe \\
\cline { 2 - 2 } 1975 & 38.0 \\
1976 & 44.3 \\
1977 & 51.3 \\
1978 & 58.4 \\
1979 & 65.5 \\
1980 & 75.5 \\
1981 & 92.3 \\
1982 & 112.7 \\
1983 & 133.9 \\
1984 & 157.4 \\
1985 & 179.4 \\
1986 & 202.0 \\
1987 & 225.6 \\
1988 & 254.0 \\
1989 & 284.0 \\
1990 & 315.6 \\
1991 & 348.7 \\
1992 & 382.7 \\
1993 & 416.6 \\
1994 & 450.7 \\
1995 & 483.9 \\
1996 & 516.2 \\
1997 & 547.6 \\
1998 & 579.1 \\
1999 & 609.7 \\
2000 & 638.6
\end{tabular}

a. Reference 7 , based on as sumptions summarized in section 3.1.2. 
TABLE 3.3. Projected Accumulation of Uranium Ore Tailings (a)

\begin{tabular}{|c|c|c|c|c|c|c|c|c|}
\hline \multirow[b]{2}{*}{ Year } & \multicolumn{4}{|c|}{ Annual Addition } & \multicolumn{4}{|c|}{ Accumulation Through End of Year } \\
\hline & $\begin{array}{c}\text { Volume } \\
\text { (Millions } \\
\text { of } \mathrm{m}^{3} \text { ) }\end{array}$ & $\begin{array}{c}\text { Heavy } \\
\text { Element } \\
\text { (MT) }\end{array}$ & $\begin{array}{c}\text { Radio- } \\
\text { activity } \\
(M C i)\end{array}$ & $\begin{array}{c}\text { Therma } 1 \\
\text { Power } \\
(\mathrm{kW})\end{array}$ & $\begin{array}{c}\text { Volume } \\
\text { (Billions } \\
\left.\text { of } \mathrm{m}^{3}\right)\end{array}$ & $\begin{array}{l}\text { Heavy } \\
\text { Element } \\
\text { (MT) }\end{array}$ & $\begin{array}{c}\text { Radio- } \\
\text { activity } \\
\text { (MCi) }\end{array}$ & $\begin{array}{c}\text { Thermal } \\
\text { Power } \\
(k w)\end{array}$ \\
\hline $\begin{array}{l}1975 \\
1976 \\
1977 \\
1978 \\
1979 \\
1980 \\
1981 \\
1982 \\
1983 \\
1984 \\
1985 \\
1986 \\
1987 \\
1988 \\
1989 \\
1990 \\
1991 \\
1992 \\
1993 \\
1994 \\
1995 \\
1996 \\
1997 \\
1998 \\
1999 \\
2000\end{array}$ & $\begin{array}{r}2.77 \\
3.15 \\
3.50 \\
3.77 \\
4.54 \\
5.77 \\
6.78 \\
7.88 \\
9.20 \\
9.77 \\
10.78 \\
11.72 \\
13.36 \\
14.58 \\
16.03 \\
17.51 \\
18.87 \\
20.14 \\
21.63 \\
23.06 \\
24.39 \\
25.81 \\
27.36 \\
28.46 \\
29.84 \\
30.86\end{array}$ & $\begin{array}{l}448 \\
510 \\
566 \\
609 \\
734 \\
933 \\
1096 \\
1274 \\
1487 \\
1579 \\
1743 \\
1895 \\
2160 \\
2357 \\
2590 \\
2830 \\
3050 \\
3255 \\
3495 \\
3726 \\
3943 \\
4171 \\
4422 \\
4600 \\
4823 \\
4987\end{array}$ & $\begin{array}{l}0.03 \\
0.04 \\
0.04 \\
0.04 \\
0.05 \\
0.07 \\
0.08 \\
0.09 \\
0.17 \\
0.11 \\
0.13 \\
0.14 \\
0.16 \\
0.17 \\
0.19 \\
0.20 \\
0.22 \\
0.24 \\
0.25 \\
0.27 \\
0.28 \\
0.30 \\
0.32 \\
0.33 \\
0.35 \\
0.36\end{array}$ & $\begin{array}{l}0.71 \\
0.80 \\
0.89 \\
0.96 \\
1.16 \\
1.47 \\
1.73 \\
2.01 \\
2.34 \\
2.49 \\
2.75 \\
2.99 \\
3.41 \\
3.72 \\
4.08 \\
4.46 \\
4.81 \\
5.13 \\
5.51 \\
5.88 \\
6.22 \\
6.58 \\
6.97 \\
7.25 \\
7.60 \\
7.86\end{array}$ & $\begin{array}{l}0.012 \\
0.015 \\
0.018 \\
0.022 \\
0.027 \\
0.032 \\
0.039 \\
0.047 \\
0.056 \\
0.066 \\
0.077 \\
0.089 \\
0.102 \\
0.117 \\
0.133 \\
0.150 \\
0.169 \\
0.189 \\
0.211 \\
0.234 \\
0.258 \\
0.284 \\
0.311 \\
0.340 \\
0.370 \\
0.400\end{array}$ & $\begin{array}{l}1893 \\
2403 \\
2969 \\
3578 \\
4312 \\
5246 \\
6341 \\
7616 \\
9102 \\
10681 \\
12424 \\
14319 \\
16479 \\
18836 \\
21426 \\
24256 \\
27306 \\
30561 \\
34056 \\
37782 \\
41725 \\
45896 \\
50318 \\
54918 \\
59740 \\
64727\end{array}$ & $\begin{array}{l}0.1 \\
0.2 \\
0.2 \\
0.3 \\
0.3 \\
0.4 \\
0.4 \\
0.5 \\
0.6 \\
0.8 \\
0.9 \\
1.0 \\
1.2 \\
1.3 \\
1.5 \\
1.7 \\
1.9 \\
2.1 \\
2.4 \\
2.7 \\
2.9 \\
3.2 \\
3.5 \\
3.9 \\
4.2 \\
4.5\end{array}$ & $\begin{array}{r}2.9 \\
3.7 \\
4.6 \\
5.6 \\
6.7 \\
8.2 \\
9.9 \\
11.8 \\
14.1 \\
16.6 \\
19.3 \\
22.2 \\
25.6 \\
29.3 \\
33.3 \\
37.7 \\
42.4 \\
47.5 \\
52.9 \\
58.7 \\
64.8 \\
71.2 \\
78.1 \\
85.2 \\
92.7 \\
100.4\end{array}$ \\
\hline
\end{tabular}

a. Reference 7 , based on assumptions summarized in Section 3.1 .2 . 
TABLE 3.4. Materials Consumed, Produced, and Stockpiled for LWR Power (metric tons) (a)

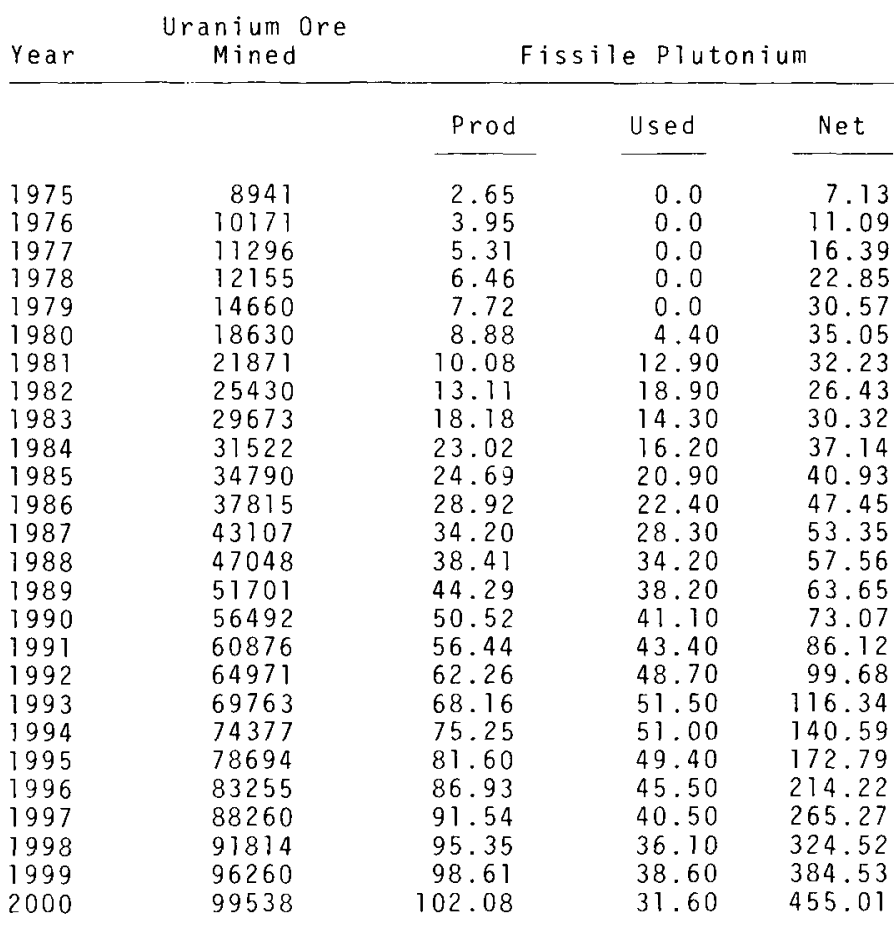

a. Reference 7, based on assumptions summarized in Section 3.1.2.

TABLE 3.5. LWR Fue 1 Fabricated (metric tons) (a)

\begin{tabular}{lrrr} 
Year & LWR-U & LWR-PU & \multicolumn{1}{c}{ Total } \\
1975 & \multicolumn{1}{c}{1278.9} & 0.0 & 1278.9 \\
1976 & 1471.8 & 0.0 & 1471.8 \\
1977 & 1683.9 & 0.0 & 1683.9 \\
1978 & 1864.2 & 0.0 & 1864.2 \\
1979 & 2176.5 & 0.0 & 2176.5 \\
1980 & 2648.6 & 144.1 & 2792.7 \\
1981 & 3073.4 & 422.3 & 3495.7 \\
1982 & 3442.9 & 618.8 & 4061.7 \\
1983 & 4221.0 & 468.2 & 4689.2 \\
1984 & 4709.4 & 530.4 & 5239.8 \\
1985 & 5091.4 & 684.3 & 5775.7 \\
1986 & 5678.5 & 733.4 & 6411.9 \\
1987 & 6370.9 & 926.5 & 7237.4 \\
1988 & 7005.1 & 1119.7 & 8124.8 \\
1989 & 7657.5 & 1250.7 & 8908.2 \\
1990 & 8488.6 & 1345.6 & 9834.2 \\
1991 & 9255.4 & 1420.9 & 10676.3 \\
1992 & 9883.4 & 1594.4 & 11477.8 \\
1993 & 10700.7 & 1686.1 & 12386.8 \\
1994 & 11513.7 & 1669.7 & 13183.4 \\
1995 & 12282.8 & 1617.4 & 13900.2 \\
1996 & 13205.6 & 1489.7 & 14695.3 \\
1997 & 14083.0 & 1326.0 & 15409.0 \\
1998 & 14963.8 & 1181.9 & 16145.7 \\
1999 & 15569.1 & 1263.8 & 16832.9 \\
2000 & 16411.4 & 1034.6 & 17446.0
\end{tabular}

a. Reference 7 , based on assumptions summarized in section 3.1.2. 
TABLE 3.6. Shipments of Plutonium by Truck

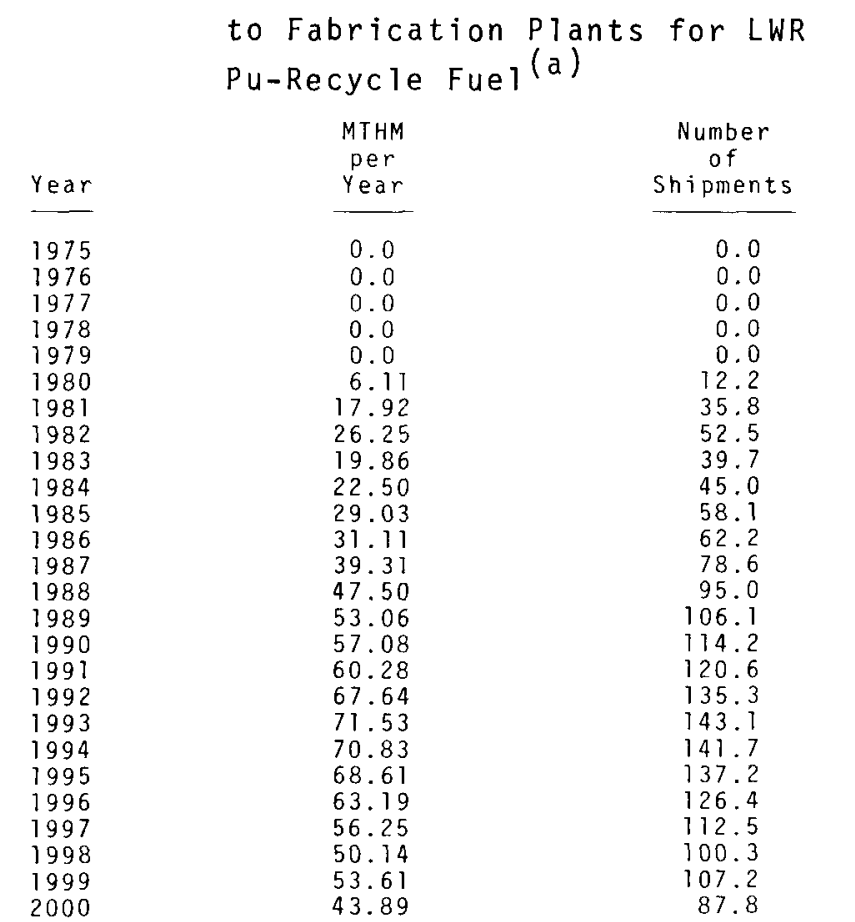

a. Reference 7 , based on assumptions summarized in section 3.1.2.

TABLE 3.7. Fresh Fuel Shipments by Truck to LWRs (a)

\begin{tabular}{|c|c|c|c|c|c|c|}
\hline \multirow[b]{2}{*}{ Year } & \multicolumn{2}{|c|}{ LWR-U } & \multicolumn{2}{|c|}{ LWR-PU } & \multicolumn{2}{|c|}{ Total } \\
\hline & $\begin{array}{c}\text { MTHM per } \\
\text { Year }\end{array}$ & $\begin{array}{l}\text { Number of } \\
\text { Shipments }\end{array}$ & $\begin{array}{c}\text { MTHM per } \\
\text { Year }\end{array}$ & $\begin{array}{l}\text { Number of } \\
\text { Shipments }\end{array}$ & $\begin{array}{c}\text { MTHM per } \\
\text { Year }\end{array}$ & $\begin{array}{l}\text { Number of } \\
\text { Shipments }\end{array}$ \\
\hline 1975 & 1279 & 233 & 0 & 0 & 1279 & 233 \\
\hline 1976 & 1472 & 268 & 0 & 0 & 1472 & 268 \\
\hline 1977 & 1684 & 306 & 0 & 0 & 1684 & 306 \\
\hline 1978 & 1864 & 339 & 0 & 0 & 1864 & 339 \\
\hline 1979 & 2177 & 396 & 0 & 0 & 2177 & 396 \\
\hline 1980 & 2649 & 482 & 144 & 26 & 2793 & 508 \\
\hline 1981 & 3073 & 559 & 422 & 77 & 3496 & 636 \\
\hline 1982 & 3443 & 626 & 619 & 113 & 4062 & 738 \\
\hline 1983 & 4221 & 767 & 468 & 85 & 4689 & 853 \\
\hline 1984 & 4709 & 856 & 530 & 96 & 5240 & 953 \\
\hline 1985 & 5091 & 926 & 684 & 124 & 5776 & 1050 \\
\hline 1986 & 5679 & 1032 & 733 & 133 & 6412 & 1166 \\
\hline 1987 & 6311 & 1147 & 927 & 168 & 7237 & 1316 \\
\hline 1988 & 7005 & 1274 & 1120 & 204 & 8125 & 1477 \\
\hline 1989 & 7658 & 1392 & 1251 & 227 & 8908 & 1620 \\
\hline 1990 & 8489 & 1543 & 1346 & 245 & 9834 & 1788 \\
\hline 1991 & 9255 & 1683 & 1421 & 258 & 10676 & 1941 \\
\hline 1992 & 9883 & 1797 & 1594 & 290 & 11478 & 2087 \\
\hline 1993 & 10701 & 1946 & 1686 & 307 & 12387 & 2252 \\
\hline 1994 & 11514 & 2093 & 1670 & 304 & 13183 & 2397 \\
\hline 1995 & 12283 & 2233 & 1617 & 294 & 13900 & 2527 \\
\hline 1996 & 13206 & 2401 & 1490 & 271 & 14695 & 2672 \\
\hline 1997 & 14083 & 2561 & 1326 & 241 & 15409 & 2802 \\
\hline 1998 & 14964 & 2721 & 1182 & 215 & 16146 & 2936 \\
\hline 1999 & 15569 & 2831 & 1264 & 230 & 16833 & 3061 \\
\hline 2000 & 16411 & 2984 & 1035 & 188 & 17446 & 3172 \\
\hline
\end{tabular}

a. Reference 7 , based on assumptions summarized in section 3.1 .2 . 
TABLE 3.8. Predicted Distribution of LWR Spent Fue 1 Reprocessing Among U.S.

$$
\text { Facilities in the Near Term (a) }
$$

\begin{tabular}{|c|c|c|c|c|c|}
\hline \multirow[b]{2}{*}{ Year } & \multicolumn{5}{|c|}{ MTHM/yr (b) } \\
\hline & AGNS & NFS & EXXON & $\begin{array}{c}\text { New } \\
\text { Capacity }\end{array}$ & Total \\
\hline $\begin{array}{l}1977 \\
1978 \\
1979\end{array}$ & $\begin{array}{r}500 \\
1000 \\
1500\end{array}$ & & & & $\begin{array}{r}500 \\
1000 \\
1500\end{array}$ \\
\hline $\begin{array}{l}1980 \\
1987 \\
1982 \\
1983 \\
1984 \\
1985 \\
1986 \\
1987\end{array}$ & $\begin{array}{l}1500 \\
1500 \\
1500 \\
1500 \\
1500 \\
1500 \\
1500 \\
1500\end{array}$ & $\begin{array}{l}300 \\
600 \\
600 \\
600 \\
600 \\
600 \\
600 \\
600\end{array}$ & $\begin{array}{r}500 \\
1000 \\
1500 \\
1500 \\
1500\end{array}$ & $\begin{array}{l}1000 \\
1000\end{array}$ & $\begin{array}{l}1800 \\
2100 \\
2100 \\
2600 \\
3100 \\
3600 \\
4600 \\
4600\end{array}$ \\
\hline
\end{tabular}

a. See Table 3.9 for projected reprocessing schedules to year 2000 .

b. Reference 7 .

TABLE 3.9. Comparison of Reprocessing Requirements and Activities (a)

\begin{tabular}{|c|c|c|}
\hline Year & $\begin{array}{c}\text { Actual LWR } \\
\text { Reprocessing Load } \\
\text { (MTHM) }\end{array}$ & $\begin{array}{c}\text { LWR Fuel } \\
\text { Reprocessed } \\
(M T H M)\end{array}$ \\
\hline $\begin{array}{l}1975 \\
1976 \\
1977 \\
1978 \\
1979 \\
1980 \\
1981 \\
1982 \\
1983 \\
1984 \\
1985 \\
1986 \\
1987 \\
1988 \\
1989 \\
1990 \\
1991 \\
1992 \\
1993 \\
1994 \\
1995 \\
1996 \\
1997 \\
1998 \\
1999 \\
2000\end{array}$ & $\begin{array}{r}494.7 \\
712.9 \\
900.3 \\
1075.2 \\
1259.5 \\
1435.2 \\
1631.5 \\
1910.0 \\
2298.4 \\
2762.0 \\
3284.0 \\
3840.2 \\
4397.3 \\
4965.4 \\
5577.8 \\
6250.3 \\
6961.0 \\
7719.4 \\
8515.0 \\
9314.4 \\
10153.8 \\
10975.9 \\
11744.9 \\
12515.3 \\
13267.7 \\
14044.8\end{array}$ & $\begin{array}{r}500.0 \\
1000.0 \\
1500.0 \\
1800.0 \\
2100.0 \\
2100.0 \\
2600.0 \\
3100.0 \\
3100.0 \\
4100.0 \\
5027.5 \\
4965.4 \\
5577.8 \\
6250.3 \\
6961.0 \\
7779.4 \\
8515.0 \\
9314.4 \\
10153.8 \\
10975.9 \\
11744.9 \\
12515.3 \\
13267.7 \\
14044.8\end{array}$ \\
\hline
\end{tabular}

a. Reference 7 , based on assumptions summarized in Section 3.1.2. 
TABLE 3.10. Shipments of Spent LWR Fuel to Reprocessing Plants (a)

\begin{tabular}{|c|c|c|c|c|c|c|}
\hline \multirow[b]{2}{*}{ Year } & \multicolumn{2}{|c|}{ LWR-U } & \multicolumn{2}{|c|}{$L W R-P U$} & \multicolumn{2}{|c|}{ Total } \\
\hline & Truck & Rail & Truck & Rait & Truck & $\mathrm{Ra} i 1$ \\
\hline 1977 & 409 & 103 & 0 & 0 & 409 & 103 \\
\hline 1978 & 795 & 210 & 0 & 0 & 795 & 210 \\
\hline 1979 & 1160 & 319 & 0 & 0 & 1160 & 319 \\
\hline 1980 & 1350 & 389 & 0 & 0 & 1350 & 389 \\
\hline 1981 & 1527 & 467 & 0 & 0 & 1527 & 461 \\
\hline 1982 & 1381 & 437 & 97 & 31 & 1478 & 468 \\
\hline 1983 & 1499 & 496 & 276 & 91 & 1775 & 587 \\
\hline 1984 & 1652 & 575 & 390 & 136 & 2042 & 710 \\
\hline 1985 & 1747 & 608 & 295 & 103 & 2042 & 710 \\
\hline 1986 & 2287 & 834 & 323 & 118 & 2610 & 952 \\
\hline 1987 & 2686 & 1029 & 402 & 154 & 3088 & 1183 \\
\hline 1988 & 2619 & 1004 & 437 & 165 & 3050 & 1169 \\
\hline 1989 & 2770 & 1120 & 523 & 212 & 3293 & 1332 \\
\hline 1990 & 2943 & 1253 & 608 & 259 & 3551 & 1512 \\
\hline 1991 & 3276 & 1395 & 679 & 289 & 3955 & 1684 \\
\hline 1992 & 3506 & 1578 & 701 & 375 & 4207 & 1893 \\
\hline 1993 & 3900 & 1755 & 740 & 333 & 4641 & 2088 \\
\hline 1994 & 4070 & 1935 & 796 & 379 & 4866 & 2314 \\
\hline $\begin{array}{l}1995 \\
1996\end{array}$ & $\begin{array}{l}4463 \\
4685\end{array}$ & $\begin{array}{l}2122 \\
2361\end{array}$ & $\begin{array}{l}842 \\
797\end{array}$ & $\begin{array}{l}400 \\
402\end{array}$ & $\begin{array}{l}5305 \\
5482\end{array}$ & $\begin{array}{l}2522 \\
2762\end{array}$ \\
\hline $\begin{array}{l}1996 \\
1997\end{array}$ & $\begin{array}{l}4085 \\
5094\end{array}$ & 2567 & 772 & $\begin{array}{l}402 \\
389\end{array}$ & 5867 & 2956 \\
\hline 1998 & 5307 & 2825 & 681 & 363 & 5988 & 3787 \\
\hline & 5730 & 3058 & 605 & 323 & 6335 & 3387 \\
\hline 2000 & 5870 & 3333 & 514 & 292 & 6384 & 3624 \\
\hline
\end{tabular}

a. Reference 7 , based on assumptions summarized in Section 3.1.2. 
TABLE 3.11. Projected Accumulation of Solidified LWR High-Level Wastes at Fuel Reprocessing Plants Before Shipment (a)

Annual Addition

\begin{tabular}{|c|c|c|c|c|}
\hline Year & $\begin{array}{l}\text { Volume } \\
\text { (Thousands } \\
\text { of } \mathrm{m}^{3} \text { ) }\end{array}$ & $\begin{array}{c}\text { Actinide } \\
\text { Mass } \\
\text { (MT) }\end{array}$ & $\begin{array}{c}\text { Radio- } \\
\text { activity } \\
(M C i)\end{array}$ & $\begin{array}{c}\text { Thermal } \\
\text { Power } \\
\text { (MW) }\end{array}$ \\
\hline $\begin{array}{l}1977 \\
1978 \\
1979 \\
1980 \\
1981 \\
1982 \\
1983 \\
1984 \\
1985 \\
1986 \\
1987 \\
1988 \\
1989 \\
1990 \\
1991 \\
1992 \\
1993 \\
1994 \\
1995 \\
1996 \\
1997 \\
1998 \\
1999 \\
2000\end{array}$ & $\begin{array}{l}0.03 \\
0.06 \\
0.08 \\
0.10 \\
0.12 \\
0.12 \\
0.15 \\
0.18 \\
0.18 \\
0.23 \\
0.28 \\
0.28 \\
0.32 \\
0.35 \\
0.39 \\
0.44 \\
0.48 \\
0.53 \\
0.58 \\
0.62 \\
0.67 \\
0.71 \\
0.75 \\
0.80\end{array}$ & $\begin{array}{r}2.7 \\
5.5 \\
8.2 \\
9.9 \\
11.5 \\
12.1 \\
16.1 \\
19.7 \\
19.0 \\
24.8 \\
30.5 \\
30.4 \\
34.6 \\
39.1 \\
43.6 \\
48.1 \\
52.8 \\
57.9 \\
62.9 \\
67.4 \\
71.4 \\
75.0 \\
78.4 \\
82.1\end{array}$ & $\begin{array}{r}959 \\
2031 \\
3202 \\
4004 \\
4817 \\
4963 \\
6240 \\
7429 \\
7369 \\
9772 \\
11981 \\
11999 \\
13580 \\
15268 \\
17029 \\
18906 \\
20886 \\
22948 \\
25083 \\
27135 \\
29062 \\
30968 \\
32810 \\
34714\end{array}$ & $\begin{array}{r}5 \\
10 \\
15 \\
19 \\
23 \\
25 \\
33 \\
40 \\
39 \\
51 \\
63 \\
63 \\
72 \\
82 \\
92 \\
101 \\
111 \\
123 \\
134 \\
143 \\
152 \\
161 \\
168 \\
176\end{array}$ \\
\hline
\end{tabular}

Accumulation Through End of Year

\begin{tabular}{cccc}
$\begin{array}{c}\text { Volume } \\
\text { (Thousands } \\
\left.\text { of }{ }^{3}\right)\end{array}$ & $\begin{array}{c}\text { Actinide } \\
\text { Mass } \\
\text { (MT) }\end{array}$ & $\begin{array}{c}\text { Radio- } \\
\text { activity } \\
\text { (MCi) }\end{array}$ & $\begin{array}{c}\text { Thermal } \\
\text { Power } \\
(\text { MW) }\end{array}$ \\
\cline { 1 - 1 } 0.03 & 2.7 & 959 & \\
0.08 & 8.2 & 2516 & 12 \\
0.17 & 16.4 & 4540 & 22 \\
0.27 & 26.3 & 6506 & 31 \\
0.39 & 37.8 & 8539 & 40 \\
0.51 & 49.9 & 9994 & 48 \\
0.66 & 66.0 & 12342 & 61 \\
0.83 & 85.7 & 15058 & 77 \\
1.01 & 104.7 & 16787 & 86 \\
1.24 & 129.4 & 20550 & 105 \\
1.53 & 160.0 & 25138 & 129 \\
1.81 & 190.3 & 28100 & 145 \\
2.12 & 224.9 & 31947 & 165 \\
2.48 & 264.0 & 36342 & 189 \\
2.87 & 307.5 & 41173 & 216 \\
3.31 & 355.7 & 46434 & 244 \\
3.79 & 408.5 & 52118 & 274 \\
4.32 & 466.5 & 58202 & 306 \\
4.89 & 529.3 & 64675 & 340 \\
5.51 & 596.7 & 71374 & 374 \\
6.18 & 668.0 & 78177 & 408 \\
6.89 & 743.1 & 85118 & 441 \\
7.64 & 821.5 & 92159 & 473 \\
8.43 & 903.6 & 99401 & 505 \\
& & &
\end{tabular}

a. Reference 7, based on assumptions summarized in Section 3.1 .2 . 


\subsection{3}

TABLE 3.12. Containers of 10-yr-01d

LWR High-Level Waste

Shipped (a)

\begin{tabular}{l} 
Year \\
\hline 1987 \\
1988 \\
1989 \\
1990 \\
1991 \\
1992 \\
1993 \\
1994 \\
1995 \\
1996 \\
1997 \\
1998 \\
1999 \\
2000 \\
2001 \\
2002 \\
2003 \\
2004 \\
2005 \\
2006 \\
2007 \\
2008 \\
2009 \\
2010
\end{tabular}

Number of

Containers

159

318

478

573

669

669

828

987

987

1306

1601

1581

1776

1991

2217

2459

2712

2967

3234

3496

3741

3986

4226

4473

a. Reference 7 , based on assumptions summarized in section 3.1.2. 
TABLE 3.13. Projected Accumulation of Solidified LWR High-Level Wastes at a Federal Repository (a)

\begin{tabular}{|c|c|c|c|c|c|c|c|c|c|}
\hline \multirow[b]{2}{*}{ Year } & \multicolumn{4}{|c|}{ Annual Addition } & \multirow[b]{2}{*}{$\begin{array}{c}\text { Annual } \\
\text { Number } \\
\text { of } \\
\text { Shipments }\end{array}$} & \multicolumn{4}{|c|}{ Accumulation Through End of Year } \\
\hline & $\begin{array}{c}\text { Volume } \\
\text { (Thousands } \\
\text { of } \mathrm{m}^{3} \text { ) }\end{array}$ & $\begin{array}{c}\text { Actinide } \\
\operatorname{Mass}(b) \\
(M T)\end{array}$ & $\begin{array}{c}\text { Radio- } \\
\text { activity } \\
(M C i)\end{array}$ & $\begin{array}{c}\text { Therma } 1 \\
\text { Power } \\
\text { (MW) }\end{array}$ & & $\begin{array}{c}\text { Volume } \\
\text { (Thousands } \\
\text { of } \mathrm{m}^{3} \text { ) }\end{array}$ & $\begin{array}{c}\text { Actinide } \\
\operatorname{Mass}(b) \\
(M T)\end{array}$ & $\begin{array}{c}\text { Radio- } \\
\text { activity } \\
(M C i)\end{array}$ & $\begin{array}{c}\text { Therma } 1 \\
\text { Power } \\
\text { (MW) }\end{array}$ \\
\hline $\begin{array}{l}1987 \\
1988 \\
1989 \\
1990 \\
1991 \\
1992 \\
1993 \\
1994 \\
1995 \\
1996 \\
1997 \\
1998 \\
1999 \\
2000 \\
2001 \\
2002 \\
2003 \\
2004 \\
2005 \\
2006 \\
2007 \\
2008 \\
2009 \\
2010\end{array}$ & $\begin{array}{l}0.03 \\
0.06 \\
0.08 \\
0.10 \\
0.12 \\
0.12 \\
0.15 \\
0.18 \\
0.18 \\
0.23 \\
0.28 \\
0.28 \\
0.32 \\
0.35 \\
0.39 \\
0.44 \\
0.48 \\
0.53 \\
0.58 \\
0.62 \\
0.67 \\
0.71 \\
0.75 \\
0.80\end{array}$ & $\begin{array}{l}2.7 \\
5.5 \\
8.2 \\
9.9 \\
11.5 \\
12.1 \\
16.1 \\
19.7 \\
19.0 \\
24.8 \\
30.5 \\
30.4 \\
34.6 \\
39.1 \\
43.6 \\
48.1 \\
52.8 \\
57.9 \\
62.9 \\
67.4 \\
71.4 \\
75.0 \\
78.4 \\
82.1\end{array}$ & $\begin{array}{r}115.29 \\
244.18 \\
385.05 \\
481.40 \\
579.14 \\
596.21 \\
748.80 \\
891.09 \\
884.37 \\
1173.11 \\
1438.17 \\
1440.14 \\
1629.63 \\
1831.86 \\
2043.22 \\
2268.51 \\
2506.41 \\
2753.65 \\
3010.12 \\
3256.91 \\
3488.78 \\
3718.36 \\
3940.38 \\
4169.76\end{array}$ & $\begin{array}{l}0.4 \\
0.8 \\
1.3 \\
1.7 \\
2.0 \\
2.5 \\
3.8 \\
4.8 \\
4.4 \\
5.5 \\
6.9 \\
7.0 \\
8.2 \\
9.5 \\
10.6 \\
11.6 \\
12.7 \\
14.0 \\
15.1 \\
16.0 \\
16.6 \\
17.1 \\
17.4 \\
17.8\end{array}$ & $\begin{array}{l}13 \\
27 \\
40 \\
48 \\
56 \\
56 \\
69 \\
82 \\
82 \\
109 \\
133 \\
132 \\
148 \\
166 \\
185 \\
205 \\
226 \\
247 \\
269 \\
291 \\
312 \\
332 \\
352 \\
373\end{array}$ & $\begin{array}{l}0.03 \\
0.08 \\
0.17 \\
0.27 \\
0.39 \\
0.51 \\
0.66 \\
0.83 \\
1.01 \\
1.24 \\
1.53 \\
1.81 \\
2.12 \\
2.48 \\
2.87 \\
3.31 \\
3.79 \\
4.32 \\
4.89 \\
5.51 \\
6.18 \\
6.89 \\
7.64 \\
8.43\end{array}$ & $\begin{array}{r}2.7 \\
8.2 \\
16.4 \\
26.3 \\
37.8 \\
49.9 \\
66.0 \\
85.7 \\
104.7 \\
129.4 \\
160.0 \\
190.3 \\
224.9 \\
264.0 \\
307.5 \\
355.7 \\
408.5 \\
466.4 \\
529.3 \\
596.7 \\
668.0 \\
743.1 \\
821.5 \\
903.6\end{array}$ & $\begin{array}{r}115 \\
355 \\
728 \\
1184 \\
1724 \\
2264 \\
2940 \\
3739 \\
4507 \\
5543 \\
6812 \\
8045 \\
9432 \\
10982 \\
12699 \\
14592 \\
16669 \\
18934 \\
21391 \\
24026 \\
26819 \\
29764 \\
32850 \\
36082\end{array}$ & $\begin{array}{r}0.4 \\
1.2 \\
2.5 \\
4.1 \\
5.9 \\
8.2 \\
11.6 \\
16.0 \\
19.8 \\
24.6 \\
30.7 \\
36.6 \\
43.6 \\
51.5 \\
60.3 \\
69.8 \\
80.1 \\
91.3 \\
103.4 \\
115.8 \\
128.5 \\
141.3 \\
153.9 \\
166.6\end{array}$ \\
\hline
\end{tabular}

a. Reference 7 , based on assumptions summarized in Section 3.1.2.

b. Note that uranium values are included in this group. 
TABLE 3.14. Projected Accumulation of LWR Cladding Wastes at a Federal Repository (a)

\begin{tabular}{|c|c|c|c|c|c|c|c|c|}
\hline \multirow[b]{2}{*}{ Year } & \multicolumn{4}{|c|}{ Annual Addition } & \multicolumn{4}{|c|}{ Accumulation Through End of Year } \\
\hline & $\begin{array}{l}\text { Volume } \\
\text { (Thousands } \\
\text { of } \mathrm{m}^{3} \text { ) }\end{array}$ & $\begin{array}{l}\text { Actinide } \\
\operatorname{Mass}(c) \\
(M T)\end{array}$ & $\begin{array}{l}\text { Radio- } \\
\text { activity } \\
\quad(M C i)\end{array}$ & $\begin{array}{c}\text { Therma } 1 \\
\text { Power } \\
\text { (MW) }\end{array}$ & $\begin{array}{l}\text { Volume } \\
\text { (Thous ands } \\
\text { of } \mathrm{m}^{3} \text { ) }\end{array}$ & $\begin{array}{l}\text { Actinide } \\
\operatorname{Mass}(c) \\
(M T)\end{array}$ & $\begin{array}{l}\text { Radio- } \\
\text { activity } \\
\text { (MCi) }\end{array}$ & $\begin{array}{c}\text { Therma } 1 \\
\text { Power } \\
\text { (MW) }\end{array}$ \\
\hline $\begin{array}{l}1978 \\
1979 \\
1980 \\
1981 \\
1982 \\
1983 \\
1984 \\
1985 \\
1986 \\
1987 \\
1988 \\
1989 \\
1990 \\
1991 \\
1992 \\
1993 \\
1994 \\
1995 \\
1996 \\
1997 \\
1998 \\
1999 \\
2000\end{array}$ & $\begin{array}{l}0.10 \\
0.24 \\
0.35 \\
0.42 \\
0.49 \\
0.49 \\
0.60 \\
0.70 \\
0.70 \\
0.94 \\
1.2 \\
1.1 \\
1.3 \\
1.4 \\
1.6 \\
1.8 \\
2.0 \\
2.1 \\
2.3 \\
2.5 \\
2.7 \\
2.9 \\
3.0\end{array}$ & $\begin{array}{l}0.24 \\
0.48 \\
0.72 \\
0.87 \\
1.01 \\
1.01 \\
1.26 \\
1.50 \\
1.50 \\
1.98 \\
2.43 \\
2.40 \\
2.69 \\
3.02 \\
3.36 \\
3.73 \\
4.11 \\
4.50 \\
4.90 \\
5.30 \\
5.67 \\
6.04 \\
6.41\end{array}$ & $\begin{array}{r}2.9 \\
6.2 \\
9.7 \\
12.7 \\
14.6 \\
14.5 \\
17.3 \\
20.2 \\
20.6 \\
27.6 \\
33.8 \\
33.6 \\
37.7 \\
42.1 \\
47.0 \\
52.3 \\
58.0 \\
63.6 \\
69.8 \\
76.0 \\
82.1 \\
88.3 \\
94.5\end{array}$ & $\begin{array}{l}0.032 \\
0.068 \\
0.107 \\
0.133 \\
0.161 \\
0.160 \\
0.792 \\
0.224 \\
0.227 \\
0.305 \\
0.373 \\
0.371 \\
0.417 \\
0.465 \\
0.519 \\
0.578 \\
0.641 \\
0.703 \\
0.771 \\
0.840 \\
0.906 \\
0.974 \\
1.042\end{array}$ & $\begin{array}{l}0.10 \\
0.35 \\
0.70 \\
1.1 \\
1.6 \\
2.1 \\
2.7 \\
3.4 \\
4.1 \\
5.0 \\
6.2 \\
7.3 \\
8.6 \\
10 \\
12 \\
13 \\
15 \\
18 \\
20 \\
22 \\
25 \\
28 \\
31\end{array}$ & $\begin{array}{r}0.24 \\
0.72 \\
1.45 \\
2.32 \\
3.33 \\
4.35 \\
5.60 \\
7.10 \\
8.60 \\
10.58 \\
13.01 \\
15.40 \\
18.10 \\
21.12 \\
24.48 \\
28.21 \\
32.32 \\
36.82 \\
41.72 \\
47.03 \\
52.70 \\
58.74 \\
65.15\end{array}$ & $\begin{array}{r}3 \\
9 \\
17 \\
26 \\
37 \\
46 \\
57 \\
69 \\
80 \\
97 \\
117 \\
135 \\
155 \\
176 \\
200 \\
226 \\
254 \\
285 \\
318 \\
353 \\
390 \\
428 \\
468\end{array}$ & $\begin{array}{l}0.03 \\
0.10 \\
0.19 \\
0.30 \\
0.42 \\
0.52 \\
0.64 \\
0.78 \\
0.91 \\
1.09 \\
1.32 \\
1.52 \\
1.74 \\
1.98 \\
2.24 \\
2.52 \\
2.84 \\
3.77 \\
3.53 \\
3.97 \\
4.31 \\
4.73 \\
5.16\end{array}$ \\
\hline
\end{tabular}

a. Reference 7 , based on assumptions summarized in Section 3.1.2.

b. Uncompacted volumes.

c. Note that uranium values are included in this group. 
TABLE 3.15. Projected Accumulation of Fission Product Tritium from LWR Fuel $(a)$

\begin{tabular}{|c|c|c|c|c|c|c|}
\hline \multirow[b]{2}{*}{ Year } & \multicolumn{3}{|c|}{ Annual Addition } & \multicolumn{3}{|c|}{ Accumulation Through End of Year } \\
\hline & $\begin{array}{c}\text { Vol ume } \\
\left(\mathrm{m}^{3}\right)\end{array}$ & $\begin{array}{l}\text { Radio- } \\
\text { activity } \\
\quad(M C i)\end{array}$ & $\begin{array}{c}\text { Thermal } \\
\text { Power } \\
\text { (Watts) }\end{array}$ & $\begin{array}{c}\text { Vol ume } \\
\left(\mathrm{m}^{3}\right)\end{array}$ & $\begin{array}{l}\text { Radio- } \\
\text { activity } \\
\quad(M C i)\end{array}$ & $\begin{array}{c}\text { Thermal } \\
\text { Power } \\
\text { (Watts) }\end{array}$ \\
\hline 1978 & 4.8 & 0.25 & 9 & 4.8 & 0.25 & 9 \\
\hline 1979 & 10.1 & 0.53 & 19 & 14.9 & 0.76 & 27 \\
\hline 1980 & 15.9 & 0.83 & 30 & 30.8 & 1.55 & 55 \\
\hline 1981 & 19.9 & 1.04 & 37 & 50.7 & 2.50 & 89 \\
\hline 1982 & 24.0 & 1.25 & 44 & 74.7 & 3.62 & 129 \\
\hline 1983 & 24.5 & 1.28 & 46 & 99.2 & 4.70 & 167 \\
\hline 1984 & 30.6 & 1.60 & 57 & 129.8 & 6.03 & 215 \\
\hline 1985 & 36.3 & 1.89 & 67 & 166.1 & 7.60 & 270 \\
\hline 1986 & 36.2 & 1.89 & 67 & 202.3 & 9.06 & 323 \\
\hline 1987 & 48.1 & 2.51 & 89 & 250.3 & 11.07 & 394 \\
\hline 1988 & 58.9 & 3.07 & 109 & 309.2 & 13.53 & 482 \\
\hline 1989 & 58.9 & 3.07 & 109 & 368.1 & 15.86 & 565 \\
\hline 1990 & 66.6 & 3.47 & 124 & 434.7 & 18.46 & 657 \\
\hline 1991 & 74.8 & 3.90 & 139 & 509.5 & 21.35 & 760 \\
\hline 1992 & 83.4 & 4.35 & 155 & 592.9 & 24.52 & 873 \\
\hline 1993 & 92.6 & 4.83 & 172 & 685.5 & 28.00 & 997 \\
\hline 1994 & 102.4 & 5.34 & 190 & 787.9 & 31.80 & 1132 \\
\hline 1995 & 112.5 & 5.87 & 209 & 900.4 & 35.92 & 1279 \\
\hline 1996 & 123.0 & 6.41 & 228 & 1023.4 & 40.36 & 1437 \\
\hline 1997 & 133.2 & 6.95 & 247 & 1156.6 & 45.09 & 1605 \\
\hline 1998 & 142.9 & 7.45 & 265 & 1299.5 & 50.06 & 1782 \\
\hline 1999 & 152.5 & 7.95 & 283 & 1452.0 & 55.26 & 1967 \\
\hline 2000 & 161.8 & 8.44 & 300 & 1613.8 & 60.66 & 2160 \\
\hline
\end{tabular}

a. Reference 7 , based on assumptions summarized in Section 3.1.2. 
TABLE 3.16. Projected Accumulation of Fission Product Iodine from LWR Fuel(a)

\begin{tabular}{|c|c|c|c|c|c|c|c|c|}
\hline \multirow[b]{2}{*}{ Year } & \multicolumn{4}{|c|}{ Annual Addition } & \multicolumn{2}{|c|}{ Accumulation } & \multicolumn{2}{|c|}{ hrough End of Year } \\
\hline & $\begin{array}{c}\text { Vol ume } \\
\left(m^{3}\right)\end{array}$ & $\begin{array}{l}\text { Iodine } \\
\text { Mass } \\
(\mathrm{kg})\end{array}$ & $\begin{array}{l}\text { Radio- } \\
\text { activity } \\
\text { (Curies) }\end{array}$ & $\begin{array}{c}\text { Therma } \\
\text { Power } \\
\text { (Watts) }\end{array}$ & $\begin{array}{c}\text { Vol ume } \\
\left(m^{3}\right)\end{array}$ & $\begin{array}{l}\text { Iodine } \\
\text { Mass } \\
(\mathrm{kg})\end{array}$ & $\begin{array}{l}\text { Radio- } \\
\text { activity } \\
\text { (Curies) }\end{array}$ & $\begin{array}{c}\text { Thermal } \\
\text { Power } \\
\text { (Watts) }\end{array}$ \\
\hline $\begin{array}{l}1976 \\
1977 \\
1978 \\
1979 \\
1980 \\
1981 \\
1982 \\
1983 \\
1984 \\
1985 \\
1986 \\
1987 \\
1988 \\
1989 \\
1990 \\
1997 \\
1992 \\
1993 \\
1994 \\
1995 \\
1996 \\
1997 \\
1998 \\
1999 \\
2000\end{array}$ & $\begin{array}{l}0.0 \\
0.0 \\
0.04 \\
0.08 \\
0.13 \\
0.16 \\
0.20 \\
0.20 \\
0.25 \\
0.30 \\
0.30 \\
0.39 \\
0.48 \\
0.48 \\
0.54 \\
0.61 \\
0.68 \\
0.76 \\
0.84 \\
0.92 \\
1.01 \\
1.09 \\
1.17 \\
1.25 \\
1.32\end{array}$ & $\begin{array}{r}0 \\
0 \\
104 \\
221 \\
348 \\
435 \\
523 \\
536 \\
669 \\
793 \\
790 \\
1050 \\
1287 \\
1287 \\
1455 \\
1634 \\
1822 \\
2024 \\
2238 \\
2458 \\
2688 \\
2911 \\
3122 \\
3332 \\
3535\end{array}$ & $\begin{array}{r}0.0 \\
0.0 \\
14.2 \\
30.2 \\
47.6 \\
59.5 \\
71.6 \\
73.2 \\
91.3 \\
108.3 \\
107.9 \\
143.4 \\
175.7 \\
175.8 \\
198.6 \\
223.0 \\
248.7 \\
276.3 \\
305.4 \\
335.5 \\
366.9 \\
397.4 \\
426.2 \\
455.0 \\
482.9\end{array}$ & $\begin{array}{l}0.0 \\
0.0 \\
0.009 \\
0.020 \\
0.031 \\
0.039 \\
0.047 \\
0.048 \\
0.060 \\
0.071 \\
0.071 \\
0.094 \\
0.116 \\
0.116 \\
0.131 \\
0.1447 \\
0.164 \\
0.182 \\
0.201 \\
0.221 \\
0.241 \\
0.261 \\
0.280 \\
0.299 \\
0.318\end{array}$ & $\begin{array}{l}0.0 \\
0.0 \\
0.04 \\
0.12 \\
0.25 \\
0.41 \\
0.61 \\
0.81 \\
1.06 \\
1.36 \\
1.65 \\
2.05 \\
2.53 \\
3.01 \\
3.55 \\
4.16 \\
4.84 \\
5.60 \\
6.44 \\
7.36 \\
8.36 \\
9.45 \\
10.62 \\
11.87 \\
13.19\end{array}$ & $\begin{array}{r}0 \\
0 \\
104 \\
325 \\
673 \\
1108 \\
1631 \\
2167 \\
2836 \\
3629 \\
4419 \\
5469 \\
6756 \\
8043 \\
9498 \\
11132 \\
12954 \\
14979 \\
17216 \\
19674 \\
22362 \\
25273 \\
28395 \\
31726 \\
35262\end{array}$ & $\begin{array}{r}0 \\
0 \\
14 \\
44 \\
92 \\
151 \\
223 \\
296 \\
388 \\
496 \\
604 \\
747 \\
923 \\
1098 \\
1297 \\
1520 \\
1769 \\
2045 \\
2350 \\
2686 \\
3053 \\
3450 \\
3876 \\
4331 \\
4814\end{array}$ & $\begin{array}{l}0.0 \\
0.0 \\
0.009 \\
0.029 \\
0.061 \\
0.100 \\
0.147 \\
0.195 \\
0.255 \\
0.326 \\
0.397 \\
0.491 \\
0.607 \\
0.722 \\
0.853 \\
1.000 \\
1.163 \\
1.345 \\
1.546 \\
1.767 \\
2.008 \\
2.269 \\
2.550 \\
2.849 \\
3.167\end{array}$ \\
\hline
\end{tabular}

a. Reference 7 , based on assumptions summarized in Section 3.1.2. 
TABLE 3.17. Projected Accumulation of Noble Gas Fission Products from LWR Fuel(a)

\begin{tabular}{|c|c|c|c|c|c|c|c|}
\hline \multirow[b]{2}{*}{ Year } & \multicolumn{3}{|c|}{ Annual Addition } & & \multicolumn{3}{|c|}{ Accumulation Through End of Year } \\
\hline & $\begin{array}{c}\text { Number } \\
\text { of } \\
\text { Cylinders }\end{array}$ & $\begin{array}{c}\text { Radio- } \\
\text { activity } \\
(M C i)\end{array}$ & $\begin{array}{c}\text { Thermal } \\
\text { Power } \\
(\mathrm{kW})\end{array}$ & $\begin{array}{c}\text { Annual } \\
\text { Number } \\
\text { of } \\
\text { Shipments }\end{array}$ & $\begin{array}{c}\text { Number } \\
\text { of } \\
\text { Cyl inders }\end{array}$ & $\begin{array}{l}\text { Radio- } \\
\text { activity } \\
(M C i)\end{array}$ & $\begin{array}{c}\text { Therma ! } \\
\text { Power } \\
(\mathrm{kW})\end{array}$ \\
\hline $\begin{array}{l}1978 \\
1979 \\
1980 \\
1981 \\
1982 \\
1983 \\
1984 \\
1985 \\
1986 \\
1987 \\
1988 \\
1989 \\
1990 \\
1991 \\
1992 \\
1993 \\
1994 \\
1995 \\
1996 \\
1997 \\
1998 \\
1999 \\
2000\end{array}$ & $\begin{array}{r}25 \\
52 \\
82 \\
103 \\
124 \\
126 \\
155 \\
183 \\
183 \\
244 \\
299 \\
299 \\
337 \\
378 \\
422 \\
469 \\
519 \\
569 \\
623 \\
676 \\
726 \\
777 \\
826\end{array}$ & $\begin{array}{r}3.9 \\
8.3 \\
13.1 \\
16.4 \\
19.7 \\
19.9 \\
24.3 \\
28.6 \\
28.8 \\
38.4 \\
47.0 \\
46.9 \\
52.8 \\
59.1 \\
66.0 \\
73.4 \\
81.2 \\
89.2 \\
97.6 \\
106.1 \\
114.2 \\
122.4 \\
130.4\end{array}$ & $\begin{array}{r}6.4 \\
13.5 \\
21.4 \\
26.7 \\
32.1 \\
32.4 \\
39.5 \\
46.5 \\
46.8 \\
62.5 \\
76.5 \\
76.4 \\
85.9 \\
96.2 \\
107.3 \\
119.4 \\
132.2 \\
145.1 \\
158.9 \\
172.6 \\
185.7 \\
199.1 \\
212.2\end{array}$ & $\begin{array}{r}4 \\
9 \\
14 \\
17 \\
21 \\
21 \\
26 \\
30 \\
31 \\
41 \\
50 \\
50 \\
56 \\
63 \\
70 \\
78 \\
86 \\
95 \\
104 \\
113 \\
121 \\
129 \\
138\end{array}$ & $\begin{array}{r}25 \\
77 \\
159 \\
262 \\
386 \\
512 \\
667 \\
849 \\
1033 \\
1277 \\
1576 \\
1875 \\
2212 \\
2590 \\
3012 \\
3481 \\
3999 \\
4569 \\
5192 \\
5868 \\
6594 \\
7371 \\
8197\end{array}$ & $\begin{array}{r}4 \\
12 \\
24 \\
39 \\
57 \\
73 \\
93 \\
116 \\
137 \\
167 \\
204 \\
238 \\
276 \\
318 \\
364 \\
415 \\
471 \\
531 \\
596 \\
665 \\
738 \\
814 \\
894\end{array}$ & $\begin{array}{r}6 \\
20 \\
40 \\
64 \\
92 \\
119 \\
151 \\
188 \\
223 \\
272 \\
332 \\
387 \\
449 \\
518 \\
593 \\
676 \\
766 \\
864 \\
969 \\
1082 \\
1200 \\
1325 \\
1455\end{array}$ \\
\hline
\end{tabular}

a. Reference 7 , based on assumptions summarized in Section 3.1.2. 
TABLE 3.18. Projected Accumulation of ${ }^{14} \mathrm{C}$ from Spent LWR Fuel (a)

\begin{tabular}{c} 
Annual \\
Addition \\
$(C i)$ \\
\hline \\
266 \\
564 \\
889 \\
1112 \\
1337 \\
1360 \\
1679 \\
1984 \\
1987 \\
2646 \\
3240 \\
3238 \\
3653 \\
4097 \\
4570 \\
5079 \\
5619 \\
6169 \\
6751 \\
7323 \\
7864 \\
8409 \\
8941
\end{tabular}

Accumulation

Year Through End of Year

1978

1979

1980

1981

1982

1983

1984

1985

1986

1987

1988

1989

1990

1991

1992

1993

1994

1995

1996

1997

1998

1999

2000 (Ci)

266
830
1719
2830
4167
5526
7205
9188
11174
13818
17056
20293
23943
28038
32604
37679
43293
49458
56203
63518
71375
79776
88707

a. Reference 7 , based on assumptions summarized in Section 3.1.2. 
TABLE 3.19. Projected Accumulation of Beta-Gamma Wastes at Surface Burial Grounds(a)

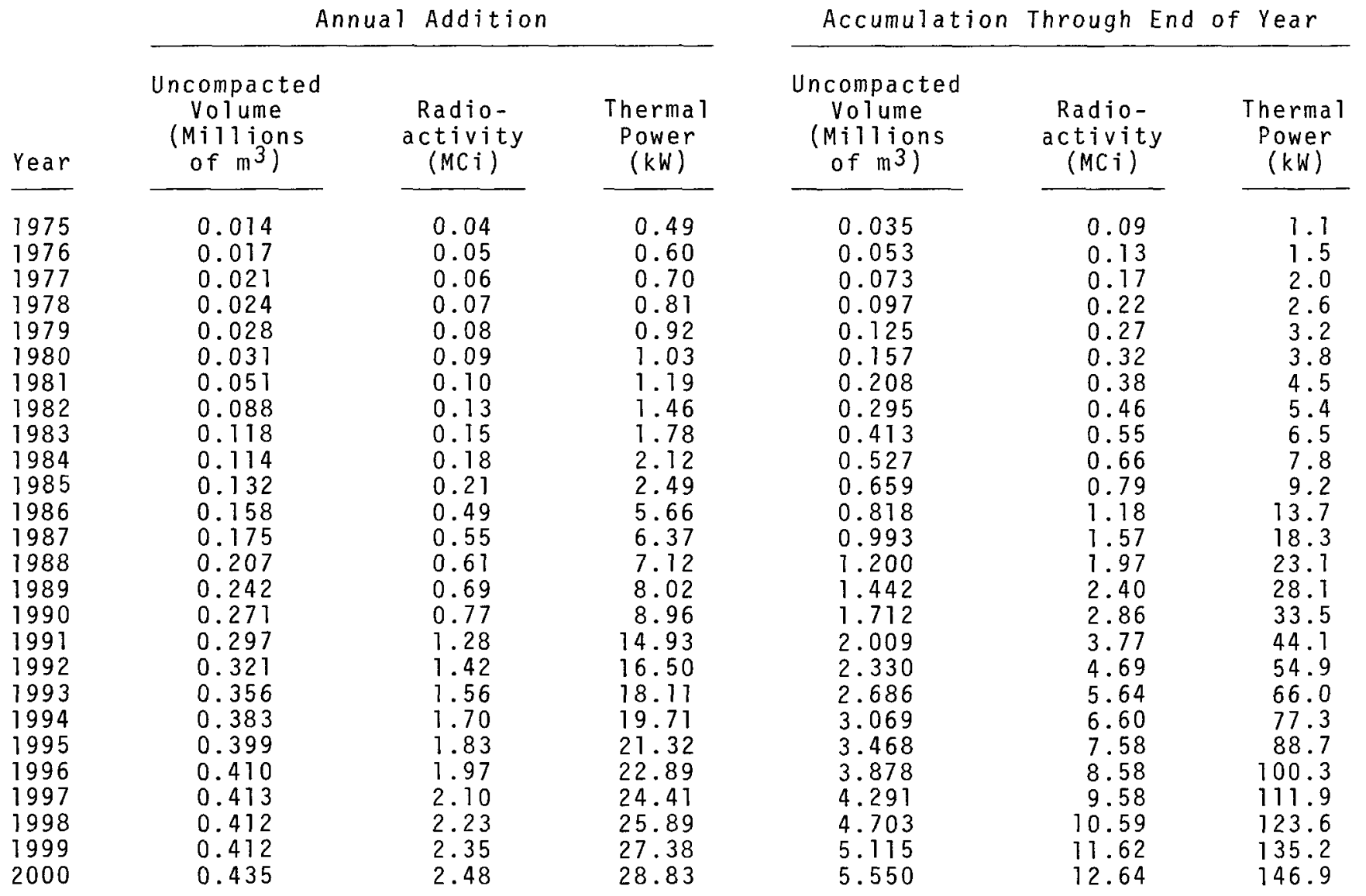

a. Reference 7 , based on assumptions summarized in Section 3.1.2. 
TABLE 3.20. Projected Accumulation of Plutonium Alpha (TRU, low level $\beta-\gamma$ ) wastes at a Federal Repository (a)

\begin{tabular}{|c|c|c|c|c|c|c|c|c|}
\hline \multirow[b]{2}{*}{ Year } & \multicolumn{4}{|c|}{ Annual Addition } & \multicolumn{4}{|c|}{ Accumulation Through End of Year } \\
\hline & $\begin{array}{l}\text { Uncompacted } \\
\text { Volume } \\
\text { (Thousands } \\
\text { of } \mathrm{m}^{3} \text { ) }\end{array}$ & $\begin{array}{c}\text { Actinjde } \\
\operatorname{Mass}(b) \\
(M T)\end{array}$ & $\begin{array}{c}\text { Radio- } \\
\text { activity } \\
(M C i)\end{array}$ & $\begin{array}{c}\text { Therma } 1 \\
\text { Power } \\
(k w)\end{array}$ & $\begin{array}{l}\text { Uncompacted } \\
\text { Volume } \\
\text { (Millions } \\
\text { of } \mathrm{m}^{3} \text { ) }\end{array}$ & $\begin{array}{l}\text { Actinide } \\
\text { Mass (b) } \\
(M T)\end{array}$ & $\begin{array}{c}\text { Radio- } \\
\text { activity } \\
(M C i)\end{array}$ & $\begin{array}{c}\text { Thermal } \\
\text { Power } \\
(k W)\end{array}$ \\
\hline $\begin{array}{l}1975 \\
1976 \\
1977 \\
1978 \\
1979 \\
1980 \\
1981 \\
1982 \\
1983 \\
1984 \\
1985 \\
1986 \\
1987 \\
1988 \\
1989 \\
1990 \\
1991 \\
1992 \\
1993 \\
1994 \\
1995 \\
1996 \\
1997 \\
1998 \\
1999 \\
2000\end{array}$ & $\begin{array}{l}0.3 \\
0.4 \\
0.6 \\
0.8 \\
1.0 \\
1.2 \\
6.6 \\
16.8 \\
24.4 \\
19.7 \\
22.7 \\
28.5 \\
31.0 \\
38.8 \\
46.4 \\
52.0 \\
56.4 \\
60.1 \\
67.3 \\
71.5 \\
72.0 \\
71.1 \\
67.4 \\
62.2 \\
57.6 \\
61.1\end{array}$ & $\begin{array}{l}0.003 \\
0.004 \\
0.005 \\
0.007 \\
0.009 \\
0.011 \\
0.058 \\
0.148 \\
0.215 \\
0.174 \\
0.201 \\
0.252 \\
0.273 \\
0.342 \\
0.410 \\
0.459 \\
0.498 \\
0.530 \\
0.594 \\
0.631 \\
0.636 \\
0.628 \\
0.595 \\
0.549 \\
0.508 \\
0.539\end{array}$ & $\begin{array}{l}0.0 \\
0.0 \\
0.1 \\
0.1 \\
0.1 \\
0.1 \\
0.7 \\
1.7 \\
2.5 \\
2.0 \\
2.3 \\
2.9 \\
3.2 \\
4.0 \\
4.8 \\
5.3 \\
5.8 \\
6.2 \\
6.9 \\
7.3 \\
7.4 \\
7.3 \\
6.9 \\
6.4 \\
5.9 \\
6.3\end{array}$ & $\begin{array}{l}0.0 \\
0.0 \\
0.1 \\
0.1 \\
0.1 \\
0.1 \\
0.6 \\
1.4 \\
2.1 \\
1.7 \\
2.0 \\
2.4 \\
2.7 \\
3.3 \\
4.0 \\
4.5 \\
4.8 \\
5.2 \\
5.8 \\
6.1 \\
6.2 \\
6.1 \\
5.8 \\
5.3 \\
4.9 \\
5.2\end{array}$ & $\begin{array}{l}0.001 \\
0.001 \\
0.002 \\
0.003 \\
0.004 \\
0.005 \\
0.011 \\
0.028 \\
0.053 \\
0.072 \\
0.095 \\
0.124 \\
0.155 \\
0.193 \\
0.240 \\
0.292 \\
0.348 \\
0.408 \\
0.476 \\
0.547 \\
0.619 \\
0.690 \\
0.758 \\
0.820 \\
0.877 \\
0.938\end{array}$ & $\begin{array}{l}0.01 \\
0.01 \\
0.02 \\
0.02 \\
0.03 \\
0.04 \\
0.10 \\
0.25 \\
0.46 \\
0.64 \\
0.84 \\
1.09 \\
1.36 \\
1.71 \\
2.12 \\
2.58 \\
3.07 \\
3.60 \\
4.20 \\
4.83 \\
5.47 \\
6.09 \\
6.69 \\
7.24 \\
7.75 \\
8.28\end{array}$ & $\begin{array}{l}0.1 \\
0.1 \\
0.2 \\
0.2 \\
0.3 \\
0.5 \\
1.1 \\
2.8 \\
5.2 \\
7.0 \\
9.0 \\
11.5 \\
14.2 \\
17.6 \\
21.6 \\
26.0 \\
30.7 \\
35.5 \\
40.9 \\
46.5 \\
51.9 \\
56.9 \\
61.4 \\
65.1 \\
68.2 \\
71.6\end{array}$ & $\begin{array}{r}0.1 \\
0.1 \\
0.2 \\
0.2 \\
0.3 \\
0.5 \\
1.0 \\
2.5 \\
4.7 \\
6.7 \\
8.9 \\
11.8 \\
15.0 \\
18.9 \\
23.7 \\
29.1 \\
35.1 \\
41.6 \\
48.9 \\
56.8 \\
65.0 \\
73.4 \\
81.6 \\
89.6 \\
97.3 \\
105.5\end{array}$ \\
\hline
\end{tabular}

a. Reference 7 , based on assumptions summarized in Section 3.1.2.

b. Note that uranium values are included in this group. 
TABLE 3.21. Projected Accumulation of Alpha-Beta-Gamma (TRU, intermediate level $\beta-\gamma$ ) Wastes (a)

\begin{tabular}{|c|c|c|c|c|c|c|c|c|}
\hline \multirow[b]{2}{*}{ Year } & \multicolumn{4}{|c|}{ Annual Addition } & \multicolumn{4}{|c|}{ Accumulation Through } \\
\hline & $\begin{array}{l}\text { Uncompacted } \\
\text { Volume } \\
\text { (Thousands } \\
\text { of } \mathrm{m}^{3} \text { ) }\end{array}$ & $\begin{array}{c}\text { Actinide } \\
\text { Mass }(b) \\
(\mathrm{kg}) \\
\end{array}$ & $\begin{array}{l}\text { Radio- } \\
\text { activity } \\
\text { (MCi) }\end{array}$ & $\begin{array}{c}\text { Thermal } \\
\text { Power } \\
(k W)\end{array}$ & $\begin{array}{c}\text { Uncompacted } \\
\text { Volume } \\
\text { (Thousands } \\
\text { of } \mathrm{m}^{3} \text { ) }\end{array}$ & $\begin{array}{c}\text { Actinide } \\
\operatorname{Mass}(\mathrm{b}) \\
(\mathrm{kg})\end{array}$ & $\begin{array}{c}\text { Radio- } \\
\text { activity } \\
\text { (MCi) }\end{array}$ & $\begin{array}{c}\text { Therma } \\
\text { Power } \\
(k w)\end{array}$ \\
\hline $\begin{array}{l}1975 \\
1976 \\
1977 \\
1978 \\
1979 \\
1980 \\
1981 \\
1982 \\
1983 \\
1984 \\
1985 \\
1986 \\
1987 \\
1988 \\
1989 \\
1990 \\
1991 \\
1992 \\
1993 \\
1994 \\
1995 \\
1996 \\
1997 \\
1998 \\
1999 \\
2000\end{array}$ & $\begin{array}{l}0.7 \\
1.0 \\
1.6 \\
2.1 \\
2.5 \\
3.0 \\
3.5 \\
4.0 \\
5.2 \\
7.2 \\
9.1 \\
9.7 \\
11.4 \\
13.4 \\
15.1 \\
17.4 \\
19.9 \\
22.2 \\
24.5 \\
26.8 \\
29.6 \\
32.1 \\
34.2 \\
36.0 \\
37.5 \\
38.8\end{array}$ & $\begin{array}{l}0.6 \\
0.9 \\
1.4 \\
1.8 \\
2.2 \\
2.7 \\
3.1 \\
3.5 \\
4.6 \\
6.3 \\
8.0 \\
8.6 \\
10.0 \\
11.9 \\
13.3 \\
15.4 \\
17.5 \\
19.6 \\
21.6 \\
23.7 \\
26.1 \\
28.3 \\
30.2 \\
31.8 \\
33.1 \\
34.2\end{array}$ & $\begin{array}{l}0.0 \\
0.0 \\
0.0 \\
0.1 \\
0.3 \\
0.4 \\
0.5 \\
0.7 \\
0.7 \\
0.8 \\
1.0 \\
1.0 \\
1.3 \\
1.6 \\
1.6 \\
1.8 \\
2.0 \\
2.2 \\
2.5 \\
2.8 \\
3.0 \\
3.3 \\
3.6 \\
3.9 \\
4.1 \\
4.4\end{array}$ & $\begin{array}{l}0.0 \\
0.0 \\
0.0 \\
0.6 \\
1.2 \\
2.0 \\
2.5 \\
3.0 \\
3.0 \\
3.7 \\
4.4 \\
4.4 \\
5.8 \\
7.2 \\
7.2 \\
8.1 \\
9.1 \\
10.1 \\
11.2 \\
12.4 \\
13.6 \\
14.9 \\
16.2 \\
17.4 \\
18.6 \\
19.8\end{array}$ & $\begin{array}{r}1.8 \\
2.8 \\
4.4 \\
6.4 \\
9.0 \\
12.0 \\
15.5 \\
19.5 \\
24.6 \\
31.8 \\
40.8 \\
50.6 \\
61.9 \\
75.4 \\
90.5 \\
107.9 \\
127.8 \\
150.0 \\
174.5 \\
201.3 \\
230.9 \\
263.0 \\
297.1 \\
333.1 \\
370.6 \\
409.4\end{array}$ & $\begin{array}{r}2 \\
2 \\
4 \\
6 \\
8 \\
11 \\
14 \\
17 \\
22 \\
28 \\
36 \\
45 \\
55 \\
67 \\
80 \\
95 \\
11 \\
132 \\
154 \\
178 \\
204 \\
232 \\
262 \\
294 \\
327 \\
361\end{array}$ & $\begin{array}{l}0.0 \\
0.0 \\
0.0 \\
0.13 \\
0.36 \\
0.69 \\
1.03 \\
1.40 \\
1.70 \\
2.11 \\
2.59 \\
2.98 \\
3.64 \\
4.45 \\
5.10 \\
5.85 \\
6.70 \\
7.64 \\
8.67 \\
9.80 \\
11.02 \\
12.33 \\
13.71 \\
15.15 \\
16.65 \\
18.21\end{array}$ & $\begin{array}{l}0.0 \\
0.0 \\
0.0 \\
0.6 \\
1.6 \\
3.0 \\
4.4 \\
5.9 \\
7.1 \\
8.7 \\
10.7 \\
12.1 \\
14.8 \\
18.0 \\
20.5 \\
23.4 \\
26.6 \\
30.3 \\
34.2 \\
38.6 \\
43.2 \\
48.2 \\
53.5 \\
59.0 \\
64.6 \\
70.4\end{array}$ \\
\hline
\end{tabular}

a. Reference 7, based on assumptions summarized in Section 3.1.2.

b. Note that uranium values are included in this group. 


\section{REFERENCES}

1. United States Atomic Energy Commission, Office of Planning and Analysis, Nuclear Power Growth 1974-2000, WASH-1139 (74), U. S. Government Printing office, Washington, D. C., February 1974.

2. J. 0. Blomeke, C. W. Kee, and J. P. Nichols, Projections of Radioactive Wastes to be Generated by the U. S. Nuclear Power Industry, ORNL-TM-3965, 0ak Ridge National Laboratory, Oak Ridge, TN, February 1974.

3. "Siting of Fuel Reprocessing Plants and Related Waste Management Facilities," Federal Register, Vol. 35, No. 222, p. 17530, November 14, 1970 .

4. J. J. Perona and J. 0. Blomeke, A Parametric Study of Shipping Casks for Solid Radioactive Wastes, ORNL-TM-3651, Oak Ridge National Laboratory, Oak Ridge, TiN, February 1972.

5. J. J. Perona, R. S. Dillon, and J. 0. Blomeke, Design and Safety Considerations of Shipping Solidified High-Level Radioactive Wastes, ORNL-TM-2971, Oak Ridge National Laboratory, Oak Ridge, TN, December 1970.

6. J. 0. Blomeke and J. J. Perona, Storage, Shipment and Disposal of Spent Fuel Cladding, ORNL-TM-3650, Oak Ridge National Laboratory, Oak Ridge, TN, January 1972 .

7. J. 0. Blomeke, personal communication (Waste Projections, "Moderate Low Growth" case), J. 0. Blomeke, 0ak Ridge National Laboratory to M. J. Steindler, Argonne National Laboratory, October 1975, December 1975. 
- 
4.0 SELECTED GLOSSARY 
-

○ 


\subsection{SELECTED GLOSSARY}

Back end of the fuel cycle: Includes reactors, spent fuel storage, fuel reprocessing, mixed-oxide fuel fabrication, and waste management.

Burial grounds: Areas designated for storage of containers of treated radioactive wastes by near-surface burial in geologic media.

Concepts: The basic methods by which waste management operations can be achieved. An example of a waste treatment concept is solidification of liquid high-level waste.

Decommissioning: Preparation of worn out or obsolete nuclear facilities for retirement. Decommissioning operations remove facilities such as reprocessing plants and burial grounds from service and reduce or stabilize radioactive contamination. Concepts include

- demolition and restoration to original conditions requiring no control

- partial demolition and fixation of residues

- minimal demolition followed by isolation and control of residues.

Deep continental geologic formations: Geologic media beneath the continents and isolated from biologic species and phenomena. Distinguished from ice sheets and sea floor geologic media.

Disposal: Operations designed to eliminate wastes from existence on earth or to permanently isolate them from mankind and his environs with no expectation of retrieval after emplacement. Isolation concepts include

- placement in subsurface geologic formations using technologies that offer no practical method for recovery

- emplacement into or beneath sea floors

- emplacement in ice sheets

- dispersion.

Elimination concepts include extraterrestrial disposal and transmutation.

Final storage: Storage operations for which a) no subsequent waste treatment or transportation operations are anticipated and b) conversion to disposal (i.e., termination of monitoring and human control) is considered possible.

The current concept for final storage is emplacement of wastes in geologic formations. The geologic formations may be on or near the earth's surface and augmented by engineering technology (e.g., burial grounds), or subsurface and augmented with engineering technology.

Head end of the fuel cycle: Mining, milling, enrichment, and fabrication of $\mathrm{UO}_{2}$ fue 1 .

High-level waste: The fission product waste resulting from reprocessing spent fuel to separate uranium and plutonium from the fission products. 
Immobilization: Treatment and/or emplacement of the wastes so as to impede their movement.

Interim storage: Storage operations for which a) monitoring and human control are provided and $b$ ) subsequent action involving treatment, transportation, or final disposition is expected.

Concepts for interim storage include bulk and unitized storage of solid, liquid, and gaseous wastes.

Alternative interim storage technologies include:

- tank storage of liquids

- canister storage in air-cooled vaults

- spent fuel storage in water basins.

Intermediate-level waste: Waste requiring some kind of action to protect personnel from radiation.

Isolation: A term encompassing both final storage and/or disposal in geologic formations.

Long-lived nuclides: Radioactive isotopes with half-lives greater than about 30 years. Most nuclides of interest to waste management have half-iives on the order of thousands to millions of years $\left({ }^{239} \mathrm{Pu}-24,400\right.$ years; ${ }^{99}$ TC $-2.1 \times 10^{5}$ years; ${ }^{129} \mathrm{I}-1.6 \times 10^{7}$ years).

Low-level waste: Wastes containing types and concentrations of radioactivity such that shielding to prevent personnel exposure is not required.

Non-high-level waste: Intermediate- or low-level waste.

Operations: Broad classification of waste management activities in terms of their basic function (e.g., waste storage, treatment, transportation or disposal).

Overpack: Secondary (or additional) external containment for packaged nuclear waste.

Primary wastes: As-generated forms and quantities of wastes.

Repository: A location containing wastes in storage or disposal.

Retrievability: Capability to remove waste from its place in final storage. The method and rate of removal and the subsequent location of the waste must satisfy retrievability criteria.

Secondary wastes: Forms and quantities of all wastes that result from applying waste treatment technologies to primary wastes.

Short-lived nuclides: Radioactive isotopes with half-lives no greater than about 30 years, e.g., ${ }^{137} \mathrm{Cs}$ and ${ }^{90} \mathrm{Sr}$. 
Solidification: Conversion of radioactive waste to a dry, stable solid.

Technologies: The specific methods for implementing concepts. An example is calcination of liquid high-level waste by using a spray calciner.

Transmutation: Conversion of a radioactive nucleus to another isotope by bombarding it with radiation or nuclear particles.

Transportation: Movement of materials between sites. Intra-site movement is not considered. Includes alternative methods for packaging, handing, and transport of waste materials and plutonium compounds. Concepts inciude all conventional methods of 1 and and water transport required by the waste management system.

Transuranic elements: Elements with mass number greater than 92 . They include neptunium, plutonium, americium, and curium.

Transuranic waste: Any waste material measured or assumed to contain more than a specified concentration (e.g., presently proposed as 10 nanocuries of alpha emitters per gram of waste) of transuranic elements.

Treatment: 0perations intended to benetit safety or economy by changing the waste characteristics. Four basic treatment concepts are defined:

- volume reduction

- immobilization of radioactivity

- change of composition

- removal of radioactivity from the waste. 